\author{
UNIVERSIDADE DE SÃO PAULO \\ Faculdade de Ciências Farmacêuticas \\ Programa de Pós-Graduação em Fármacos e Medicamentos \\ Área de Produção e Controle Farmacêuticos
}

\title{
Caracterização físico-química e analítica de fibras capilares e ingredientes cosméticos para proteção
}

\section{Cibele Rosana Ribeiro de Castro Lima}

Tese apresentada para a obtenção do Grau de

Doutor

Orientador: Prof. Dr. Jivaldo do Rosário Matos

\section{SÃO PAULO}

2016 


\author{
UNIVERSIDADE DE SÃO PAULO \\ Faculdade de Ciências Farmacêuticas \\ Programa de Pós-Graduação em Fármacos e Medicamentos \\ Área de Produção e Controle Farmacêuticos
}

\title{
Caracterização físico-química e analítica de fibras capilares e ingredientes cosméticos para proteção
}

\author{
Cibele Rosana Ribeiro de Castro Lima
}

Versão corrigida da Tese conforme resolução CoPGr 6018.

O original encontra-se disponível no Serviço de Pós Graduação da FCF/USP.

Tese apresentada para a obtenção do Grau de

Doutor

Orientador: Prof. Dr. Jivaldo do Rosário Matos

SÃO PAULO 


\section{Ficha Catalográfica}

Elaborada pela Divisão de Biblioteca e

Documentação do Conjunto das Químicas da USP.
L732c Caracterização físico-química e analítica de fibras capilares e ingredientes cosméticos para proteção / Cibele Rosana Ribeiro de Castro Lima. -- São Paulo, 2016.
$210 \mathrm{p}$.

Tese (doutorado) - Faculdade de Ciências Farmacêuticas da Universidade de São Paulo. Departamento de Farmácia.

Orientador: Matos, Jivaldo do Rosário

1. Cabelo: Tratamento químico: Cosméticos 2. Análise térmica I. T. II. Matos, Jivaldo do Rosário, orientador. 


\section{Cibele Rosana Ribeiro de Castro Lima}

Caracterização físico-química e analítica de fibras capilares e ingredientes cosméticos para proteção.

Comissão julgadora

da

Tese para obtenção do Título de Doutor

Prof. Dr. Jivaldo do Rosário Matos

Orientador/Presidente

$1^{\circ}$ Examinador

$2^{\circ}$ Examinador

$3^{\circ}$ Examinador

$4^{\circ}$ Examinador

São Paulo, de de 2016. 
Dedico este trabalho à

À Deus, por tudo.

Aos meus filhos, anjos que Deus me enviou na Terra, Gabriel e Lucas, fonte de vida, minha inspiração, meus pequenos grandes amores.

Aos meus pais, Adalberto e Carmen, pelo incentivo aos estudos, pelo exemplo de vida, de humildade e de amor. Modelo de família que inspira.

Ao Cristiano, meu eterno companheiro, amor da minha vida! Pelo imenso apoio nas decisões, ideias e tantos sonhos!

Aos meus queridos irmãos, Fabiana, Camila, Carlos e Flávio, meus sobrinhos, Daniel, Guilherme e Gabriel, pelos momentos de pura alegria e amor compartilhados! 
A mente que se abre à uma nova ideia, jamais voltará ao seu tamanho original.

Albert Einstein 


\section{A idade de ser feliz}

"Existe somente uma idade para a gente ser feliz.

Somente uma época na vida de cada pessoa

em que se pode sonhar e fazer planos,

e ter energia bastante para realizá-los,

a despeito de todas as dificuldade e obstáculos.

Uma só idade para a gente se encontrar com a vida

e viver apaixonadamente,

com o entusiasmo dos amantes

e a coragem dos aventureiros.

Fase dourada em que se pode criar e recriar a vida à imagem e semelhança

dos nossos desejos;

e sorrir e cantar, e brincar e dançar,

e vestir-se com todas as cores

e experimentar todos os sabores

e desfrutar de tudo com toda a intensidade, sem preconceito nem pudor.

Tempo em que cada limitação humana

é só mais um convite ao crescimento;

um desafio a lutar com toda energia

e a tentar algo novo, de novo e de novo

e quantas vezes for preciso.

Essa idade tão especial e tão única chama-se presente...

E tem apenas a duração do instante que passa..."

Mário Quintana 


\section{Agradecimentos}

Em especial agradecimento, ao querido Professor Dr. Jivaldo do Rosário Matos, pelo imenso apoio, orientação, disponibilidade, confiança e amizade.

À querida Professora Dra. Luci Diva Brocardo Machado, pela imensa ajuda, conselhos, amizade e por ceder o laboratório para tantos experimentos.

À Professora Dra. Maria Valéria Robles Velasco, pela disponibilidade e ajuda.

À amiga querida Vanessa Franco Tavares, pela paciência, disponibilidade e grande ajuda para a realização deste trabalho!

À amiga Juliana Ferreira de Oliveira pela amizade, disponibilidade e grande ajuda com as imagens de MEV e discussões do trabalho.

À amiga Simone Garcia de Ávila, pela amizade, conselhos e parceira em tantos trabalhos.

À minha querida sogra e amiga, Maria de Lourdes Porto de Carvalho, pela disponibilidade, amizade, amor e pelo exemplo de vida.

À querida Luiza Laforgia Gavaldon, pelo grande incentivo, paciência, disponibilidade e conselhos sempre tão oportunos.

À amiga Juliana Reiko II, pela amizade, ajuda, disponibilidade e tantos conselhos.

À Ana Lúcia Miranda, pelo carinho com meus pequenos e grande ajuda.

Às amigas e técnicas Luciana e Priscila, sempre tão disponíveis à ajudar.

Às amigas Mariana Mandelli de Almeida e Joyce Quenca Guillen, pela amizade, pelos momentos de descontração e por tantos trabalhos e congressos em conjunto!!!

Aos queridos amigos do Latig, pela ajuda, apoio, amizade e tantos momentos de descontração.

Ao Lucas Offenbecker Guerra, por abrir as portas do laboratório tão gentilmente e disponibilizá-lo para tantos ensaios.

À Lays Paulino Leonel, pela gentileza, disponibilidade e grande ajuda com os testes de eficácia.

À Ana Carolina Ramos, pela gentileza, disponibilidade e pelas amostras cedidas. 
À Tânia Cristina Sá Dias, pelas amostras cedidas e trabalhos em conjunto.

Ao Alfredo Duarte e Adriana Yamaguti Matsukuma, pela paciência em se obter os melhores ângulos nas imagens de MEV.

Ao Francisco Alberto Pino, pela ajuda com ensinamentos de estatística.

À Leila Aparecida Bonadio, pela paciência em corrigir as referências bibliográficas.

À Allergisa, pela grande colaboração nos ensaios de penteabilidade e tensãodeformação e quebra por escovação.

À Clariant S.A., Daltomare e Mapric pelas amostras cedidas.

Ao Programa de Pós-Graduação em Fármacos e Medicamentos da Faculdade de Ciências Farmacêuticas - USP, pela oportunidade.

À todos aqueles que, direta ou indiretamente, foram prestativos, voluntários, compreensivos, mas acima de tudo, companheiros. Meus sinceros agradecimentos!

Ao CNPq e CAPES pelo auxílio financeiro. 


\section{RESUMO}

LIMA, C.R.R.C. Caracterização físico-química e analítica de fibras capilares e ingredientes cosméticos para proteção. 2016. 210f. Tese (Doutorado) Faculdade de Ciências Farmacêuticas, Universidade de São Paulo, São Paulo, 2016.

Com o aumento dos tratamentos químicos e/ou físicos nos cabelos aos quais são realizados mediante o uso de dispositivos térmicos, há uma maior preocupação a respeito dos danos causados aos cabelos por estes tipos de tratamentos. $O$ conhecimento dos efeitos, benefícios e/ou malefícios, de ingredientes cosméticos em cabelos torna-se necessário, pois facilita a busca por produtos baseada no tipo de cabelo. O principal objetivo do trabalho foi a caracterização físico-química, analítica e térmica de mechas de cabelo de diferentes etnias (caucasiano, oriental e afro-étnico virgem e brasileiro virgem e descolorido) antes e após o uso de ingredientes cosméticos seguido de um tratamento térmico (utilizando piastra) e intercalando com lavagens. O estudo das amostras de cabelo e de uma amostra de queratina animal envolveu a utilização das técnicas de TG/DTG, DSC, análise elementar, FTIR, MEV e técnicas de avaliação de eficácia, como tensão/deformação, penteabilidade e quebra por escovação. A partir da TG/DTG, foi possível avaliar as etapas de decomposição térmica das amostras de cabelo virgem e de queratina animal e estas apresentaram um comportamento térmico semelhante entre si. $O$ estudo cinético não isotérmico por TG mostrou que, dos diferentes tipos de amostras de cabelo virgem, o afro-étnico apresentou menor estabilidade térmica e o oriental foi o mais estável termicamente. Os resultados de DSC corroboraram os obtidos por TG, demonstrando que a amostra de cabelo afro-étnico apresentou temperatura de desnaturação térmica das cadeias de $\alpha$ queratina menor $\left(T_{D}=223^{\circ} \mathrm{C}\right)$ do que as amostras dos outros tipos de cabelo $\left(T_{D}\right.$ $=236^{\circ} \mathrm{C}$ ). As mechas de cabelo virgem e clareadas foram tratadas com formulações cosméticas contendo silicones e avaliadas quanto a eficiência destes na proteção térmica dos cabelos. Algumas delas mostraram eficiência na proteção térmica das cadeias de a-queratina, diminuindo o seu grau de desnaturação. Foi possível observar que a associação do calor da piastra com as lavagens sucessivas causou danos tanto à cutícula (conforme resultados de FTIR e MEV), como também, ao córtex dos cabelos (conforme resultados de DSC). Em alguns casos, os danos causados foram tão graves que as camadas mais superficiais da cutícula sofreram descamações. O estudo mostrou, também, que a eficiência da proteção térmica nos cabelos depende do tipo da formulação cosmética em que estes protetores estão incorporados e do estado em que os cabelos se encontram. A DSC permitiu a avaliação da modificação termicamente induzida das cadeias de $\alpha$-queratina e sua posterior desnaturação. $O$ estudo envolvendo a associação das diferentes técnicas apresentou-se viável na avaliação tanto dos danos causados aos cabelos quanto na eficiência dos ingredientes cosméticos na proteção térmica dos mesmos.

Palavras-chave: cabelos, etnia, dano térmico, proteção térmica, cosméticos, eficácia, análise térmica, MEV, propriedades mecânicas. 


\begin{abstract}
LIMA, C.R.R.C. Caracterização físico-química e analítica de fibras capilares e ingredientes cosméticos para proteção. 2016. 210f. Tese (Doutorado) Faculdade de Ciências Farmacêuticas, Universidade de São Paulo, São Paulo, 2016.

With the increase of chemical and/or physical hair treatments, there is an increased concern about the damage caused by the continued use of thermal equipment. This is due to products identified as "progressive brush", widely used by individuals of various types of hair, in order to straighten them that are employed with the mandatory use of piastra. Thus, knowledge about the effects, benefits and/or detriments, of cosmetic ingredients in hair of different ethnic groups becomes necessary because it facilitates the search for products based on the type of hair. The main objective this work was the physicochemical, analytical and thermal characterization of hair samples of different ethnic groups (caucasian, oriental, african-ethnic and brazilian type II) before and after the use of cosmetic ingredients followed by heat treatment, using piastra, interleaved by washes. For such purpose, it was used the TG/DTG, DSC, EA, FTIR, SEM and techniques for evaluation of effectiveness as stress/strain and combing. By TG/DTG, it was possible to evaluate the thermal decomposition events of hair and animal keratin samples and these showed a similar thermal behavior between them. The TG-non isothermal kinetic study showed that, from the different types of virgin hair samples, the african-ethnic hair samples had the lowest thermal stability and oriental hair samples were more thermally stable. The DSC results confirm the results obtained by TG, demonstrating that african-ethnic hair samples had thermal denaturation temperature of $\alpha$-keratin chains $\left(T_{D}=223^{\circ} \mathrm{C}\right)$ lower than the samples from other types of hair $\left(T_{D}=236^{\circ} \mathrm{C}\right)$. The virgin and bleached hair tresses were treated with cosmetic formulations containing silicones and evaluated the efficiency of the thermal protection of the hair. Some of the formulations tested have shown to be efficient as to its protective effect on the degradation of the akeratin chains, decreasing the degree of denaturation. It was observed that the combination of the heat of piastra with successive washes caused damage to the hair cuticle (according to the IR and SEM results) as well as the cortex of hair (according DSC results). In some cases, the damage was so severe that the most superficial layers of the cuticle suffered flaking. The study also showed that the efficiency of the thermal protection in the hair depends on the type of cosmetic formulation that these protectors are incorporated and the condition of the hair. DSC technique allowed monitoring of the thermally induced modification of the akeratin chains and subsequent denaturation. The study of the combination of all the techniques, as presented, is feasible in measuring damage to hair and the efficiency of cosmetic ingredients in protecting them.
\end{abstract}

Keywords: hair, ethnicity, thermal damage, thermal protection, cosmetics, efficacy, thermal analysis, SEM, mechanical properties. 


\section{SUMÁRIO}

RESUMO

vii

ABSTRACT

viii

LISTA DE FIGURAS

xiii

LISTA DE TABELAS

$\mathbf{X X}$

LISTA DE ABREVIATURAS E SÍMBOLOS

xxiv

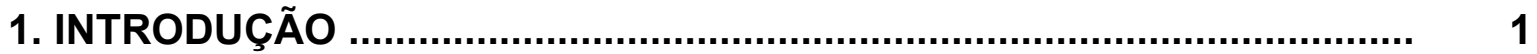

2. REVISÃO DA LITERATURA ……......................................................

2.1. Histórico ....................................................................................

2.2. Anatomia do cabelo ....................................................................... 4

2.3. A estrutura do cabelo …................................................................. 8

2.4. Variedade étnica .......................................................................... 11

2.5. O processo de clareamento de cabelos ............................................. 14

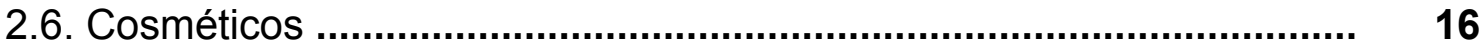

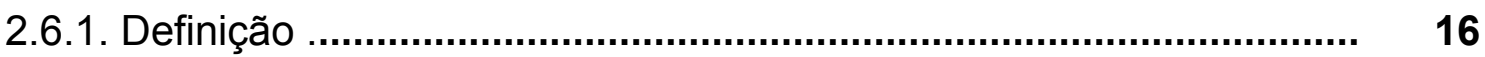

2.6.2. Estabilidade de cosméticos .......................................................... 16

2.6.3. Condicionadores ......................................................................... 16

2.6.3.1. Condicionadores leave-on ......................................................... 18

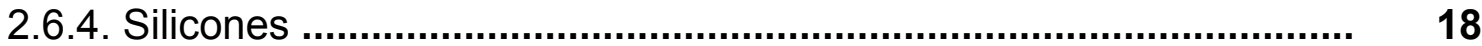

2.6.5. Escolha dos ingredientes cosméticos e veículos para o estudo das formulações ................................................................................... 19

2.7. Análise Térmica ....................................................................... 22

2.7.1. Cinética de decomposição utilizando a termogravimetria ................. 23

2.7.2. A análise térmica aplicada ao estudo de cabelos ............................ 26

2.8. Espectroscopia na região do infravermelho com transformada de Fourier (FTIR) com Refletância Total Atenuada (ATR) ............................. 35

2.9. Microscopia eletrônica de varredura (MEV) …................................... 36

2.10. Estrutura do Trabalho .................................................................... 38 
5.1.1. Seleção das mechas de cabelo

5.1.1.1. Caracterização de amostras de cabelo sem tratamento e de queratina animal

5.1.1.2. Caracterização de amostras de cabelo tratadas com formulações cosméticas antes e após a utilização de dispositivos térmicos

5.1.2. Seleção dos ingredientes cosméticos adquiridos do mercado

5.1.3. Seleção dos veículos utilizados para a incorporação dos ingredientes cosméticos

5.1.4. Equipamentos e Acessórios

5.2. MÉTODOS

5.2.1. Pré-tratamento das mechas de cabelo padronizadas

5.2.2. Procedimento de descoloração das mechas de cabelo brasileiro ..

5.2.3. Caracterização das amostras de cabelo padrão virgem de diferentes etnias e queratina animal

5.2.3.1. Termogravimetria/Termogravimetria derivada (TG/DTG)

5.2.3.1.1. Estudo cinético por TG de amostras de cabelo virgem padrão e de queratina animal pelo método não isotérmico

5.2.3.2. Calorimetria Exploratória Diferencial (DSC)

5.2.3.3. Análise elementar

5.2.3.4. Espectroscopia de absorção na região do infravermelho com transformada de Fourier - FTIR-ATR

5.2.3.5. Microscopia eletrônica de varredura

5.2.3.6. Avaliação de resistência a penteabilidade

5.2.3.7. Avaliação das propriedades mecânicas pelo método de tensãodeformação das mechas de cabelo padrão virgem

5.2.3.7.1. Determinação do diâmetro dos fios

5.2.3.7.2. Ensaios de tensão-deformação 
5.2.4. Incorporação dos ingredientes cosméticos aos veículos selecionados

5.2.5. Estudo de estabilidade das formulações cosméticas ....................... 53

5.2.5.1. Teste de centrifugação .............................................................. 53

5.2.5.2. Teste de estabilidade acelerada .............................................. 53

5.2.5.3. Avaliação das formulações cosméticas ...................................... 54

5.3. Caracterização das mechas de cabelo submetidas às formulações cosméticas

5.3.1. Tratamento das mechas de cabelo com as formulações sem a utilização de dispositivo térmico (piastra)

5.3.2. Tratamento das mechas de cabelo com as formulações com a utilização de dispositivo térmico (piastra) .

5.3.2.1. Eficácia pelo método de quebra por escovação

6. RESULTADOS E DISCUSSÃO

6.1. Caracterização das amostras de cabelo virgem padrão e de queratina animal

6.1.1. Termogravimetria/Termogravimetria derivada (TG/DTG)

6.1.1.1. Estudo cinético de amostras de cabelo virgem padrão pelo método não isotérmico por TG

6.1.2. Calorimetria exploratória diferencial (DSC)

6.1.3. Análise elementar (AE)

6.1.4. Espectroscopia de absorção na região do infravermelho com transformada de Fourier/Refletância Total Atenuada (ATR-FTIR)

6.1.5. Avaliação da resistência a tração à ruptura (tensão-deformação) ...

6.1.6. Avaliação da resistência à penteabilidade

6.1.7. Microscopia eletrônica de varredura (MEV)

6.1.7.1. Cabelo caucasiano

6.1.7.2. Cabelo oriental

6.1.7.3. Cabelo afro-étnico

6.2. Caracterização dos ingredientes cosméticos isolados e incorporados às formulações

6.2.1. Termogravimetria/Termogravimetria derivada 
6.2.2. Análise elementar

6.2.3. Espectroscopia na região do infravermelho com Transformada de Fourier

6.2.3.1. Ingredientes cosméticos e formulações

6.3. Estudo de estabilidade das formulações cosméticas

6.3.1. Teste de estabilidade preliminar

6.3.2. Estudo de estabilidade acelerada

6.4. Caracterização e avaliação de amostras de cabelo submetidas a tratamentos com ingredientes cosméticos

6.4.1.1. Termogravimetria/Termogravimetria derivada

6.4.1.2. Calorimetria exploratória diferencial (DSC) .

6.4.1.3. Análise elementar

6.4.1.4. Espectroscopia na região do infravermelho com transformada de Fourier- Refletância total atenuada (FTIR-ATR)

6.4.1.5. Microscopia eletrônica de varredura (MEV)

6.4.1.6. Avaliação de resistência à penteabilidade

6.4.1.7. Eficácia pelo método de quebra por escovação 


\section{LISTA DE FIGURAS}

Figura 2.1 llustração de um folículo piloso com detalhe da glândula sebácea

Figura 2.2 Reação de condensação de aminoácidos .

Figura 2.3 llustração das ligações presentes na queratina do cabelo humano

Figura 2.4 Ligação de hidrogênio entre amida e grupos carbonila da $\alpha$ queratina

Figura 2.5 llustração da fibra de cabelo e as subestruturas da cutícula e córtex (ROBBINS, 1994, modificado)

Figura 2.6 Imagem de MEV de uma amostra de cabelo oriental indicando a cutícula e a CMC. Imagem registrada no presente trabalho

Figura 2.7 Classificação dos diversos tipos de cabelo com sua curvatura e torção de acordo com a classificação definida De La Mettrie et al. (2007)

Figura 2.8 Esquema do mecanismo de clivagem S-S para o processo de clareamento de cabelos

Figura 2.9 Estrutura química do amodimeticone

Figura 2.10 Estrutura química do cyclopentasiloxane

Figura 2.11 Estrutura química do dimeticone

Figura 2.12 Sobreposição de curvas TGs hipotéticas com diferentes $\beta$. Gráfico de Ozawa construído a partir das curvas TG com diferentes $\beta$ (ÁVILA, 2015, adaptado)

Figura 2.13 Fluxograma representativo do desenvolvimento do trabalho...

Figura 5.1 Imagens das mechas de cabelo virgem escolhidas

Figura 5.2 Ilustração do compartimento para secagem e armazenagem das mechas de cabelo 
Figura 5.3 llustração do equipamento empregado nos testes de penteabilidade e tensão deformação utilizado no trabalho .....

Figura 5.4 Fluxograma do procedimento de tratamento das mechas de cabelo com as formulações utilizando dispositivo térmico .......

Figura 5.5 Ilustração do equipamento empregado nos testes de quebra por escovação utilizado trabalho

Figura 6.1 Curvas TG e DTG obtidas a $10^{\circ} \mathrm{C} \mathrm{min}^{-1}$, sob atmosfera dinâmica de ar e empregando cápsula de Pt contendo cerca de $15 \mathrm{mg}$ de amostras de queratina ou de cabelos caucasiano, oriental ou afro-étnico padrão

Figura 6.2 Resultados dos parâmetros cinéticos de uma amostra de cabelo caucasiano virgem padrão obtidas sob diferentes razões de aquecimento e atmosfera dinâmica de ar

Figura 6.3 Resultados dos parâmetros cinéticos de uma amostra de cabelo oriental virgem padrão obtidas sob diferentes razões de aquecimento e atmosfera dinâmica de ar

Figura 6.4 Sobreposição das curvas TGs obtidas com diferentes razões de aquecimento e sob atmosfera dinâmica de ar de uma amostra de cabelo afro-étnico virgem padrão

Figura 6.5 Curvas DSC obtidas a $10^{\circ} \mathrm{C} \mathrm{min}{ }^{-1}$, sob atmosfera dinâmica de $\mathrm{N}_{2}$ e empregando cápsula de Al parcialmente fechada contendo cerca de $2 \mathrm{mg}$ de amostras de queratina animal e de cabelo padrão virgem caucasiano, oriental e afro-étnico $\left(22 \pm 2^{\circ} \mathrm{C} ; 65 \pm 2 \%\right.$ U.R. $)$

Figura 6.6 Curvas DSC obtidas a $10^{\circ} \mathrm{C} \mathrm{min}^{-1}$, sob atmosfera dinâmica de $\mathrm{N}_{2}$ e empregando cápsula de Al parcialmente fechada contendo cerca de $2 \mathrm{mg}$ de amostras de cabelo virgem padrão caucasiano, oriental e afro-étnico $\left(22 \pm 2^{\circ} \mathrm{C} ; 20 \pm 2 \%\right.$ U.R.)

Figura 6.7 Modos de vibração das bandas de amida I, amida II e amida III, respectivamente da proteína queratina

Figura 6.8 Espectros de absorção na região do IV de amostras de cabelo padrão virgem das etnias caucasiana, oriental e afroétnica 
Figura 6.9 Gráfico de Tensão versus deformação obtido a partir do ensaio mecânico de 20 fios de cabelo padrão virgem lavados com LESS $10 \%(\mathrm{~m} / \mathrm{m})$

Figura 6.10 Imagens de MEV de uma amostra de cabelo virgem caucasiano. No detalhe: as camadas da cutícula e sua medida de espessura

Figura 6.11 Imagens de MEV de uma amostra de cabelo virgem oriental. No detalhe: as camadas da cutícula e sua medida de espessura

Figura 6.12 Imagens de MEV de uma amostra de cabelo virgem afroétnico. No detalhe: a cutícula

Figura 6.13 Curvas TG e DTG obtidas a $10^{\circ} \mathrm{C} \mathrm{min}^{-1}$, sob atmosfera dinâmica de ar e empregando cápsula de Pt contendo cerca de $15 \mathrm{mg}$ de amostras dos ingredientes cosméticos

Figura 6.14 Curvas TG e DTG obtidas a $10^{\circ} \mathrm{C} \mathrm{min}^{-1}$, sob atmosfera dinâmica de ar e empregando cápsula de Pt contendo cerca de $15 \mathrm{mg}$ das formulações: dimeticone (F2), F2A, F2B e F2C (dimeticone + ingredientes cosméticos $\mathrm{A}$, B e $\mathrm{C}$ )

Figura 6.15 Curvas TG e DTG obtidas a $10^{\circ} \mathrm{C} \mathrm{min}^{-1}$, sob atmosfera dinâmica de ar e empregando cápsula de Pt contendo cerca de $15 \mathrm{mg}$ das formulações cosméticas: F3 (condicionador leave-on), F3A, F3B e F3C (condicionador leave-on + ingredientes cosméticos $A, B$ e $C$ )

Figura 6.16 Espectros de absorção na região do IV de amostras dos ingredientes cosméticos estudados (A, B e C)

Figura 6.17 Espectros de absorção na região do IV das amostras: F2 (dimeticone) e das formulações F2A, F2B e F2C (dimeticone + ingredientes cosméticos A, B e C)

Figura 6.18 Espectros de absorção na região do IV das amostras: F3 (condicionador leave-on) e das formulações F3A, F3B e F3C (condicionador leave-on + ingredientes cosméticos A, B e C )

Figura 6.19 Imagem dos frascos das formulações F3A, F3B e F3C no teste de estabilidade acelerada (ciclos de congelamento $5 \pm$ $2^{\circ} \mathrm{C}$ e descongelamento $45 \pm 2^{\circ} \mathrm{C}$, geladeira a $5 \pm 2^{\circ} \mathrm{C}$, temperatura ambiente, estufa a $45 \pm 2^{\circ} \mathrm{C}$ e radiação solar) .... 
Figura 6.20 Curvas TG e DTG obtidas a $10^{\circ} \mathrm{C} \mathrm{min}^{-1}$, sob atmosfera dinâmica de ar e empregando cápsula de Pt contendo cerca de $15 \mathrm{mg}$ de amostras das mechas controle de cabelo caucasiano e tratadas com as formulações cosméticas ( $F 2 A$, F2B e F2C)

Figura 6.21 Curvas TG e DTG obtidas a $10^{\circ} \mathrm{C} \mathrm{min}{ }^{-1}$, sob atmosfera dinâmica de ar e empregando cápsula de Pt contendo cerca de $15 \mathrm{mg}$ de amostras das mechas controle de cabelo caucasiano e tratadas com as formulações cosméticas ( $F 3 A$, F3B e F3C)

Figura 6.22 Curvas TG e DTG obtidas a $10^{\circ} \mathrm{C} \mathrm{min}^{-1}$, sob atmosfera dinâmica de ar e empregando cápsula de Pt contendo cerca de $15 \mathrm{mg}$ de amostras das mechas controle de cabelo oriental e tratadas com as formulações cosméticas ( $F 2 A$, F2B e F2C)

Figura 6.23 Curvas TG e DTG obtidas a $10^{\circ} \mathrm{C} \mathrm{min}{ }^{-1}$, sob atmosfera dinâmica de ar e empregando cápsula de Pt contendo cerca de $15 \mathrm{mg}$ de amostras das mechas controle de cabelo oriental e tratadas com as formulações cosméticas ( $\mathrm{F} 3 \mathrm{~A}$, F3B e F3C)

Figura 6.24 Curvas DSC obtidas a $10^{\circ} \mathrm{C} \mathrm{min}^{-1}$, atmosfera dinâmica de $\mathrm{N}_{2}$ e empregando cápsula de Al parcialmente fechada contendo cerca de $2 \mathrm{mg}$ de amostra das mechas de cabelo virgem padrão caucasiano e tratadas com as formulações F2A, F2B e F2C sem tratamento térmico

Figura 6.25 Curvas DSC obtidas a $10^{\circ} \mathrm{C} \mathrm{min}^{-1}$, atmosfera dinâmica de $\mathrm{N}_{2}$ e empregando cápsula de Al parcialmente fechada contendo cerca de $2 \mathrm{mg}$ de amostras das mechas de cabelo virgem caucasiano e tratadas com as formulações F3A, F3B e F3C sem tratamento térmico

Figura 6.26 Curvas DSC obtidas a $10^{\circ} \mathrm{C} \mathrm{min}^{-1}$, atmosfera dinâmica de $\mathrm{N}_{2}$ e empregando cápsula de Al parcialmente fechada contendo cerca de $2 \mathrm{mg}$ de amostras das mechas de cabelo virgem padrão oriental e tratadas com as formulações F2A, F2B e F2C sem tratamento térmico 
Figura 6.27 Curvas DSC obtidas a $10^{\circ} \mathrm{C} \mathrm{min}^{-1}$, atmosfera dinâmica de $\mathrm{N}_{2}$ e empregando cápsula de Al parcialmente fechada contendo cerca de $2 \mathrm{mg}$ de amostras das mechas de cabelo virgem padrão oriental e tratadas com as formulações $F 3 A$, F3B e F3C sem tratamento térmico

Figura 6.28 Curvas DSC obtidas a $10^{\circ} \mathrm{C} \mathrm{min}^{-1}$, atmosfera dinâmica de $\mathrm{N}_{2}$ e empregando cápsula de Al parcialmente fechada contendo cerca de $2 \mathrm{mg}$ de amostras das mechas de cabelo brasileiro virgem e descoloridas tratadas com as formulações F2A, $\mathrm{F} 2 \mathrm{~B}$ e $\mathrm{F} 2 \mathrm{C}$ sem tratamento térmico

Figura 6.29 Curvas DSC obtidas a $10^{\circ} \mathrm{C} \min ^{-1}$, atmosfera dinâmica de $\mathrm{N}_{2}$ e empregando cápsula de Al parcialmente fechada contendo cerca de $2 \mathrm{mg}$ de amostras das mechas de cabelo brasileiro virgem e descoloridas tratadas com as formulações F3A, F3B e F3C sem tratamento térmico

Figura 6.30 Curvas DSC obtidas a $10^{\circ} \mathrm{C} \mathrm{min}^{-1}$, sob atmosfera dinâmica de $\mathrm{N}_{2}$ e empregando cápsula de Al parcialmente fechada contendo cerca de $2 \mathrm{mg}$ de amostras das mechas de cabelo virgem caucasiano e tratadas com as formulações F2A, F2B e F2C após o tratamento térmico

Figura 6.31 Curvas DSC obtidas a $10^{\circ} \mathrm{C} \mathrm{min}^{-1}$, sob atmosfera dinâmica de $\mathrm{N}_{2}$ e empregando cápsula de Al parcialmente fechada contendo cerca de $2 \mathrm{mg}$ de amostras das mechas de cabelo virgem caucasiano e tratadas com as formulações F3A, F3B e F3C após o tratamento térmico

Figura 6.32 Curvas DSC obtidas a $10^{\circ} \mathrm{C} \mathrm{min}^{-1}$, sob atmosfera dinâmica de $\mathrm{N}_{2}$ e empregando cápsula de Al parcialmente fechada contendo cerca de $2 \mathrm{mg}$ de amostra das mechas controle de cabelo virgem oriental e tratadas com F2A, F2B e F2C após o tratamento térmico

Figura 6.33 Curvas DSC obtidas a $10^{\circ} \mathrm{C} \mathrm{min}^{-1}$, sob atmosfera dinâmica de $\mathrm{N}_{2}$ e empregando cápsula de Al parcialmente fechada contendo $2 \mathrm{mg}$ de amostras das mechas de cabelo virgem oriental e tratadas com as formulações F3A, F3B e F3C após o tratamento térmico 
Figura 6.34 Curvas DSC obtidas a $10^{\circ} \mathrm{C} \mathrm{min}{ }^{-1}$, sob atmosfera dinâmica de $\mathrm{N}_{2}$ e empregando cápsula de Al parcialmente fechada contendo cerca de $2 \mathrm{mg}$ de amostras das mechas de cabelo brasileiro virgem e descoloridas tratadas com as formulações F2A, F2B e F2C após tratamento térmico

Figura 6.35 Curvas DSC obtidas a $10^{\circ} \mathrm{C} \mathrm{min}{ }^{-1}$, sob atmosfera dinâmica de $\mathrm{N}_{2}$ e empregando cápsula de Al parcialmente fechada contendo cerca de $2 \mathrm{mg}$ de amostras das mechas de cabelo brasileiro virgem e descoloridas tratadas com as formulações F3A, F3B e F3C após o tratamento térmico

Figura 6.36 Resultados de \% de proteção da proteína helicoidal calculados com base nas diferenças de $\Delta \mathrm{H}_{\mathrm{D}}$ das amostras de cabelo submetidas ao tratamento térmico com as respectivas mechas controle

Figura 6.37 Espectros de absorção na região do IV de amostras das mechas de cabelo caucasiano padrão tratadas com as formulações F2A, F2B e F2C após tratamento térmico

Figura 6.38 Espectros de absorção na região do IV de amostras das mechas de cabelo caucasiano padrão tratadas com as formulações F3A, F3B e F3C após tratamento térmico

Figura 6.39 Espectros de absorção na região do IV de amostras das mechas de cabelo oriental padrão tratadas com as formulações F2A, F2B e F2C após tratamento térmico

Figura 6.40 Espectros de absorção na região do IV de amostras das mechas de cabelo oriental padrão tratadas com as formulações F3A, F3B e F3C após tratamento térmico

Figura 6.41 Espectros de absorção na região do IV de amostras das mechas de cabelo brasileiro virgem e descolorido tratadas com as formulações F2A, F2B e F2C após tratamento térmico

Figura 6.42 Espectros de absorção na região do IV de amostras das mechas de cabelo brasileiro virgem e descolorido tratadas com as formulações F3A, F3B e F3C após tratamento térmico

Figura 6.43 Imagens de MEV de amostras das mechas de cabelo caucasiano padrão virgem e submetidas às formulações: a) MCCont1; b) MCDM+A; c) MCDM+B; d) $M C D M+C$; e) MCLo+A; f) MCLo+B; g) MCLo+C 
Figura 6.44 Imagens de MEV de amostras das mechas de cabelo oriental padrão virgem e submetidas às formulações: a) MOCont1; b) MODM+A; c) MODM+B; d) MODM+C; e) MOLo+A; f) MOLo+B; g) MOLo+C

Figura 6.45 Imagens de MEV de amostras das mechas de cabelo brasileiro (grau de ondulação II) virgem e descoloridas submetidas às formulações: a) MBCont; b) MBCont1; c) $M B D M+A$; d) $M B D M+B$; e) $M B D M+C$; f) $M B L o+A$; g) MBLo+B; h) MBLo+C

Figura 6.46 Gráfico de valores individuais por tratamento nas mechas de cabelo brasileiro descolorido submetidas ao teste de penteabilidade

Figura 6.47 Gráfico de Intervalo de confiança de 95\% por tratamento das mechas de cabelo brasileiro descolorido submetidas ao teste de penteabilidade

Figura 6.48 Gráfico de valores individuais por tratamento nas mechas de cabelo brasileiro descolorido submetido ao teste de quebra por escovação

Figura 6.49 Gráfico de Intervalo de confiança de 95\% por tratamento das mechas de cabelo brasileiro descolorido submetidas ao teste de quebra por escovação 


\section{LISTA DE TABELAS}

Tabela 2.1 Composição de aminoácidos de cabelo humano das principais raças $(\mu \mathrm{mol} / \mathrm{g})$ (WOLFRAM, 2003) ........................ 6

Tabela 5.1 Ingredientes cosméticos selecionados .....................................

Tabela 5.2 Denominação das formulações obtidas para o tratamento das mechas de cabelo .............................................................

Tabela 6.1 Resultados de TG/DTG das amostras de queratina animal, cabelo caucasiano, oriental e afro-étnico

Tabela 6.2 Parâmetros obtidos do estudo cinético pelo método não isotérmico (Ozawa, 1965) de amostras de cabelo caucasiano, oriental e afro-étnico

Tabela 6.3 Resultados das temperaturas e $\Delta \mathrm{H}$ obtidos por DSC das amostras de queratina animal e de cabelo virgem padrão caucasiano, oriental e afro-étnico

Tabela 6.4 Resultados de Análise Elementar (CHNS) de amostras de queratina animal e de cabelo virgem caucasiano, oriental e afro-étnico

Tabela 6.5 Atribuição das bandas nos espectros no IV das amostras de cabelo virgem caucasiano, oriental e afro-étnico

Tabela 6.6 Valores dos diâmetros $(\mathrm{em} \mu \mathrm{m})$ de amostras de cabelo virgem padrão caucasiano e oriental

Tabela 6.7 Modelo de ANOVA para os resultados obtidos das medidas de diâmetro das mechas de cabelo caucasiano e oriental utilizando micrômetro Mitutoyo

Tabela 6.8 Valores de tensão na força máxima $\left(\mathrm{N} / \mathrm{m}^{2}\right)$ obtidos no teste de tensão-deformação (média de leituras obtidas até a ruptura do fio) das amostras de cabelo virgem padrão caucasiano e oriental

Tabela 6.9 Modelo de ANOVA para os resultados obtidos de tensão na força máxima das mechas de cabelo caucasiano e oriental ...

Tabela 6.10 Valores de extensão $(\mathrm{m})$, força $(\mathrm{N})$ e trabalho $(\mathrm{J})$ obtidos no teste de penteabilidade para as amostras de cabelo virgem padrão caucasiano e oriental 
Tabela 6.11 Modelo de ANOVA para os resultados obtidos no teste de penteabilidade das mechas de cabelo caucasiano e oriental .

Tabela 6.12 Resultados de TG/DTG de amostras dos ingredientes cosméticos

Tabela 6.13 Resultados de TG/DTG de amostras de dimeticone (F2) e das formulações F2A, F2B e F2C

Tabela 6.14 Resultados de TG/DTG de amostras de leave-on (F3) e das formulações F3A, F3B e F3C.

Tabela 6.15 Resultados de análise elementar ( $\mathrm{CHN})$ de amostras dos ingredientes cosméticos e das formulações cosméticas

Tabela 6.16 Avaliação das características organolépticas (aspecto, cor e odor), valores de $\mathrm{pH}$, viscosidade aparente do condicionador leave-on contendo os ingredientes $A, B$ e $C$ submetidos ao teste de estabilidade acelerada (F3A, F3B e F3C)

Tabela 6.17 Técnicas utilizadas nas etapas de caracterização das amostras de cabelo submetidas aos tratamentos com formulações cosméticas sem e com o emprego de dispositivo térmico

Tabela 6.18 Denominação das mechas de cabelo empregadas no estudo de avaliação da proteção dos ingredientes/formulações cosméticas

Tabela 6.19 Resultados de TG/DTG de amostras das mechas de cabelo caucasiano e oriental submetidas às formulações contendo os ingredientes cosméticos

Tabela 6.20 Resultados de $T_{d}$ e $\Delta H_{H_{2}} \mathrm{O}$ (evento da desidratação) de amostras das mechas de cabelo caucasiano, oriental e brasileiro submetidas às formulações contendo os ingredientes cosméticos e estocadas em ambiente controlado $22 \pm 2^{\circ} \mathrm{C} ; 20 \pm 2 \%$

Tabela 6.21 Resultados de $T_{D}$ e $\Delta H D$ (evento da fusão da fase cristalina da queratina) de amostras das mechas de cabelo caucasiano, oriental e brasileiro submetidas às formulações contendo os ingredientes cosméticos e estocadas em ambiente controlado $22 \pm 2^{\circ} \mathrm{C} ; 20 \pm 2 \%$ 
Tabela 6.22 Resultados de $\mathrm{T}_{\mathrm{d}}$ e $\Delta \mathrm{H}_{2} \mathrm{O}$ de amostras das mechas de cabelo caucasiano, oriental e brasileiro tratadas com as formulações cosméticas, submetidas ao tratamento térmico (piastra/lavagem com LESS $10 \% \mathrm{~m} / \mathrm{m}$ ) e estocadas em ambiente controlado $22 \pm 2^{\circ} \mathrm{C} ; 20 \pm 2 \%$

Tabela 6.23 Resultados de $T_{D}$ e $\Delta H_{D}$ de amostras das mechas de cabelo caucasiano, oriental e brasileiro tratadas com as formulações cosméticas, submetidas ao tratamento térmico (piastra/lavagem com LESS $10 \% \mathrm{~m} / \mathrm{m}$ ) e estocadas em ambiente controlado $22 \pm 2^{\circ} \mathrm{C} ; 20 \pm 2 \%$

Tabela 6.24 Resultados de $\Delta H_{D}$ e porcentagens de proteção térmica de amostras das mechas de cabelos caucasiano oriental e brasileiro tratadas com as formulações e submetidas ao tratamento térmico (piastra/lavagem com LESS $10 \% \mathrm{~m} / \mathrm{m}$ ) ..

Tabela 6.25 Resultados de análise elementar (CHN) de amostras das mechas de cabelo caucasiano, oriental e brasileiro tratadas com as formulações contendo os ingredientes cosméticos ....

Tabela 6.26 Atribuição das principais bandas dos espectros no IV de amostras das mechas de cabelo virgem caucasiano tratadas com as formulações e submetidas ao tratamento térmico (piastra/lavagem com LESS 10\% $\mathrm{m} / \mathrm{m}$ )

Tabela 6.27 Atribuição das principais bandas dos espectros no IV de amostras das mechas de cabelo virgem oriental tratadas com as formulações e submetidas ao tratamento térmico (piastra/lavagens com LESS $10 \% \mathrm{~m} / \mathrm{m}$ )

Tabela 6.28 Atribuição das principais bandas dos espectros no IV de amostras das mechas de cabelo brasileiro (virgem e descolorido, antes e após tratamento térmico) e das mechas de cabelo brasileiro descolorido tratadas com as formulações e submetidas ao tratamento térmico (piastra/lavagens com LESS $10 \% \mathrm{~m} / \mathrm{m}$ )

Tabela 6.29 Valores de extensão $(\mathrm{m})$, força média $(\mathrm{N})$ e trabalho $(\mathrm{J})$ obtidos no teste de penteabilidade a seco das mechas de cabelo brasileiro tratadas com as formulações e submetidas ao tratamento térmico (piastra/lavagem com LESS 10\% $\mathrm{m} / \mathrm{m}$ ) 
Tabela 6.30 Modelo de ANOVA para os resultados obtidos no teste de penteabilidade a seco das mechas de cabelo brasileiro (virgem e descolorido) tratadas com as formulações $\mathrm{e}$ submetidas ao tratamento térmico (sem tratamento com as formulações)

Tabela 6.31 Modelo de ANOVA para os resultados obtidos no teste de penteabilidade a seco das mechas de cabelo brasileiro descolorido tratadas com as formulações e submetidas ao tratamento térmico (piastra/lavagens com LESS 10\% $\mathrm{m} / \mathrm{m}$ ) ..

Tabela 6.32 Quantidade de fios quebrados obtida no teste de quebra por escovação das mechas de cabelo brasileiro descolorido e submetidas ao tratamento térmico (piastra/lavagens com LESS $10 \% \mathrm{~m} / \mathrm{m}$ )

Tabela 6.33 Modelo de ANOVA para os resultados obtidos no teste de quebra por escovação das mechas de cabelo brasileiro (virgem e descolorido) tratadas com as formulações e submetidas ao tratamento térmico (piastra/lavagens com LESS $10 \% \mathrm{~m} / \mathrm{m}$ )

Tabela 6.34 Resultados dos testes de quebra por escovação das mechas de cabelo brasileiro (virgem e descolorido) submetidas ao tratamento térmico (piastra/lavagens com LESS $10 \% \mathrm{~m} / \mathrm{m}$ ) ...

Tabela 6.35 Tratamento de Fisher (LSD)/Análise das diferenças entre as categorias com intervalo de confiança de $95 \%$ 


\section{LISTA DE ABREVIATURAS, SIGLAS E SÍMBOLOS}

A - ingrediente $A$

$A E$ - Análise elementar

Al - Alumínio

ANVISA - Agência Nacional de Vigilância Sanitária

ATR - Attenuated Total Reflection

$\mathrm{B}$ - ingrediente $\mathrm{B}$

$\beta$ - Razão de aquecimento

$\mathrm{C}$ - ingrediente $\mathrm{C}$

CMC - Complexo da membrana celular

CG/DCT - Cromatografia em fase gasosa/Detector de condutividade térmica

DM - Dimeticone

$\mathrm{DM}+\mathrm{A}$ - Dimeticone $+\mathrm{A}$

$\mathrm{DM}+\mathrm{B}-$ Dimeticone $+\mathrm{B}$

$\mathrm{DM}+\mathrm{C}-$ Dimeticone $+\mathrm{C}$

DSC - Calorimetria Exploratória Diferencial

DTA - Análise térmica diferencial

$E_{a}$ - Energia de ativação

EO - Óxido de eteno

FTIR - Espectroscopia na região do infravermelho com Transformada de Fourier (Fourier transform infrared spectroscopy)

F2 - Formulação 2 - Dimeticone

F2A - Formulação 2 + ingrediente A

F2B - Formulação 2 + ingrediente $B$

F2C - Formulação 2 + ingrediente C

F3 - Formulação 3 - condicionador Leave-on

F3A - Formulação 3 + ingrediente $A$

F3B - Formulação 3 + ingrediente B

F3C - Formulação 3 + ingrediente C

GC-MSD - Cromatografia a Gás - Detector de Massa Seletiva (Gas chromatography - mass selective detector)

IF - Filamentos intermediários 
IFAPs - Proteínas associadas aos filamentos intermediários $\mathrm{INCl}$ - International Nomenclature of Cosmetic Ingredient LESS - Lauril Éter Sulfato de Sódio

Lo - leave-on

Lo $+\mathrm{A}$ - leave-on $+A$

Lo $+\mathrm{B}$ - leave-on $+B$

Lo $+\mathrm{C}-$ leave-on $+C$

$\mathrm{LiTaO}_{3}-$ Tantalato de lítio

LSD - Least Significant Difference

MCCont - Mecha caucasiana controle

$\mathrm{MCDM}+\mathrm{A}-$ Mecha caucasiana dimeticone $+\mathrm{A}$

$\mathrm{MCDM}+\mathrm{B}-$ Mecha caucasiana dimeticone $+\mathrm{B}$

$M C D M+C-$ Mecha caucasiana dimeticone $+C$

MCLo+A - Mecha caucasiana Leave-on + A

MCLo+B - Mecha caucasiana Leave-on + B

MCLo+C - Mecha caucasiana Leave-on + C

MOCont - Mecha oriental controle

MODM+A - Mecha oriental dimeticone $+A$

MODM+B - Mecha oriental dimeticone $+B$

MODM $+C-$ Mecha oriental dimeticone $+C$

MOLo+A - Mecha oriental leave-on + A

MOLo+B - Mecha oriental leave-on + B

MOLo+C - Mecha oriental leave-on + C

MBCont - Mecha brasileira tipo // controle

MBCont1 - Mecha brasileira tipo // controle 1

MBDM+A - Mecha brasileira tipo // dimeticone + A

$\mathrm{MBDM}+\mathrm{B}-$ Mecha brasileira tipo // dimeticone + B

$\mathrm{MBDM}+\mathrm{C}-$ Mecha brasileira tipo // dimeticone $+\mathrm{C}$

MBLo+A - Mecha brasileira tipo II leave-on + A

MBLo+B - Mecha brasileira tipo II leave-on + B

MBLo+C - Mecha brasileira tipo II leave-on + C

MEV - Microscopia eletrônica de varredura

PEG-12 - Polietilenoglicol 12 
PVP - polivinilpirrolidona

$\mathrm{Pt}$ - Platina

RDC - Resolução da Diretoria Colegiada

rpm - rotações por minuto

TG/DTG - Termogravimetria/Termogravimetria derivada

TDTG - Temperatura inicial de decomposição térmica

$T_{\text {onset }}$ - Temperatura inicial de um evento em Análise Térmica

$T_{d}$ - Temperatura de desidratação

$T_{D}$ - Temperatura de desnaturação

TG/DTA - Termogravimetria/Análise Térmica Diferencial

U.R. - Umidade relativa

UV - Ultravioleta

VCBS - Valor calculado na base seca

VE - Valor experimental

VP/DMAPA - vinylpyrrolidone and dimethylaminopropyl methacrylamide

$\Delta \mathrm{H}_{\mathrm{D}}$ - Entalpia de desnaturação

$\Delta \mathrm{H}_{2} \mathrm{O}$ - Entalpia de desidratação 


\section{INTRODUÇÃO}

O cabelo é constituído de uma proteína, denominada a-queratina. Em cada fio de cabelo, milhares de cadeias de a-queratina estão entrelaçadas em uma forma espiral, sob a forma de placas que se sobrepõem, resultando em um longo e fino "cordão" proteico. Estas proteínas interagem fortemente entre si, por diferentes maneiras resultando na forma característica de cada tipo de cabelo: liso, enrolado, ondulado, etc (ROBBINS, 1994).

O termo raça se aplica a subpopulações ou grupos de pessoas similares em várias características biológicas. Para os propósitos de classificação dos tipos de cabelo, os grupos raciais podem ser separados em três: caucasiano, oriental e afro-étnico. Etnia é um fator importante na determinação de formulações para produtos de beleza, porque diferentes tipos de cabelo étnicos são diferentes em sua estrutura e propriedades (ROBBINS, 1994).

Em uma busca na literatura, observou-se uma quantidade limitada de artigos científicos que diferenciam os tipos de cabelos e que discutam os efeitos provocados pela adição de produtos destinados a proteção térmica destes quando da aplicação de dispositivos térmicos nos cabelos. Por isso, cada vez mais, torna-se necessário o desenvolvimento de estudos que estejam desvinculados dos aspectos comerciais visto que os tratamentos com uso de modeladores térmicos tem aumentado.

Neste contexto, o presente trabalho busca o entendimento quanto à composição química da fibra capilar (e seu componente majoritário, a queratina) dos três tipos principais de etnias. Então, amostras de cabelo caucasiano, oriental e afro-étnico foram caracterizadas quanto à composição química e estrutural e ao comportamento térmico empregando termogravimetria/termogravimetria derivada, calorimetria exploratória diferencial, análise elementar, espectroscopia na região do infravermelho, microscopia eletrônica de varredura e também, as técnicas de avaliação de eficácia como tensão/deformação e penteabilidade.

Da literatura, sabe-se que o cabelo é composto em sua grande maioria por queratina, em uma faixa de 65 a 95\% (ROBBINS, 1994; BHUSHAN, 2010). Desta forma, uma amostra de queratina pura (animal) foi caracterizada por TG/DTG e 
DSC com intuito de comparar o comportamento térmico entre esta última e as amostras de cabelo.

Em seguida, ingredientes cosméticos (silicones) com diferentes funções químicas, contendo grupos amino e/ou siloxanos, foram incorporados a diferentes veículos resultando, desta maneira, em diferentes formulações e as mesmas foram aplicadas nas mechas de cabelo. Posteriormente, as mechas foram submetidas a procedimentos alternando ciclos de aquecimento e lavagem de maneira a simular a realidade, porém mais agressivos, do que aqueles que normalmente ocorrem, diariamente, com os cabelos. Os danos causados a essas mechas de cabelo e o efeito dos tratamentos poliméricos foram investigados utilizando-se DSC, FTIR-ATR, análise elementar e análise de imagens por MEV.

Amostras de cabelo brasileiro virgem e descolorido foram caracterizadas sob as mesmas condições com o intuito de comparar o comportamento destas últimas com as virgens. Isto porque, de acordo com a literatura, cabelos submetidos aos processos de clareamento tornam-se mais frágeis, quebradiços e porosos, e desta maneira mais suscetíveis à umidade (BROWN, 1997). Após o os procedimentos de lavagem e tratamento térmico, estas mechas (virgens e descoloridas), foram, também, submetidas ao teste de eficácia de quebra por escovação. 


\section{REVISÃO DA LITERATURA}

\subsection{Propriedades gerais}

Os cabelos e os pêlos do corpo se originam em estruturas denominadas folículos (Figura 2.1), os quais estão distribuídos por toda a superfície do organismo, exceto na pele glabra (palmas das mãos e sola dos pés). $O$ folículo capilar se desenvolve com um crescimento oblíquo ou curvado de células epidermais dentro da derme ou hipoderme, sendo canalizado para formar uma estrutura relativamente imóvel da raiz (HARRIS, 2009).

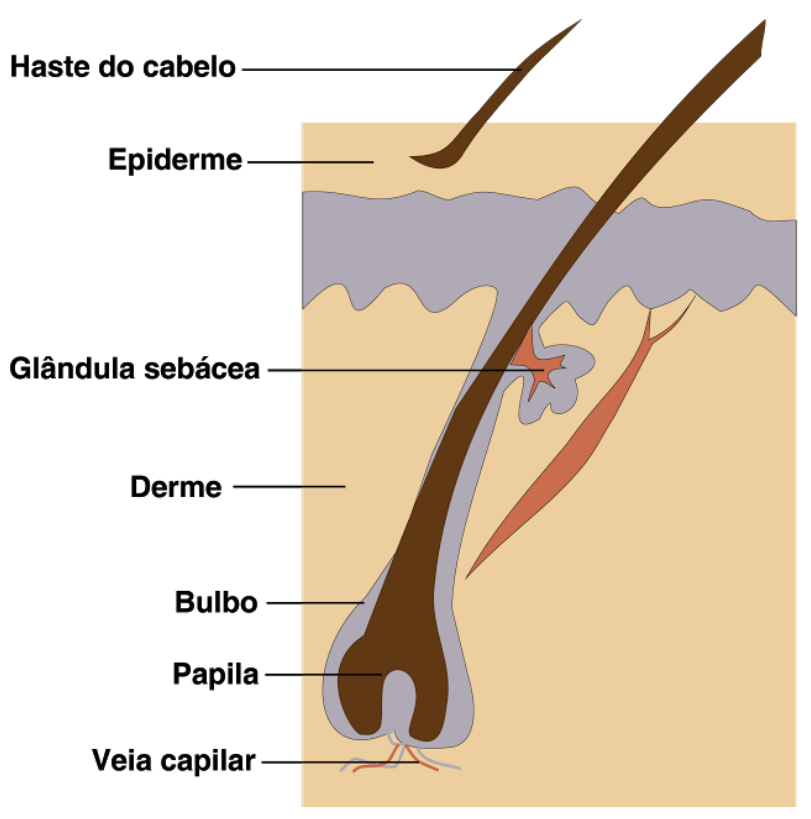

Figura 2.1 llustração de um folículo piloso com detalhe da glândula sebácea.

Em média, o ser humano possui de 100 mil a 150 mil folículos distribuídos irregularmente no organismo, responsáveis pela produção de diferentes tipos de fios:

- folículos de pêlos terminais: produzem cabelos e barbas e possuem glândulas sebáceas médias ou grandes;

- folículos de velos: presentes no restante do organismo, exceto nas regiões cobertas com a pele glabra, possuem pêlos finos e pequenos, com glândulas sebáceas pequenas, quando presentes; 
- folículos sebáceos: com pêlos muito pequenos que não chegam à superfície e glândulas multiglobulares.

A densidade de folículos varia ao longo da vida, porém quando nascemos o seu número total já está determinado. Conforme nos desenvolvemos, com o crescimento da cabeça, há uma diminuição da densidade de fios, mas o seu número total permanece inalterado (HARRIS, 2009).

Os folículos são permanentemente regenerados, passando ao longo da vida por cerca de vinte ciclos completos (HARRIS, 2009).

Os pêlos são, antes de tudo, um órgão sensorial, sendo também uma proteção como sobrancelhas e cílios que protegem os olhos (HARRIS, 2009).

Os velos são mais curtos, com até $1 \mathrm{~cm}$ ou $2 \mathrm{~cm}$ de comprimento, possuem pouca ou nenhuma pigmentação e são oriundos de folículos que não estão associados às glândulas sebáceas (se estas estão presentes são minúsculas). As unidades de folículos que produzem os velos não são alteradas com as taxas hormonais, produzindo o mesmo tipo de haste durante toda a vida (HARRIS, 2009).

Os pelos terminais são maiores, variando em comprimento, diâmetro e forma conforme a região do corpo e são associados a glândulas sebáceas (HARRIS, 2009).

\subsection{Fisiologia da fibra capilar}

O cabelo é uma fibra natural constituída de uma proteína denominada queratina que se organiza na forma de duas hélices enroladas, combinadas com outras para formar uma microfibrila (WILKINSON \& MOORE, 1990).

Existem duas classes de queratina. As $\alpha$-queratinas são relativamente ricas em resíduos de cistina e contêm a maioria dos aminoácidos comuns. Consiste em um material proteico insolúvel que compreende mais de $85 \%$ da estrutura capilar, sendo formada por cadeias peptídicas arranjadas em paralelo, que interagem entre si por três tipos de ligações cruzadas: de cisteína, iônicas e de hidrogênio (LEHNINGER, 1976; VILLA et al., 2008; HALAL, 2011). As $\beta$ queratinas são encontradas nas fibras produzidas pelas aranhas e bichos-daseda, nas escamas, nas conchas e nos bicos de répteis e pássaros 
(LEHNINGER, 1976).

As $\alpha$-queratinas incluem os tipos moles (contêm cerca de 10 a $14 \%$ de cistina) e duras (possuem um elevado teor de cistina - até $22 \%$ ). Ambos os tipos são encontrados nos folículos pilosos, sendo que a queratina mole recobre a pele de maneira generalizada e a dura é encontrada em certos anexos, como por exemplo, cutículas e córtex dos pêlos do homem, penas, garras e cascos de animais (LEHNINGER, 1976; HAM \& CORMACK, 1983). A queratina é um polipeptídio de elevado peso molecular contendo cadeias formadas pela condensação de L-aminoácidos (Figura 2.2).

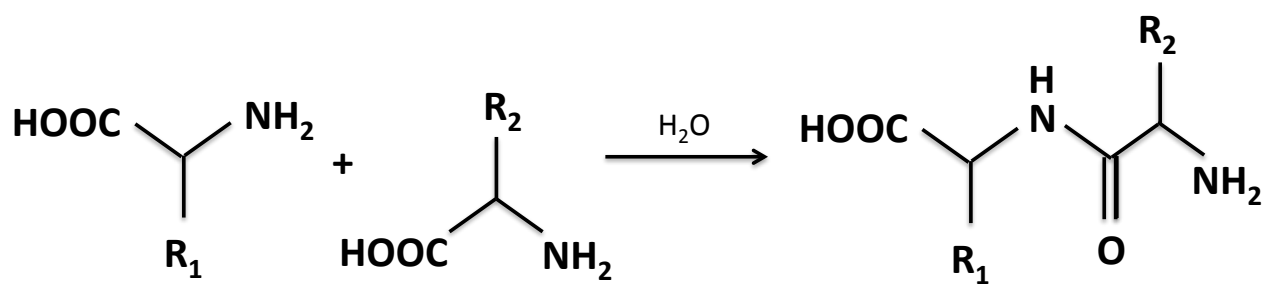

Figura 2.2 Reação de condensação de aminoácidos

A ligação que se forma mediante condensação que liga os aminoácidos é chamada de ligação peptídica. A cadeia polipeptídica torna-se a estrutura da fibra a-queratina. Os grupos $\mathrm{R} 1$ e $\mathrm{R} 2$ representam as cadeias laterais dos resíduos de aminoácidos da a-queratina correspondente a 18 composições diferentes de cabelos das raças humanas principais (Tabela 2.1).

As ligações químicas responsáveis pela estrutura da queratina podem ser de 5 tipos: ligação iônica, ligação de hidrogênio, força de Van der Waals, ligação peptídica ou éster e ligação dissulfeto (RIEGER \& BRECHNER, 1988) (Figura 2.3).

Interações de Coulomb, ocasionalmente referidas como ligações salinas, são forças eletrostáticas que atuam entre cadeias laterais de ácido carboxílico negativamente carregados (-COO-) e grupos básicos positivamente carregados $\left(-\mathrm{NH}_{3}{ }^{+}\right)$. As interações iônicas entre estes grupos são enfraquecidas pela água e facilmente rompidas por ácidos ou álcalis fracos. Estas ligações são responsáveis por cerca de um terço da força total dos cabelos e são afetadas pelas mudanças de $\mathrm{pH}$. Em níveis elevados, a carga de aminoácidos pode mudar de positiva para 
negativa e, como resultado, teremos dois aminoácidos negativamente carregados lado a lado. Como cargas iguais se repelem e se afastam, o cabelo se intumesce e a cutícula se abre quando soluções alcalinas são aplicadas (QUADFLIEG, 2003; HALAL, 2011).

Tabela 2.1 Composição de aminoácidos de cabelo humano das principais raças $(\mu \mathrm{mol} / \mathrm{g})$ (WOLFRAM, 2003).

\begin{tabular}{|c|c|c|c|}
\hline \multirow{2}{*}{ Aminoácidos } & \multicolumn{3}{|c|}{ Cabelo } \\
\hline & Caucasiano & Oriental & Afro-étnico \\
\hline Alanina & $345-475$ & $370-415$ & $370-509$ \\
\hline Arginina & $466-534$ & $492-510$ & $482-540$ \\
\hline Ácido aspártico & $407-455$ & $456-500$ & $436-452$ \\
\hline Ácido cisteico & $22-58$ & $35-41$ & $10-30$ \\
\hline Ácido Glutâmico & $868-1063$ & $1026-1082$ & $915-1017$ \\
\hline Glicina & $450-544$ & $454-498$ & $467-542$ \\
\hline Histidina & $56-70$ & $57-63$ & $60-85$ \\
\hline Isoleucina & $188-255$ & $205-244$ & $224-282$ \\
\hline Leucina & $442-558$ & $515-546$ & $484-573$ \\
\hline Lisina & $178-220$ & $182-196$ & $198-236$ \\
\hline Metionina & $8-54$ & $21-37$ & $6-42$ \\
\hline Fenilalanina & $124-150$ & $129-143$ & $139-181$ \\
\hline Prolina & $588-753$ & $615-683$ & $642-697$ \\
\hline Serina & $851-1076$ & $986-1101$ & $672-1130$ \\
\hline Treonina & $542-654$ & $568-593$ & $580-618$ \\
\hline Tirosina & $126-194$ & $131-170$ & $179-202$ \\
\hline Valina & $405-542$ & $421-493$ & $442-573$ \\
\hline $1 / 2$ Cistina & $1268-1608$ & $1175-1357$ & $1310-1420$ \\
\hline
\end{tabular}




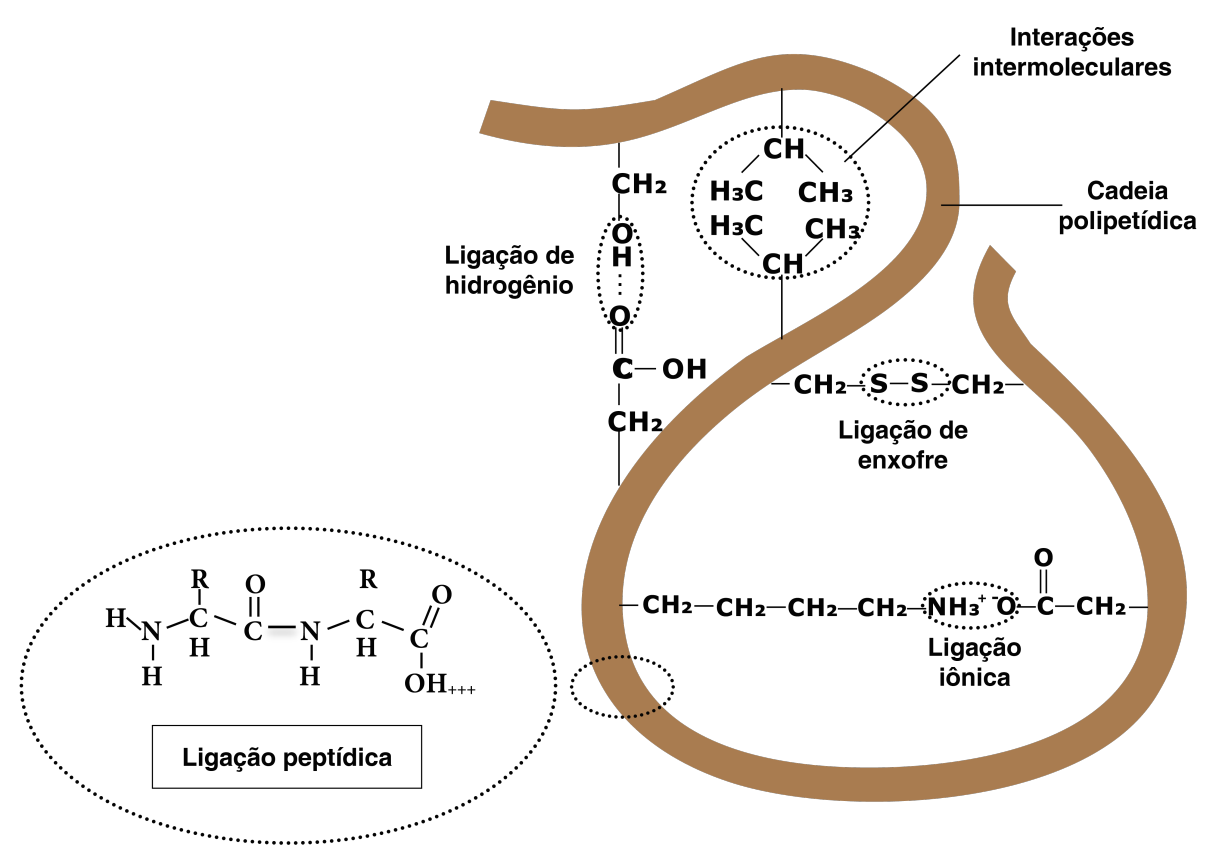

Figura 2.3 Ilustração das ligações presentes na queratina do cabelo humano (Fonte:http://pt.slideshare.net/jestigaribia/ana-nery-indstria-de-cosmticos-ecuidados-de-higiene; adaptado).

As ligações de hidrogênio são um tipo especial de ligação iônica. Existem dois tipos de ligações de hidrogênio na a-queratina: um grupo realiza ligação entre as moléculas de água e grupos hidroxila $(-\mathrm{O} . . . \mathrm{H}-\mathrm{O})$ e outro estabelece ligações entre uma amida e um grupo carbonila e a amida $\mathrm{C}=\mathrm{O}$ da cadeia lateral (Figura 2.4). As ligações de hidrogênio são mais fracas e menos resistentes que todas as outras ligações e facilmente rompidas - basta molhar o cabelo -, porém se regeneram quando o cabelo seca (QUADFLIEG, 2003; HALAL, 2011).

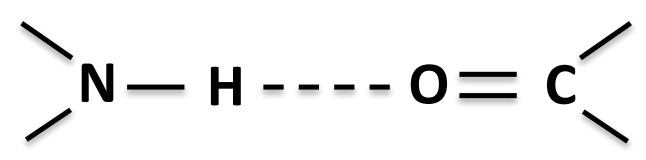

Figura 2.4 Ligação de hidrogênio entre amida e grupos carbonila da a-queratina.

As ligações covalentes de cistina ou dissulfeto (-SS-) contribuem significativamente para as propriedades físicas e químicas da queratina cabelo. 
Estas são o resultado de uma reação de oxidação entre os grupos tiol adjacentes (-SH) de moléculas de cisteína opostas na cadeia polipeptídica, consequentemente, formando uma molécula de cistina. Este aminoácido pode ser reduzido e posteriormente re-oxidado sob a forma de ligação dissulfídica. Os resíduos de cisteína adjacentes dos filamentos de queratina formam ligações covalentes dissulfeto, criando uma forte ligação transversal entre as cadeias de queratina adjacentes. As ligações dissulfeto contribuem muito para a forma, a estabilidade e textura do cabelo. Essa é a base para o processo de ondulação permanente. A cistina é muito estável, motivo pelo qual o cabelo humano pode ser encontrado relativamente intacto, mesmo muitos anos após a morte do indivíduo (WILKINSON \& MOORE, 1990; FEUGHELMAN, 1997). Tratam-se de ligações mais fracas do que as peptídicas, porém mais fortes que as salinas ou as ligações de hidrogênio, sendo alteradas apenas quimicamente (QUADFLIEG, 2003; HALAL, 2011).

\subsection{A estrutura do cabelo}

A fibra capilar é formada basicamente por cutícula, córtex e medula. A Figura 2.5 apresenta as principais camadas das fibras capilares.

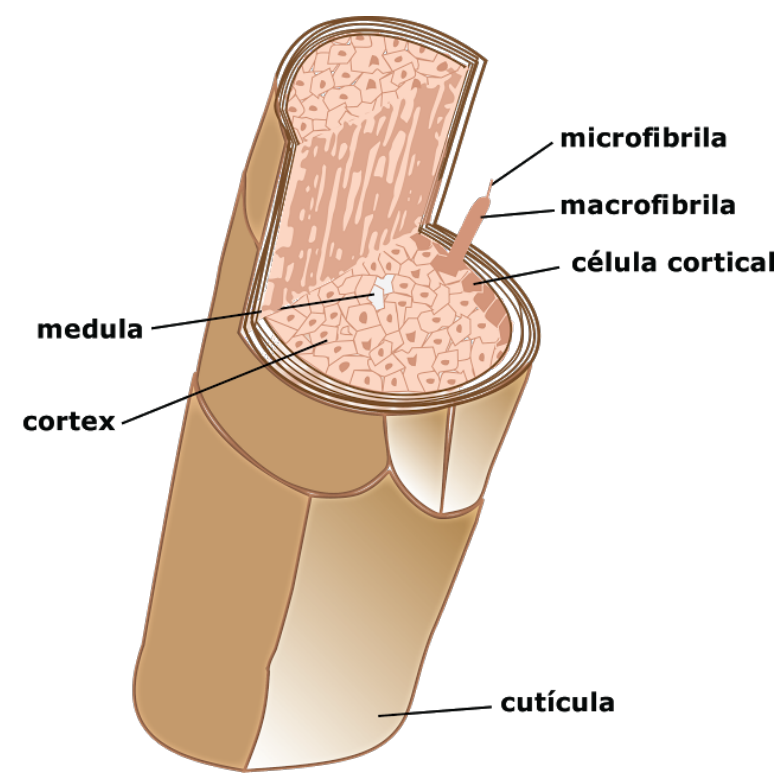

Figura 2.5 llustração da fibra de cabelo e das subestruturas da cutícula e córtex (ROBBINS, 1994, adaptado). 
A cutícula (parte externa) é a principal barreira à penetração de agentes químicos e enzimáticos no interior do fio e é também a responsável pelas propriedades superficiais do cabelo. É a camada mais externa da fibra capilar e é constituída de uma camada de várias células semelhantes. Essa estrutura tem um grande efeito sobre a permeação de substâncias no cabelo (ROBBINS, 1971; BHUSHAN, 2010). A superfície da célula da cutícula é coberta por uma fina camada de lipídios chamada camada $\beta$. Entre células adjacentes, estes lipídeos são separados pela camada $\delta$ de componentes proteicos. Esta estrutura tripla entre as células adjacentes é chamada de complexo da membrana celular (CMC). CMC é a única subestrutura que continuamente preenche os espaços intercelulares de uma fibra capilar. Por isso, é considerado um caminho importante para a penetração das substâncias (INOUE et al., 2005; BHUSHAN, 2010) (Figura 2.6). A camada $A$, que está adjacente à principal componente da cutícula, a exocutícula, representa dois terços da estrutura de cutícula é rica em cisteína (cerca de 30\%). Caracteriza-se como uma camada bioquimicamente estável, que resiste fortemente a forças físicas e químicas. As proteínas da exocutícula são densamente reticuladas por ligações dissulfeto (cerca de 15\% em cistina), mas não tão extensivas como as proteínas da camada A (ROBBINS, 1994). A próxima camada adjacente é a endocutícula, porém é deficiente em cistina (cerca de $3 \%$ ), contendo muitos dos fragmentos celulares nãoqueratinizados e um teor elevado de proteínas ácidas e básicas (WOLFRAM, 2003).

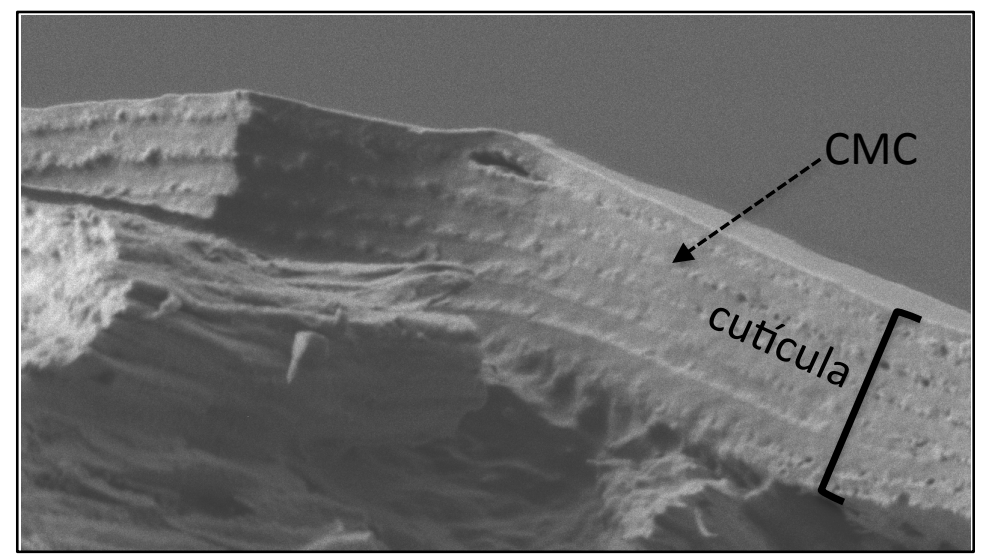

Figura 2.6 Imagem de MEV de uma amostra de cabelo oriental indicando a cutícula e o complexo de membrana celular. Imagem registrada no presente trabalho. 
A medula é uma camada cilíndrica fina localizada no centro do fio de cabelo que possui um elevado teor de lipídeos, sendo pobre em cistina. A literatura relata que sua função ainda não está completamente esclarecida, porém é sabido que suas células desidratam-se e os espaços podem ser preenchidos com ar, afetando a cor e o brilho nos cabelos. A medula é fracamente queratinizada e mal interconectada, nem todos os fios possuem medula (ROBBINS, 1994; VELASCO et al., 2009).

O córtex forma o interior do fio e é o maior constituinte da fibra do cabelo, sendo o responsável pela sua resistência mecânica. É formado por macrofibrilas de queratina alinhadas na direção do fio, onde se encontram distribuídos aleatoriamente os grânulos de melanina cujo tipo, tamanho e quantidade determinam a cor do cabelo. Desta maneira, é no córtex que ocorrem as transformações químicas que resultam em alisamento, ondulação definitiva e tintura, dentre outras (KOLAR \& MILLER, 1972; HARRIS, 1979; OBUKOWHO \& BIRMAN, 1996; FEUGHELMAN, 1997; VELASCO et al., 1999; BHUSHAN, 2010). As proteínas com estrutura de $\alpha$-hélice estão enroladas umas nas outras como cordas esticadas (enroladas entre si, onduladas). Quando o cabelo é esticado, essa ondulação confere certa elasticidade. As proteínas enroladas no cabelo organizam-se na forma de microfibrilas, as quais se unem para formar estruturas maiores, a fim de produzir as células do córtex. Essa estrutura encadeada oferece à fibra capilar mais força e elasticidade (WILKINSON \& MOORE, 1990; ROBBINS, 2012).

Três tipos de células corticais têm sido observadas na fibra capilar: ortocorticais, para-corticais e meso-corticais, e estas são algumas vezes segregadas em regiões distintas na fibra capilar. A região do orto-córtex revelou conter maior matriz intermacrofibrilar de não-queratina que a do para-córtex (THIBAUT et al., 2007). Wortmann e Deutz (1991) identificaram dois tipos de células, as orto- e para-corticais, as quais foram separadas e identificados de maneira a diferenciar as células pela sua coloração. $O$ orto-córtex contém menor concentração de ligações dissulfeto do que o para-córtex (WORTMANN E DEUTZ, 1991).

Segundo trabalho publicado por Thibaut et al. (2007) que avaliou mechas de cabelos de diferentes formas (lisos, encaracolados e crespos) os diferentes tipos de células corticais têm uma distribuição característica de acordo com o tipo 
de cabelo. Cabelos ondulados são caracterizados por possuírem as macrofibrilas orto-corticais e meso-corticais entrelaçadas em volta das macrofibrilas paracorticais. Aumentando o grau do ondulamento, nos cabelos crespos desaparece o meso-córtex, predominando as células orto-corticais. No cabelo liso os três tipos de macrofibrilas assumem a conformação reta, sendo as células meso-corticais predominantes (THIBAUT et al., 2007).

\subsection{Variedade étnica}

O termo raça se aplica a subpopulações ou grupos de pessoas similares em várias características biológicas. No passado, as raças se desenvolviam e persistiam porque viajar longas distâncias era limitado, então pessoas similares interagiam e procriavam. As diferenças raciais ou geográficas que são encontradas hoje nos tipos de pele e cabelo podem ser remanescentes das primeiras adaptações à temperatura e a outras influencias ambientais. Os diferentes tipos de cabelos podem ser classificados genericamente em três grandes grupos: caucasiano, oriental e afro-étnico (ou negróide) (ROBBINS, 1994). Considerando a população mundial na década de $70,56 \%$ era composta pela raça caucasiana, $34 \%$ pela raça oriental/mongol e $10 \%$ pela raça negra.

O cabelo caucasiano é proveniente de pessoas de ancestralidade européia e possui características como diâmetro menor, curvatura lisa e levemente ondulada, secção transversal redonda a levemente ovalada, diâmetro entre 50 a $120 \mu \mathrm{m}$ e cor que pode variar do loiro ao castanho escuro. O diâmetro está diretamente relacionado à estrutura do córtex, pois o diâmetro do córtex é determinado pelo número de células no bulbo capazes de atividade mitótica e sua taxa de divisão celular, onde as microfibrilas são embebidas em uma matriz proteica com alta taxa de enxofre, que fornece uma matriz fibrosa muito resistente (HARRIS, 2009).

As variações na curvatura da fibra e na forma da secção transversal são determinadas geneticamente. Consequentemente, informações raciais das características capilares são úteis (ROBBINS, 1994).

O cabelo oriental é o mais resistente e de maior diâmetro, seguido do cabelo caucasiano, sendo que ambos tipos de cabelo tem uma secção transversal 
circular, predominantemente. Cabelo oriental é geralmente muito liso ao longo do seu eixo e o cabelo caucasiano varia de liso ondulado a moderadamente encaracolado. Cabelo afro-étnico apresenta uma estrutura enovelada característica. Estas variações na forma (diâmetro, elipticidade e curvatura) de cabelo a partir de diferentes origens étnicas dependem de vários fatores, incluindo a forma do folículo de cabelo e a sua abertura; estes variam de uma pessoa para outra e também entre as raças (GRAY, 1997; GRAY, 2001; THIBAUT et al., 2005).

O cabelo afro-étnico possui um alto grau de irregularidade no diâmetro ao longo da fibra quando comparado aos demais tipos étnicos. Sabe-se também que a secção transversal de sua fibra é mais oval do que os cabelos caucasiano e oriental, que são mais cilíndricos. Também apresenta menor resistência ao estiramento e quebra mais facilmente do que o cabelo caucasiano e necessita de uma maior força para ser penteado, apresentando menor conteúdo de água em relação ao cabelo caucasiano e oriental (FRANBOURG et al., 2003). Outra característica importante é que o cabelo afro-étnico adquire maior carga estática residual quando penteado, esteja na sua forma natural ou tratado (permanente, alisamento, tintura). O cabelo caucasiano consegue reter cerca de $5 \%$ a mais de umidade que o afro-étnico, sendo este, portanto, levemente mais seco em relação à hidratação (GOMES, 2008).

Sob o aspecto químico, em termos de proteínas e aminoácidos, os cabelos caucasiano, afro-étnico e oriental são similares (FRANBOURG et al., 2003). A partir da análise de aminoácidos de fibra capilar das três raças principais observou-se a coincidência entre as quantidades de todos os aminoácidos do cabelo do escalpo para esses três maiores grupos raciais (ROBBINS, 1994).

Entre outros grupos étnicos importantes estão os orientais, cujo cabelo se assemelha bastante ao caucasiano em termos de estrutura e penteabilidade. Uma diferença marcante entre os diversos grupos étnicos é o estilo de penteado. Quase que exclusivos de cada grupo, eles buscam identificação com sua cultura e diferenciação em relação às demais (GOMES, 2008).

A classificação geral dos três tipos de etnias, segundo De La Mettrie et al. (2007) é muito ampla e não explica a alta complexidade da diversidade biológica humana, resultante de ambas as múltiplas e passadas ou recentes origens mistas. Os autores avaliaram amostras de cabelo de 1442 indivíduos de 18 países 
(dentre eles, 162 indivíduos brasileiros da cidade do Rio de Janeiro) com base em quatro parâmetros relacionados a características físicas de cabelo humano (medidas curvatura e de torsão do cabelo) sem se referirem à etnia humana. Foi definida uma caracterização a qual está ilustrada na Figura 2.7. De acordo com este estudo, as amostras de cabelos afro-étnicos coletados de indivíduos da África do Sul, Gana e Chicago foram classificados principalmente como tipos $\mathrm{V}$ a VIII. Embora os tipos de VI a VIII prevaleceram nas amostras coletados dos indivíduos da África do Sul e Gana, tipo $V$ foi mais frequente nas amostras coletadas em Chicago e provavelmente reflete uma população de origem mista passado. Já os cabelos coletados da China foram essencialmente do tipo I e tipo Il e no Japão e na Coréia as amostras de cabelos coletados atingiram $20 \%$ do tipo III. Amostras de cabelos coletados de voluntários brasileiros mostraram uma grande diversidade variando dos tipos I a VI. Segundo os autores, este fato advém, provavelmente do resultado de origens mistas do passado, levando às populações étnicas múltiplas (DE LA METTRIE et al., 2007).

Lisbôa (2007) estudou a sorção de ácido oleico, colesterol e colato de sódio em cabelos caucasiano e afro-étnico e verificou que existem diferenças entre as interações destes tipos de cabelos com os compostos estudados. Este resultado se mostrou importante uma vez que a literatura estabelece uma similar composição de aminoácidos entre os diferentes grupos étnicos. Segundo o autor, esta pesquisa evidenciou também a importância da investigação das interações lipídicas nos diferentes tipos de cabelos, pois o tipo e o conteúdo desses compostos presentes na fibra capilar podem modificar significativamente as características físico-químicas do cabelo e estas precisam ser consideradas no desenvolvimento de produtos cosméticos que visem contemplar as especificidades dos diferentes tipos étnicos de cabelo (LISBÔA, 2007).

THIBAUT et al. (2007) realizaram um estudo comparativo entre amostras de cabelo variando de liso a crespo com o objetivo de investigar a organização do córtex do bulbo até a ponta da fibra capilar, por meio da técnica de micrografia de transmissão eletrônica. Foi realizado também um exame imuno-histoquímico dos bulbos capilares o qual permitiu a diferenciação precoce de células corticais, no que diz respeito ao padrão de curvatura das amostras de cabelo. Os autores observaram que a organização da macrofibrila está fortemente relacionada com 
ondulação do cabelo. Os folículos de cabelo encaracolado exibiram uma curvatura independente da origem étnica. Em cabelos cacheados, a queratina do cabelo acumulou no lado côncavo da curvatura, enquanto que, no cabelo liso, células corticais foram distribuídas uniformemente pela fibra circular (THIBAUT et al., 2007).

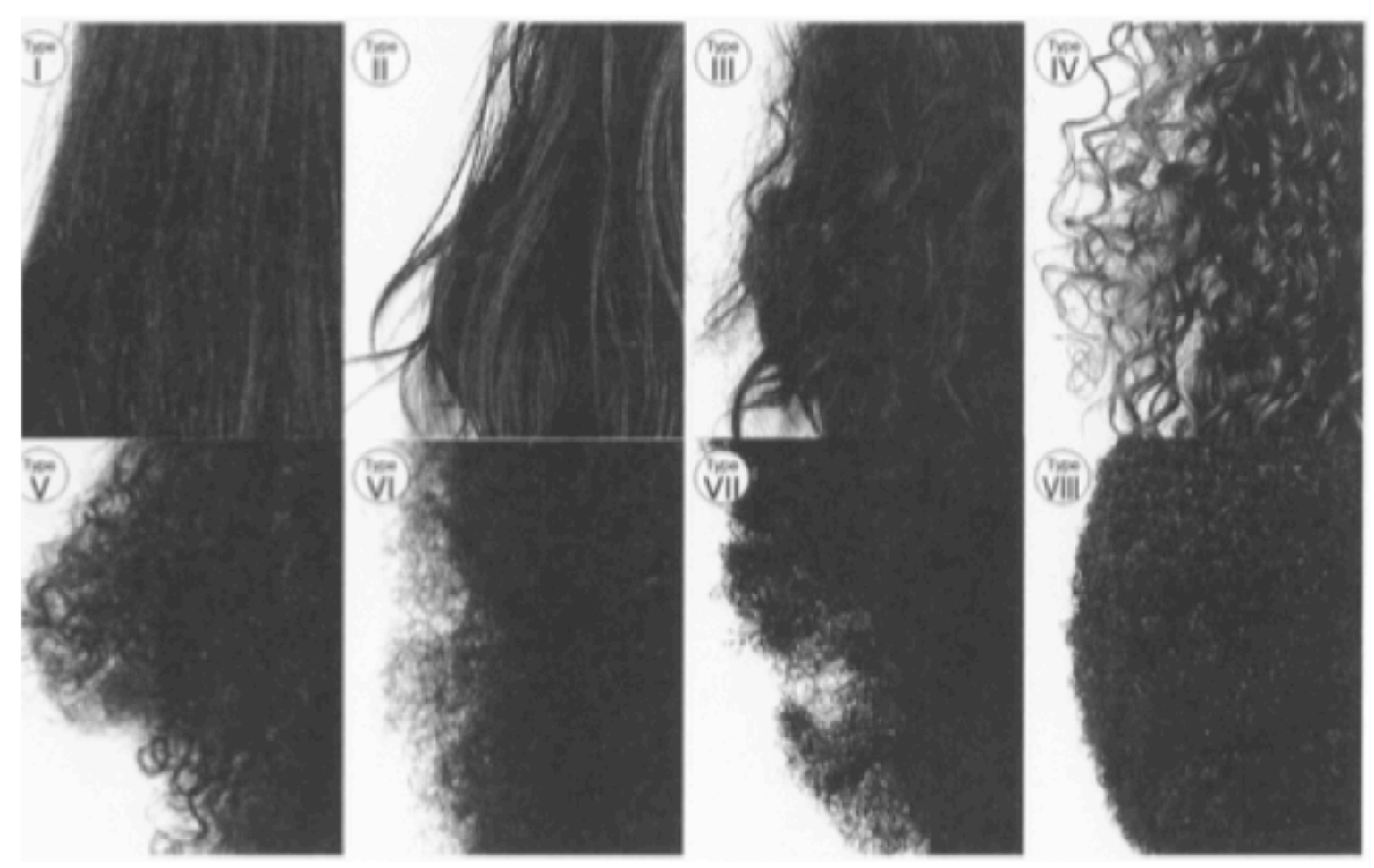

Figura 2.7 Classificação dos diversos tipos de cabelo com sua curvatura e torção de acordo com a classificação definida De La Mettrie et al. (2007).

\subsection{0 processo de clareamento de cabelos}

A cor natural dos cabelos pode ser clareada pela oxidação de colorações permanentes, temporárias ou semi-permanentes ou pela descoloração convencional da melanina, com a aplicação de uma mistura de pó descolorante com água oxigenada cremosa 20,30 ou 40 volumes. Para isto, é utilizado uma solução de peróxido de hidrogênio $\left(\mathrm{H}_{2} \mathrm{O}_{2}\right)$ em água e termo volume indica o volume deste na solução aquosa. $O$ termo volume se refere ao volume de gás oxigênio que é liberado quando o $\mathrm{H}_{2} \mathrm{O}_{2}$ se decompõe (HALAL, 2011). O processo de clareamento de cabelos ocorre em duas etapas, sendo que a primeira é mais 
rápida e envolve a dissolução dos grânulos de pigmentos, ou seja, as melaninas. Em seguida, ocorre uma etapa mais lenta onde é observada a descoloração dos cabelos. Como consequência da descoloração, podem ocorrer danos oxidativos como um efeito secundário na queratina dos cabelos. Este dano é causado pela clivagem oxidativa das ligações dissulfeto para formar o ácido cistéico conforme Figura 2.8 (JACHOWICZ, 1987; JOHNSON, 1997,).

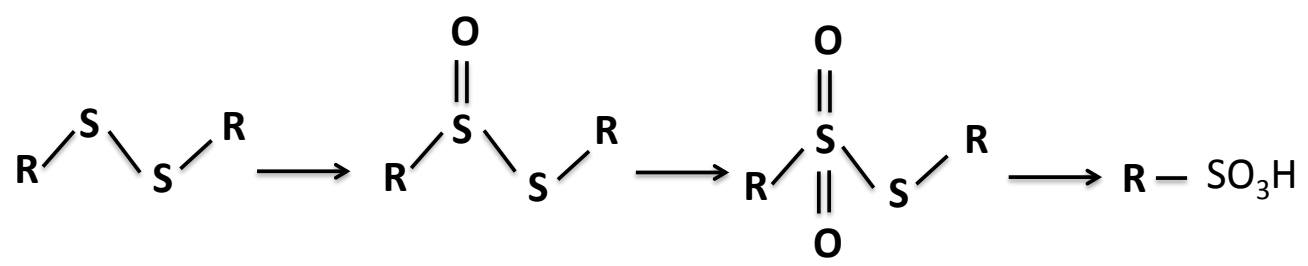

Figura 2.8 Esquema do mecanismo de clivagem S-S para o processo de clareamento de cabelos (BARTON, 2011; adaptado).

O clareamento severo também reduz a concentração dos grupos sulfidrilo livres e, em menor grau de extensão, degrada outros resíduos de aminoácidos, tais como tirosina, treonina e metionina. Como resultado, a estrutura de fibras é enfraquecida com a menor densidade de reticulação e em geral, a sua natureza hidrofilica é aumentada, devido à formação de sítios aniônicos p.ex. resíduos de ácido cistéico. Em particular, a fibra se torna mais frágil, mais susceptível à ruptura, mais porosa e, consequentemente, irá absorver maiores quantidades de água. O mecanismo para a clivagem oxidativa da ligação dissulfeto durante o clareamento químico do cabelo é realizado por meio de um processo de clivagem S-S. Esta clivagem da cistina produz principalmente ácido cistéico ou sulfônico ($\mathrm{SO}_{3} \mathrm{H}$ ), como também ocorre a formação de intermediários de oxidação tais como o monóxido de cistina (-SO-S-) e dióxido de cistina (-SO ${ }_{2}-\mathrm{S}-$ ) (ROBBINS, 1971).

Uma ferramenta utilizada para identificar este tipo de clivagem oxidativa é a espectroscopia na região do infravermelho. Estudos de FTIR têm demonstrado que existem determinadas bandas de absorbância que identificam quando as amostras de cabelo passaram por estes tipos de clivagens (BARTON, 2011). Mais adiante será discutido sobre este assunto. 


\subsection{Cosméticos}

No presente trabalho, foram escolhidos, separadamente, três ingredientes cosméticos e dois veículos (um silicone e uma base condicionadora leave-on) para a incorporação dos mesmos, obtendo, consequentemente, seis formulações cosméticas. Primeiramente, as mesmas foram submetidas ao estudo de estabilidade acelerada para posteriormente serem aplicadas e avaliadas nas amostras de cabelo.

\subsubsection{Definição}

De acordo com a Resolução RDC $n^{0} 7$, de 10 de fevereiro de 2015 da Agência Nacional de Vigilância Sanitária (ANVISA), cosméticos, produtos de higiene pessoal e perfumes são preparações constituídas por substâncias naturais ou sintéticas, de uso externo nas diversas partes do corpo humano, pele, sistema capilar, unhas, lábios, órgãos genitais externos, dentes e membranas mucosas da cavidade oral, com o objetivo exclusivo ou principal de limpá-las, perfumá-las, alterar sua aparência e ou corrigir odores corporais e ou protegê-las ou mantê-las em bom estado (ANVISA, 2004).

\subsubsection{Estabilidade de emulsões cosméticas}

A estabilidade de uma emulsão relaciona-se principalmente à viscosidade da fase interna. Partículas pequenas dispersas em um líquido (ou gás) estão em constante choque devido ao movimento browniano. Diversas manifestações de instabilidade podem ocorrer no sistema devido a estas movimentações e interações entre as fases: inversão de fases, coalescência, formação de creme ou creaming e até a quebra total da emulsão (FLORENCE \& ATWOOD, 2003).

\subsubsection{Condicionadores}

Quando o cabelo não é submetido a tratamentos, ele tende a permanecer em um estado condicionado, isto é, a cutícula permanece intacta e uma camada de sebo fornece proteção ao cabelo frente à fricção mecânica. No entanto, o 
acúmulo de sebo dá aos cabelos uma aparência indesejável, e quando umedecidos, tornam-se vulneráveis à abrasão mecânica que, junto com determinados tratamentos, pode danificá-los (HOSHOWSKI, 1997; SYED, 1997).

Há algumas décadas, acreditava-se que as formulações de limpeza não causassem danos internos ao cabelo. Entretanto, pesquisas recentes têm demonstrado que os lipídios internos podem ser removidos pelos tensoativos durante repetidas lavagens. Outras investigações indicaram, ainda, que sucessivas lavagens com xampu extraem pequenas quantidades de proteína da endocutícula deixando-as com orifícios em seu interior (SCANAVEZ, 2001).

Outros causadores de danos capilares são: escovação, exposição frequente à luz solar, tratamentos químicos como descoloração, tinturas, permanentes, alisamentos e relaxamentos, entre outros. Estes agentes causam alterações na estrutura capilar e tornam os cabelos fracos e quebradiços, difíceis de pentear e ainda podem promover a alteração de sua cor (HOSHOWSKI, 1997).

Condicionadores são produtos formulados para serem utilizados após a lavagem dos cabelos. Lavando-os com xampu de natureza aniônica, empregamse enxágues e condicionadores, emulsionados ou não, de natureza catiônica (CORRÊA, 2012). Foram desenvolvidos para restaurar a capacidade de brilho e maciez normalmente fornecida por sebo. São utilizados para recondicionar os cabelos na sequência de tratamentos químicos, como a ondulação, defrisagem e coloração. São utilizados também após traumas físicos induzidos por dispositivos eletrônicos como secador de cabelos, baby-liss e piastra e até mesmo no escovar e styling. A maioria destes processos muitas vezes levam à diminuição da resistência à tração, fragilidade e porosidade (BOLDUC \& SHAPIRO, 2001). Condicionadores podem proporcionar maleabilidade aos cabelos, diminuindo a eletricidade estática e, reduzindo o atrito entre os cabelos e os eixos, os quais podem levar a emaranhamento. A eletricidade estática é diminuída mediante 0 depósito de íons carregados positivamente sobre o eixo do cabelo, que neutralizam cargas negativas induzidas por pentear ou escovar. $O$ atrito é reduzido pelo alisamento das cutículas e pelo aumento da sua aderência com o eixo da fibra fazendo com que os cabelos reflitam mais luz (BOLDUC \& SHAPIRO, 2001). 


\subsubsection{Condicionadores leave-on}

Os condicionadores leave-on são desenvolvidos para permanecer no cabelo até a sua remoção pela lavagem seguinte. Estes produtos formadores de película aplicam uma camada fina de polímero sobre o cabelo, por exemplo, a polivinilpirrolidona (PVP). O polímero preenche os "defeitos" da haste capilar criando uma superfície lisa para aumentar o brilho, eliminando a eletricidade estática devido à sua natureza catiônica. E estas qualidades lhe conferem um excelente efeito condicionador (DRAELOS, 2013).

\subsubsection{Silicones}

Silicones são compostos semiorgânicos com silício na cadeia principal combinado principalmente com oxigênio. São polímeros quimicamente inertes, incolores, insípidos e inodoros que permitem combinações com outras substâncias sem perder suas características. São resistentes à decomposição pelo calor, água ou agentes oxidantes, além de serem bons isolantes elétricos. Cada átomo de silício é ligado a dois grupos substituintes de carbono, que são geralmente grupos metil. As ligações do silício com outros elementos químicos recebem diferentes denominações: $\mathrm{Si}-\mathrm{H}$ : silanas, Si-O: siloxanas, Si-C: silcarbanas e Si-Si: siltianas. As ligações (Si-O-Si-O) dos silicones oferecem alta estabilidade térmica e excelente inércia química, devido a força da ligação Si-O (CORRÊA, 2012). Essas substâncias são usadas abundantemente pela indústria cosmética para obtenção de produtos para cabelos, oferecendo proteção, condicionamento, melhorando o aspecto sensorial, a penteabilidade e o desembaraçamento. Também auxiliam na interação entre os cabelos e a água; protegem os cabelos estilizados com resinas orgânicas frente à umidade externa e melhoram o efeito de longa duração; auxiliam na retenção de umidade e podem agir com barreira de proteção contra excessiva desidratação causada pela estilização térmica e/ou pela radiação solar, podendo também reduzir o tempo de secagem dos cabelos. Existem, no mercado, vários tipos de silicones com variadas funções (CORRÊA, 2012, DAVIS-SIVASOTHY, 2011). 
Silicones especiais podem ser utilizados para proteção térmica do cabelo, o que é explicado pelas suas propriedades de formação de película e de baixa condutividade térmica. Estas características resultam na redução do fluxo de calor a partir da fonte para a fibra do cabelo, e em subsequente perda de água reduzida a partir do cabelo (DAVIS-SIVASOTHY, 2011; HARTUNG et al., 2013).

\subsubsection{Escolha dos ingredientes cosméticos e veículos para o estudo das formulações}

$\mathrm{Na}$ literatura foram encontrados estudos envolvendo a avaliação de danos causados por aquecimento utilizando polímeros de alto peso molecular contendo grupos amino e outros, mas não contendo siloxanos. Estes últimos têm sido avaliados, na literatura, de acordo com suas propriedades sensoriais, penteabilidade e resistência à ruptura, mas não foram encontrados estudos envolvendo-o na avaliação quanto ao seu efeito na proteção das cadeias de proteína da queratina presente nos cabelos.

Devido às suas propriedades de lubrificação e reduzida tensão superficial, os silicones se espalham mais adequadamente ao longo das superfícies, através da formação de uma película hidrofóbica uniforme e contínua. Essa película atua sobre o fio de cabelo e, uma vez que é resistente à água, melhora a resistência do cabelo. Estes produtos substituem o sebo natural, sem fornecer uma sensação oleosa, e reduzem os danos causados pela oxidação tratamentos como alisamento e tratamentos permanentes (O'LENICK Jr., 2008; SÁ DIAS et al., 2008; DAVIS-SIVASOTHY, 2011; CORREAA, 2012). Comparando com outros tipos de agentes de proteção, como óleos minerais e outros, os silicones possuem menor condutividade térmica e desta forma, pode bloquear a rápida transferência de calor para as mechas (DAVIS-SIVASOTHY, 2011). Silicones mais utilizados são os polidimetilsiloxanos (O'LENICK Jr., 2008; SÁ DIAS et al., 2008).

Desta forma, optou-se, no presente trabalho, por avaliar o efeito de ingredientes cosméticos contendo diferentes grupos funcionais como amino e siloxanos na degradação das cadeias a-hélice de queratina nos cabelos. As funções químicas principais dos ingredientes são (INCI): Amodimethicone e Cyclopentasiloxane. 
A seleção e a incorporação destes agentes de proteção foram realizadas priorizando as suas principais funções químicas presentes e por meio de informações confirmadas na literatura e em publicações de seus fornecedores.

- Amodimethicone foi selecionado por suas propriedades condicionadoras. Trata-se de um polímero de silicone fechado terminalmente com grupo amino funcional (Figura 2.9). Proporciona substantividade em produtos para cabelos por atuar como um agente condicionante que se deposita seco sobre o fio de cabelo, formando uma película por reticulação. Especialmente eficiente em cabelos danificados, e em benefícios incluem-se uma melhoria do penteado seco e úmido, proporcionando brilho e maleabilidade aos cabelos (CORRÊA, 2012).

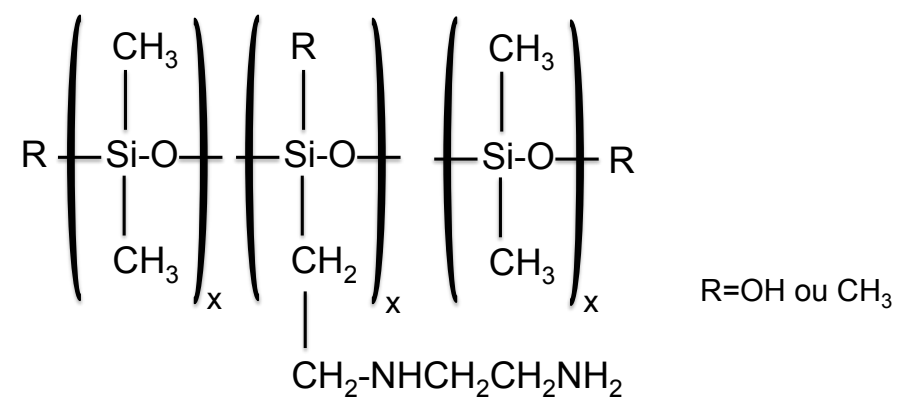

Figura 2.9 Fórmula estrutural do amodimeticone.

- Cyclopentasiloxane (Figura 2.10) foi selecionado por suas propriedades sensoriais, proteção ao danos causados por dispositivos térmicos, por propiciar maior retenção de umidade, formação de filme, resistência a lavagens, melhoria na facilidade de pentear e no brilho dos cabelos. Pertence à classe dos siloxanos. Tem a função de emoliente utilizado em condicionadores, sprays, tinturas e colorantes para cabelo (HALAL, 2011). Um estudo realizado por Sá Dias et al. (2008) avaliou os efeitos de alguns ingredientes cosméticos incorporados em emulsões para alisamento químico, dentre eles o cyclopentasiloxane (and) PEG12 dimethicone crosspolymer, aplicados em amostras de cabelo afro-étnico. Os autores observaram uma melhora na resistência mecânica do fio quando submetido à emulsão contendo este ingrediente (SÁ DIAS et al., 2008). 


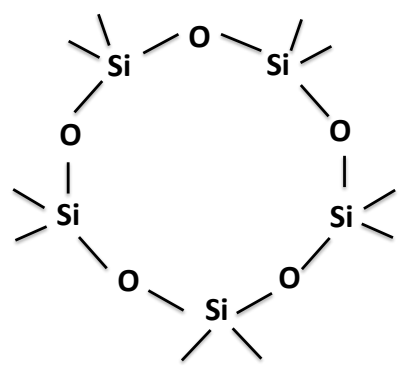

Figura 2.10 Fórmula estrutural do cyclopentasiloxane.

Os veículos aos quais os ingredientes foram incorporados foram escolhidos de acordo com sua natureza química. Optou-se pela escolha de um silicone (dimeticone) e uma emulsão (condicionador leave-on) para que, desta forma, fosse avaliada a influência das formulações e não apenas os ingredientes isolados. Além disto, esta escolha também baseou-se na avaliação dos efeitos a partir de diferentes tipos de veículos.

- Dimeticone foi selecionado por se tratar do silicone mais amplamente utilizado em produtos cosméticos e de cuidados especiais sendo encontrado em uma grande variedade de produtos rinse off e leave on, como xampus, condicionadores capilares, hidratantes para pele e cosméticos coloridos. Compreende uma mistura de polímeros lineares de siloxanos completamente metilados e fechados com unidades de trimetilsiloxanos nos extremos da cadeia polimérica (Figura 2.11) (CORREAA, 2012). Apesar de sua estrutura química ser relativamente simples, o dimeticone apresenta propriedades físicas exclusivas que o tornam efetivo no condicionamento e proteção de cabelos e pele, além de melhorar os atributos sensoriais das formulações (FEVOLA, 2013). Essas propriedades são geradas por atributos do nível molecular, que os distinguem dos polímeros orgânicos cuja composição da cadeia principal é carbono. Os átomos de Si têm raios atômicos maiores e são menos eletronegativos do que os átomos de $\mathrm{C}$, fazendo que as ligações O-Si-O sejam mais longas e os ângulos das ligações sejam maiores, em comparação com as ligações C-C ou C-O-C, respectivamente encontradas na cadeia principal dos polímeros orgânicos. Por causa de suas fracas forças de interação intermoleculares, o dimeticone apresenta baixa energia superficial e elevado coeficiente de difusão em gás. Esses atributos lhe permitem espalhar-se facilmente sobre as películas finas, 
uniformes e repelentes de água, mas altamente permeáveis a gases como oxigênio, dióxido de carbono e vapor de água (O'LENICK Jr., 2008, CORRÊA, 2012).

$$
\left(\mathrm{CH}_{3}\right)_{3} \text {-Si-O }\left(\left.\right|_{\mathrm{CH}_{3}} ^{\mathrm{Si}_{3} \mathrm{O}}-\mathrm{Si}-\left(\mathrm{CH}_{3}\right)_{3}\right.
$$

Figura 2.11 Fórmula estrutural do dimeticone.

- Base condicionadora leave-on foi escolhida por conter ingredientes cosméticos diferentes daqueles que foram incorporados. Isto para que fosse possível avaliar os efeitos causados pelos ingredientes na mesma concentração em todas as formulações preparadas. Sua composição está especificada no item 5.1.3.

\subsection{Análise Térmica}

A análise térmica é definida como "grupo de técnicas por meio das quais uma propriedade física de uma substância e/ou de seus produtos de reação é medida em função da temperatura, enquanto essa substância é submetida a um programa controlado de temperatura" (IONASHIRO \& GIOLITO, 1980).

A calorimetria exploratória diferencial (DSC) e a termogravimetria (TG) são as técnicas termoanalíticas mais difundidas e empregadas no desenvolvimento de diferentes estudos sendo aplicadas a uma grande variedade de materiais farmacêuticos (SILVA et al., 2007).

A TG fornece informações com relação às variações de massa em função do tempo e/ou temperatura sob uma atmosfera específica. As curvas obtidas fornecem informações relativas à composição e estabilidade térmica da amostra, dos produtos intermediários e do resíduo formado. A DTG é a derivada primeira da curva TG, os "degraus" correspondem às variações de massa, visualmente, mais accessíveis e com melhor resolução (CAMMENGA \& EPPLE, 1995; VELASQUEZ et al., 2004; RODRIGUES et al., 2005). 
DSC é a técnica de análise térmica, na qual se mede a diferença de energia fornecida à substância e a um material de referência (termicamente estável), em função da temperatura, enquanto a substância e o material de referência são submetidos a uma programação controlada de temperatura. A amostra e o material de referência são colocados em cápsulas idênticas, localizadas sobre o disco termoelétrico e aquecidas por uma única fonte de calor, obtendo-se desta maneira, as curvas DSC onde picos ascendentes caracterizam eventos exotérmicos, enquanto os descendentes eventos endotérmicos (WENDLANDT, 1986; MACHADO \& MATOS, 2004).

É importante a associação de dados provenientes dos ensaios de TG/DTG e DSC, para melhor caracterização de materiais, visto que a TG/DTG indica eventos térmicos relacionados a variações de massa, enquanto a DSC detecta eventos associados ou não à perda de massa.

Alguns autores têm contribuído com trabalhos em que aplicam a análise térmica em estudos de matérias-primas de uso cosmético e à aplicação das várias técnicas termoanalíticas no desenvolvimento, produção e controle de produtos cosméticos.

\subsubsection{Cinética de decomposição térmica utilizando a termogravimetria}

A utilização dos processos de reações de decomposição térmica de sólidos vem crescendo consideravelmente em diversas áreas tais como: metalurgia, geologia, medicamentos, alimentos, cerâmica, e outros. Esta tem sido uma das principais razões pelas quais o conhecimento da cinética e do mecanismo de tais reações tem se tornado um dos estudos primordiais da investigação química (SILVA et al., 2008).

O estudo cinético de reações tem como objetivo determinar parâmetros cinéticos que possam ser utilizados para predizer a estabilidade de determinadas substâncias químicas. A cinética de reação estimulada termicamente é normalmente estudada sob condições de aquecimento isotérmico e/ou nãoisotérmico (dinâmico). A análise térmica pode ser empregada na realização de estudos de reações no estado sólido a fim de se determinar parâmetros cinéticos como a energia de ativação $(E a)$, o fator frequência $(A)$ e a ordem de reação 
(MARIAN et al., 2013; BUDRUGEAC et al.,1996; CIDES et al., 2006). A partir destes parâmetros, é possível mensurar a variação de uma propriedade da amostra quando esta é aquecida (estudo cinético dinâmico) ou mantida a uma temperatura constante (estudo cinético isotérmico).

Para a realização dos estudos cinéticos isotérmicos, as amostras são submetidas a pelo menos quatro temperaturas constantes, enquanto que para o estudo não-isotérmico, os métodos envolvem o aquecimento das amostras sob uma ou mais razões de aquecimento $(\beta)$ constantes. Os métodos isotérmicos se assemelham àqueles usados em cinéticas homogêneas para produzir resultados dependentes do tempo $(\mathrm{t})$.

Os métodos não-isotérmicos, por sua vez, produzem resultados que dependem da temperatura $(\mathrm{T})$. O método convencional para o estudo isotérmico por termogravimetria utiliza a equação de Arrhenius para a determinação de parâmetros cinéticos, como por exemplo, a energia de ativação (Ea). Para o estudo cinético não-isotérmico ou dinâmico por termogravimetria, o método descrito por OZAWA, feito por aproximação linear baseado em cálculos integrais a partir da equação de Arrhenius, é muito empregado, e também permite determinar tais parâmetros (OZAWA, 1965; BUDRUGEAC et al., 1996; CIDES et al., 2006; MARIAN et al., 2013).

O método cinético não isotérmico é baseado em ensaios termogravimétricos em diferentes razões de aquecimento. Em análise térmica, a temperatura $(T)$ é uma função do tempo $(\mathrm{t})$, e geralmente, a relação $d T / d t=\beta$ (constante) é verdadeira, onde $\beta$ é a razão de aquecimento $\left({ }^{\circ} \mathrm{C} \min ^{-1}\right)$.

A Figura 2.12 ilustra a representação das curvas TG em diferentes $\beta$ bem como o gráfico de Ozawa construído. 

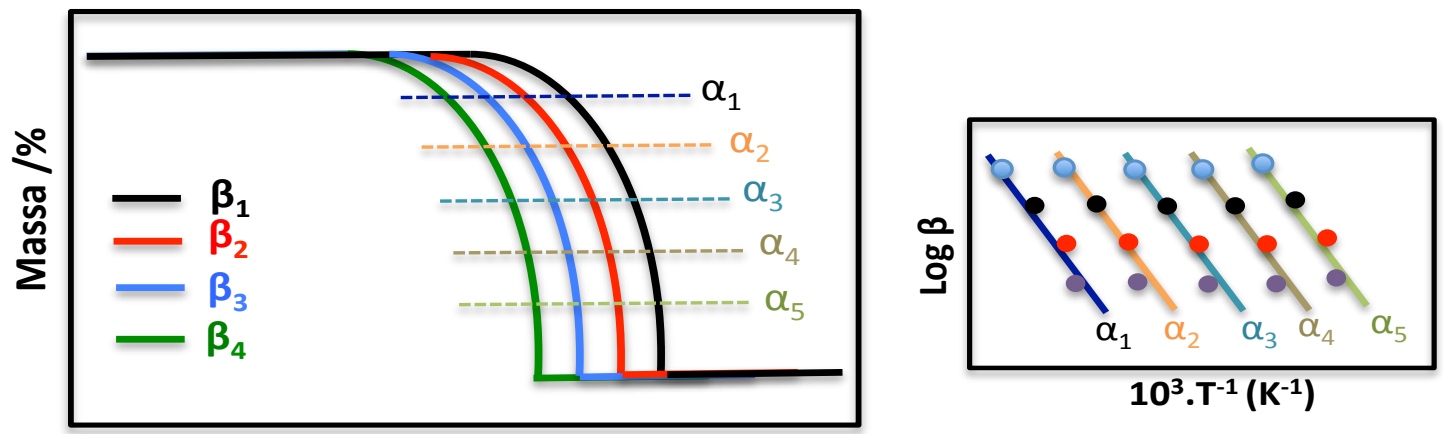

\section{Temperatura /K}

Figura 2.12 Sobreposição de curvas TGs hipotéticas com diferentes $\beta$. Gráfico de Ozawa construído a partir das curvas TG com diferentes $\beta$ (ÁVILA, 2015, adaptado).

A fração decomposta durante o ensaio termogravimétrico é definida pela equação 1.

$$
\alpha=\left(m_{0}-m_{\alpha}\right) /\left(m_{0}-m_{f}\right)
$$

onde a é a fração mássica decomposta.

A taxa de decomposição pode ser escrita de acordo com a equação 2.

$$
\frac{d \alpha}{d t}=k(T) f(\alpha)
$$

onde $\mathrm{k}(\mathrm{T})$ é a constante de velocidade de Ahrrenius e $\mathrm{f}(\alpha)$ uma função relacionada ao mecanismo da reação.

A constante de Arrhenius é utilizada para realizar a correlação dos parâmetros cinéticos de decomposição com a temperatura através da expressão de Arrhenius, como apresentado pelas equações (3) e (4).

$$
\begin{aligned}
& k=A e^{-E a / R T} \\
& \frac{d \alpha}{d t}=A e^{-\frac{E a}{R T}} f(\alpha) \\
& \text { Se } \beta=\frac{d T}{d t}, \text { então: } \\
& \frac{d \alpha}{d T}=\frac{A}{\beta} e^{-\frac{E a}{R T}} f(\alpha)
\end{aligned}
$$




$$
g(\alpha)=\int_{0}^{\alpha} \frac{d \alpha}{\mathrm{f}(\alpha)}=\frac{A}{\beta} \int_{T o}^{T} e^{\left(-\frac{E a}{R T}\right)} d T
$$

Ozawa (1965) propôs um modelo cinético a partir das curvas TG dinâmicas em diferentes taxas de aquecimento e demonstrou ser possível medir experimentalmente a temperatura necessária para que determinada fração da amostra se decomponha. O gráfico log $\beta$ versus $1 /$ T deve ser linear e a inclinação da reta que melhor contém os valores deve ser igual a -0,4567 Ea/R, assim, é possível estimar a Ea, A e t. As retas obtidas por meio dos diferentes valores de $\alpha$ devem ser paralelas, indicando uma menor dispersão dos valores de energia de ativação (KOGA, 2013).

\subsubsection{A análise térmica aplicada ao estudo de cabelos}

Para o contexto de análise térmica, o cabelo é considerado como sendo um composto de filamentos/matriz, tal como proposto originalmente por Feughelman (1959). Neste modelo, a fracção helicoidal dos filamentos intermediários (IF) compreende a fase cristalina que está embebida em filamentos de uma matriz amorfa, que é representada pelas proteínas associadas aos filamentos intermediários (IFAPs).

Os primeiros estudos envolvendo análise térmica em amostras de fibras de lã e cabelo humano revelaram a semelhança da queratina presente nestes materiais (SCHWENKER \& DUSENBURY, 1960; FELIX et al., 1963; CRIGHTON \& HAPPEY, 1968; CRIGHTON \& HOLE, 1976; CRIGHTON \& HOLE, 1985).

Uma busca na literatura detectou que os primeiros autores a investigar as propriedades térmicas de várias fibras de queratina por DTA foram Schwenker \& Dusenbury, em 1960. Os autores observaram que quando um fio de cabelo é aquecido, ocorre uma série de mudanças e/ou fases que precedem de sua degradação. Eles relataram que entre $80-140^{\circ} \mathrm{C}$ ocorre a remoção/evaporação (evento endotérmico) da água livremente e fortemente ligada à fibra capilar. Os autores observaram a presença de dois picos: em aproximadamente $110^{\circ} \mathrm{C}$ que representa a perda de água adsorvida e outro em cerca de $160^{\circ} \mathrm{C}$ referente à 
perda endotérmica da água fortemente ligada nos sítios hidrofílicos na fibra capilar (SCHWENKER \& DUSENBURY, 1960).

Em 1963, Felix et al. avaliaram amostras diferentes de lã e pelo de cabra por DTA não observando diferenças significativas entre as amostras estudadas. As curvas DTA apresentaram três eventos endotérmicos: entre $130-145^{\circ} \mathrm{C}$, entre $220-230^{\circ} \mathrm{C}$ e $230-250^{\circ} \mathrm{C}$, os quais os autores atribuíram à vaporização da água, à carbonização e à liberação de produtos gasosos de decomposição e liquefação, respectivamente (FELIX et al., 1963).

Humphries et al. (1972) estudaram amostras de cabelo virgem e tratados quimicamente por TG/DTA. Os autores reportaram um evento de decomposição térmica por TG com perda de massa em $252^{\circ} \mathrm{C}$ para amostras de cabelo virgem e observaram que esta temperatura aumenta com os diferentes tipos de tratamentos (com solução de formaldeído $37 \%$ : $276^{\circ} \mathrm{C}$, solução $\mathrm{H}_{2} \mathrm{O}_{2} 30 \%$ : $270^{\circ} \mathrm{C}$ ). Eles explicam que esse fato se deve à alta reatividade destes últimos com os grupos funcionais da queratina. Os resultados de DTA evidenciaram os picos endotérmicos da fusão e desnaturação da queratina em 235 e $243^{\circ} \mathrm{C}$, respectivamente em amostras de cabelo virgem e estas aumentaram nas amostras de cabelo tratadas (com solução de formaldeído $36 \%$ : 240 e $252^{\circ} \mathrm{C}$, solução de $\mathrm{H}_{2} \mathrm{O}_{2} 30 \%$ : 250 e $270^{\circ} \mathrm{C}$ ) (HUMPHRIES et al., 1972).

Mais tarde, Milczarek et al (1992) utilizaram a DSC para estudar as interações entre água e queratina em amostras de cabelo caucasiano tratado e não tratado. Segundo os autores foram observados três eventos: a remoção de água fracamente ligada a cerca de $70^{\circ} \mathrm{C}$, uma transição na fase amorfa $\left(155^{\circ} \mathrm{C}\right) \mathrm{e}$ fusão/desnaturação da fase a-queratina $\left(233^{\circ} \mathrm{C}\right)$. Os autores descreveram que este evento em $155^{\circ} \mathrm{C}$ tem um carácter oposto a uma transição vítrea ("transição de endurecimento") (MILCZAREK et al., 1992).

Em trabalho desenvolvido por Guthrie et al. (1995) foram avaliadas fibras capilares tingidas e não tingidas por meio da DSC e os autores verificaram que as primeiras apresentaram uma maior tendência para absorver a água/umidade do que as segundas. Relataram, também, que o cabelo tingido apresentou uma tendência significativamente maior em vincular essa água absorvida mais fortemente, baseado nos valores de $\Delta \mathrm{H}$ desidratação e $\mathrm{T}_{\text {pico }}$ de desidratação (GUTHRIE et al., 1995). 
Ao longo do tempo, o comportamento térmico de fibras de queratina foi estudado por dois métodos principais de DSC, a saber, pelo chamado DSC à seco e DSC em meio aquoso. O primeiro método compreende investigações realizadas permitindo que o conteúdo da amostra de queratina evapore com o aumento da temperatura e da umidade. A investigação em ambiente seco evidencia efeitos endotérmicos acima de $200^{\circ} \mathrm{C}$, às vezes com a apresentação de picos duplos na curva, o qual está discutido mais adiante (CAO et al, 1997; MILCZAREK et al. 1992). Pelo segundo método, a queratina é investigada em excesso de água, em cápsulas de pressão seladas e resistentes que mantêm a água durante o aquecimento. Este último evidencia os efeitos endotérmicos em torno de $150{ }^{\circ} \mathrm{C}$. A análise dos picos endotérmicos nos mostra que qualquer um dos métodos baseia-se no modelo de propriedades físicas e mecânicas que descrevem o comportamento das fibras queratínicas e as semelhanças com o comportamento de aquecimento de proteínas globulares (ISTRATE, 2011).

Cao e colaboradores (1997) observaram que existem características térmicas específicas que podem inviabilizar a interpretação de uma medição por DSC de amostras de lã: entalpia de fusão, temperatura de degradação térmica relativamente baixas e um teor de umidade dependente da temperatura de fusão. Desta forma, os autores desenvolveram um método por DSC de análise de amostras lã utilizando o óleo de silicone como meio de análise. Em um estudo posterior, Cao (1999) estudou o comportamento térmico por DSC de amostras de cabelo caucasiano empregando o método desenvolvido para analisar amostras de lã, porém foram utilizados dois meios diferentes: óleo de silicone e água. De acordo com os resultados obtidos pelo autor, há semelhanças nas características térmicas do cabelo humano com a queratina da lã obtidas por Cao e colaboradores (1997). De acordo com Cao (1999) o óleo de silicone mostrou ser um meio térmico eficaz para determinação da entalpia de fusão dos cristais de $\alpha$ hélice de cabelo humano por DSC. A amostra de cabelo humano acondicionada a $20^{\circ} \mathrm{C}$ e $65 \%$ de umidade relativa apresentou pico de fusão de $175^{\circ} \mathrm{C}$ e o seu valor de entalpia de fusão $12,8 \mathrm{~J} \mathrm{~g}^{-1}$, valor equivalente a $14,5 \mathrm{~J} \mathrm{~g}^{-1}$, que foi obtido para a amostra de cabelo seco, ou seja, que não foi submetida a condições de umidade. Isso indica que o cabelo humano apresenta maior cristalinidade que a lã de 
carneiro, que apresentou o valor de $10,0 \mathrm{~J} \mathrm{~g}^{-1}$ para a lã seca (CAO et al. 1997; CAO 1999).

Segundo McMullen e Jachowicz (1998), a técnica de espectroscopia de fluorescência permitiu monitorar o teor de triptofano, que é progressivamente destruído pela aplicação de um polímero catiônico (VP/DMAPA Acrylates copolymer) hidrolisado de proteína do trigo e um tensoativo catiônico (quaternium 70) em cabelos submetidos a um procedimento de modelagem a quente. Todos os componentes testados apresentaram uma redução na decomposição do triptofano em 10-20\% em um tempo de 4 a 12 minutos de exposição térmica dos cabelos (McMULLEN e JACHOWICZ, 1998). Os autores também quantificaram o dano superficial das fibras capilares pela análise de penteabilidade e mostraram que o uso do VP/DMAPA Acrylates copolymer ou do tensoativo catiônico pode suprimir um aumento desta força. Por outro lado, os cabelos não tratados com os ingredientes apresentaram maior força de penteabilidade após a exposição aos modeladores a quente. Segundo os autores, este fato está, provavelmente, associado à decomposição térmica da camada lipídica da superfície. Os autores relataram que houve um aumento na proteção das fibras capilares tratadas com polímero comparadas às não tratadas. Esse fato pode ser resultado de rearranjos estruturais nos cabelos, consistindo em: (a) um aumento no conteúdo da fase cristalina nos cabelos não tratados e (b) um aumento da adsorção de polímero, que produzem as ligações entre as fibras (McMULLEN \& JACHOWICZ, 1998).

Wortmann et al. (2002) estudaram os efeitos dos tratamentos de descoloração e de ondulação permanente em fibras capilares em água por DSC. De acordo com os autores, a entalpia depende da quantidade e da integridade estrutural do material $\alpha$-hélice dos filamentos intermediários de cabelo humano (WORTMANN et al., 2002).

Estudos realizados por Belletti et al. (2003) combinaram as técnicas de DSC e cromatografia em fase gasosa (CG) com o intuito de obter uma avaliação precisa da concentração de água em cabelo. Para assegurar que o vapor liberado do cabelo aquecido continha apenas água, foi necessário determinar a composição química do vapor porque outras substâncias, além da água, podem volatilizar a estas temperaturas. Análises de CG/DCT (cromatografia em fase 
gasosa/detector de condutividade térmica) do vapor confirmaram a presença de água e permitiram a sua quantificação. Os autores determinaram a energia correspondente à etapa de desidratação (utilizando DSC) e a concentração de água presente (utilizando $\mathrm{CG}$ ) em amostras de cabelo caucasiano padrão submetido a tratamentos com produtos cosméticos do mercado. Uma avaliação sensorial pós-tratamento destas mechas foi realizada para averiguar se os resultados de DSC e CG correspondiam à sensação hidratante percebida pelo consumidor.

Foram adotados dois tratamentos com produtos leave-on recomendados para cabelos danificados e dois com produtos rinse-off para cabelos normais. Para os tratamentos com produtos leave-on, as mechas foram descoloridas durante 30 minutos em uma solução contendo peróxido de hidrogênio (20 volumes). Os autores observaram que, comparando os resultados obtidos para a mecha controle e para as submetidas aos tratamentos com produtos leave-on, houve diferença nos valores de $\Delta \mathrm{H}_{\text {vap }}\left(268\right.$ e $\left.210 \mathrm{~J} \mathrm{~g}^{-1}\right)$ e na porcentagem de água $(12,8$ e $7,4 \%)$ presente nas mechas. Já os tratamentos com produtos rinse-off, os autores encontraram uma diferença mais acentuada nos valores de $\Delta \mathrm{H}_{\text {vap }}$ (193 e

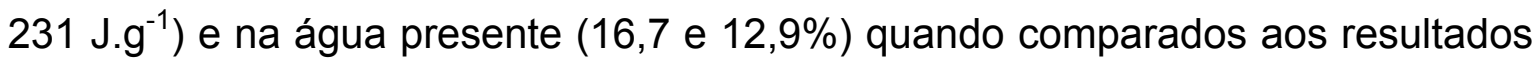
obtidos pelos tratamentos leave-on. Os autores atribuíram os resultados à composição do produto cosmético, que pode adicionar água às fibras do cabelo e/ou protegê-las contra perda de água (por exemplo, por meio da formação de uma película em torno da fibra), e estes dados podem ou não resultar em valores proporcionais em DSC e CG. Portanto, a associação das duas técnicas de análise revelou-se particularmente útil na avaliação da hidratação das fibras de cabelo (Belletti et al., 2003).

Segundo os autores, a quantidade de energia consumida fornece uma indicação do grau de proteção e por este motivo os dados de DSC mostram também que esta técnica pode ser aplicada para avaliar as propriedades de proteção térmica nas fibras capilares. Porém, durante a pesquisa com consumidores, os atributos de maciez, brilho, sensação de deslizamento foram avaliados pelo painel de membros, e estes não identificaram diferenças significativas entre os tratamentos nas mechas de cabelo. Com efeito, estes atributos, portanto, não dependem exclusivamente de hidratação e indicou que 
este teste de consumo é inadequado para avaliar hidratação no cabelo. Os autores sugerem que os resultados das avaliações são subjetivos, envolvem diferenças psicológicas e fisiológicas individuais e não proporcionam a exatidão necessária para determinar o nível de hidratação oferecida pelos produtos. Os autores sugeriram duas hipóteses para explicar a maior energia necessária para a liberação de água do cabelo. Primeiro, os tratamentos aumentam o teor de água nas fibras, ou seja, quanto maior a concentração de água ligada às fibras, maior será a energia necessária para liberá-la. Em segundo lugar, os tratamentos, de alguma forma, impedem a liberação de água e, portanto, necessitam de mais energia. Essa interferência pode ser devido à formação de uma barreira (filme) e/ou a presença de substâncias hidrófilas. É importante ressaltar que o detector de CG identificou apenas água dentro deste intervalo de temperatura, a primeira secção das curvas DSC corresponde apenas à água presente nas amostras do teste. Um aumento no teor de água acima de $200^{\circ} \mathrm{C}$ foi observado. Esta quantidade adicional de água pode resultar da formação das fibras do cabelo, bem como a partir da combustão do material orgânico presente em todo o cabelo (BELLETTI et al., 2003).

Em trabalho desenvolvido por Éhen et al. (2004) foi estudado o comportamento térmico de amostras de cabelo por TG e DSC. As curvas TG apresentaram uma perda de massa entre 5 e 8\%, correspondendo ao teor de água absorvida pelo cabelo. Entre $230-233^{\circ} \mathrm{C}$, as curvas DSC das amostras de cabelo, evidenciaram a fusão da a-queratina e após $250^{\circ} \mathrm{C}$ iniciou-se a decomposição térmica da fibra capilar (ÉHEN et al., 2004).

Cao \& Leroy (2005) estudaram o comportamento da temperatura de fusão da a-queratina de amostras de cabelo humano submetidas a diferentes condições de umidade por DSC. Os autores adotaram uma técnica usando silicone como meio térmico. Os resultados mostraram que a temperatura de fusão da a-queratina variou com o teor de umidade de $205^{\circ} \mathrm{C}$ para o cabelo seco a $155^{\circ} \mathrm{C}$ para a amostra de cabelo com um conteúdo de umidade de $23 \%$. Porém, a entalpia de fusão com base no peso seco do cabelo foi mantida quase constante, levando a conclusão de que há cristalitos bem definidos na queratina do cabelo humano (CAO \& LEROY, 2005). 
A desnaturação da proteína a-helicoidal e os efeitos de tratamentos cosméticos redutores e oxidativos em amostras de cabelo em água foi estudada por Wortmann e colaboradores (2008), utilizando a técnica DSC. Os resultados mostraram que existem diferenças na desnaturação térmica da fracção $\alpha$ helicoidal de amostras de cabelo humano submetidas a esses tratamentos (WORTMANN et al., 2008).

Rigoletto et al. (2009) apresentaram um método para testar a capacidade de uma composição cosmética proporcionar efeitos de proteção térmica em cabelos submetidos ao calor excessivo causado pelo uso de modeladores térmicos. Os autores validaram um método em que utilizaram a medição de "fragmentação das fibras capilares" por meio da penteabilidade controlada. Este método pode ser usado como uma medida da redução do enfraquecimento do cabelo causado pela composição de proteção térmica. A técnica de DSC foi utilizada para medir o calor de absorção da fibra capilar. Foram avaliados dois ativos cosméticos incorporados à hidroxietilcelulose: copolímero de acrilatos VP/DMAPA e poliquaternium 55. As amostras que foram submetidas ao procedimento com as composições cosméticas apresentaram uma menor quebra de seus fragmentos durante o teste de penteabilidade. Os ensaios de DSC mostraram que as fibras capilares apresentaram maior proteção térmica não só na superfície, como também no córtex (RIGOLETTO et al., 2009).

Silva et al. (2010) avaliaram o comportamento térmico de amostras de fibras de cabelo caucasiano e de queratina, ambos em pó e do cabelo em fio, por TG/DTG e DSC. Os resultados indicaram que há uma grande semelhança no perfil termogravimétrico das amostras, comprovando que na fibra capilar há aproximadamente $85 \%$ de queratina. Também foi realizado um estudo cinético de desidratação da amostra de cabelo em pó, empregando TG não isotérmica (Método de Ozawa). Os dados forneceram um ajuste adequado para as curvas de $\log \beta\left({ }^{\circ} \mathrm{C} \mathrm{min}{ }^{-1}\right)$ vs $1 / T(K)$ possibilitando encontrar o valor da energia de ativação da etapa de desidratação. Por meio de ensaios de DSC, foi possível detectar a temperatura em que se inicia a decomposição térmica da fibra, ou seja, a desnaturação da queratina (SILVA et al., 2010).

De acordo com estudo feito por Farwick et al. (2010), no qual foi avaliada a degradação da queratina de fibras capilares quimicamente tratadas com creatina, 
guanidina e produtos do mercado por DSC, foi observado que a guanidina, a creatina e os dois produtos do mercado tiveram respectivamente 15,5 e $8 \%$ de proteção aos cabelos. Os autores concluíram que danos causados pela alta temperatura de uma piastra podem ser evitados por meio da aplicação de uma solução aquosa simples de guanidina. Observaram também a ocorrência de uma diminuição da temperatura de denaturação e também da ruptura dos cabelos (FARWICK et al., 2010).

ZHOU et al. (2011) investigaram os danos térmicos em cabelos causados pelo uso de piastra e os efeitos térmicos protetores de cosméticos utilizando a técnica DSC e espectroscopia de absorção na região do infravermelho. Os resultados indicaram a degradação térmica da queratina dos cabelos, e também que o pré-tratamento com polímero Polyquaternium-55, VP/DMAPA Acrylates copolymer e VP/Acrylates/Lauryl Methacrylate Copolymer reduziu significativamente a degradação da proteína helicoidal em torno de $97 \%$ do prétratamento com VP/Acrylates/Lauryl Methacrylate Copolymer (ZHOU et al., 2011).

Estudos realizados por Gama et al. (2011) demonstraram a influência de agentes condicionantes em cabelos tingidos via TG/DTG e DSC. Os autores demonstraram que estes tratamentos químicos podem prejudicar as fibras de cabelo, reduzindo o seu teor de umidade em relação aos cabelos tratados. A incorporação de agentes de condicionamento (Silanetriol e pantenol; PEG-12 dimeticona; seda hidrolisada, proteína hidrolisada do leite e lactose) em tinturas capilares, segundo os autores, diminuiu os danos causados aos cabelos pelo processo de coloração (GAMA et al., 2011).

Brebu \& Spiridon (2011) estudaram a degradação térmica de amostras de lã de ovelha, de cabelo humano e de penas de galinha pelas técnicas de TG/DSC acopladas ao FTIR e espectrômetro de massa com detector MSD (Mass Selective Detector) e por pirólise utilizando GC-MSD, a fim de identificar os compostos de degradação e a temperatura em que eles são formados. Foram observadas apenas pequenas diferenças entre as amostras estudadas de queratina como uma mudança nas temperaturas características de degradação da queratina e em relativas quantidades de compostos em produtos de degradação, especialmente em fase aquosa. A degradação iniciou-se com formação a de amoníaco e $\mathrm{CO}_{2}$ (a partir de 167 e $197^{\circ} \mathrm{C}$, respectivamente, e com a evolução máxima a 273 e $287^{\circ} \mathrm{C}$, 
respectivamente), em seguida com a formação de compostos contendo enxofre inorgânicos (SCS, SCO, $\mathrm{H}_{2} \mathrm{~S}$ e SO $\mathrm{SO}_{2}$ em 240, 248, 255 e 253-260 ${ }^{\circ} \mathrm{C}$, respectivamente) e de água $\left(255^{\circ} \mathrm{C}\right)$. Segundo os autores, tióis são formados em duas fases $\left(257\right.$ e $\left.320^{\circ} \mathrm{C}\right)$, enquanto a evolução de nitrilos é máxima em $340^{\circ} \mathrm{C}$ e continua-se a cerca de $480^{\circ} \mathrm{C}$. Fenol e 4-metilfenol são os compostos de degradação mais importantes, formados a 370 e $400^{\circ} \mathrm{C}$, respectivamente. Nitrogênio esteve presente principalmente na forma de nitrilos alifáticos/aromáticos, piridinas e amidas, enquanto enxofre, foi encontrado principalmente como sulfuretos, tióis, triazoles e tiofenos (BREBU \& SPIRIDON, 2011).

Prasong \& Wasan (2011) analisaram filmes de queratina (extraída de amostras de cabelo) e gelatina utilizando as técnicas TG/DTG e FTIR. A partir dos resultados de FTIR da queratina nativa, os autores observaram bandas fortes e características de amida I em $1684 \mathrm{~cm}^{-1}$ e amida II em $1652 \mathrm{~cm}^{-1}$, indicando a presença de beta e alfa-queratina, respectivamente. De acordo com os autores, as temperaturas dos eventos endo/exotérmicos dos materiais foram obtidas por TG/DTG (PRASONG \& WASAN, 2011).

HARTUNG et al. (2013) estudaram a incorporação de um silicone catiônico (quaternium 22) em uma microemulsão condicionadora e aplicada em amostras de fibras capilares. As mechas tratadas com a emulsão foram submetidas a ensaios de penteabilidade e de DSC para medidas de condicionamento e proteção contra o calor, respectivamente. Resistência à lavagem de cor também foi testada utilizando um espectrofotômetro. Segundo os autores, a microemulsão do silicone estudado apresentou ser um bom agente de condicionamento. Os autores mostraram que os cosméticos mantêm de forma eficiente e regenera o condicionamento das mechas de cabelos estudadas. De acordo com os resultados de DSC, os autores observaram que houve uma redução na temperatura de desnaturação causada por danos térmicos. Ao incorporar a microemulsão contendo o quaternium-22, a temperatura necessária para desnaturar o cabelo aumentou, indicando que o cabelo apresentava-se menos danificado pelo tratamento térmico. A melhora foi de $70-80 \%$ na proteção ao calor, o que pode ser atribuído à melhoria da deposição de silicone quaternium-22 a partir da microemulsão (HARTUNG et al., 2013). 
De acordo com Hartung et al. (2013), cabelo virgem tem uma fase de grande transição (desnaturação) de temperatura. Quanto mais danificado o cabelo é, por exemplo, por tratamento de calor, menor será a temperatura de transição de fase. A temperatura de desnaturação do cabelo, conforme determinado pelo DSC é, portanto, um significativo parâmetro na avaliação do grau de destruição das estruturas de queratina (HARTUNG et al., 2013).

\subsection{Espectroscopia na região do infravermelho com transformada de Fourier (FTIR) com Refletância Total Atenuada (ATR)}

A radiação na região do infravermelho é passada através da amostra, sendo que parte dela é absorvida e parte é transmitida. Esta última é comparada com aquela transmitida na ausência de amostra. $O$ resultado da interação radiação-amostra gera um espectro molecular de absorção e transmissão, ou seja, a criação de uma impressão digital molecular do alvo estudado. Os espectros produzidos terão diferenças, mesmo que mínimas, tornando desta forma a espectroscopia no infravermelho útil para vários tipos de análise (SILVERSTEIN et al., 1991; SMITH, 1998; SOLOMONS, 2001). FTIR é uma técnica muito importante na análise orgânica qualitativa e é amplamente utilizada nas áreas de química e de produtos naturais, síntese e transformações orgânicas (SILVERSTEIN et al., 1991). Apresenta-se também como uma ferramenta útil nos estudos de cabelos, pois fornece as principais bandas das fibras capilares e é utilizada para determinar as alterações estruturais no cabelo quando exposto a vários tratamentos (MOITA, 1989).

Espectroscopia na região do infravermelho pode ser utilizada para identificar estrutura secundária da proteína, como é o caso da queratina, maior constituinte de materiais contendo moléculas biológicas como lã, unhas e cabelos (SMITH, 1998).

Vários estudos na literatura têm utilizado a FTIR como ferramenta para a identificação de grupos funcionais em amostras de cabelo. Colenci (2007) estudou o efeito de uma formulação cosmética em amostras de cabelo caucasiano por FTIR e obteve os espectros das principais bandas presentes na queratina do cabelo bem como a presença de picos relacionados a compostos da 
formulação utilizada (COLENCl, 2007). Lisboa (2007) estudou a sorção de lipídeos em amostras de cabelo caucasiano e afro-étnico por FTIR-ATR. O autor observou a diferença na absorção de compostos lipídicos por estudados, mostrando que a amostra de cabelo afro-étnico apresentou maior tendência em absorvê-los (LISBÔA, 2007).

A espectroscopia de reflexão interna é uma técnica não destrutiva que permite a obtenção de espectros na região do infravermelho de amostras difíceis de serem manipuladas, como sólidos pouco solúveis, pós, pastas, filmes, adesivos, e outros (SKOOG et al., 2009). Devido ao seu funcionamento simples, o ATR permite a obtenção de espectros com maior rapidez, quando comparado ao modo clássico de obtenção de espectros de Infravermelho.

Barton (2011) estudou amostras de diferentes tipos de cabelo por espectroscopia na região do IV com Refletância Total Atenuada (ATR) e obteve as principais bandas existentes bem como as mudanças na estrutura devido a tratamentos químicos em amostras de cabelo de diferentes etnias. $O$ autor demonstrou também a diferença nos espectros gerados por diferentes métodos e observou vantagens do método ATR perante outros, dentre eles tem-se que:

- Os espectros obtidos foram de melhor qualidade,

- Não houve perda de informação estrutural química como ocorre com outras técnicas, identificando elementos da superfície como a cutícula e as regiões mais periféricas do córtex;

- Apresentou-se como uma técnica econômica em termos de tempo;

- A preparação das amostras é simples; não destrutiva.

\subsection{Microscopia eletrônica de varredura (MEV)}

Outra ferramenta muito utilizada para analisar a superfície do cabelo é o microscópio eletrônico de varredura (MEV). Este pode dar uma ideia sobre a extensão dos danos da cutícula bem como o número de escamas visíveis. A partir das micrografias obtidas, é possível visualizar algum espaço (se existir) entre as células que se sobrepõem (BELLARE et al., 2001).

Bellare et al. (2001) avaliaram o efeito do condicionamento de diferentes xampus contendo extratos de plantas em cabelos por meio de imagens de MEV. 
Os autores observaram um efeito de condicionamento melhor comparados com aqueles disponíveis comercialmente (BELLARE et al., 2001).

Dankers (2007) analisaram amostras de cabelo submetidos a tratamentos químicos de redução e oxidação, e estes quebram a ligação de dissulfeto de cistina e convertem a ácido cistéico, monóxido de cistina (R-SOS-R), e dióxido de cistina (R-SO ${ }_{2} \mathrm{~S}-\mathrm{R}$ ) (DANKERS, 2007).

O efeito de três ativos botânicos (Cystoseira compressa extract, Lepidium meyenii extract e Carob tree extract) em amostras de cabelo foi estudado por Benaiges e colaboradores (2013). A eficácia destas matérias primas foi avaliada por Microscopia Eletrônica de Varredura (MEV) e medidas de brilho. Amostras de cabelo foram descoloridas a fim de modificar as propriedades mecânicas do cabelo e aumentar a permeabilidade da fibra. Os autores concluíram que a aplicação dos extratos botânicos melhorou as propriedades mecânicas, reduzindo a permeabilidade das fibras, revestindo-as e aumentando o material cristalino das mesmas. Os valores médios de tensão-deformação das amostras de cabelo mostraram que o tratamento clareador realizado nas mechas provocaram uma modificação na integridade da fibra com uma diminuição dos valores de alongamento na ruptura em relação às mechas não tratadas. Dos três extratos estudados, os autores observaram que houve um aumento à resistência à ruptura as amostras de cabelo tratadas com extrato de Lepidium meyenii, indicando uma melhoria na integridade das fibras. Considerando que um aumento na deformação da ruptura indica um aumento na plasticidade das fibras, os autores sugerem que este aumento pode ser explicado por duas hipóteses: a primeira é que houve um aumento no teor de água nas fibras, devido aos ativos botânicos, e por este motivo, houve um aumento na capacidade da fibra de ser deformada. A outra hipótese é que a ligação de alguns grupos funcionais presentes nos ingredientes ativos com a cistina no interior da fibra capilar restaurou algumas ligações dissulfeto quebradas no tratamento de oxidação (BENAIGES et al., 2013). 


\subsection{Estrutura do presente estudo}

Para a melhor a visualização do presente trabalho foi elaborado um fluxograma demonstrando a rota experimental deste estudo (Figura 2.13).

A parte experimental deste trabalho foi dividida em três etapas principais:

1) Escolha das mechas de cabelo caucasiano, oriental e afro-étnico virgens e submetidas a um tratamento térmico: caracterização utilizando técnicas físico-químicas, analíticas e de propriedades mecânicas.

2) Escolha das mechas de cabelo brasileiro as quais foram tratadas quimicamente com descolorante e submetidas a um tratamento térmico: caracterização utilizando técnicas físico-químicas, analíticas e de eficácia.

3) Escolha dos ingredientes e veículos cosméticos, resultando em seis formulações diferentes: caracterização utilizando técnicas físicoquímicas e analíticas. Os ingredientes cosméticos escolhidos para a realização deste estudo foram detalhados nas pág. 19-22 (item 2.6.5.). 


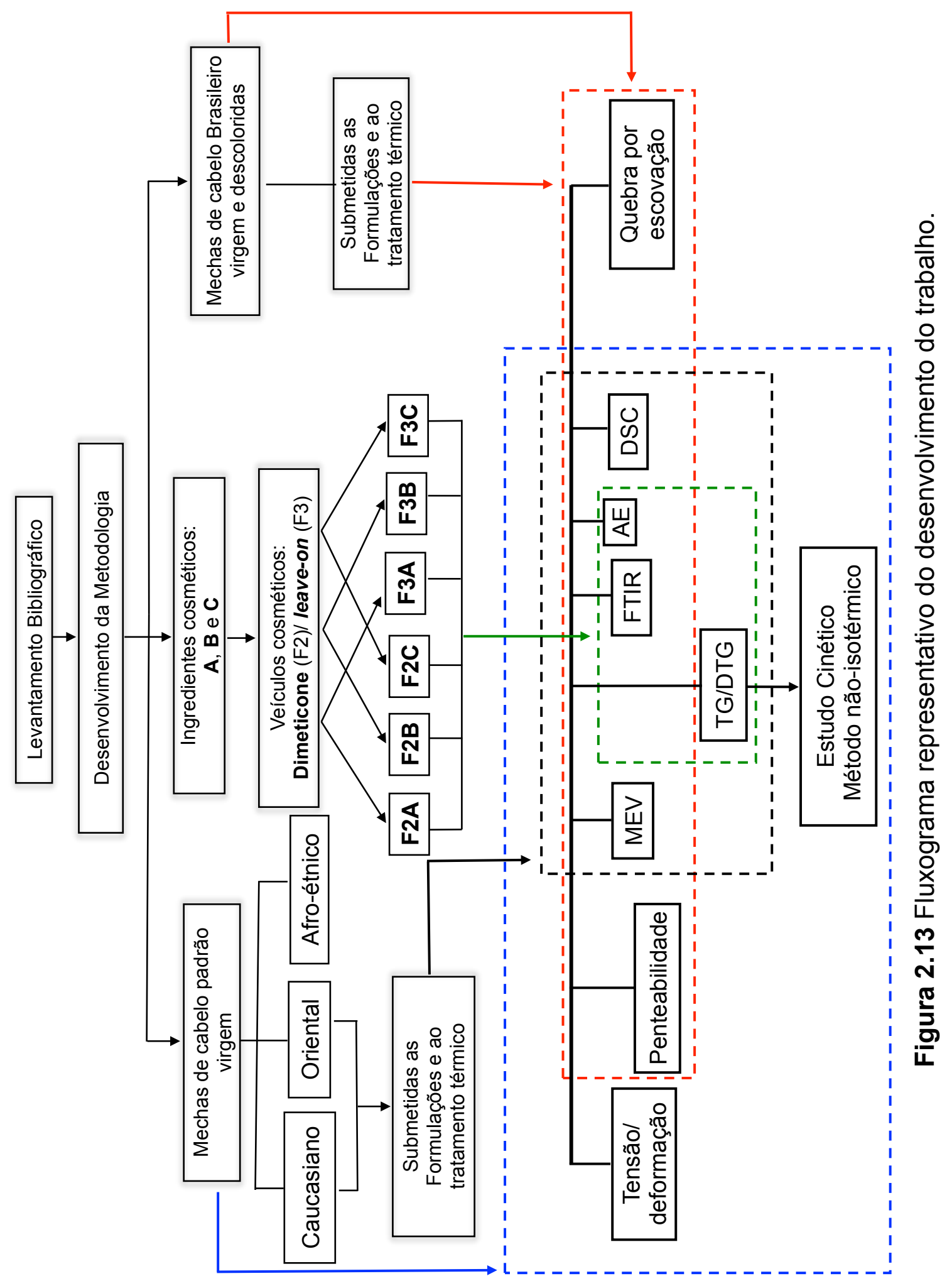




\section{JUSTIFICATIVA}

Nos trabalhos da literatura, foram encontrados poucos estudos que envolvam a associação de várias técnicas de caracterização de amostras de cabelos de diferentes etnias que possibilitem diferenciá-los do ponto de vista de comportamento térmico. Este fato instigou o desenvolvimento de uma pesquisa científica de forma sistemática, visando ampliar esse conhecimento.

Com o crescente uso de modeladores térmicos de cabelos (piastras, baby liss e secadores), empresas do ramo cosmético vêm demonstrando interesse em desenvolver formulações cosméticas que visam a proteção de cabelos dos danos causados pela utilização destes equipamentos. Por este motivo, faz-se necessário um estudo para determinação de mudanças estruturais, químicas e térmicas nos cabelos quando expostos a estes tratamentos térmicos. Além disso, alguns questionamentos existem: - Qual é a influência causada quando esses tratamentos são realizados na presença de ingredientes cosméticos que são protetores? - como esses ingredientes cosméticos contribuem como agente protetor das fibras capilares? Respostas a esses questionamentos só serão possíveis a partir de estudos sistemáticos, que visam avaliar a extensão do dano causado aos cabelos pelo uso contínuo deste tipo de tratamento e, também se houver a possibilidade de associar várias técnicas físico-químicas e analíticas que permitem a caracterização antes e após o tratamento das fibras capilares.

Por outro lado, há uma grande necessidade de um maior número de pesquisas científicas em cabelo, desvinculadas dos aspectos comerciais, e é neste contexto que este trabalho de investigação de ingredientes cosméticos para proteção térmica de danos na fibra capilar se faz importante. 


\section{OBJETIVOS}

\section{Objetivo Geral}

Estudo da caracterização físico-química e analítica de amostras de cabelos padrão virgem das principais etnias e avaliação do comportamento de amostras de cabelos virgem e tratadas quimicamente quanto à composição química, estrutural e térmica submetidas ao uso de ingredientes cosméticos do mercado que atuem como protetores.

\section{Objetivos Específicos}

Amostras de cabelo virgem das principais etnias (oriental, caucasiano e afroétnico), amostras de cabelo virgem submetidas a formulações contendo ingredientes cosméticos para proteção e amostra de queratina animal.

- Investigação do comportamento térmico via TG/DTG e DSC, visando avaliar a estabilidade térmica, efeitos de desidratação/hidratação, fusão desnaturação da a-queratina e decomposição térmica.

- Estudo cinético por TG pelo método não isotérmico a fim de avaliar o comportamento da etapa de degradação térmica da queratina presente no cabelo, bem como comparar a estabilidade térmica de cabelos dos três tipos de etnia.

- Determinação de teores dos principais elementos $(C, H, N$ e $S)$ e de grupos funcionais presentes empregando a análise elementar e a espectroscopia de absorção na região do infravermelho, respectivamente.

- Avaliação estrutural por microscopia eletrônica de varredura.

- Avaliação da eficácia pelos métodos de penteabilidade e de resistência à ruptura.

- Avaliação de danos causados pelo uso de piastra antes e após tratamento térmico (consecutivos ciclos de aquecimento/lavagem). 
Amostras de cabelo brasileiro quimicamente tratadas e submetidas a formulações contendo ingredientes cosméticos para proteção.

- Investigação do comportamento térmico via DSC, visando avaliar a estabilidade térmica, efeitos de desidratação/hidratação, fusão/desnaturação da a-queratina e decomposição térmica dos cabelos.

- Determinação de teores dos principais elementos $(C, H, N$ e $S)$ e de grupos funcionais presentes, empregando a análise elementar e a espectroscopia de absorção na região do infravermelho, respectivamente.

- Avaliação estrutural por microscopia eletrônica de varredura.

- Avaliação de danos causados pelo uso de piastra antes e após tratamento térmico (consecutivos ciclos de aquecimento/lavagem).

Ingredientes cosméticos e formulações

- Incorporação de ingredientes cosméticos (silicones) em diferentes veículos, visando avaliar a influência destes na estabilidade térmica dos ingredientes cosméticos e dos efeitos de desidratação/hidratação nos cabelos utilizando as técnicas de TG/DTG e DSC.

- Determinação de teores dos principais elementos (C, H, N e S) e de grupos funcionais presentes, empregando a análise elementar e a espectroscopia de absorção na região do infravermelho, respectivamente.

- Estudo do efeito de silicones amino-funcional e não amino-funcional na proteção térmica de amostras de cabelo. 


\section{MATERIAL E MÉTODOS}

\subsection{MATERIAL}

\subsubsection{Seleção das mechas de cabelo}

5.1.1.1. Caracterização de amostras de cabelo sem tratamento e de queratina animal

Foram utilizadas mechas de cabelo virgem (sem tratamento químico) de três principais etnias:

- caucasiana na cor castanha-escura, oriental e afro-étnica. Elas foram adquiridas através da empresa DeMeo Brothers ${ }^{\circledR}$ (NY- EUA), a qual certifica que o cabelo padrão fornecido trata-se de uma blenda de fios de cabelo de vários indivíduos com a mesma característica étnica, o que garante a representatividade de dados, permitindo a comparação destes com a literatura.

- queratina animal obtida da Eversil Produtos Farmacêuticos Indústria e Comércio Ltda (São Paulo- Brasil).

\subsubsection{Caracterização de amostras de cabelo tratadas com formulações} cosméticas antes e após a utilização de dispositivos térmicos

- As mechas de cabelo utilizadas foram:

a) caucasiana e oriental castanha-escura virgens adquiridas através da empresa De Meo Brothers ${ }^{\circledR}$ (NY- EUA), com comprimento cerca de $15 \mathrm{~cm}$. Pela dificuldade em se encontrar mechas de cabelo padrão afro-étnico com comprimento maior de $3 \mathrm{~cm}$ não foi possível a realização desta etapa neste tipo de amostra.

b) brasileira, grau de ondulação II virgem (de acordo com o estudo de De La Mettrie et al., 2007, descrito item 2.4 p.11), castanha-escura, adquiridas da fornecedora Andrea Lopes (São Paulo- Brasil) e descoloridas.

\subsubsection{Seleção dos ingredientes cosméticos adquiridos do mercado}

Para facilitar a discussão dos resultados obtidos no presente trabalho, os ingredientes cosméticos foram denominados conforme Tabela 5.1. Foram 
escolhidos dois silicones amino-funcionais e um não amino-funcional com o intuito de avaliar o efeito destes nos tratamentos das mechas. Os ingredientes cosméticos foram obtidos do mercado como matéria-prima.

O pó descolorante (marca ElisaFer ${ }^{\circledR}$ Professional) e a água oxigenada (40 volumes; marca Alphaline) utilizados para a mistura clareadora das mechas de cabelo brasileiro grau de ondulação II foram obtidos do mercado.

Tabela 5.1 Ingredientes cosméticos selecionados.

\begin{tabular}{c|c}
\hline \hline INCI & Denominação \\
\hline \hline Trideceth-9 PG-Amodimethicone (and) Trideceth-12 & Ingrediente A \\
\hline Amodimethicone Glycerocarbamate & Ingrediente B \\
\hline $\begin{array}{c}\text { Cyclopentasiloxane (and) dimethiconol (and) dimethicone } \\
\text { crosspolymer }\end{array}$ & Ingrediente C \\
\hline \hline
\end{tabular}

\subsubsection{Seleção dos veículos utilizados para a incorporação dos ingredientes cosméticos}

Foram utilizados dois veículos para a incorporação dos ingredientes cosméticos: dimeticone e uma base condicionadora leave-on, ambas obtidas pela empresa Mapric Produtos Farmacocosméticos LTDA.

Composição da base condicionadora leave-on escolhida: água deionizada, óleo mineral, dimticone, álcool cetoestearílico 20EO, álcool cetoestearílico, cloreto de cetil trimetil amônio 50\%, glicerina, álcool de lanolina acetilada, lanolina 75EO, metilparabeno, propilparabeno, butilparabeno, fenoxietanol, ácido cítrico, metilcloroisotiazolinona, metilisotiasolinona, aminoácido do leite, benzofenona 4, composição aromática.

\subsubsection{Equipamentos e Acessórios}

- Célula DSC $50\left(\right.$ Shimadzu $\left.^{\circledR}\right)$

- Termobalança modelo TGA-51 (Shimadzu $\left.{ }^{\circledR}\right)$

- Espectrômetro Infravermelho FTIR PerkinElmer Frontier MIR single range 
- Microscópio eletrônico de varredura - Quanta 600 FEI (1kV)

- Analisador elementar $2400 \mathrm{CHN}$ (PerkinElmer)

- Agitador mecânico digital - $60 \mathrm{~Hz} / 87 \mathrm{~W}$ com haste tipo hélice

- Balança eletrônica decimal $5000 \mathrm{~g}$ divisão $0,1 \mathrm{~g}-60 \mathrm{~Hz} / \mathrm{VA} 7,5$

- Centrífuga Heraeus intruments modelo Megafuge 2.0

- Estufa de secagem

- pHmetro marca Digimed DM 21

- Viscosímetro digital Brookfield LV modelo DV II + Pro

- Termo-higrômetro digital Incoterm

- Modelador térmico Marca Lizz

- Secador de cabelos Lizz

- Micrômetro Mitutoyo modelo No 203-805

- Equipamento universal de ensaios mecânicos marca Instron ${ }^{\circledR}$ modelo: 5565 (testes de tensão/deformação e penteabilidade)

- Penteador automatico marca Bioluz - modelo BPLA 100

\subsection{MÉTODOS}

\subsubsection{Pré-tratamento das mechas de cabelo padronizadas}

As mechas de cabelo com aproximadamente $2 \mathrm{~g}$ e comprimento de cerca de $10 \mathrm{~cm}$ foram lavadas com solução de $10 \%(\mathrm{~m} / \mathrm{m})$ de lauril éter sulfato de sódio (LESS) com massagem digital por 2 minutos. Em seguida, elas foram enxaguadas com água destilada corrente de modo a eliminar completamente o detergente presente (NAKANO, 2006).

A primeira etapa do trabalho consistiu na caracterização de amostras de cabelo virgem padronizadas de diferentes etnias (caucasiano, oriental e afroétnico) e de queratina animal sob diferentes técnicas analíticas. As mechas de cabelo não foram tratadas com nenhum cosmético, apenas lavadas com LESS $10 \%(\mathrm{~m} / \mathrm{m})$.

A etapa seguinte consistiu na caracterização de mechas de cabelo caucasiano, oriental e brasileiro submetidas a formulações cosméticas antes e após a aplicação de uma piastra. A amostra de cabelo afro-étnico não foi caracterizada nesta etapa pois o fornecedor nos informou sobre a dificuldade em 
se obter mechas de cabelo afro-étnicos maiores de $3 \mathrm{~cm}$ (este tipo de cabelo contém um índice de crescimento baixo). As mechas de cabelo caucasiano e oriental foram caracterizadas em sua forma virgem e as mechas de cabelo brasileiro foram descoloridas conforme procedimento descrito no próximo item. A Figura 5.1 apresenta as mechas submetidas as formulações antes da etapa de utilização da piastra.
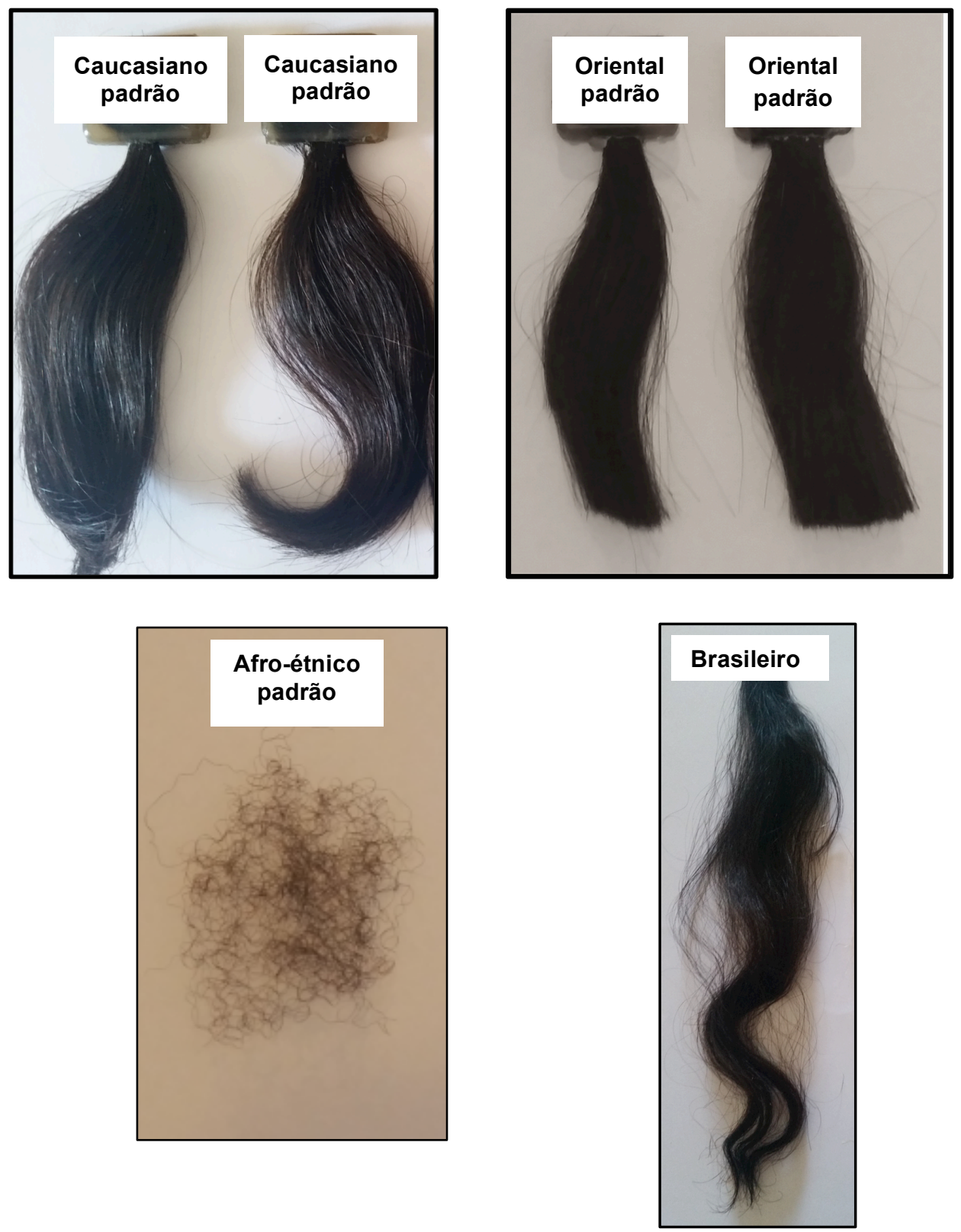

Figura 5.1 Imagens das mechas de cabelo virgem escolhidas. 


\subsubsection{Procedimento de descoloração das mechas de cabelo brasileiro}

O pó descolorante $(\mathrm{m}=50 \mathrm{~g})$ foi misturado à agua oxigenada (40 volumes; $v=75 \mathrm{~mL}$ ) em um gral e misturados com pistilo. Utilizando luvas, a mistura foi aplicada nas mechas de cabelo com o auxílio de um pincel. As mechas permaneceram em contato com a mistura por um tempo de 40 minutos, sendo que após, as mesmas foram enxaguadas em água destilada e corrente à vazão de $240 \mathrm{~mL} \mathrm{~min}^{-1} \mathrm{e}$, em seguida, lavadas conforme procedimento descrito no item 5.2.1.

Para o estudo de caracterização das fibras de diferentes etnias, as mechas foram secas dentro de um compartimento, confeccionado na oficina do IQ-USP, especificamente para a secagem e armazenagem das mesmas (Figura 5.2). Este compartimento contém um termômetro digital e um higrômetro.

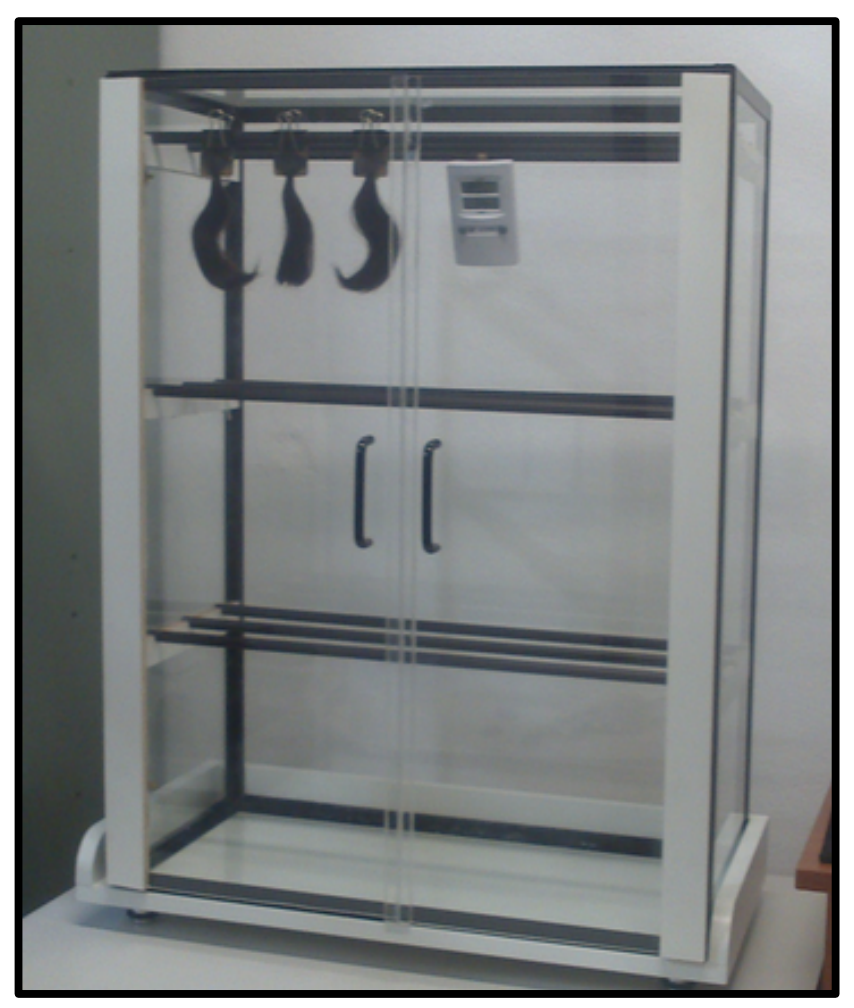

Figura 5.2 Ilustração do compartimento para secagem e armazenagem das mechas de cabelo.

No presente trabalho considerou-se como mecha de referência "Controle", a respectiva mecha de cabelo caucasiano, oriental e brasileiro, sem tratamento de 
qualquer natureza química. Apenas as mechas de cabelo brasileiro foram consideradas dois tipos de "mechas controle": virgem e descolorido sem tratamento com as formulações cosméticas.

\subsubsection{Caracterização das amostras de cabelo padrão virgem de diferentes etnias e queratina animal}

Após as mechas de cabelo serem lavadas segundo procedimento 5.2.1., fios aleatórios foram cortados em pequenas porções e submetidos aos testes de TG/DTG, DSC, FTIR e AE. As mechas de cabelo inteiras foram separadas em sacos herméticos para os ensaios de tensão/deformação e penteabilidade. Para os ensaios de DSC, as pequenas porções de cabelo cortadas foram pesadas em cadinho de alumínio e estocadas em ambiente sob temperatura e umidade relativa (U.R.) controlados. As mechas foram avaliadas em triplicata.

\subsubsection{Termogravimetria/Termogravimetria derivada (TG/DTG)}

As amostras de mechas de cabelo, queratina animal, ingredientes cosméticos e das formulações obtidas foram submetidas aos ensaios de termogravimetria empregando termobalança modelo TGA-51 (Shimadzu), sob atmosfera dinâmica de ar (vazão de $50 \mathrm{~mL} \mathrm{~min}^{-1}$ ), faixa de temperatura de 25 até $900^{\circ} \mathrm{C}$, taxa de aquecimento de $10^{\circ} \mathrm{C} \mathrm{min}^{-1}$ e cadinho de Pt contendo cerca de 15 mg de amostra.

\subsection{Estudo cinético por TG de amostras de cabelo virgem padrão e de queratina animal pelo método não isotérmico}

O estudo cinético não-isotérmico foi realizado a partir de ensaios termogravimétricos pelo método de OZAWA (1965), com as amostras de cabelo caucasiano, oriental e afro-étnico. Os ensaios foram realizados em termobalança modelo TGA-51 da marca Shimadzu, com aquecimento das amostras até $300^{\circ} \mathrm{C}$, e $\beta$ de 5,$0 ; 7,5 ; 10,0 ; 15,0$ e $20,0^{\circ} \mathrm{C} \mathrm{min}^{-1}$, sob atmosfera dinâmica de ar $(50 \mathrm{~mL}$ $\mathrm{min}^{-1}$ ), utilizando-se cadinho de Pt e massas de amostra em torno de $15 \mathrm{mg}$. Para 
o tratamento dos dados, utilizou-se o modelo proposto por OZAWA (1965), para uma perda de massa definida em 10\%, conforme programa de análise cinética desenvolvido pela Shimadzu. O coeficiente angular (slope) do gráfico que correlaciona Log $\beta$ vs. 1/T $\left(\mathrm{K}^{-1}\right)$ fornece a energia de ativação do processo de decomposição térmica. Os valores do fator frequência $(A)$ e ordem de reação são obtidos também neste estudo cinético. A ordem de reação é obtida a partir do gráfico que correlaciona a massa residual da amostra com tempo reduzido em minutos (OZAWA, 2000; CIDES et al., 2006).

Durante os ensaios de cinética, observou-se uma dificuldade em se obter as curvas TG não-isotérmicas. Isto porque diferentes teores de água contidos nas amostras que são liberados na primeira etapa de perda de massa interferiam na segunda etapa de perda de massa, na qual o modelo cinético seria aplicado. Em outras palavras, a etapa da desidratação da fibra capilar acarreta erros na próxima etapa, que está relacionada à decomposição térmica dos cabelos.

Desta forma, uma metodologia foi desenvolvida a fim de se diminuir em erros acometidos pela etapa de perda de água presente nas fibras capilares. $A$ metodologia consistiu no aquecimento do material até $120^{\circ} \mathrm{C}$ e mantido a esta temperatura até que toda a água presente fosse eliminada. O aquecimento foi interrompido para que em seguida fossem adicionados os novos parâmetros de aquecimento ao equipamento de termogravimetria. Todas as curvas de aquecimento foram obtidas da mesma maneira. Esta metodologia apresentou-se eficaz, uma vez que foi possível obter as curvas TG não isotérmicas reprodutíveis.

\subsubsection{Calorimetria Exploratória Diferencial (DSC)}

As curvas DSC das amostras das fibras capilares virgens e queratina animal foram obtidas em uma célula DSC, modelo 50 da marca Shimadzu, sendo adotadas as seguintes condições experimentais: razão de aquecimento de $10^{\circ} \mathrm{C}$ $\min ^{-1}$, faixa de temperatura de 25 a $550^{\circ} \mathrm{C}$, sob atmosfera dinâmica de $\mathrm{N}_{2}(50 \mathrm{~mL}$ $\min ^{-1}$ ), cápsula de Al parcialmente fechada contendo cerca de $2 \mathrm{mg}$ de amostra.

Para os ensaios com as amostras de cabelo, pequenas porções cortadas foram pesadas em cadinho de alumínio e estocadas em duas condições de ambiente controlado por $48 \mathrm{~h}: 22 \pm 2^{\circ} \mathrm{C}$ e $65 \pm 2 \%$ U.R e $22 \pm 2^{\circ} \mathrm{C}$ e $20 \pm 2 \%$. As 
condições ambientais foram escolhidas com 0 intuito de verificar se estas influenciam nos parâmetros de DSC obtidos para as amostras de cabelo.

\subsubsection{Análise elementar}

Os teores dos elementos $\mathrm{C}, \mathrm{N}, \mathrm{H}$ e S das amostras de queratina, das fibras capilares virgens, dos ingredientes cosméticos e das formulações foram obtidos utilizando o equipamento Elemental Analyzer $2400 \mathrm{CHN}$ (PerkinElmer).

\subsubsection{Espectroscopia de absorção na região do infravermelho com transformada de Fourier - FTIR-ATR}

Os espectros vibracionais na região do infravermelho das amostras dos ingredientes cosméticos, formulações e das fibras capilares foram registrados na faixa de 500 a $4000 \mathrm{~cm}^{-1}$ utilizando-se o espectrômetro FTIR PerkinElmer Frontier MIR single range, resolução $4 \mathrm{~cm}^{-1}, 20$ varreduras (scan) e detector de $\mathrm{LiTaO}_{3}$.

\subsubsection{Microscopia eletrônica de varredura}

As análises das amostras de fibras capilares virgens foram realizadas em microscópio eletrônico de varredura, modelo Quanta 600 FEl (1kV), com filamento de tungstênio e operando em pressão reduzida. As amostras foram coladas em suporte específico para MEV utilizando-se fita adesiva de cobre. Os fios foram afixados com o auxílio de uma pinça de modo que as amostras ficassem na posição horizontal e vertical.

\subsubsection{Avaliação de resistência a penteabilidade}

Um pente para cabelo foi adaptado ao equipamento universal de ensaios mecânicos da marca Instron contendo célula de carga de $10 \mathrm{~N}$ e velocidade constante de $100 \mathrm{~mm} \mathrm{~min}^{-1}$, medindo este a força para pentear cada mecha de cabelo foi medida pelo software Bluehill 3. Foram preparados conjuntos de três mechas para as medidas, em cada tratamento, conforme o seguinte:

1. Mechas de cabelo caucasiano virgem padrão; 
2. Mechas de cabelo oriental virgem padrão e;

3. Mechas de cabelo brasileiro grau de ondulação II (conforme estudo realizado por De La Mettrie et al. (2007) virgem e descolorido, tratados com as seis formulações.

\subsubsection{Avaliação das propriedades mecânicas pelo método de tensão- deformação das mechas de cabelo padrão virgem}

Foram preparados conjuntos de três mechas para as medidas de cada etnia.

\subsubsection{Determinação do diâmetro dos fios}

Foram selecionadas 20 fios de cada mecha de cabelo. Antes de submeter os fios de cabelo aos testes de tensão/deformação, o diâmetro de cada fio foi medido em três locais diferentes (próximo à raiz, meio e ponta do fio) e calculadas as médias destes valores, usando-se um micrômetro Mitutoyo. O valor médio das determinações foi utilizado no cálculo dos parâmetros relacionados às propriedades mecânicas.

\subsubsection{Ensaios de tensão-deformação}

Os fios de cabelo (20 fios de cada mecha) foram fixados nos anteparos metálicos e colocados no equipamento da marca Instron. Garras especiais para cabelo foram adaptadas no equipamento utilizando-se célula de carga de $10 \mathrm{~N}$ e velocidade constante de $10 \mathrm{~mm} \mathrm{~min}^{-1}$. Em seguida, iniciou-se o estiramento das fibras individualmente, medindo a força até o rompimento das mesmas. Foi obtida a curva de tensão-deformação, sendo calculados os parâmetros das propriedades mecânicas a partir do software Bluehill 3. A Figura 5.3 mostra o equipamento no qual foram realizados os testes de tensão-deformação e penteabilidade. A imagem mostra uma mecha de cabelo virgem (brasileiro grau de ondulação II) sendo penteada, porém, para os testes de tensão-deformação é utilizado outro tipo de acessório que se conecta ao mesmo equipamento. 


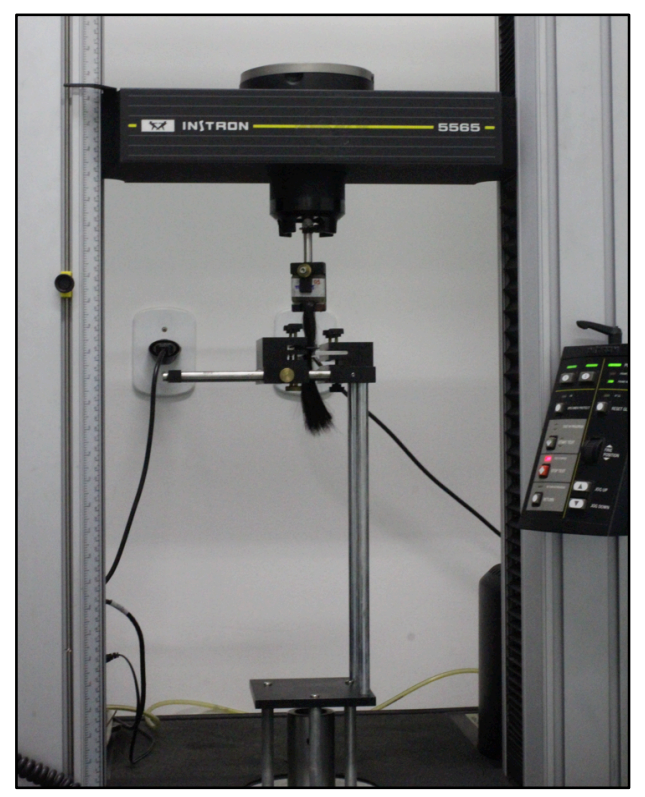

Figura 5.3 Ilustração do equipamento empregado nos testes de penteabilidade e tensão deformação utilizado no trabalho.

\subsubsection{Incorporação dos ingredientes cosméticos aos veículos selecionados}

Os ingredientes cosméticos foram misturados a frio aos veículos em uma concentração final de $3 \%(\mathrm{~m} / \mathrm{m})$ (valor mínimo sugerido pelos fornecedores) empregando-se um agitador mecânico com haste hélice, obtendo-se desta maneira, as formulações abaixo citadas (Tabela 5.2).

Tabela 5.2 Denominação das formulações obtidas para o tratamento das mechas de cabelo.

\begin{tabular}{ccc}
\hline \hline Formulação & Veículo & Ingrediente cosmético \\
\hline \hline F2 & Dimeticone & ----- \\
F2A & Dimeticone & Ingrediente A \\
F2B & Dimeticone & Ingrediente B \\
F2C & Dimeticone & Ingrediente C \\
F3 & Cond. Leave-on & ---- \\
F3A & Cond. Leave-on & Ingrediente A \\
F3B & Cond. Leave-on & Ingrediente B \\
F3C & Cond. Leave-on & Ingrediente C \\
\hline \hline
\end{tabular}




\subsubsection{Estudo de estabilidade das formulações cosméticas}

A base condicionadora leave-on foi adquirida do mercado com o teste de estabilidade já realizado e estabelecido, porém com a adição dos ingredientes, fez-se necessário um novo estudo de estabilidade para avaliar o comportamento da incorporação dos ingredientes. O Teste de estabilidade acelerada foi realizado de acordo com as normas do Guia de Estabilidade da ANVISA e foi realizado nas formulações leave-on (contendo os ingredientes A, B e C).

\subsubsection{Teste de centrifugação}

O teste de centrifugação produz estresse na amostra simulando um aumento na força de gravidade, aumentando a mobilidade das partículas e antecipando possíveis instabilidades. Estas poderão ser observadas na forma de precipitação, separação de fases ou coalescência, entre outras (ANVISA, 2004).

Foram pesadas alíquotas de $5 \mathrm{~g}$ das formulações e acondicionadas em tubo graduado para centrífuga. As amostras foram centrifugadas, em ciclos de 30 minutos na velocidade de $3000 \mathrm{rpm}$ à temperatura de $25^{\circ} \mathrm{C}$ antes de iniciar o estudo de estabilidade.

\subsubsection{Teste de estabilidade acelerada}

Foram obtidas $500 \mathrm{~g}$ de cada formulação, consideradas estáveis pelos testes de estabilidade preliminar e divididas nas seguintes embalagens de vidro incolor com tampas de plástico e formas de armazenamento (BRASIL, 2004):

- $\quad$ Estufa à temperatura controlada de $45,0 \pm 2,0^{\circ} \mathrm{C}$.

- $\quad$ Geladeira a $5,0 \pm 2,0^{\circ} \mathrm{C}$.

- $\quad$ Ambiente a $25,0 \pm 2,0{ }^{\circ} \mathrm{C}$.

- $\quad$ Exposição a radiação solar.

- Ciclos de congelamento e descongelamento de 24 horas a 45,0 \pm 2,0 ${ }^{\circ} \mathrm{C}$, e 24 horas a $-5,0 \pm 2,0{ }^{\circ} \mathrm{C}$, completando um ciclo. As leituras dos parâmetros de estabilidade foram realizadas antes do início do teste (24 horas após o preparo) e ao final do $6^{\circ}$ ciclo consecutivo $\left(12^{\circ} \mathrm{dia}\right)$. 
Durante o envase não foi completado o volume total da embalagem permitindo um espaço vazio (headspace) de aproximadamente um terço da capacidade do frasco para possíveis trocas gasosas (ANVISA, 2004).

\subsubsection{Avaliação das formulações cosméticas}

As avaliações foram realizadas nos tempos: zero $\left(T_{0}\right)$; sete $\left(T_{7}\right)$; quinze $\left(T_{15}\right)$; trinta $\left(T_{30}\right)$ quanto ao aspecto, cor, odor, $\mathrm{pH}$ e viscosidade aparente (BRASIL, 2004). Os resultados foram compilados sob a forma de tabela.

Para as medidas de $\mathrm{pH}$, pesou-se $1 \mathrm{~g}$ de cada formulação em tubo de ensaio, acrescentando-se $9 \mathrm{~mL}$ de água destilada. Após dispersão da mistura, o $\mathrm{pH}$ foi mensurado à temperatura ambiente.

Para a medida da viscosidade aparente, utilizou-se viscosímetro rotativo, com sensor $\mathrm{n}^{\circ} 31$, à velocidade de $0,30 \mathrm{rpm}$ e massa de amostra de cerca de 15 g. Para todas as amostras, as leituras foram efetuadas após 1 minuto de estabilização das preparações, a temperatura de $25,0 \pm 2,0^{\circ} \mathrm{C}$. Para os testes de estabilidade acelerada, a seguinte nomenclatura foi empregada para classificar as formulações quanto ao aspecto, cor e odor: $\mathbf{N}=$ Normal, sem alteração; $\mathbf{L M}=$ Levemente Modificado; $\mathbf{M}$ = Modificado e $\mathbf{I M}=$ Intensamente Modificado.

\subsection{Caracterização e avaliação de amostras de cabelo submetidas ao tratamento com os ingredientes cosméticos}

Nesta etapa, além das mechas de cabelo padrão caucasiano e oriental, mechas de cabelo brasileiro classificadas como tipo II (conforme De La Mettrie et al., 2007) foram submetidas às formulações cosméticas. No decorrer do trabalho serão citadas como brasileira grau de ondulação II. Estas últimas foram avaliadas virgem e descoloridas.

Este estudo envolveu duas etapas as quais estão descritas e demonstradas na forma de fluxograma mais adiante:

1) Sem tratamento térmico (piastra): Dois ciclos consecutivos de lavagens com LESS $10 \%(\mathrm{~m} / \mathrm{m})$ intercalando com a aplicação das formulações e 
deixando permanecer os produtos nas mechas de cabelos antes dos experimentos (vide item 5.3.2. logo adiante) e,

2) Com tratamento térmico (piastra): Três ciclos de lavagem com LESS 10\% $(\mathrm{m} / \mathrm{m})(2 \mathrm{~min})$ e aquecimento com piastra à $200^{\circ} \mathrm{C}(4 \mathrm{~min})$ intercalando com a aplicação das formulações cosméticas e retirando os produtos das mechas de cabelo antes dos experimentos. Duração do tempo total das mechas em contato com a piastra: 12 min (vide item 5.3.3. logo adiante).

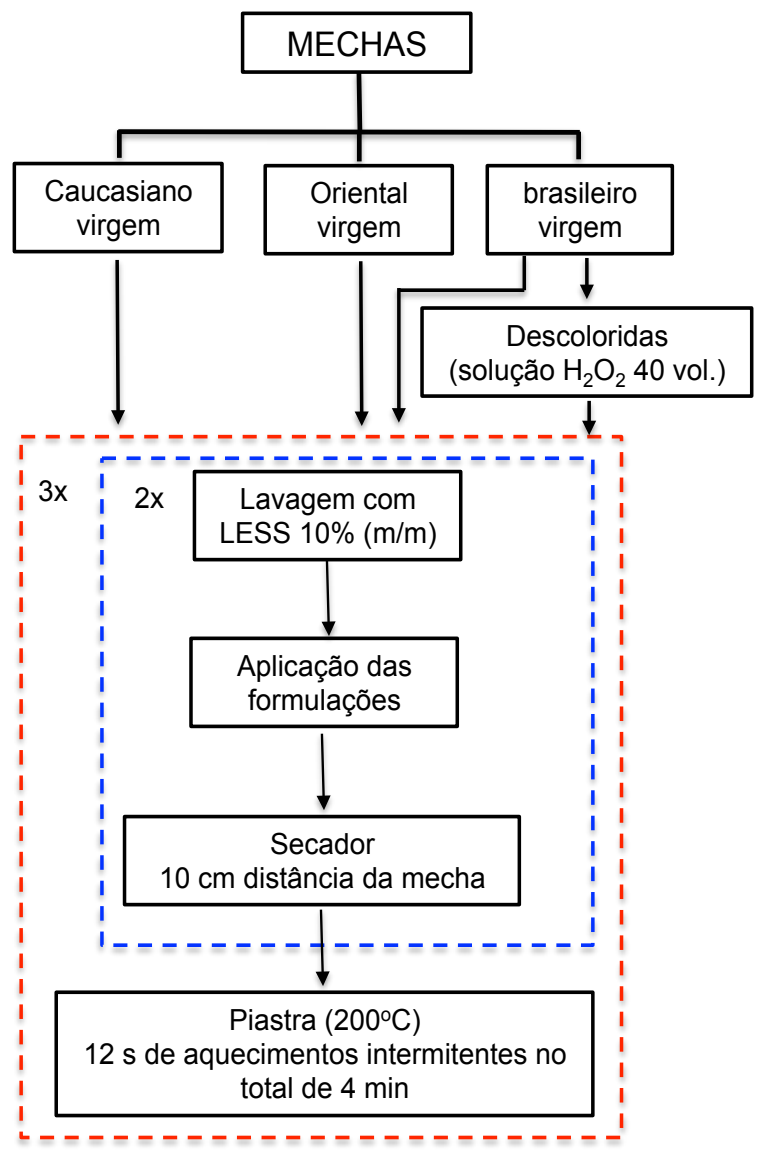

Figura 5.4 Fluxograma do procedimento de tratamento das mechas de cabelo com as formulações sem e com a utilização de dispositivo térmico.

\subsubsection{Tratamento das mechas de cabelo com as formulações sem a utilização de dispositivo térmico (piastra)}

As formulações foram aplicadas nas mechas úmidas e lavadas (aproximadamente $2 \mathrm{~g}$; em triplicata) de acordo com o item 5.2.1. em dois procedimentos distintos: para as formulações contendo dimeticone (F2A, F2B e F2C) utilizou-se uma proporção de 1:0,3 (m/m) (mecha:formulação) e as 
formulações leave-on (F3A, F3B e F3C) utilizou-se $1 \mathrm{~g}$ por mecha $(\mathrm{m} / \mathrm{m})$; e em ambos os casos realizando-se uma massagem com os dedos (MONTEMAYOR et al., 2012). Após 10 minutos as mechas foram secas com um secador de cabelos na posição quente a uma distância de $10 \mathrm{~cm}$ aproximadamente (procedimento conforme LEE et al., 2011). O procedimento foi repetido duas vezes. As formulações foram mantidas nos cabelos para a secagem com o secador de cabelos. O condicionador leave-on (sem enxágue), é utilizado no mercado, não apenas antes de se fazer o uso de algum tipo de dispositivo térmico, mas sim com o intuito de melhorar as propriedades superficiais dos cabelos.

Em seguida, fios aleatórios foram cortados e submetidos aos ensaios de TG/DTG, DSC e AE. Para os ensaios de DSC, as pequenas porções de cabelo cortados, cerca de $2 \mathrm{mg}$, foram inseridas em cadinho de Al e estocadas em ambiente controlado de $22 \pm 2^{\circ} \mathrm{C}$ e $20 \pm 2 \%$ U.R. por um período de $48 \mathrm{~h}$. Estas condições foram escolhidas para que a água presente no ambiente não influenciasse nos parâmetros de DSC.

\subsubsection{Tratamento das mechas de cabelo com as formulações utilizando dispositivo térmico (piastra)}

As mechas de cabelo caucasiano, oriental e brasileiro (todas em triplicata) foram submetidas a uma avaliação de possíveis danos causados pelo uso contínuo da piastra.

As mechas foram lavadas conforme procedimento descrito no item 5.2.1. e, em seguida submetidas à aplicação das formulações conforme procedimento descrito no item 5.2.3.1. e secas com o auxílio de um secador de cabelos na posição quente a uma distância de cerca de $10 \mathrm{~cm}$. Posteriormente, as mesmas foram expostas a curtos ciclos de aquecimento intermitentes de 12 segundos com duração total de 12 minutos intercalados com lavagens com LESS 10\% $(\mathrm{m} / \mathrm{m})$ e aplicação das formulações a cada quatro minutos (de acordo com estudo de ZHOU et al., 2011). A temperatura da piastra utilizada foi $200^{\circ} \mathrm{C}$ (especificação do fabricante e conferida).

Após o ciclo total de 12 minutos de exposição das mechas ao tratamento térmico, as mesmas foram cortadas em pequenas porções e armazenadas para 
as medidas de DSC, AE, IV e MEV. Para os ensaios de DSC, as pequenas porções de cabelo cortados, cerca de $2 \mathrm{mg}$, foram inseridas em cadinho de $\mathrm{Al}$ e estocadas em ambiente controlado a $22 \pm 2{ }^{\circ} \mathrm{C}$ e $20 \pm 2 \%$ U.R. Esta condição foi escolhida com o intuito de evitar a influência da água na avaliação calorimétrica das formulações.

As mechas de cabelo brasileiro (virgem e descolorido, em triplicata) grau de ondulação II foram separadas e submetidas a testes de eficácia por penteabilidade e quebra por escovação.

Os procedimentos das técnicas acima mencionadas (DSC, AE, IV, MEV, penteabilidade e quebra por escovação) já foram descritos pois foram utilizadas na etapa anterior, com exceção do teste de eficácia pelo método de quebra por escovação o qual está descrito a seguir.

\subsubsection{Eficácia pelo método de quebra por escovação}

As mechas úmidas de cabelo brasileiro grau de ondulação II conforme estudo realizado por De La Mettrie et al. (2007): virgens, descoloridas e descoloridas tratadas com as seis formulações (em triplicata), foram escovadas 10000 vezes com o auxílio de um penteador automático e o número de fios quebrados foram contados. A Figura 5.5 apresenta o equipamento para estes testes bem como as mechas virgens de cabelo brasileiro sendo escovadas.

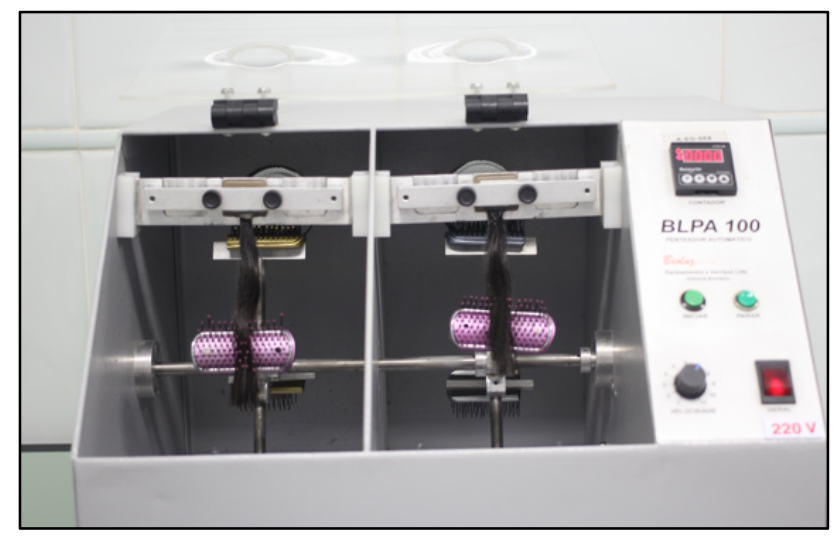

Figura 5.5 Ilustração do equipamento empregado nos testes de quebra por escovação utilizado no trabalho. 


\section{RESULTADOS E DISCUSSÃO}

\subsection{Caracterização das amostras de cabelo virgem padrão e de queratina animal}

Após a lavagem das mechas de cabelo, conforme descrito no item 5.2.1, fios aleatórios de cabelo foram retirados das mechas caucasianas, orientais e afro-étnicas e cortados em pequenas porções. Em seguida, as mesmas foram submetidas a estudos de caracterização quanto ao seu perfil térmico, químico e físico-químico. Uma amostra de queratina animal em pó também foi caracterizada sob mesmas condições.

\subsubsection{Termogravimetria/Termogravimetria derivada (TG/DTG)}

As curvas TG/DTG (Figura 6.1) ilustram o comportamento térmico de amostras de queratina animal em pó e de cabelo padrão virgem das três principais etnias: caucasiano, oriental e afro-étnica. De acordo com os resultados, observaram-se três perdas de massa principais para todas as amostras (Tabela 6.1), indicando um perfil térmico semelhante entre elas.

A primeira etapa de perda de massa corresponde à desidratação, ou seja, à eliminação de água presente nas amostras de cabelo (eventos 1 - Tabela 6.1) e de queratina.

Comparando as três etnias, observou-se que a amostra de cabelo afroétnico apresentou o menor teor de água (cabelo caucasiano: 12,0\%; cabelo oriental: $13 \%$, cabelo afro-étnico: 10,5\%). Este fato pode ser confirmado nos resultados de $\mathrm{AE}$ (Tabela 6.4) que indicam que a amostra de cabelo afro-étnico apresentou o menor teor de hidrogênio. Segundo a literatura, este tipo de cabelo apresenta-se o mais seco dentre as etnias devido à sua forma ondulada e a distribuição da oleosidade sobre sua fibra é irregular (FRANBOURG et al., 2003). A amostra de queratina animal apresentou um teor de água menor do que amostras de cabelo. 


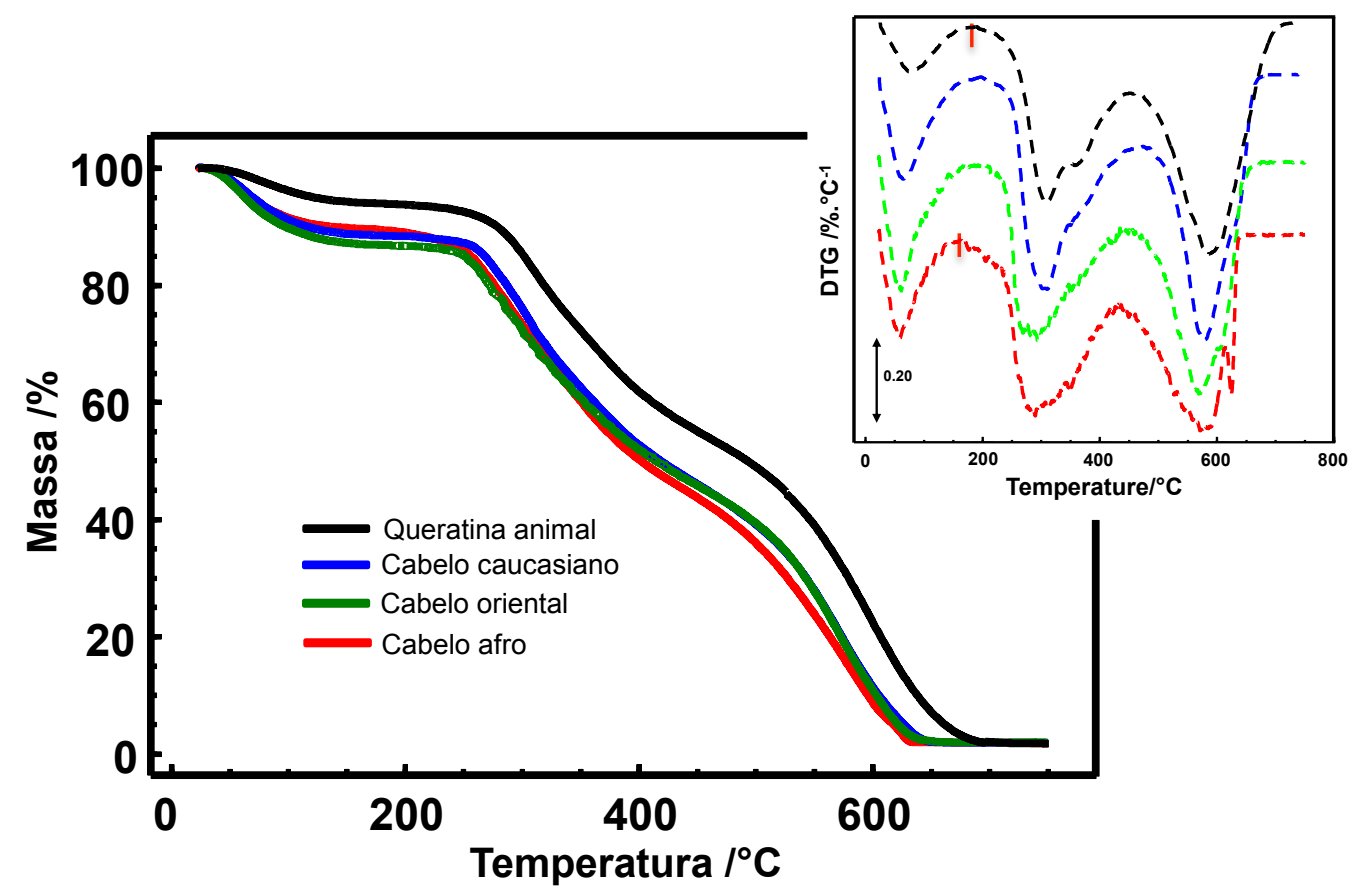

Figura 6.1 Curvas TG e DTG obtidas a $10^{\circ} \mathrm{C} \mathrm{min}^{-1}$, sob atmosfera dinâmica de ar e empregando cápsula de Pt contendo cerca de $15 \mathrm{mg}$ de amostras de queratina ou de cabelos caucasiano, oriental ou afro-étnico padrão.

Em uma pesquisa, utilizando as técnicas de TG e DSC, com amostras de cabelo de diferentes indivíduos, Éhen et al. (2004) obtiveram valores de perda de água entre $5-8 \%$, na faixa de temperatura de 30 a $120^{\circ} \mathrm{C}$ (ÉHEN et al., 2004). Monteiro et al. (2005) obtiveram 5,9\% de água na primeira etapa de perda de massa em amostras de cabelo caucasiano (estocados em ambiente controlado com umidade de $45 \%$ e temperatura de $20-22^{\circ} \mathrm{C}$ ) por TG (MONTEIRO et al., 2005). Colenci (2007) relatou o valor de $9 \%$ de água para a primeira etapa de perda de massa, em um estudo com amostras de cabelo caucasiano por TG (COLENCl, 2007). No entanto, a autora não mencionou se houve o armazenamento das amostras em condições climáticas controladas.

A segunda etapa de perda de massa observada nas curvas TG/DTG é devida à decomposição térmica da cadeia polipeptídica da queratina presente na amostra de cabelo e da amostra de queratina animal (eventos 2 - Tabela 6.1).

De acordo com os resultados, a amostra de cabelo afro-étnico iniciou seu processo de decomposição térmica antes do que ocorreu com as amostras de cabelo caucasiano e oriental. Os resultados listados na Tabela 6.1 evidenciaram 
que as faixas de temperatura para esta etapa foram de $200-460^{\circ} \mathrm{C}$ e $195-450^{\circ} \mathrm{C}$ $170-432^{\circ} \mathrm{C}$ e perdas de massa, de $42,6,40,4$ e $43,7 \%$ para as amostras de cabelo caucasiano, oriental e afro-étnico, respectivamente. Essa menor estabilidade térmica observada para a amostra de cabelo afro-étnico, também, por ser confirmada a partir dos resultados de DSC apresentados logo adiante no item 6.1.2.

Tabela 6.1 Resultados de TG/DTG das amostras de queratina animal, cabelo caucasiano, oriental e afro-étnico.

\begin{tabular}{ccccc}
\hline \hline Amostra & Eventos & $\begin{array}{c}\text { Faixa de } \\
\text { Temperatura } /{ }^{\circ} \mathbf{C}\end{array}$ & $\mathbf{T}_{\text {pico }} /{ }^{\circ} \mathbf{C}$ & Massa/\% \\
\hline Queratina & 1 & $25-167$ & 76 & 7,4 \\
& 2 & $177-450$ & 310 & 45,2 \\
Caucasiano & 1 & $450-780$ & 584 & 46,0 \\
& 2 & $25-200$ & 62 & 12,3 \\
Oriental & 3 & $200-460$ & 308 & 42,6 \\
& 1 & $460-690$ & 578 & 42,6 \\
& 2 & $25-195$ & 61 & 13,3 \\
& 3 & $200-460$ & 296 & 40,4 \\
Afro-étnico & 1 & $460-685$ & 569 & 45,1 \\
& 2 & $25-170$ & 59 & 10,4 \\
& 3 & $170-432$ & 290 & 43,7 \\
\hline \hline
\end{tabular}

Éhen et al. (2004) estudaram a decomposição térmica de quatro aminoácidos pertencentes à a-queratina capilar: ácidos aspártico, glutâmico, histidina e tirosina. Foi demonstrado que os mesmos, com exceção da histidina (que iniciou seu processo de decomposição em aproximadamente $150^{\circ} \mathrm{C}$ ), todos os outros se decompõem acima de $200^{\circ} \mathrm{C}$. Porém, os autores relataram que as 
amostras de cabelo analisadas apresentaram o pico de fusão de $\alpha$-queratina entre 230 e $233^{\circ} \mathrm{C}$ seguida da decomposição térmica do cabelo acima de $250^{\circ} \mathrm{C}$, com perda de massa registrada entre 45 e $55 \%$ da massa inicial. Observaram que todos os aminoácidos quando avaliados separadamente apresentaram estabilidade térmica menor que quando associados a queratina capilar. Este fato pode explicar o motivo pelo qual a queratina, submergida na matriz capilar, apresenta-se estável termicamente até $230^{\circ} \mathrm{C}$ (ÉHEN et al., 2004).

Monteiro et al. (2005) relataram que o segundo evento ocorreu entre 131$400^{\circ} \mathrm{C}$, com perda de massa de $36 \%$ em amostras de cabelo caucasiano virgem, quando a curva TG foi obtida a $3 \mathrm{~K} \mathrm{~min}^{-1}$ e sob atmosfera dinâmica de ar. Deve-se relembrar que, no presente trabalho, a razão utilizada para este experimento foi de $10^{\circ} \mathrm{C} \mathrm{min}^{-1}$ (vide item 5.3.1). Sabe-se que um dos fatores que influenciam no perfil de curvas TG/DTG é a razão de aquecimento, podendo deslocar as temperaturas dos eventos térmicos para valores maiores ou menores. Também, pode influenciar no número de etapas de decomposição térmica e também, causar variações nos valores de perda de massa (MATOS et al., 2000).

A terceira etapa corresponde à degradação completa das cadeias carbônicas da queratina capilar e eliminação do material carbonáceo formado na etapa anterior (eventos 3 - Tabela 6.1). Nesta etapa, as amostras de cabelo caucasiano e oriental apresentaram as faixas de temperaturas de decomposição em $460-685^{\circ} \mathrm{C}$, seguida da amostra de cabelo afro-étnico, que foi de $432-650^{\circ} \mathrm{C}$. Monteiro et al. (2005) obtiveram, para este evento, a faixa de $400-700^{\circ} \mathrm{C}$ em estudo realizado empregando razão de aquecimento de $3 \mathrm{~K} \mathrm{~min}{ }^{-1}$ e sob atmosfera dinâmica de ar em amostras de cabelo caucasiano virgem.

As curvas TG/DTG da amostra de queratina animal são muito similares àquelas observadas para as amostras de cabelo, evidenciando que há uma grande semelhança entre o comportamento térmico de ambos os materiais. Este resultado confirma que o componente majoritário, em amostras de cabelo, é a queratina (ROBBINS, 2000).

Após a temperatura de $700^{\circ} \mathrm{C}$, para todas as amostras, o teor de resíduo foi cerca de $1-2 \%$ da massa inicial e está relacionado ao material inorgânico presente nas amostras, ou formado durante o processo de decomposição térmica. Em cabelo humano, este resíduo pode estar associado à exposição do indivíduo a 
espécies químicas ou devido à ingestão de alguma substância que após um certo período pode estar presente no cabelo (BERMEJO-BARRERA \& ROSSI, 1995; ARNOLD \& SACHS, 1994). Estas espécies podem ser $\mathrm{Ca}, \mathrm{Mg}, \mathrm{Na}, \mathrm{K}$ e Cl, considerados macrominerais, e $\mathrm{Fe}, \mathrm{Zn}, \mathrm{Cu}, \mathrm{Mn}, \mathrm{I}, \mathrm{Cr}$, Se e Mo considerados traços (PASSWATER \& CRANTON, 1983).

\subsubsection{Estudo cinético da decomposição térmica de amostras de cabelo virgem padrão pelo método não isotérmico por TG}

O estudo cinético baseado na termogravimetria é um método efetivo na elucidação dos prováveis mecanismos de reações do estado sólido tais como: a decomposição térmica e a desidratação. A estabilidade térmica de uma amostra pode ser avaliada a partir de parâmetros cinéticos (energia de ativação, ordem de reação e fator pré-exponencial da equação de Ahrrenius) (YOSHIDA, 1993). Os valores de parâmetros cinéticos encontrados para as amostras de cabelo caucasiano e oriental estão listados na Tabela 6.2.

O estudo cinético das amostras de cabelo virgem das etnias caucasiana, oriental e afro-étnica foi realizado para a segunda etapa de perda de massa (relacionada com a etapa de decomposição da queratina presente no cabelo), utilizando-se curvas TGs não-isotérmicas.

As Figuras 6.2 a 6.4 ilustram as curvas TG obtidas a diferentes razões de aquecimento $\left(5 ; 7,5 ; 10 ; 15\right.$ e $\left.20^{\circ} \mathrm{C} \mathrm{min}^{-1}\right)$ bem como o gráfico de Ozawa e $G(X)$ vs tempo reduzido que conduziram à determinação dos parâmetros cinéticos das amostras de cabelo caucasiano e oriental, respectivamente, conforme o método de Ozawa (1965).

Os resultados obtidos desse estudo cinético demonstraram que se tratam de eventos cujo mecanismo da reação é complexo envolvendo várias etapas, uma vez que a ordem de reação encontrada para ambas as amostras de cabelo foi igual a 3. Istrate et al. (2009) propuseram um modelo de três fases de queratina de a-hélice, utilizando um modelo de cinética não-isotérmico na etapa de decomposição térmica de fibras caucasianas por DSC. De acordo com os autores, os resultados indicaram que o mecanismo de desnaturação térmica da aqueratina é mais complexo do que de uma cinética de primeira ordem e não pode 
ser reduzido a um único passo. Além disso, os autores concluíram que a quebra das ligações S-S foi o passo limitante no processo de desnaturação térmica.

Para a amostra de cabelo afro-étnico analisada neste trabalho, não foi possível obter uma boa correlação entre os resultados a partir das curvas TG que possibilitassem calcular os parâmetros cinéticos para este tipo de método cinético (Figura 6.4). Ou seja, as curvas TGs obtidas, em conjunto, para esta amostra, não apresentaram o perfil mencionado na Figura 2.12, o qual permite uma boa correlação para obtenção dos parâmetros cinéticos. A sobreposição destas curvas TGs mencionada acima pode ser observada na Figura 6.4. mais adiante. No entanto, foi possível observar que este tipo de cabelo se decompõe em temperaturas mais baixas do que aquelas observadas para as amostras de cabelo das outras etnias.

As energias de ativação envolvidas nestes processos foram respectivamente, $147 \mathrm{~kJ} \mathrm{~mol}^{-1} \pm 0,3$ (calculada na faixa de 87 a $97 \%$ de perda de massa) e $162 \mathrm{~kJ} \mathrm{~mol}^{-1} \pm 0,2$ (perda de massa na faixa de 87 a $97 \%$ ), para as amostras de cabelo caucasiano e oriental, respectivamente. Como a ordem de reação é a mesma nos dois processos e os fatores pré-exponenciais da equação de Ahrrenius são equiparáveis $\left(2,5 \times 10^{13} \mathrm{~min}^{-1}\right.$ para o caucasiano, e $7,2 \times 10^{14} \mathrm{~min}^{-1}$ para o oriental), é possível dizer que as amostras de cabelo oriental necessitam de uma maior energia na decomposição térmica quando comparado às amostras de cabelo caucasiano. Desse modo, estes dados nos permitem inferir que o cabelo oriental possui maior estabilidade térmica do que as amostras de cabelo caucasiano.

Alguns modificadores são capazes de alterar a cinética de desnaturação das proteínas durante o aquecimento, por exemplo, $\mathrm{pH}$, pode mudar tanto a entalpia de ativação quanto o fator de frequência (BISCHOF, 2005).

Tabela 6.2 Parâmetros obtidos do estudo cinético pelo método não isotérmico (Ozawa, 1965) de amostras de cabelo caucasiano, oriental e afro étnico.

\begin{tabular}{ccccc}
\hline Cabelo & $\mathbf{E}_{\mathrm{a}} / \mathbf{k J ~ m o l}^{-1}$ & $\mathbf{A}$ & $\begin{array}{c}\text { Ordem de } \\
\text { reação }\end{array}$ & $\boldsymbol{\alpha}$ \\
\hline Caucasiano & 147 & $2,49 \times 10^{13}$ & 3 & $0.97-0.87$ \\
Oriental & 162 & $7,29 \times 10^{14}$ & 3 & \\
\hline \hline
\end{tabular}



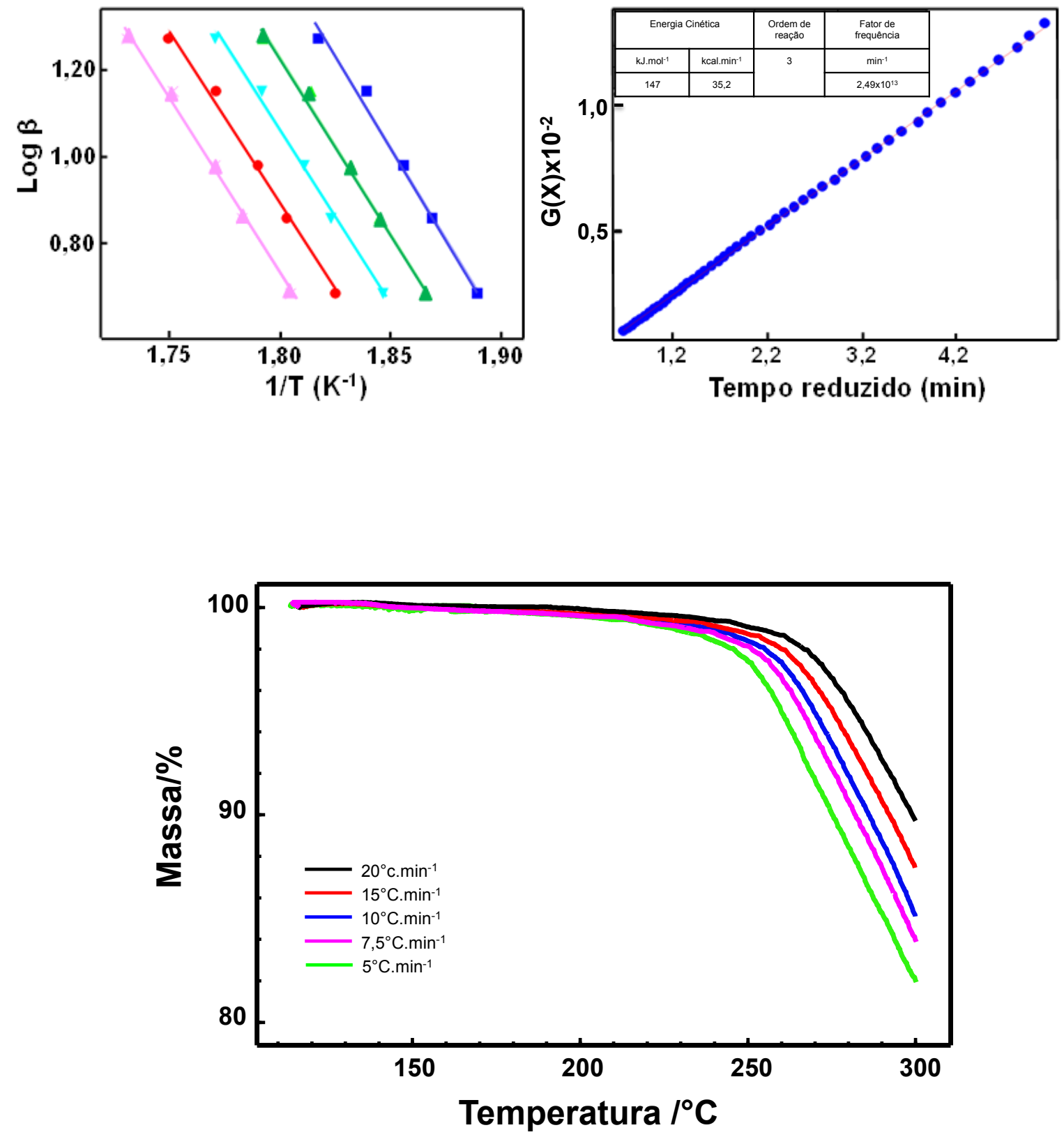

Figura 6.2 Resultados dos parâmetros cinéticos de uma amostra de cabelo caucasiano virgem padrão obtidas sob diferentes razões de aquecimento e atmosfera dinâmica de ar. 

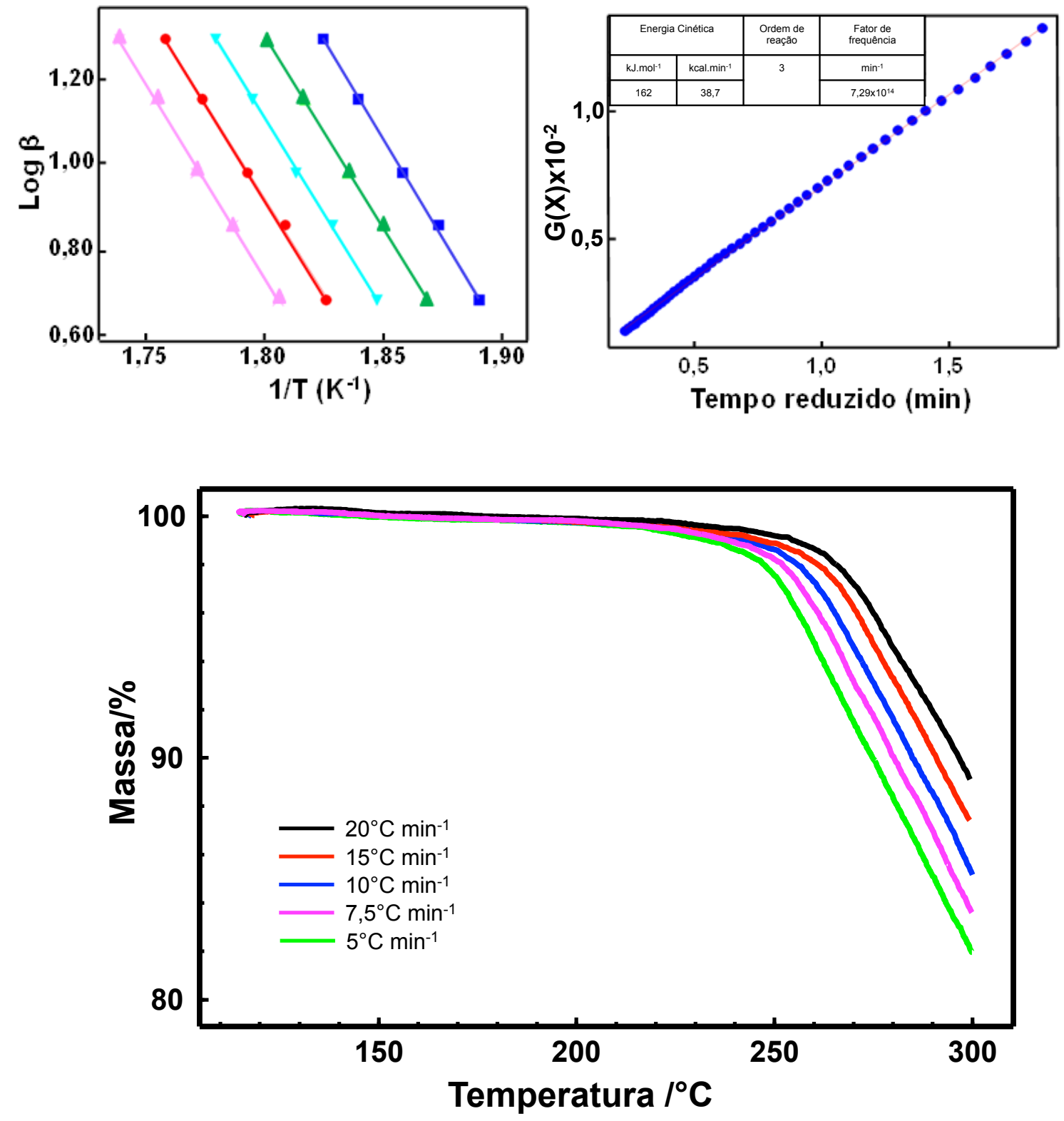

Figura 6.3 Resultados dos parâmetros cinéticos de uma amostra de cabelo oriental virgem padrão obtidas sob diferentes razões de aquecimento e atmosfera dinâmica de ar. 


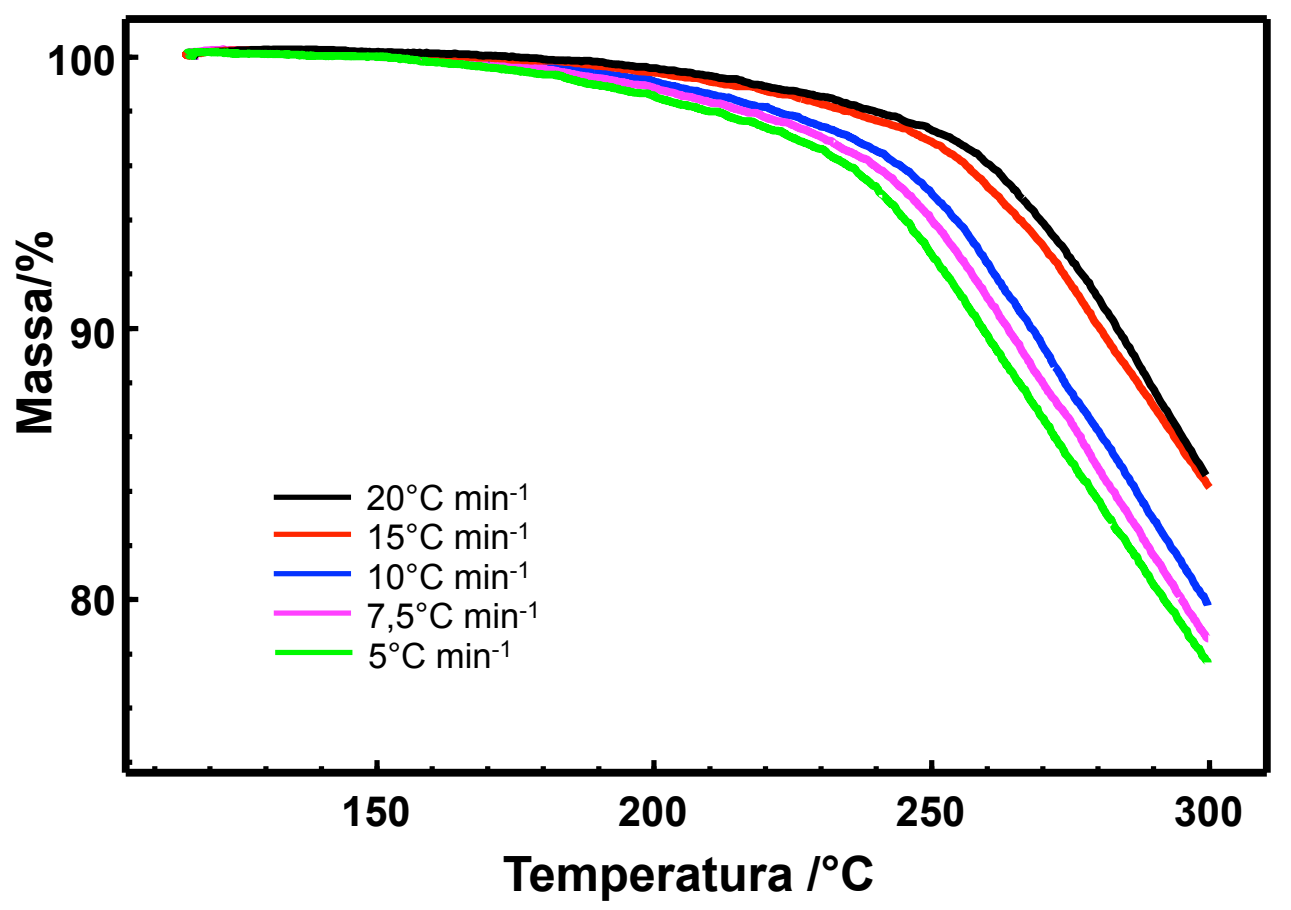

Figura 6.4 Sobreposição das curvas TGs obtidas com diferentes razões de aquecimento e sob atmosfera dinâmica de ar de uma amostra de cabelo afro-étnico virgem padrão.

\subsubsection{Calorimetria exploratória diferencial (DSC)}

A Figura 6.5 ilustra a sobreposição das curvas DSC das amostras de queratina animal em pó e de cabelo padrão virgem das três principais etnias: caucasiano, oriental e afro-étnico.

A curva correspondente à amostra de queratina evidenciou três eventos distintos: o primeiro evento, endotérmico, está relacionado à desidratação do material $\left(T_{\text {pico }}=56^{\circ} \mathrm{C}\right.$ e $\left.\Delta \mathrm{H}=-76 \mathrm{~J} \mathrm{~g}^{-1}\right)$; o segundo, também endotérmico, trata-se da decomposição térmica da queratina $\left(T_{\text {pico }}=268^{\circ} \mathrm{C}\right)$; e o terceiro, exotérmico, é devido à queima do material carbonáceo restante do evento anterior.

As curvas DSC das amostras de cabelo caucasiano, oriental e afro-étnico evidenciaram quatro eventos principais para todas as amostras. Assim, como o que ocorre com a queratina animal, o primeiro evento é endotérmico e está relacionado à desidratação do material, o qual foi observado nas curvas TG/DTG, tratando-se de um evento de origem física com variação na massa. Esses 
resultados corroboram estudos realizados por vários autores (MONTEIRO et al., 2005; BELLETI et al., 2003; CONLENCI, 2007; MILCZAREK et al., 1992).

O segundo evento, também endotérmico, refere-se à temperatura de fusão do material cristalino presente no cabelo ou desnaturação $\left(T_{D}\right)$. Este evento é de origem física, motivo pelo qual não é observado perda de massa na mesma faixa de temperatura nas curvas TG/DTG. Alguns autores (MILCZAREK et al., 1992, CAO, 1999) referem-se a este pico evidenciado na curva DSC de amostras de cabelo como "pico cristalino", pois está relacionado à fusão da fase cristalina ( $\boldsymbol{\alpha}$ hélice) da queratina capilar. Segundo Istrate (2011) este evento é devido ao desdobramento das cadeias de alfa-hélice que é denominado como a desnaturação térmica das fibras de queratina. O processo é irreversível e cineticamente controlado pelo meio envolvente, o qual é a fase amorfa da matriz, em que as cadeias de alfa-hélices são incorporadas (ISTRATE, 2011).

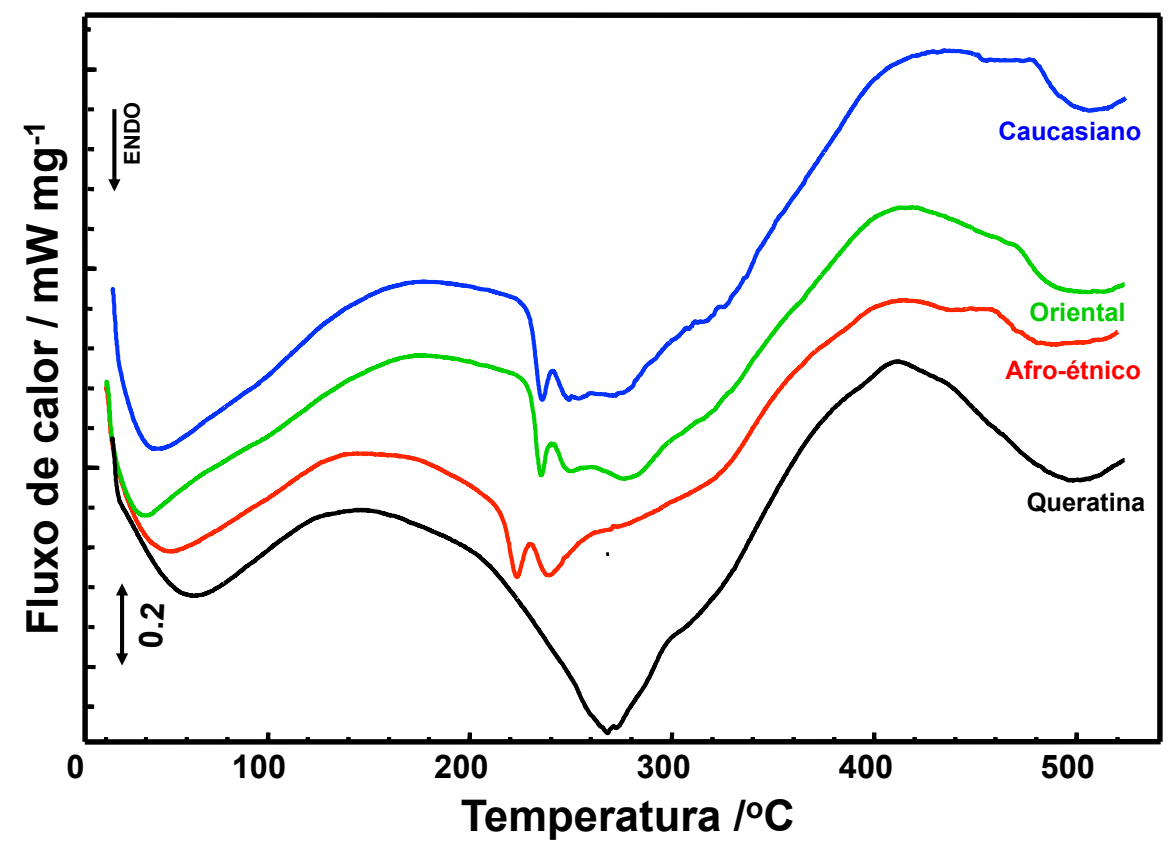

Figura 6.5 Curvas DSC obtidas a $10^{\circ} \mathrm{C} \mathrm{min}^{-1}$, sob atmosfera dinâmica de $\mathrm{N}_{2} \mathrm{e}$ empregando cápsula de Al parcialmente fechada contendo cerca de $2 \mathrm{mg}$ de amostras de queratina animal e de cabelo padrão virgem caucasiano, oriental e afro-étnico (22 \pm $2^{\circ} \mathrm{C} ; 65 \pm 2 \%$ U.R.). 
Pelas curvas DSC das amostras de cabelo foram obtidas $T_{D}$ (pico cristalino) e $\Delta H_{D}$ em J g ${ }^{-1}$ para este evento (Tabela 6.3). As $T_{D}$ foram de $236^{\circ} \mathrm{C}$ para as amostras de cabelo caucasiano e oriental e $223^{\circ} \mathrm{C}$ para a amostra de cabelo afro-étnico.

Os resultados de temperatura de fusão e decomposição obtidos neste trabalho corroboram vários estudos da literatura, dentre eles o estudo realizado por Humphries et al. (1972) em amostras de cabelo virgem por TG/DTA que apresentaram os picos endotérmicos da fusão e desnaturação da queratina em 235 e $243^{\circ} \mathrm{C}$ (HUMPHRIES et al., 1972). Milczarek et al. (1992) encontraram o valor de $T_{D}$ da fase cristalina em $233^{\circ} \mathrm{C}$ em estudo com amostras de cabelo humano a partir da DSC (MILCZAREK et al., 1992). Cao (1999) também estudou a fusão da fase cristalina de amostras de cabelo humano por DSC e obteve o valor de $230^{\circ} \mathrm{C}$ (CAO, 1999). Énen et al. (2004) estudaram amostras de cabelo por TG e DSC e observaram a fusão da a-queratina entre $230-233^{\circ} \mathrm{C}$, e após $250^{\circ} \mathrm{C}$ iniciou-se a decomposição térmica da fibra capilar (ÉHEN et al., 2004). Wortmann et al. (2012) estudaram a desnaturação térmica da proteína $\alpha$ helicoidal em amostras de cabelo humano por DSC modulado. Os autores relataram que este evento se iniciou em $210-220^{\circ} \mathrm{C}$ e está relacionado a pirólise das proteínas do córtex (WORTMANN et al., 2012). Os autores sustentam seus resultados com base em estudos realizados por Joerissen (1982) e Istrate et al. (2011). Estes últimos estudaram a decomposição térmica por DSC de amostras de fragmentos de cabelo aquecidas até $250^{\circ} \mathrm{C}$ e demonstraram por imagens de MEV que o material do córtex funde e flui para fora da área da cutícula circundante, formando, desta maneira, micro tubos de material cuticular envolto. Segundo ele, o córtex, que contém cerca de $21-22 \%$ de material ordenado (cristalino) se funde, enquanto a cutícula é constituída de material reticulado amorfo, permanece intacta. Eles atribuem este resultado à morfologia diferente de ambas camadas, que é, muito provavelmente, a razão para a formação destes micro-tubos (ISTRATE et al., 2011).

Neste trabalho, o valor obtido de $T_{D}$ da amostra de cabelo afro-étnico foi aproximadamente $13^{\circ} \mathrm{C}$ menor quando comparados aos valores de $T_{D}$ das outras amostras de cabelo estudadas. Estes resultados estão em concordância com os resultados TG/DTG descritos no item 6.1.1. Sabendo-se que o tipo de cabelo 
dessa etnia apresenta-se mais frágil e suscetível à quebras, este dado é muito importante para as indústrias e/ou grupos de desenvolvimento de produtos capilares pois as mulheres que possuem este tipo de etnia são as que mais procuram por transformações químicas (como alisamentos) que envolvem o emprego de piastras e ou/secadores de cabelo. Estes equipamentos podem alcançar temperaturas superiores à $250^{\circ} \mathrm{C}$.

É sabido que a água desempenha um papel fundamental na resistência mecânica global da fibra capilar e é parte integrante da estrutura molecular da queratina. Ela afeta tanto as fases amorfa e cristalina de queratina. Sendo a água uma molécula polar, ela pode estar associada de duas maneiras à proteína $\alpha$ queratina: absorvida ou ligada e adsorvida ou livre (ROBBINS, 1994; FEUGHELMAN, 1997).

Com o intuito de avaliar a influência das condições climáticas nos valores de entalpia das etapas de desidratação e fusão da fase cristalina, as amostras de cabelo padrão dos três tipos de etnias foram armazenadas em duas condições ambientais: $22 \pm 2^{\circ} \mathrm{C}, 65 \pm 2 \%$ U.R. e $22 \pm 2^{\circ} \mathrm{C}, 20 \pm 2 \%$ U.R., para posterior caracterização. A escolha por esta última condição foi baseada nos resultados do trabalho realizado por Cao \& Leroy (2005) que estudaram amostras de cabelo em diferentes condições ambientais controladas. Os autores observaram que a temperatura de fusão da forma $\alpha$-queratina variou para as amostras em ambiente completamente seco ( $0 \%$ U.R.) em comparação com as amostras de cabelo armazenadas em cerca de $23 \%$ U.R. Porém a entalpia de fusão foi mantida praticamente a mesma, levando os autores à conclusão de que existem cristalitos bem definidos na queratina do cabelo humano. A endoterma de fusão da fase cristalina permitiu os autores calcular assim o grau de cristalinidade do material presente naquela amostra de cabelo humano, que foi de 22\% (CAO \& LEROY, 2005).

As curvas DSC das amostras de cabelo armazenadas em $22 \pm 2^{\circ} \mathrm{C}, 20 \pm$ $2 \%$ U.R. se apresentam na Figura 6.6. A Tabela 6.3 apresenta a comparação entre os resultados de DSC das amostras de cabelo de diferentes etnias armazenadas nestas condições diferentes $\left(22 \pm 2^{\circ} \mathrm{C}, 65 \pm 2 \%\right.$ e $22 \pm 2^{\circ} \mathrm{C}, 20 \pm$ $2 \%)$. Os resultados indicaram, como esperado, que o cabelo exposto a um ambiente mais seco apresenta menor teor de água em sua matriz e isto foi 
observado em todas as amostras. Comparando os resultados nos dois ambientes controlados, é possível observar que as amostras do cabelo afro-étnico e oriental apresentaram maior e menor diminuição no teor de água (a amostra de cabelo afro-étnico apresentou uma diminuição na entalpia de desidratação de cerca de $58 \%$, em seguida do cabelo caucasiano que apresentou $45 \%$, e o oriental $34 \%$ ). Estes dados corroboram com a literatura, que mostram a menor capacidade do cabelo afro-étnico em reter água (FRANBOURG et al., 2003). É possível observar, também, que as temperaturas de pico de fusão da fase cristalina não variaram significantemente entre os diferentes tipos de amostras. Notou-se que a amostra de cabelo caucasiano foi a que apresentou uma diminuição no valor de entalpia de fusão, o que não ocorreu com as outras amostras. Desta forma, verifica-se que o teor de água não afetou as temperaturas de decomposição da queratina capilar nestas condições. Essa é uma indicação de que a absorçãoo/fixação e/ou eliminação de água da fibra capilar até a temperatura de $100^{\circ} \mathrm{C}$ é um fenômeno puramente físico.

O terceiro evento, endotérmico, refere-se à decomposição térmica do restante da matriz capilar, possivelmente relacionado com a decomposição dos aminoácidos cistina, que ocorre logo em seguida da $T_{D}$, ou seja, a partir de aproximadamente $250^{\circ} \mathrm{C}$ e o dano causado é irreversível. Estes dados corroboram com estudos realizados por Milczarek et al. (1992) e Monteiro et al. (2005), no qual foram obtidos valores de temperatura $250^{\circ} \mathrm{C}$ e $250,9^{\circ} \mathrm{C}$ para amostras de cabelo humano a partir da DSC.

O quarto e último evento é exotérmico e está relacionado à energia envolvida na eliminação do material carbonáceo resultante do terceiro evento.

Observando a faixa de temperatura entre $210-240^{\circ} \mathrm{C}$ nas curvas DSC das três amostras de cabelo (Figuras 6.5 e 6.6), verificaram-se dois picos referentes aos eventos 2 e 3 apresentados na Tabela 6.3. Alguns estudos têm relatado que este perfil é observado em vários materiais compostos por queratina. Cao et al. (1997) investigaram a origem destes dois picos na curva DSC em amostras de lã e os relacionaram com a sobreposição de formas $\alpha$-queratina com a degradação de outros componentes histológicos presentes no material (CAO et al.,1997). Wortmann and Deutz (1998) confirmaram que as células do orto-córtex possuem uma menor temperatura de fusão do que as células do para-córtex, o qual pode 
elucidar este comportamento dos picos na curva DSC. O orto-córtex possui menor concentração de ligações dissulfídicas que o para-córtex. Eles consideraram que a ocorrência da endoterma dupla de desnaturação da queratina da amostra de lã é provavelmente devida ao conteúdo da cisteína e ligações dissulfídicas, sendo suficientemente maior para separar os picos. A curva DSC evidenciou os dois picos de desnaturação da queratina em 230 e $240^{\circ} \mathrm{C}$, referindo-se às células ortoe para-corticais, respectivamente (WORTMANN e DEUTZ, 1998).

Em cabelos encaracolados, sabe-se que as células do para-córtex estão presentes em um lado côncavo da curvatura da fibra de cabelo, enquanto as células do orto-córtex estão presentes ao lado oposto da fibra, e as células mesocorticais estão ausentes. Em cabelos lisos, a distribuição das células é concêntrica, com as células corticais distribuídas ao longo de todo perímetro da fibra, cercado da camada de células meso-corticais e ambas envoltas da camada de células de para-córtex (ROBBINS, 2002).

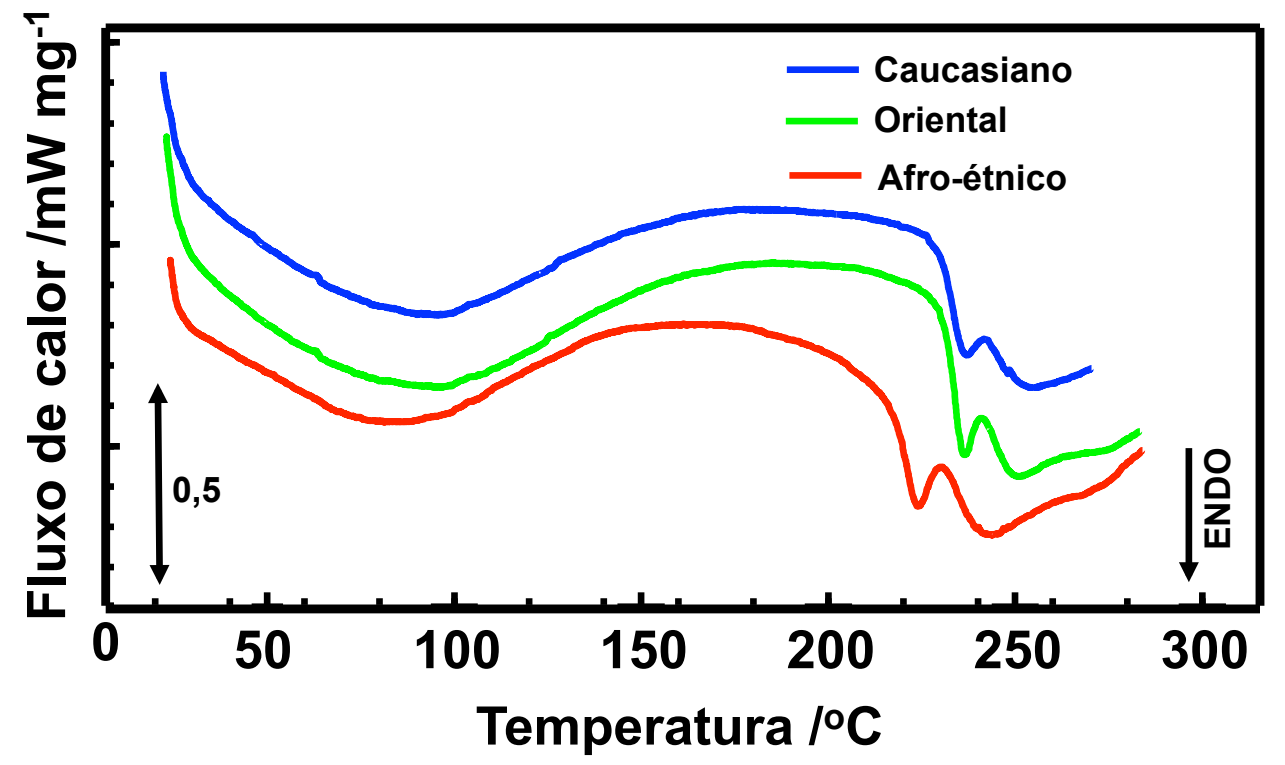

Figura 6.6 Curvas DSC obtidas a $10^{\circ} \mathrm{C} \mathrm{min}^{-1}$, sob atmosfera dinâmica de $\mathrm{N}_{2} \mathrm{e}$ empregando cápsula de Al parcialmente fechada contendo cerca de $2 \mathrm{mg}$ de amostras de cabelo virgem padrão caucasiano, oriental e afro-étnico $\left(22 \pm 2^{\circ} \mathrm{C} ; 20 \pm 2 \%\right.$ U.R. $)$. 
Tabela 6.3 Resultados das temperaturas e entalpias obtidos por DSC em amostras de queratina animal e de cabelo virgem padrão caucasiano, oriental e afro-étnico.

\begin{tabular}{c|cc|cc|cc|cc|cc}
\hline \hline Eventos & \multicolumn{3}{|c|}{1} & \multicolumn{3}{c|}{2} & \multicolumn{2}{c}{3} \\
\hline \hline & \multicolumn{2}{|c|}{$\mathrm{T}_{\mathrm{d}} /{ }^{\circ} \mathrm{C}$} & \multicolumn{2}{|c|}{$\Delta \mathrm{H}_{2} \mathrm{O} / \mathrm{J} \mathrm{g}^{-1}$} & \multicolumn{2}{|c|}{$\mathrm{T}_{\mathrm{D}} /{ }^{\circ} \mathrm{C}$} & \multicolumn{2}{|c|}{$\Delta \mathrm{H}_{\mathrm{D}} / \mathrm{J} \mathrm{g}^{-1}$} & \multicolumn{2}{c}{$\mathrm{T}_{\mathrm{D}}$} \\
\hline \multirow{2}{*}{ Amostra } & $60 \%$ & $20 \%$ & $60 \%$ & $20 \%$ & $60 \%$ & $20 \%$ & $60 \%$ & $20 \%$ & $60 \%$ & $20 \%$ \\
& $\mathrm{U} . \mathrm{R}$. & U.R. & U.R. & U.R. & U.R. & U.R. & U.R. & U.R. & U.R. & U.R. \\
\hline Queratina & 56 & - & 76 & - & - & - & - & - & - & - \\
Caucasiano & 46 & 95 & 305 & 168 & 236 & 237 & 7,1 & 5,6 & 241 & 242 \\
Oriental & 40 & 97 & 273 & 179 & 236 & 237 & 7,0 & 6,6 & 241 & 241 \\
Afro-étnico & 51 & 81 & 270 & 112 & 223 & 224 & 7,0 & 6,8 & 230 & 230 \\
\hline \hline
\end{tabular}

*Eventos (1): desidratação, (2) e (3) fusão e decomposição da a-queratina presente no cabelo.

\subsubsection{Análise elementar (AE)}

A Tabela 6.4 apresenta os resultados de $\mathrm{AE}(\mathrm{C}, \mathrm{H}, \mathrm{N}$ e S) das amostras de cabelo padrão das três principais etnias e de queratina animal.

Tabela 6.4 Resultados de análise elementar (CHNS) das amostras de queratina animal e de cabelo virgem caucasiano, oriental e afro-étnico.

\begin{tabular}{cccccccccccc}
\hline \hline \multirow{2}{*}{ Amostra } & \multirow{2}{*}{$\% \mathrm{H}_{2} \mathrm{O}$} & \multicolumn{2}{c}{$\% \mathrm{C}$} & \multicolumn{2}{c}{$\% \mathrm{H}$} & \multicolumn{2}{c}{$\% \mathrm{~N}$} & \multicolumn{3}{c}{$\% \mathrm{~S}$} & \multicolumn{2}{c}{$\begin{array}{c}\text { Queratina } \\
\text { (\%) }\end{array}$} \\
\hline \hline Queratina & 7,4 & 47,0 & 50,8 & 4,8 & 5,1 & 13,4 & 14,5 & 3,9 & 4,2 & 100 \\
Caucasiano & 12,0 & 43,0 & 48,8 & 7,3 & 8,3 & 13,8 & 15,7 & 3,6 & 4,1 & 96,2 \\
Oriental & 13,0 & 42,9 & 49,3 & 7,1 & 8,1 & 13,8 & 15,9 & 3,5 & 4,0 & 97,1 \\
Afro-étnico & 10,5 & 41,3 & 46,2 & 6,4 & 7,1 & 12,3 & 13,7 & 3,3 & 3,8 & 91,0 \\
\hline \hline
\end{tabular}

*VE=valor experimental (valor obtido pela $\mathrm{AE}$ ); $\mathrm{VCBS}=$ valor calculado na base seca (obtido considerando a amostra anidra); \% $\mathrm{H}_{2} \mathrm{O}$ obtidos por TG/DTG extraídos da Tabela 6.1.

As amostras de queratina e de cabelos caucasiano, oriental e afro-étnico apresentaram faixas de teores entre $41,3-47,0 \% \mathrm{C}, 4,8-7,3 \% \mathrm{H}, 12,3-13,3 \% \mathrm{~N}$ e 3,4-3,9\% S. De acordo com Popescu \& Höcker (2007), a análise elementar de 
amostras de cabelo apresentou $50 \%$ C, $7 \%$ H, 16\% N e 5\% S. Choi et al. (1995) detectaram 3,3-4,3\% S em amostras de cabelo humano utilizando cromatografia em fase gasosa por pirólise.

No presente trabalho, o teor de $S$ detectado em todas as amostras de cabelo foi baixo quando comparado aos teores de $\% \mathrm{C}$ e $\% \mathrm{~N}$, e este fato corrobora a literatura que indica que a concentração de aminoácidos contendo $S$ [tais como cistina $\left(\mathrm{C}_{6} \mathrm{H}_{12} \mathrm{~N}_{2} \mathrm{O}_{4} \mathrm{~S}_{2}\right)$ que apresenta $30 \%$ de $\mathrm{C}, 26,7 \%$ de $\mathrm{S}$ e $11,7 \%$ de $\mathrm{N}$ ] em cabelos é menor que aqueles aminoácidos contendo apenas $\mathrm{C}$ e $\mathrm{N}$.

A amostra de queratina apresentou um teor de hidrogênio menor do que aquele encontrado nas amostras de cabelo, dado que corrobora os resultados obtidos em TG/DTG, e é explicado pela menor quantidade de água em sua matriz (Tabela 6.1). Todas as amostras de cabelo apresentaram um teor maior de água do que aquele encontrado na amostra de queratina.

Os resultados de TG/DTG listados na Tabela 6.1 revelam porcentagens médias de água presente nas amostras de queratina e cabelos caucasiano, oriental e afro-étnico, respectivamente, $7,4 \% ; 12 \% ; 13 \%$ e 10,5\%. A partir desses percentuais de água e dos resultados de análise elementar pode-se estimar o teor de queratina em cada amostra de cabelo e associar os valores com a estabilidade térmica e/ou outras propriedades. Para facilitar o entendimento e ter o mesmo padrão de comparação, os percentuais de $\mathrm{C}, \mathrm{H}, \mathrm{N}$ e $\mathrm{S}$ encontrados experimentalmente por $\mathrm{AE}$, foram recalculados considerando cada amostra na base seca (como anidra), isto é, fez-se uma normalização. Então, subtraindo a quantidade relativa média (\%) de água determinados por TG, os percentuais totais das amostras na base seca para a queratina e cabelos caucasiano, oriental e afro-étnico, respectivamente, são 92,6\%; 88\%; 87\% e 89,5\%. A partir desses valores, podem-se calcular os percentuais de $\mathrm{C}, \mathrm{H}, \mathrm{N}$ e $\mathrm{S}$ em cada amostra, na base seca. Por exemplo, se na amostra de queratina (na base úmida) foi encontrado um valor experimental (VE) de \%C de 47,00, na base seca esse valor será $50,8 \%$ (VCBS = valor calculado na base seca). Da mesma forma os valores percentuais dos outros elementos foram calculados para todas as amostras, conforme listados na Tabela 6.4.

A partir da \%C (VCBS), para cada amostra de cabelo, pode-se estimar a quantidade de queratina presente nessas amostras, considerando que a \%C é 
unicamente devido a essa espécie presente no cabelo. Por exemplo, se na amostra de cabelo caucasiano a \%C na base seca é $48,82 \%$, isso significa dizer que essa amostra possui cerca de $96,2 \%$ e as amostras de cabelo oriental e afroétnico possuem, respectivamente, cerca de 97,1 e 91,0\% de queratina. Dados da literatura indicam que a queratina é o componente majoritário em cabelos, há outras espécies em menor quantidade, como matérias graxas, elementos inorgânicos, etc. (DRAELOS, 1991). Os cálculos de normalização para a base seca são apenas especulativos, mas permitem algumas conclusões.

A partir dos valores listados na Tabela 6.4 verifica-se que os teores de todos os elementos $(\mathrm{C}, \mathrm{H}, \mathrm{N}$ e S$)$ aumentaram em todas as amostras. Então, comparando estes valores, observa-se que as amostras de cabelo caucasiano e oriental apresentaram, entre si, semelhança nas concentrações destes elementos, ao contrário da amostra de cabelo afro-étnico, que apresentou os menores teores. Também, permite concluir que, pelo fato da amostra de cabelo afro-étnico, analisada neste trabalho, apresentar menor quantidade relativa de queratina em sua matriz, a maior instabilidade térmica da amostra deste tipo de cabelo em relação aos outros tipos pode ser explicada. Por isso os cuidados com o cabelo afro-étnico devem ser maiores.

\subsubsection{Espectroscopia de absorção na região do infravermelho com transformada de Fourier/ Refletância Total Atenuada (ATR-FTIR)}

Em cabelo humano, a ligação peptídica é a mais abundante, sendo que os átomos envolvidos nesta ligação dão origem a uma série de bandas de vibração, os quais estão ilustrados na Figura 6.7.

Três grupos específicos que constituem a estrutura da queratina podem originar diferentes bandas de absorção vibracional que podem ser devido:

1) A ligação peptídica (estrutura proteica primária): Formada a partir de uma reação de condensação entre os grupos de ácido carboxílico e amina de aminoácidos adjacentes. É a mais abundante no interior da queratina e originam as bandas amida I, II e III no espectro infravermelho (BARTON, 2011);

2) A cadeia de polipeptídica (proteína estrutura secundária): Pertence ao das ligações $C-C$ do esqueleto dorsal de todas as proteínas da queratina e podem 
apresentar de um a três padrões conformacionalmente sensíveis, sendo essas estruturas $\alpha$-helicoidal, de folha $\beta$ e espiral aleatória ou amorfas diretamente relacionadas com as bandas de amida (BARTON, 2011);

3) As cadeias laterais de aminoácidos (grupos R): As vibrações provenientes de $-\mathrm{CH},-\mathrm{CH}_{2}$ e $-\mathrm{CH}_{3}$ de anéis alifáticos e aromáticos de fenilalanina, tirosina, triptofano e as vibrações significativas dos intermediários oxidativos do aminoácido cistina (isto é $\mathrm{S}=\mathrm{O}, \mathrm{SO}_{2}, \mathrm{SO}_{3}$, e -S-SO $3^{-}$) (BARTON, 2011).
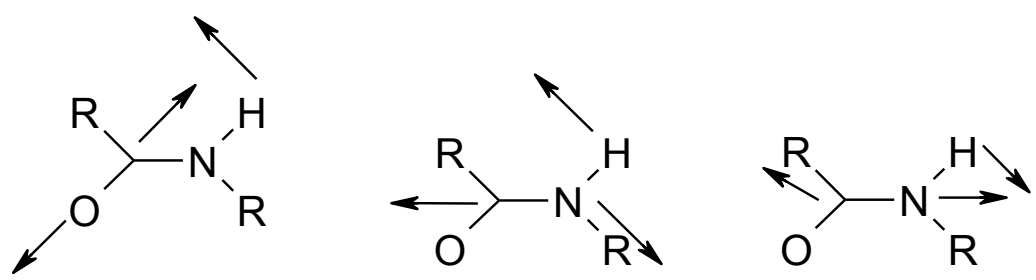

Figura 6.7 Modos de vibração das bandas de amida I, amida II e amida III, respectivamente da queratina.

Pauling e Corey (1953) demonstraram por meio de análise de raios $\mathrm{X}$ que a cadeia polipeptídica pode interagir com ela mesma, em duas conformações principais: $\alpha$-hélice e folha $\beta$. A conformação $\alpha$-helicoidal é constituída de:

a) ligação de hidrogênio intra-moleculares entre o oxigénio da carbonila de uma ligação peptídica e o átomo de hidrogênio do outro, bem como da cadeia lateral de amino e grupos carbóxilo;

b) ligação de hidrogênio da água com grupos amida, carboxilícos e hidroxílicos;

c) as interações coulombicas entre as cadeias laterais carregadas de lisina, arginina, histidina e ácido glutâmico e ácido aspártico, e

d) ligações covalentes, dissulfeto entre cadeias diferentes ou entre diferentes partes da mesma cadeia.

A ligação peptídica da queratina (estrutura proteica primária) é bastante rígida devido ao caráter da dupla ligação parcial. Isto é causado por ressonância de elétrons entre os átomos de oxigênio e de nitrogênio obtendo-se uma ligação parcial $\mathrm{C}=\mathrm{N}$. Os modos de vibrações da ligação peptídica dão origem a bandas características conhecidas como as bandas de amida I, II e III. As frequências são 
sensíveis à conformação peptídica e do tipo de ligação de hidrogênio. Esta sensibilidade da ligação peptídica afeta a estrutura secundária da proteína definida pela conformação local da cadeia polipeptídica. A sequência dos aminoácidos na proteína é chamada de estrutura primária. Unidades de ligações de amidas secundárias se repetem na proteína. Por causa da rigidez da ligação da amida C-N, cadeias de proteínas podem formar estruturas tridimensionais tal como hélices, espiral e folhas. Estas compreendem as estruturas secundárias das proteínas (SOLOMONS, 1996; SMITH, 1998). Queratina possui bandas de estiramentos $\mathrm{N}-\mathrm{H}$ em $3305 \mathrm{~cm}^{-1}, \mathrm{C}=\mathrm{O}$ em $1653 \mathrm{~cm}^{-1}$, e um no plano N-H em 1516 $\mathrm{cm}^{-1}$. Também possui bandas em $3065 \mathrm{~cm}^{-1}$ (ligação $\mathrm{N}-\mathrm{H}$ ) e $1232 \mathrm{~cm}^{-1}$ (C-N) (SMITH, 1998).

Figura 6.8 apresenta os espectros no infravermelho de amostras de cabelo padrão virgem caucasiano, oriental e afro-étnico de 4000 até $500 \mathrm{~cm}^{-1}$. As bandas de absorção dos principais grupos funcionais presentes na queratina do cabelo obtidas neste trabalho estão apresentados na Tabela 6.5. Foi possível observar as mesmas bandas de absorção presentes nas amostras de cabelo com aquelas citadas na literatura (ESPINOZA et al., 2008, LAU et al., 2011; PRASONG e WASAN, 2011, ZHOU et al, 2011; KIM e PARK, 2013). As bandas típicas de proteínas de estrutura secundária ( $\alpha$-hélice e folha $\beta$ ): Amida $A\left(3000-3700 \mathrm{~cm}^{-1}\right.$ ) e Amidas I, II e III (1200-1700 $\mathrm{cm}^{-1}$ ) (BADDLEL, 1968; WOJCIECHOWSKA et al, 1999; ZHOU et al, 2011) foram observadas em todos os espectros das amostras analisadas. As bandas na região de $1480-1700 \mathrm{~cm}^{-1}$ são sensíveis às alterações na conformação estrutural secundária da proteína. Portanto, esta região é a mais importante para a identificação de mudanças estruturais em amostras de cabelo (ZHOU et al., 2011; KIM \& PARK, 2013).

Observou-se a semelhança entre os espectros, porém a amostra de cabelo afro-étnico apresentou três bandas com maior intensidade quando comparadas as outras amostras, são elas: 2918, 2850 e $1044 \mathrm{~cm}^{-1}$. As duas primeiras podem ser atribuídas as vibrações dos grupos $\mathrm{CH}_{3}$ e $\mathrm{CH}_{2}$ em modos assimétrico e simétrico, respectivamente, e derivam de bandas de aminoácidos (BADDLEL, 1968; HELEN, 2004). 


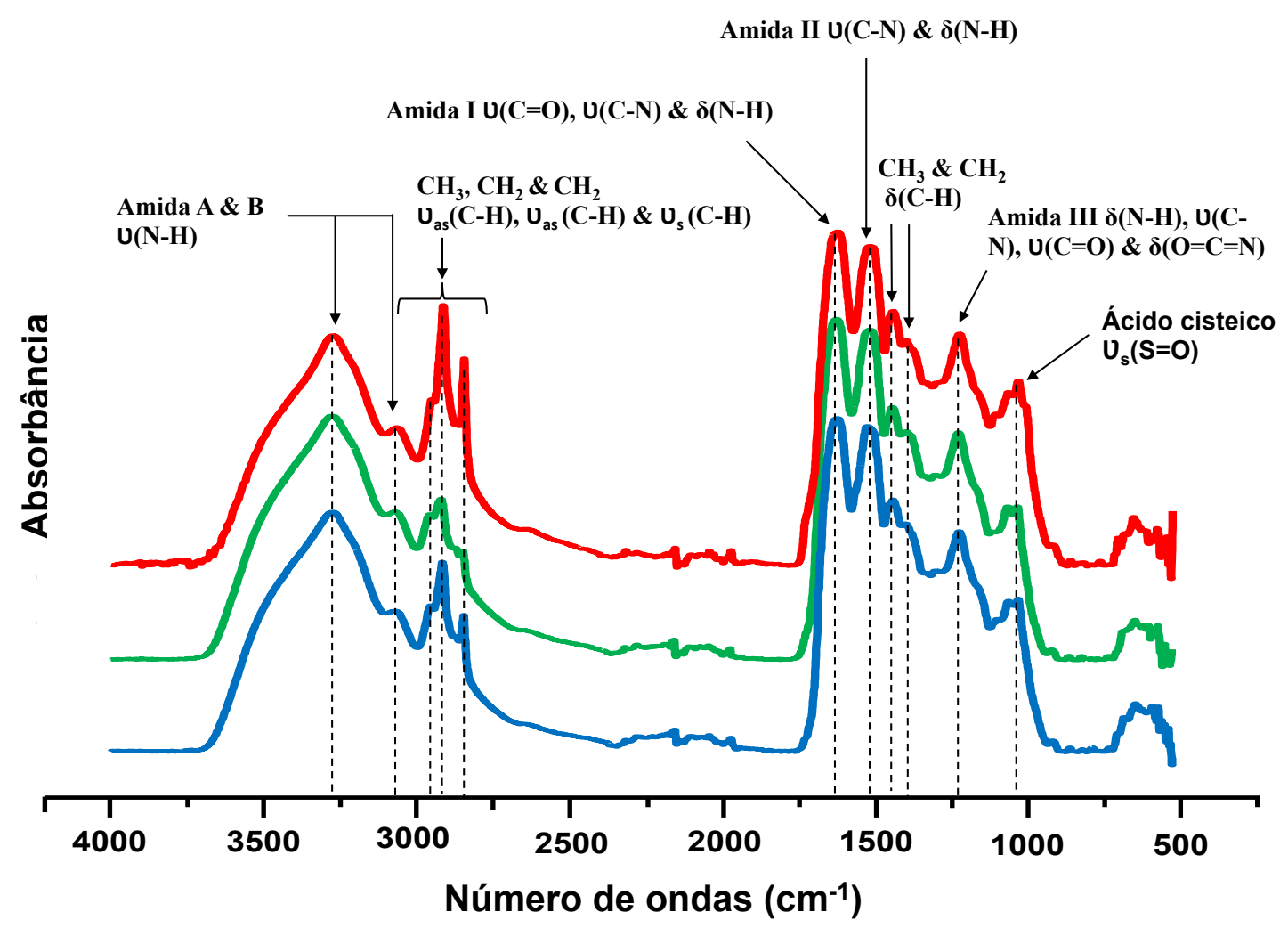

Figura 6.8 Espectros de absorção na região do IV de amostras de cabelo padrão virgem das etnias caucasiana, oriental e afro-étnica.

Tabela 6.5 Atribuição das bandas nos espectros no IV das amostras de cabelo virgem caucasiano, oriental e afro-étnico.

\begin{tabular}{ccccc}
\hline \hline \multirow{2}{*}{ Grupo funcional } & \multicolumn{4}{c}{ Número de onda $/ \mathbf{c m}^{-1}$} \\
\cline { 2 - 5 } & Literatura & Caucasiano & Oriental & Afro-étnico \\
\hline \hline Amida A & 3290 & 3277 & 3279 & 3278 \\
Amida B & 3072 & 3073 & 3075 & 3072 \\
$\mathrm{CH}_{3}$ Assim & $2959-2963$ & 2958 & 2960 & 2956 \\
$\mathrm{CH}_{2}$ Assim & $2919-2920$ & 2920 & 2923 & 2918 \\
$\mathrm{CH}_{2}$ Sim & $2849-2851$ & 2851 & 2852 & 2850 \\
Amida I & $1690-1600$ & 1633 & 1633 & 1634 \\
Amida II & $1575-1480$ & 1535 & 1521 & 1530 \\
$\mathrm{CH}_{2}$ (lipídeos) & 1451 & 1451 & 1451 & 1453 \\
Amida III & $1320-1210$ & 1236 & 1235 & 1236 \\
Monóxido de cistina & $1071-1072$ & 1075 & 1074 & 1076 \\
Ácido sulfônico & $1040-1042$ & 1043 & 1043 & 1044 \\
\hline \hline
\end{tabular}


A banda típica em $1044 \mathrm{~cm}^{-1}$ refere-se à vibração de estiramento assimétrico da ligação $\mathrm{S}=\mathrm{O}$, dos grupos $-\mathrm{SO}_{3}{ }^{-}$e $-\mathrm{S}-\mathrm{SO}_{2}{ }^{-}$, que são componentes da oxidação da cistina, observados em cabelos que passaram por transformações químicas (MOITA, 1989). Porém, em cabelos virgens, esta banda também pode ser observada, devido a oxidação da cistina provocada pela radiação UV, que promove a clivagem oxidativa das ligações dissulfídicas na queratina para grupos sulfônicos (SIGNORI e LEWIS, 1997).

As bandas das amidas A e B foram detectadas em 3277 e $3073 \mathrm{~cm}^{-1}$ para a amostra de cabelo caucasiano, 3279 e $3075 \mathrm{~cm}^{-1}$ para o oriental e 3278 e 3072 $\mathrm{cm}^{-1}$ para o afro-étnico. A banda de amida A é resultante do estiramento de $\mathrm{N}-\mathrm{H}$ e é sensível às ligações de hidrogênio, que é essencial para estruturar a água e na manutenção das proteínas juntas (KIM \& PARK, 2013).

As bandas de amida I foram evidenciadas em 1633, 1633 e $1634 \mathrm{~cm}^{-1}$ e as bandas de amida II em 1535, 1521 e $1530 \mathrm{~cm}^{-1}$ nas amostras de cabelo caucasiano, oriental e afro-étnico, respectivamente. A amida I consiste na vibração causada pela combinação do estiramento $\mathrm{C}=\mathrm{O}(80 \%)$ acoplado com uma flexão do plano $\mathrm{N}-\mathrm{H}$ e C-N e apresenta-se como um pico largo e forte e permanece notavelmente consistente entre os gêneros e raça (BARTON, 2011). A amida II consiste na vibração causada pela combinação do estiramento C-N $(60 \%)$ acoplado com a inclinação no mesmo plano $\mathrm{N}-\mathrm{H}$.

As bandas de amida III foram identificadas em 1236, 1235 e $1236 \mathrm{~cm}^{-1}$ para as amostras de cabelo caucasiano, oriental e afro-étnico, respectivamente. Sua vibração é causada pela combinação do estiramento C-N (30\%) e N-H (30\%) no mesmo plano, estiramento $C=O$ e torção $O=C=N(K I M$ \& PARK, 2013).

Absorções de IV associadas com a oxidação do aminoácido cistina, ocorrem em cerca de 1200-1000 cm $\mathrm{cm}^{-1}$. As bandas desta região fornecem evidências de alterações químicas decorrentes de danos oxidativos à fibra como consequência de clareamento, tingimento, alisamento e ondulação permanente. Sob estas condições as cistinas das ligações cruzadas dissulfeto são oxidadas em ácido cisteico $\left(\mathrm{SO}_{3}\right)$ e os intermediários oxidativos, monóxido de cistina $(\mathrm{S}=\mathrm{O})$, dióxido de cistina $\left(\mathrm{SO}_{2}\right)$ e tiossulfato de cisteína.

Barton (2011) estudou amostras de diferentes tipos de cabelo por FTIR. O autor observou que amostras de cabelo caucasiano não tratadas apresentaram 
níveis mais elevados de aminoácidos cistina e ácido cistéico comparados a amostras de cabelo oriental. Porém quando estas amostras foram tratadas quimicamente, fibras do cabelos oriental e caucasiano se apresentaram semelhantes, enquanto que as fibras de cabelo do tipo afro são diferentes (BARTON, 2011).

As mudanças nas propriedades químicas do cabelo induzidas pelo envelhecimento foram investigados por espectroscopia FTIR por Kim \& Park (2013). Os autores identificaram as principais bandas típicas de queratina. Algumas bandas de absorção específicas foram deslocados para regiões mais altas ou baixas de número de ondas pelo envelhecimento. $\mathrm{O}$ teor de componentes químicos, incluindo a amida A, amida II, cistina variaram.

\subsubsection{Avaliação da resistência a tração à ruptura (tensão-deformação)}

As variações das propriedades mecânicas dos cabelos já foram estudadas por diversos autores e podem indicar variações da estrutura capilar interna e externa.

A medida das propriedades mecânicas dos cabelos está estreitamente relacionada à geometria e ao estado de conservação dos fios. Aplicando-se uma força tensora sobre a fibra, é possível avaliar a deformação do fio, que ocorre em três fases distintas até seu rompimento: até $3 \%$ de alongamento do seu comprimento inicial (região elástica ou Hookeana), entre 3 e $30 \%$ (região plástica); e acima de 30\% (região pós-plástica), sendo que após o fio se enrijece e rompe (HARRIS, 2009; BHUSHAN, 2010). A Figura 6.9 apresenta estas curvas características de tensão-deformação obtidas após ensaios mecânicos de 20 fios de cabelo caucasiano padrão virgem. É possível observar, pela imagem, as três regiões distintas citadas logo acima.

O objetivo deste experimento foi comparar as propriedades mecânicas de amostras de cabelo virgem padrão caucasiano e oriental. Foram avaliadas as variações de diâmetro e resistência à tensão/deformação destas mechas de cabelo. 


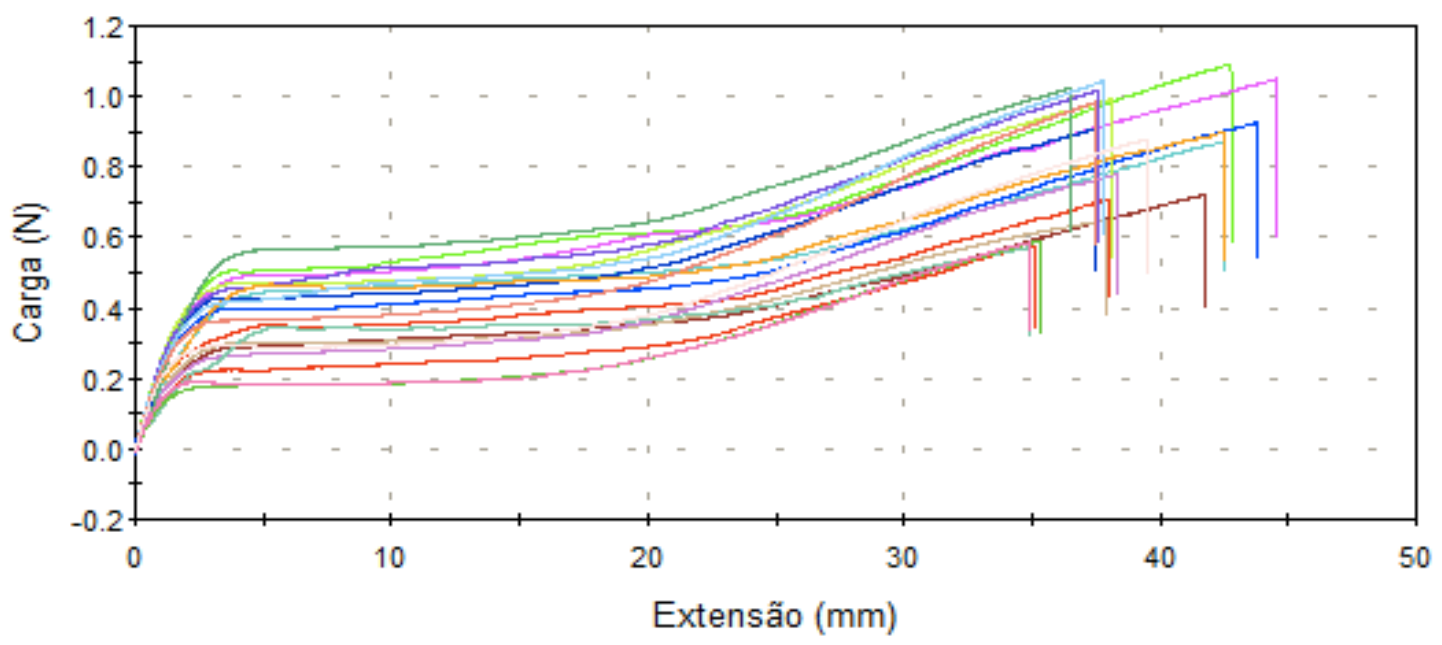

Figura 6.9 Gráfico de Tensão versus deformação obtido a partir do ensaio mecânico de 20 fios de cabelo padrão virgem lavados com LESS 10\%.

Primeiramente foram executadas as medidas, em triplicata, de diâmetro dos fios das mechas de cabelo caucasiano e oriental, e os valores estão listados na Tabela 6.6. Foi calculada a média de três medidas em três pontos diferentes no mesmo fio de cabelo. Como esse procedimento foi realizado em 20 fios de cada mecha de cabelo, foi calculada a média do diâmetro de cada mecha. A partir destes valores foram calculados os desvios-padrão dos valores de diâmetros dos fios de cabelos das amostras de cada etnia.

Observando os resultados das médias parciais dos diâmetros (média para cada mecha), é possível verificar que estes valores variaram em uma ampla faixa que foi de 48 a $85 \mu \mathrm{m}$ para ambas amostras cabelo. Porém, os valores de diâmetros na faixa menor foram obtidos nas mechas de cabelo caucasiano, demonstrando este ser comparativamente menor que o cabelo oriental. Estes resultados corroboram com os obtidos por Nakano (2006), porém o autor obteve valores médios de diâmetros em torno de 64 e $76 \mu \mathrm{m}$ para amostra de cabelo virgem caucasiano e oriental, respectivamente. Gama (2010) obteve valor médio de diâmetro para amostras de cabelo virgem em torno de $58 \mu \mathrm{m}$, com uma faixa de 47 a $70 \mu \mathrm{m}$ em uma mesma mecha.

Os dados obtidos pelas medidas de diâmetro utilizando o micrômetro foram submetidos à análise de variância para verificar diferenças estatísticas significativas entre as amostras e estão mostrados na Tabela 6.7. 
Tabela 6.6 Valores dos diâmetros $(\mathrm{em} \mu \mathrm{m})$ de amostras de cabelo virgem padrão caucasiano e oriental.

\begin{tabular}{|c|c|c|c|c|c|c|c|c|c|c|c|c|c|c|}
\hline \multicolumn{7}{|c|}{ Mecha 1} & \multicolumn{3}{|c|}{ Mecha 2} & \multicolumn{4}{|c|}{ Mecha 3} & \multirow[b]{2}{*}{$\mathrm{MT} \pm \mathrm{DV}$} \\
\hline & Fios & D1 & D2 & D3 & MP & D1 & D2 & D3 & MP & D1 & D2 & D3 & MP & \\
\hline \multirow{20}{*}{ 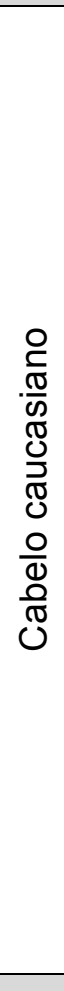 } & 1 & 60 & 64 & 63 & 62 & 56 & 59 & 61 & 59 & 67 & 70 & 70 & 69 & \\
\hline & 2 & 76 & 72 & 82 & 77 & 74 & 74 & 75 & 74 & 70 & 72 & 60 & 67 & \\
\hline & 3 & 89 & 73 & 74 & 79 & 63 & 61 & 63 & 62 & 56 & 57 & 54 & 56 & \\
\hline & 4 & 44 & 48 & 51 & 48 & 78 & 75 & 77 & 77 & 60 & 58 & 59 & 59 & \\
\hline & 5 & 52 & 51 & 48 & 50 & 76 & 74 & 77 & 76 & 75 & 68 & 66 & 70 & \\
\hline & 6 & 51 & 49 & 46 & 49 & 70 & 72 & 69 & 70 & 57 & 60 & 59 & 59 & \\
\hline & 7 & 62 & 62 & 65 & 63 & 72 & 62 & 66 & 67 & 82 & 79 & 64 & 75 & \\
\hline & 8 & 59 & 53 & 54 & 55 & 60 & 64 & 63 & 62 & 58 & 57 & 54 & 56 & \\
\hline & 9 & 67 & 69 & 67 & 68 & 65 & 68 & 67 & 67 & 59 & 60 & 60 & 60 & \\
\hline & 10 & 61 & 60 & 57 & 59 & 63 & 69 & 66 & 66 & 64 & 66 & 63 & 64 & \\
\hline & 11 & 76 & 64 & 61 & 67 & 62 & 67 & 66 & 65 & 58 & 57 & 54 & 56 & \\
\hline & 12 & 66 & 63 & 61 & 63 & 78 & 77 & 70 & 75 & 65 & 70 & 73 & 69 & \\
\hline & 13 & 57 & 56 & 55 & 56 & 60 & 69 & 77 & 69 & 65 & 59 & 54 & 59 & \\
\hline & 14 & 52 & 47 & 44 & 48 & 83 & 84 & 88 & 85 & 54 & 54 & 52 & 53 & \\
\hline & 15 & 64 & 66 & 67 & 66 & 62 & 60 & 58 & 60 & 72 & 71 & 72 & 72 & \\
\hline & 16 & 75 & 70 & 73 & 73 & 53 & 51 & 52 & 52 & 47 & 48 & 51 & 49 & \\
\hline & 17 & 61 & 64 & 61 & 62 & 49 & 51 & 52 & 51 & 57 & 57 & 58 & 57 & \\
\hline & 18 & 67 & 63 & 62 & 64 & 77 & 80 & 81 & 79 & 67 & 72 & 75 & 71 & \\
\hline & 19 & 63 & 62 & 61 & 62 & 68 & 60 & 57 & 62 & 60 & 65 & 68 & 64 & \\
\hline & 20 & 53 & 52 & 53 & 53 & 54 & 54 & 48 & 52 & 61 & 54 & 58 & 58 & \\
\hline & \multicolumn{4}{|c|}{ Média parcial } & 61 & & & & 66 & & & & 62 & $63 \pm 9$ \\
\hline \multirow{21}{*}{ 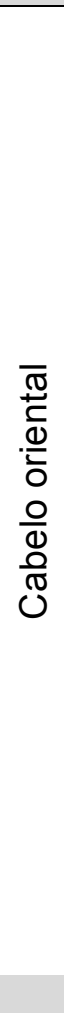 } & 1 & 54 & 53 & 55 & 54 & 80 & 77 & 74 & 77 & 49 & 46 & 48 & 48 & \\
\hline & 2 & 77 & 78 & 76 & 77 & 73 & 75 & 77 & 75 & 82 & 84 & 82 & 83 & \\
\hline & 3 & 71 & 66 & 66 & 68 & 68 & 79 & 73 & 73 & 78 & 70 & 72 & 73 & \\
\hline & 4 & 69 & 68 & 67 & 68 & 58 & 57 & 56 & 57 & 61 & 61 & 60 & 61 & \\
\hline & 5 & 67 & 68 & 68 & 68 & 61 & 58 & 58 & 59 & 54 & 51 & 51 & 52 & \\
\hline & 6 & 59 & 57 & 56 & 57 & 55 & 55 & 57 & 56 & 62 & 68 & 66 & 65 & \\
\hline & 7 & 65 & 68 & 63 & 65 & 65 & 64 & 64 & 64 & 72 & 70 & 70 & 71 & \\
\hline & 8 & 77 & 67 & 66 & 70 & 70 & 74 & 72 & 72 & 78 & 70 & 67 & 72 & \\
\hline & 9 & 79 & 77 & 75 & 77 & 58 & 58 & 60 & 59 & 59 & 59 & 60 & 59 & \\
\hline & 10 & 65 & 64 & 66 & 65 & 63 & 58 & 55 & 59 & 66 & 74 & 74 & 71 & \\
\hline & 11 & 56 & 56 & 65 & 59 & 59 & 57 & 52 & 56 & 89 & 89 & 80 & 86 & \\
\hline & 12 & 62 & 64 & 64 & 63 & 70 & 73 & 77 & 73 & 82 & 80 & 82 & 81 & \\
\hline & 13 & 54 & 54 & 58 & 55 & 69 & 69 & 73 & 70 & 65 & 63 & 59 & 62 & \\
\hline & 14 & 55 & 54 & 56 & 55 & 76 & 81 & 73 & 77 & 65 & 66 & 69 & 67 & \\
\hline & 15 & 62 & 60 & 62 & 61 & 60 & 62 & 57 & 60 & 60 & 61 & 64 & 62 & \\
\hline & 16 & 62 & 58 & 62 & 61 & 68 & 68 & 67 & 68 & 65 & 69 & 67 & 67 & \\
\hline & 17 & 78 & 78 & 79 & 78 & 69 & 69 & 63 & 67 & 62 & 61 & 63 & 62 & \\
\hline & 18 & 60 & 60 & 63 & 61 & 67 & 65 & 70 & 67 & 71 & 69 & 73 & 71 & \\
\hline & 19 & 67 & 69 & 70 & 69 & 60 & 63 & 59 & 61 & 62 & 59 & 61 & 61 & \\
\hline & 20 & 65 & 63 & 64 & 64 & 67 & 68 & 69 & 68 & 66 & 71 & 79 & 72 & \\
\hline & \multicolumn{4}{|c|}{ Média parcial } & 65 & & & & 66 & & & & 67 & $66 \pm 8$ \\
\hline
\end{tabular}


Primeiramente foi aplicado o teste (ANOVA one-way, $\alpha=0,05$ ) nos resultados obtidos nas medidas de diâmetro das mechas de cabelo caucasiano e oriental virgem padrão. O valor de $p$ foi igual a 0,202, e desta forma, os valores de diâmetro das mechas de cabelo não diferiram significativamente entre si para um nível de significância maior que 5\% (Tabela 6.7). Em outras palavras, as amostras de cabelo padrão virgem caucasiano e oriental não se diferem significantemente em termos de diâmetro.

Tabela 6.7 Modelo de ANOVA para os resultados obtidos das medidas de diâmetro das mechas de cabelo caucasiano e oriental utilizando micrômetro Mitutoyo.

\begin{tabular}{ccccccc}
\hline \hline Fonte da variação & SQ & gl & MQ & $F$ & valor-P & F crítico \\
\hline \hline Entre grupos & 11,025 & 1,000 & 11,025 & 2,331 & $\mathbf{0 , 2 0 2}$ & 7,709 \\
Dentro dos grupos & 18,923 & 4,000 & 4,731 & & & \\
Total & 29,948 & 5,000 & & & & \\
\hline \hline
\end{tabular}

Dos valores de diâmetro calculados foi possível calcular a área dos fios de cabelo para cada mecha e uma média destes valores. Considerando os fios como sendo cilíndricos, foi possível calcular os valores das áreas pela fórmula correspondente à área do cilindro, equação (7):

$$
A_{T}=A_{L}+2 A_{B}=2 \pi r h+2 \pi r^{2}=2 \pi r(h+r)
$$

onde $\mathrm{r}$ representa o raio e $\mathrm{h}$ a altura.

A partir dos cálculos de área, foi possível calcular os valores de tensão na força máxima, que são obtidos por meio de uma relação entre os valores de diâmetro da fibra (área do fio) e a força máxima de ruptura do fio obtida pelos experimentos de tensão-deformação, equação (8).

$$
\tau=\frac{F}{A}\left(\frac{N}{m^{2}}\right)
$$

onde $\mathrm{F}$ é a força em Newton para a ruptura da fibra, $\mathrm{A}=$ área $\mathrm{em} \mathrm{mm}^{2}$ da fibra 
capilar.

Desta forma, foram calculadas a tensão na força máxima para cada tipo de cabelo para cada etnia e os resultados estão mostrados na Tabela 6.8. Tensão na força máxima é a força necessária para ruptura das fibras capilares, diâmetro médio das três porções (calculados na Tabela 6.6) das fibras e sua área média e a tração à ruptura calculada.

Lembrando que os três valores apresentados na Tabela 6.8, são médias de 20 fios de cada mecha (triplicata). Pelo volume de dados, optou-se por mostrar apenas as médias dos valores obtidos das três médias das três mechas. Destas médias foram obtidas as médias finais dos parâmetros para cálculos de propriedades mecânicas das fibras capilares.

Tabela 6.8 Valores de tensão na força máxima $\left(\mathrm{N} / \mathrm{m}^{2}\right)$ obtidos no teste de tensãodeformação (média de leituras obtidas até a ruptura do fio) das amostras de cabelo virgem padrão caucasiano e oriental.

\begin{tabular}{|c|c|c|c|c|c|}
\hline Etnia & Força (N) & $\begin{array}{c}\text { Diâmetro } \\
(\mathrm{mm})\end{array}$ & Raio (mm) & $\begin{array}{l}\text { Área } \\
(\mathrm{mm})\end{array}$ & $\begin{array}{c}\text { Tensão } \\
\left(\mathrm{N} / \mathrm{mm}^{2}\right)\end{array}$ \\
\hline \multirow{3}{*}{ Caucasiana } & 0,751 & 0,061 & 0,031 & 19,202 & 0,039 \\
\hline & 0,852 & 0,067 & 0,033 & 20,872 & 0,041 \\
\hline & 0,668 & 0,062 & 0,031 & 19,537 & 0,034 \\
\hline M.F. \pm D.V. & $0,757 \pm 0,092$ & $0,063 \pm 0,003$ & $0,032 \pm 0,001$ & $19,870 \pm 0,884$ & $0,038 \pm 0,003$ \\
\hline \multirow{3}{*}{ Oriental } & 0,637 & 0,065 & 0,032 & 20,349 & 0,031 \\
\hline & 0,781 & 0,066 & 0,033 & 20,689 & 0,038 \\
\hline & 0,757 & 0,067 & 0,034 & 21,129 & 0,036 \\
\hline M.F. \pm D.V. & $0,725 \pm 0,077$ & $0,066 \pm 0,001$ & $0,033 \pm 0,001$ & $20,722 \pm 0,391$ & $0,035 \pm 0,003$ \\
\hline
\end{tabular}

Os resultados de tensão da força máxima obtidos para as amostras das mechas de cabelo virgem padrão caucasiano e oriental foram submetidos ao teste de ANOVA (one-way, $\alpha=0,05$ ). O valor de $p$ foi igual a 0,366 , e desta forma, os valores de tensão da força máxima das mechas de cabelo não diferiram significativamente entre si para um nível de significância maior que 5\% (Tabela 6.9). 
Tabela 6.9 Modelo de ANOVA para os resultados obtidos de tensão na força máxima das mechas de cabelo caucasiano e oriental.

\begin{tabular}{lcccccc}
\hline \multicolumn{1}{c}{ Fonte da variação } & SQ & gl & MQ & $F$ & valor-P & F crítico \\
\hline \hline Entre grupos & 0,00001 & 1,00000 & 0,00001 & 1,03846 & 0,36580 & 7,70865 \\
Dentro dos grupos & 0,00005 & 4,00000 & 0,00001 & & & \\
Total & 0,00007 & 5,00000 & & & & \\
\hline \hline
\end{tabular}

Os resultados de força $(\mathrm{N})$ e tensão na força máxima $\left(\mathrm{N} / \mathrm{mm}^{2}\right)$ obtidos para as amostras de cabelo caucasiano e oriental foram 0,76 e $0,73 \mathrm{~N}$ e 0,038 e 0,035 $\mathrm{N} / \mathrm{mm}^{2}$, respectivamente. Gama (2010) obteve os valores de 1,036 e 0,113 $\mathrm{N} / \mathrm{mm}^{2}$ para amostras de cabelo caucasiano, três vezes maior do que obtidos neste trabalho. Porém a área média obtida para os fios das amostras de cabelo caucasiano analisada por aquele autor foi aproximadamente a metade dos valores obtidos no presente trabalho, pois esta depende dos valores do diâmetros dos fios analisados (GAMA, 2010). França (2014) também avaliou a força (N) para ruptura em amostras de cabelo caucasiano virgem e obtiveram o valor médio de 1,1 $\mathrm{N}$ para romper fios de cabelo com média de 0,02 $\mathrm{mm}$ de diâmetro (FRANÇA, 2014). Sá Dias (2015) obteve o valor de trabalho na ruptura de 0,008 J, porém os valores de área dos fios de cabelo obtidos pelo autor também apresentou-se diferente dos aqui obtidos, isto porque, os valores de diâmetros dos fios analisados pelo autor eram diferentes destes (SÁ DIAS, 2015). Esta diferença nos resultados mostra que as propriedades mecânicas dos cabelos variam muito de acordo com as propriedades e o tipo do cabelo.

Segundo Bhushan (2010), o efeito da tensão sobre caucasiano e oriental cabelo é bastante semelhante, como observado a partir dos resultados obtidos no presente trabalho. Segundo o autor, o efeito mais significativo da tensão em ambos os casos é o levantamento da camada de cutícula externa. Para cabelo caucasiano virgem, este falha da cutícula interna e externa ocorre em cerca de $20 \%$ de tensão, enquanto que para o cabelo oriental ocorre mais tarde em cerca de $24 \%$ de deformação (BHUSHAN, 2010). 


\subsubsection{Avaliação da resistência à penteabilidade}

A penteabilidade pode ser definida como a percepção subjetiva da dificuldade ou da facilidade com que o cabelo pode ser penteado. Isso está diretamente relacionado às forças que se opõem à ação de pentear o cabelo (SÁ DIAS et al., 2008; VELASCO et al., 2009).

Foram calculadas as médias dos valores de extensão $(\mathrm{mm})$ e força $(\mathrm{N})$ ao longo das fibras capilares das amostras de cabelo virgem caucasiano e oriental. Destes valores foram calculados os valores do trabalho necessário para pentear a úmido as mechas de cabelo padrão caucasiano e oriental virgem bem como os seus respectivos desvios-padrão. Os resultados estão apresentados na Tabela 6.10 .

Tabela 6.10 Valores de extensão $(\mathrm{m})$, força $(\mathrm{N})$ e trabalho $(\mathrm{J})$ obtidos no teste de penteabilidade para as amostras de cabelo virgem padrão caucasiano e oriental.

\begin{tabular}{cccc}
\hline \hline Etnia & Extensão $(\mathbf{m})$ & Força $(\mathbf{N})$ & Trabalho $(\mathbf{J})$ \\
\hline \hline & 0,059 & 1,696 & 0,100 \\
Caucasiana & 0,059 & 1,283 & 0,075 \\
& 0,065 & 1,461 & 0,095 \\
M.F.土 D.V. & $0,061 \pm 0,004$ & $1,480 \pm 0,207$ & $0,090 \pm 0,013$ \\
Oriental & 0,066 & 0,988 & 0,066 \\
& 0,063 & 1,733 & 0,109 \\
M.F.土 D.V. & 0,060 & 1,778 & 0,106 \\
\hline \hline M.F. média final: D.V. & $0,063 \pm 0,003$ & $1,500 \pm 0,443$ & $0,093 \pm 0,024$ \\
\hline
\end{tabular}

Os resultados de penteabilidade obtidos para as amostras das mechas de cabelo virgem padrão caucasiano e oriental foram submetidos ao teste de ANOVA (one-way, $\alpha=0,05$ ). O valor de $p$ foi igual a 0,492, e desta forma, os valores de trabalho $(\mathrm{J})$ das mechas de cabelo não diferiram significativamente entre si para um nível de significância maior que 5\% (Tabela 6.11). A literatura relata que os cabelos destas duas etnias são semelhantes em termos de estrutura e penteabilidade (ROBBINS, 1994; GOMES, 2008). 
Tabela 6.11 Modelo de ANOVA para os resultados obtidos no teste de penteabilidade das mechas de cabelo virgem padrão caucasiano e oriental.

\begin{tabular}{ccccccc}
\hline \hline Fonte da variação & $\mathrm{SQ}$ & $\mathrm{gl}$ & $\mathrm{MQ}$ & $\mathrm{F}$ & valor-P & $\mathrm{F}$ crítico \\
\hline \hline Entre grupos & 0,0000 & 1,0000 & 0,0000 & 0,5714 & 0,4918 & 7,7086 \\
Dentro dos grupos & 0,0000 & 4,0000 & 0,0000 & & & \\
Total & 0,0000 & 5,0000 & & & & \\
\hline \hline
\end{tabular}

O valor de trabalho obtido para as mechas de cabelo caucasiano virgem de 0,090 J apresentou-se menor do que o obtido por Gama (2010), que foi $4 \mathrm{~J}$, porém as condições experimentais empregadas por esse autor foram diferentes, dentre outras estão incluídas a célula de carga e a velocidade de penteabilidade. Diferentes condições experimentais podem gerar resultados diferentes nas propriedades mecânicas dos fios de cabelo. Desta forma, não é possível comparar os resultados obtidos nestes trabalhos pois foram realizados sob condições experimentais diferentes.

\subsubsection{Microscopia eletrônica de varredura (MEV)}

As mechas de cabelo foram cortadas em pequenas frações e submetidas a analise de imagem por MEV.

\subsubsection{Cabelo caucasiano}

As imagens de MEV da amostra de cabelo caucasiano virgem em corte seccional (Figura 6.10) ilustram as camadas da cutícula e do córtex.

A partir da utilização da ferramenta do software do MEV foi medida a espessura da cutícula que foi aproximadamente $2 \mu \mathrm{m}$. Porém, a literatura diz que a cutícula pode variar de espessura nos cabelos. Esse fato está relacionado à inclinação do folículo em relação à superfície cutânea na fase de queratinização que é mais acentuada quanto maior for a inclinação (BARNICOT, 1959). 


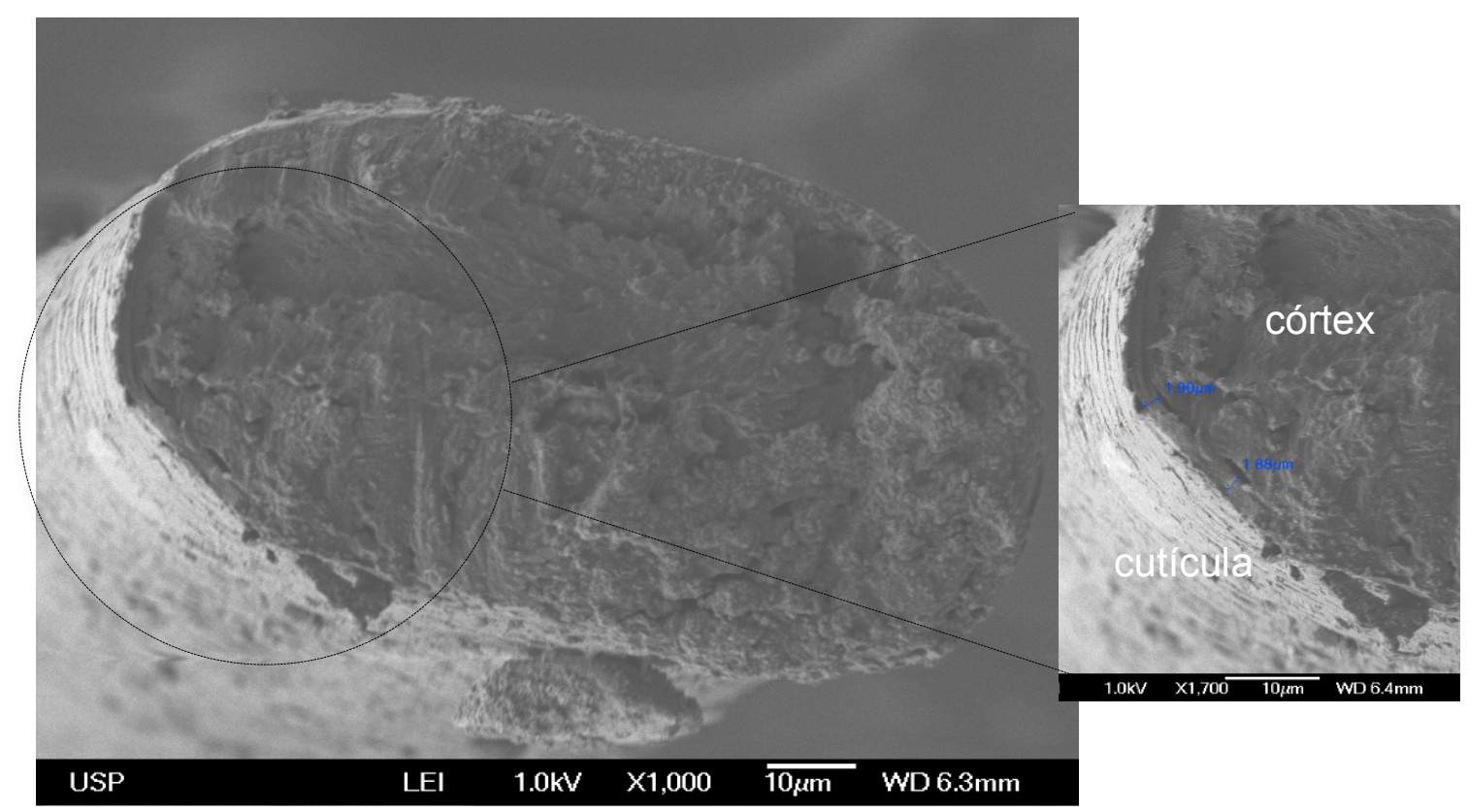

Figura 6.10 Imagens de MEV de uma amostra de cabelo virgem caucasiano. No detalhe: as camadas da cutícula e sua medida de espessura.

\subsubsection{Cabelo oriental}

A partir das imagens de MEV (Figura 6.11) foi possível observar as camadas da cutícula na amostra de cabelo oriental. Segundo Inoue et al. (2005) estas camadas estão separadas entre si por "linhas" um pouco mais claras, que segundo a literatura, correspondem às camadas de lipídeos existentes formando, desta maneira, o CMC (complexo de membrana celular).

Morfologicamente, a cutícula do cabelo é constituída por seis a dez camadas de células sobrepostas na direção longitudinal da fibra. Cada célula possui forma retangular com cerca de 30-40 $\mu \mathrm{m}$ de comprimento e 0,3 $\mu \mathrm{m}$ de espessura e, devido ao modo como as células se sobrepõem, somente 1/6 delas ficam expostas na superfície do cabelo (SWIFT \& BEWS, 1974). Observando o detalhe da Figura 6.11 é possível verificar a presença de no mínimo seis camadas formando a cutícula. Foi medida, utilizando a ferramenta do software do MEV, a espessura da cutícula que foi aproximadamente $2 \mu \mathrm{m}$, apresentando uma semelhança neste valor com as amostras de cabelos caucasiano. 


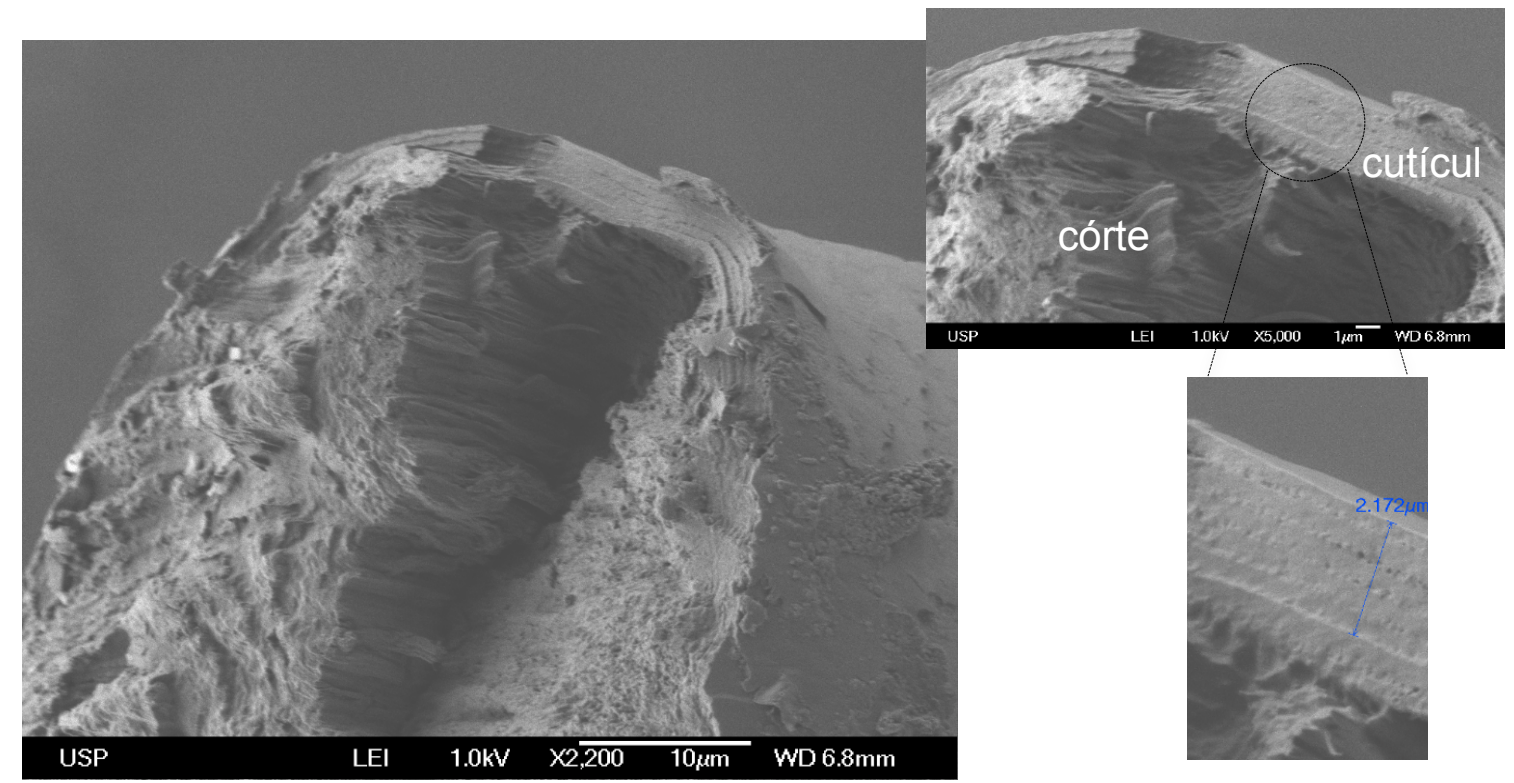

Figura 6.11 Imagens de MEV de uma amostra de cabelo virgem oriental. No detalhe: as camadas da cutícula e sua medida de espessura.

\subsubsection{Cabelo afro-étnico}

As imagens de MEV da amostra de cabelo afro-étnico virgem em corte transversal (Figura 6.12) mostram as camadas da cutícula e do córtex. Podemos observar a partir do corte de sua secção transversal à camada da cutícula e do córtex.

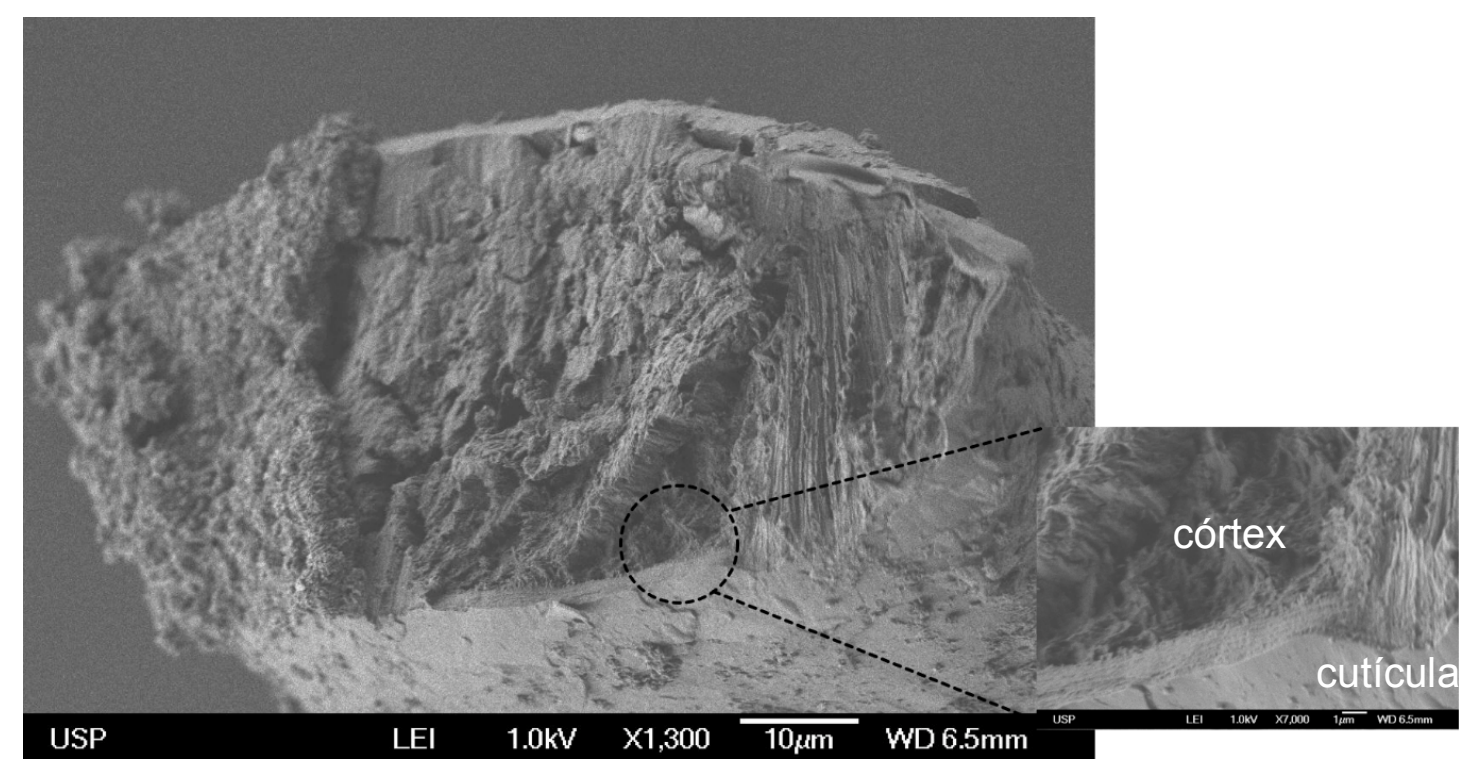

Figura 6.12 Imagens de MEV de uma amostra de cabelo virgem afro-étnico. No detalhe: a cutícula. 


\subsection{Caracterização dos ingredientes cosméticos isolados e incorporados às formulações}

De acordo com os resultados obtidos a partir das medidas de DSC no item 6.1.2, pode-se afirmar que o cabelo começa a ser degradado em torno de $240^{\circ} \mathrm{C}$. Considerando este dado, torna-se necessário um estudo de caracterização térmica dos ingredientes que são destinados à proteção térmica dos cabelos, uma vez que estes devem suportar altas temperaturas oriundas dos modeladores térmicos comumente utilizados. Portanto, esta etapa compreende a caracterização química e térmica dos ingredientes cosméticos isolados e incorporados às formulações.

No mercado, atualmente, estão disponíveis alguns tipos diferentes de formulações direcionadas à proteção térmica dos cabelos submetidos a tratamentos térmicos. Desta maneira, os ingredientes cosméticos foram incorporados a dois veículos diferentes com o intuito de avaliar a influência destes nos resultados de proteção térmica dos cabelos.

\subsubsection{Termogravimetria/Termogravimetria derivada}

A Tabela 6.12 apresenta os resultados obtidos a partir dos ensaios de termogravimetria dos ingredientes cosméticos. As curvas TG/DTG da Figura 6.13 ilustram o comportamento térmico dos três ingredientes. Observou-se que os ingredientes $\mathrm{A}$ e $\mathrm{C}$ apresentaram três eventos de perda de massa, enquanto para o B o processo ocorreu em duas etapas. As curvas TG/DTG evidenciaram que o ingrediente $\mathrm{C}$ perdeu cerca de $90 \%$ de sua massa inicial entre 25 e $170^{\circ} \mathrm{C}$ e as outras duas etapas ocorrem acima de $320^{\circ} \mathrm{C}$ e o produto final acima de $600^{\circ} \mathrm{C}$ corresponde a $6,5 \%$ da massa inicial. A observação visual do aquecimento desse produto em tubo de ensaio evidenciou a ocorrência de fervura e volatilização do material. No aquecimento, os ingredientes A e B perdem, lentamente, cerca de $5 \%$ de sua massa inicial até $220^{\circ} \mathrm{C}$, porém $\mathrm{O}$ ingrediente $\mathrm{A}$ se decompõe rapidamente entre 250 e $376^{\circ} \mathrm{C}$ com $\Delta \mathrm{m}=37 \%$ e entre 376 e $650^{\circ} \mathrm{C}$ com $\Delta \mathrm{m}=$ $41 \%$. Para o ingrediente $B$ a perda de massa prossegue mais lentamente até cerca de $350^{\circ} \mathrm{C}(\Delta \mathrm{m}=10 \%)$ e entre 350 e $650^{\circ} \mathrm{C}$ a perda de massa de cerca de $68 \%$, ocorre de forma mais rápida e em duas etapas. O produto final acima de 
$650^{\circ} \mathrm{C}$, para ambos os ingredientes, se mantém estável termicamente até $900^{\circ} \mathrm{C}$ e corresponde a cerca de $17 \%$ da massa inicial dos respectivos produtos. No caso do Ingrediente A, a perda de massa inicial é referente a liberação de água presente no material com $\mathrm{T}_{\text {pico DTG }}$ de $82^{\circ} \mathrm{C}$. Já, para o Ingrediente $\mathrm{B}$, a perda de massa pode ser atribuída à lenta volatilização de um dos componentes.

Tabela 6.12 Resultados de TG/DTG de amostras dos ingredientes cosméticos.

\begin{tabular}{ccccc}
\hline $\begin{array}{c}\text { Ingrediente } \\
\text { cosmético }\end{array}$ & Eventos & $\begin{array}{c}\text { Faixa de } \\
\text { temperatura } \\
{ }^{\circ} \mathbf{C}\end{array}$ & $\begin{array}{c}\mathbf{T}_{\text {pico DTG }} \\
/^{\circ} \mathbf{C}\end{array}$ & Perda de massa /\% \\
\hline \hline \multirow{2}{*}{ A } & 1 & $25-155$ & 82 & 3,3 \\
& 2 & $155-376$ & 253 & 37,0 \\
\hline B & 3 & $376-650$ & 505 & 41,0 \\
\hline & 1 & $25-350$ & 483 & 51,0 \\
& 2 & $350-650$ & 496 & 32,3 \\
\hline & 1 & $25-170$ & 139 & 89,0 \\
& 2 & $320-440$ & 394 & 3,4 \\
& 3 & $450-650$ & 508 & 1,1 \\
\hline
\end{tabular}

*INCI dos ingredientes: $A$ = Trideceth-9 PG-Amodimethicone (and) Trideceth-12;

$B=$ Amodimethicone Glycerocarbamate e

$C=$ Cyclopentasiloxane (and) Dimethiconol (and) Dimethicone Crosspolymer.

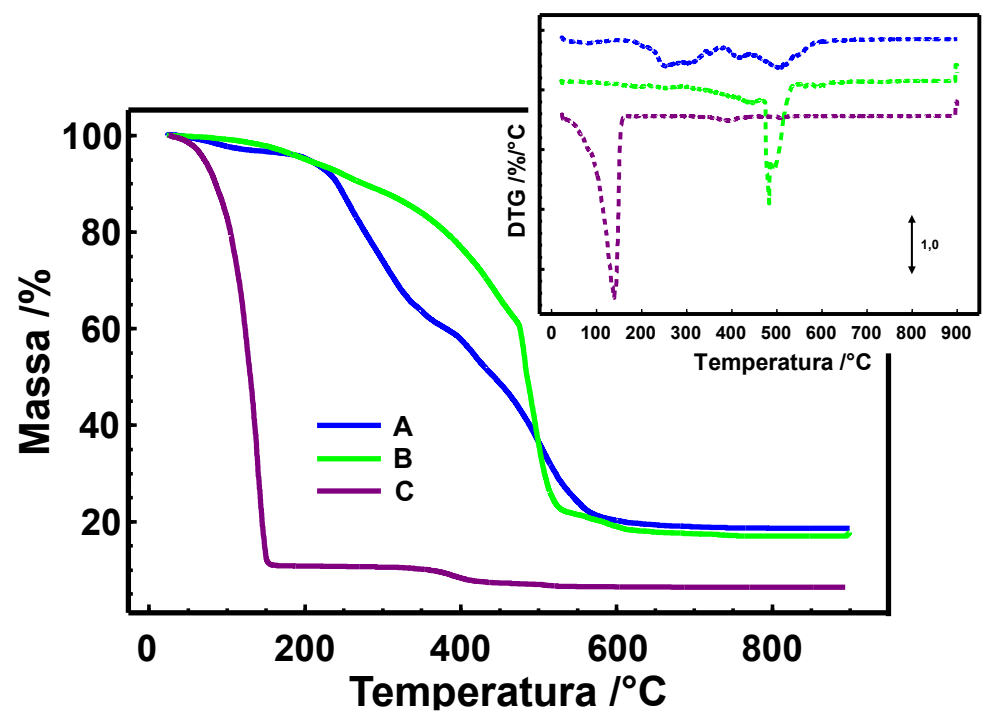

Figura 6.13 Curvas TG e DTG obtidas a $10^{\circ} \mathrm{C} \mathrm{min}^{-1}$, sob atmosfera dinâmica de ar e empregando cápsula de Pt contendo cerca de $15 \mathrm{mg}$ de amostras dos ingredientes cosméticos. 
De acordo com as curvas TG/DTG ilustradas na Figura 6.14, observa-se que o dimeticone é estável termicamente até $300^{\circ} \mathrm{C}$ e apresentou sete eventos de perda de massa parcialmente simultâneos. Acima de $600^{\circ} \mathrm{C}$ o produto final corresponde a $35 \%$ da massa inicial. Os ingredientes, quando incorporados ao dimeticone ( $3 \%$ em massa), se mostraram mais estáveis termicamente (F2A, F2B e F2C). F2A e F2B apresentaram perda de massa a partir de $220^{\circ} \mathrm{C}$ (Tabela 6.13), resultados diferentes daqueles obtidos para a estes ingredientes isoladamente. $O$ Ingrediente $C$ também apresentou um aumento em sua estabilidade térmica quando associada ao dimeticone (temperatura do início da perda de massa se elevou de $25^{\circ} \mathrm{C}$ para $56^{\circ} \mathrm{C}$ ). Esses dados indicam que pode ter ocorrido alguma interação química e/ou física entre os materiais, havendo uma melhora na estabilidade térmica dos ingredientes cosméticos.

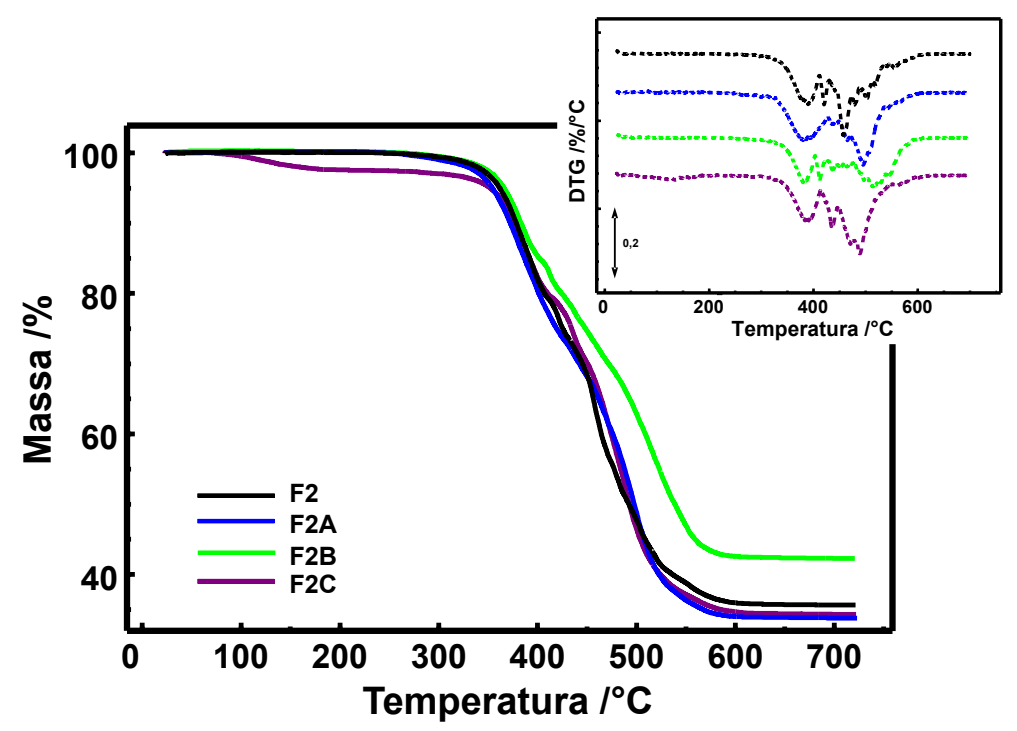

Figura 6.14 Curvas TG e DTG obtidas a $10^{\circ} \mathrm{C} \mathrm{min}^{-1}$, sob atmosfera dinâmica de ar e empregando cápsula de Pt contendo cerca de $15 \mathrm{mg}$ das formulações: dimeticone (F2), F2A, F2B e F2C.

As curvas TG/DTG (Figura 6.15) ilustram que a decomposição térmica da amostra do condicionador leave-on ocorre em duas etapas principais. A primeira, entre 25 e $120^{\circ} \mathrm{C}(\Delta \mathrm{m} \sim 75 \%)$ é devido à eliminação de água presente no produto e a segunda etapa, que ocorre entre 120 e $250^{\circ} \mathrm{C}$, pode ser atribuída à decomposição térmica dos outros componentes. 
Tabela 6.13 Resultados de TG/DTG de amostras de dimeticone (F2) e das formulações F2, F2A, F2B e F2C.

\begin{tabular}{|c|c|c|c|c|}
\hline Formulação & Eventos & $\begin{array}{c}\text { Faixa de } \\
\text { temperatura } /{ }^{\circ} \mathrm{C}\end{array}$ & $\begin{array}{c}\text { T pico DTG } \\
/{ }^{\circ} \mathrm{C}\end{array}$ & Massa $/ \%$ \\
\hline \multirow{7}{*}{$\mathrm{F} 2$} & $\overline{\overline{1}}$ & $235-410$ & 390 & $\overline{20,7}$ \\
\hline & 2 & $410-430$ & 420 & 5,8 \\
\hline & 3 & $430-473$ & 457 & 17,4 \\
\hline & 4 & $473-488$ & 478 & 5,2 \\
\hline & 5 & $488-513$ & 503 & 6,4 \\
\hline & 6 & $513-540$ & 519 & 4,5 \\
\hline & 7 & $540-623$ & 555 & 4,0 \\
\hline \multirow{4}{*}{$\mathrm{F} 2 \mathrm{~A}$} & 1 & $220-425$ & 380 & 26,5 \\
\hline & 2 & $425-449$ & 438 & 5,6 \\
\hline & 3 & $449-470$ & 465 & 6,5 \\
\hline & 4 & $470-618$ & 596 & 27,7 \\
\hline \multirow{6}{*}{$\mathrm{F} 2 \mathrm{~B}$} & 1 & $220-403$ & 381 & 15,1 \\
\hline & 2 & $403-427$ & 412 & 5,6 \\
\hline & 3 & $427-444$ & 436 & 3,5 \\
\hline & 4 & $444-456$ & 452 & 3,0 \\
\hline & 5 & $456-468$ & 460 & 2,5 \\
\hline & 6 & $468-625$ & 513 & 27,4 \\
\hline \multirow{6}{*}{$\mathrm{F} 2 \mathrm{C}$} & 1 & $56-224$ & 135 & 2,5 \\
\hline & 2 & $224-414$ & 391 & 18,1 \\
\hline & 3 & $414-447$ & 436 & 8,8 \\
\hline & 4 & $447-479$ & 471 & 13,2 \\
\hline & 5 & $479-548$ & 489 & 20,7 \\
\hline & 6 & $548-630$ & 560 & 2,8 \\
\hline
\end{tabular}

${ }^{*} F 2=$ dimeticone; $F 2 A=$ dimeticone $+A ; F 2 B=$ dimeticone $+B ; F 2 C=$ dimeticone $+C$.

As formulações F3A, F3B e F3C, em que $3 \%$ em massa dos ingredientes foram incorporados, apresentaram o comportamento térmico semelhante aquele do leave-on puro, visto que este é o componente majoritário. Nesse caso não foi possível inferir a ocorrência de qualquer alteração na estabilidade térmica dos 
ingredientes presentes na formulação, principalmente por se tratar de emulsões cosméticas, que possuem grande quantidade de água em sua matriz. A Tabela 6.14 lista os resultados extraídos das curvas TG/DTG.

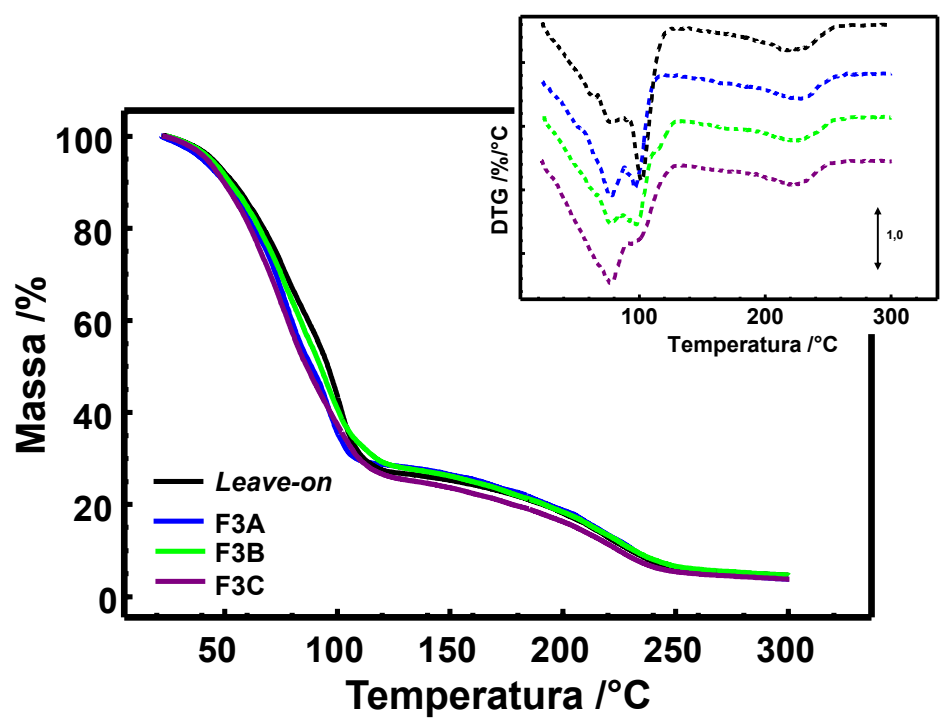

Figura 6.15 Curvas TG e DTG obtidas a $10^{\circ} \mathrm{C} \mathrm{min}^{-1}$, sob atmosfera dinâmica de ar e empregando cápsula de Pt contendo cerca de $15 \mathrm{mg}$ das formulações cosméticas: Condicionador leave-on (F3), F3A, F3B e F3C.

Tabela 6.14 Resultados de TG/DTG de amostras de leave-on (F3) e das formulações F3A, F3B e F3C.

\begin{tabular}{ccccc}
\hline \hline Formulação & Eventos & $\begin{array}{c}\text { Faixa de } \\
\text { temperatura } /{ }^{\circ} \mathbf{C}\end{array}$ & $\begin{array}{c}\text { T pico DTG } \\
{ }^{\circ} \mathbf{C}\end{array}$ & $\begin{array}{c}\text { Perda de massa } \\
\text { /\% }\end{array}$ \\
\hline \hline \multirow{4}{*}{ Leave-on F3 } & 1 & $25-68$ & 66 & 21,0 \\
& 2 & $68-88$ & 77 & 19,9 \\
& 3 & $88-133$ & 102 & 32,2 \\
& 4 & $133-260$ & 219 & 21,0 \\
F3A & 1 & $25-88$ & 79 & 43,4 \\
& 2 & $88-130$ & 97 & 23,5 \\
& 3 & $130-268$ & 228 & 23,8 \\
F3B & 1 & $25-86$ & 77 & 43,0 \\
& 2 & $86-133$ & 97 & 29,4 \\
\multirow{2}{*}{ F3C } & 3 & $133-273$ & 222 & 22,1 \\
& 1 & $25-130$ & 77 & 75,0 \\
\hline \hline
\end{tabular}

$\overline{F 3}=$ Cond. leave-on; $F 3 A=$ Cond. leave-on $+A ; F 3 B=$ Cond. leave-on+B; $F 3 C=$ Cond. leave-on $+C$. 


\subsubsection{Análise elementar}

Os resultados de $\mathrm{CHN}$ dos ingredientes cosméticos $\mathrm{A}, \mathrm{B}$ e $\mathrm{C}$, dos veículos dimeticone e leave on e das formulações estão listados na Tabela 6.15. Como era de se esperar o teor de $\mathrm{C}$ é maior em todos os componentes puros ou nas formulações. No caso do ingrediente $\mathrm{C}$, dimeticone e leave-on foram determinados apenas $\mathrm{C} \mathrm{e} \mathrm{H}$, visto que não há a presença de amida na composição desses produtos. Por outro lado, para os ingredientes A e B o elemento $\mathrm{N}$ foi determinado por pertencer ao amodimethicone presente em ambos os ingredientes. No caso das formulações, as percentagens dos elementos se aproximam daquelas dos veículos puros. Algumas discrepâncias nos teores de $\mathrm{H}$ podem estar relacionadas a absorção de água pela formulação antes dos ensaios de análise elementar.

Tabela 6.15 Resultados de análise elementar $(\mathrm{CHN})$ de amostras dos ingredientes e formulações cosméticas.

\begin{tabular}{cccc}
\hline \hline Ingrediente/Veículo & \%C & \%H & $\% \mathbf{N}$ \\
\hline \hline A & 43,0 & 9,0 & 0,4 \\
B & 33,7 & 8,1 & 0,9 \\
C & 31,7 & 8,0 & ---- \\
Dimeticone (F2) & 32,6 & 7,9 & --- \\
F2A & 32,3 & 8,7 & --- \\
F2B & 32,8 & 8,4 & --- \\
F2C & 32,2 & 8,3 & --- \\
Leave-on (F3) & 18,7 & 8,1 & --- \\
F3A & 19,4 & 10,7 & --- \\
F3B & 19,7 & 10,6 & --- \\
F3C & 19,5 & 10,8 & --- \\
\hline
\end{tabular}

*INCI dos ingredientes: A = Trideceth-9 PG-Amodimethicone (and) Trideceth-12;

$\mathrm{B}=$ Amodimethicone Glycerocarbamate e

$\mathrm{C}=$ Cyclopentasiloxane (and) Dimethiconol (and) Dimethicone Crosspolymer. 


\subsubsection{Espectroscopia na região do infravermelho com Transformada de}

Fourier

\subsubsection{Ingredientes cosméticos e formulações}

A Figura 6.16 apresenta os espectros no IV dos ingredientes cosméticos estudados. Os espetros das amostras dos ingredientes A e B apresentaram bandas em 3363 e $3477 \mathrm{~cm}^{-1}$, respectivamente, relativos a bandas $\mathrm{O}-\mathrm{H}$.

Comparando os três espectros, observou-se que apenas o ingrediente $B$ apresentou uma banda em $1702 \mathrm{~cm}^{-1}$ referente ao grupo carbonila $(\mathrm{C}=\mathrm{O})$ presente no carbamato (ZHAl et al., 2012). Porém esta banda diminui de intensidade quando $3 \%$ deste ingrediente foi incorporado ao dimeticone, que também apresenta uma banda de baixa intensidade na mesma região. Outras bandas características dos ingredientes (silicones) apareceram nos espectros IV de todas as amostras em número de ondas de 1410, 1262, 1088, 1021, 803 e 700 $\mathrm{cm}^{-1}$ correspondentes, respectivamente, aos grupos $\mathrm{Si}-\mathrm{CH}_{3}, \mathrm{Si}-\mathrm{O}-\mathrm{C}$, Si-O-Si, Si-C e Si- $\left(\mathrm{CH}_{3}\right)_{3}$. Outras bandas de absorção, também, são observados em 2961 e $2904 \mathrm{~cm}^{-1}$, devido a vibrações de grupos C-H e $\mathrm{CH}_{3}$ (TORRADO et al., 1999; YANG et al., 2011; HASSANA et al., 2013).

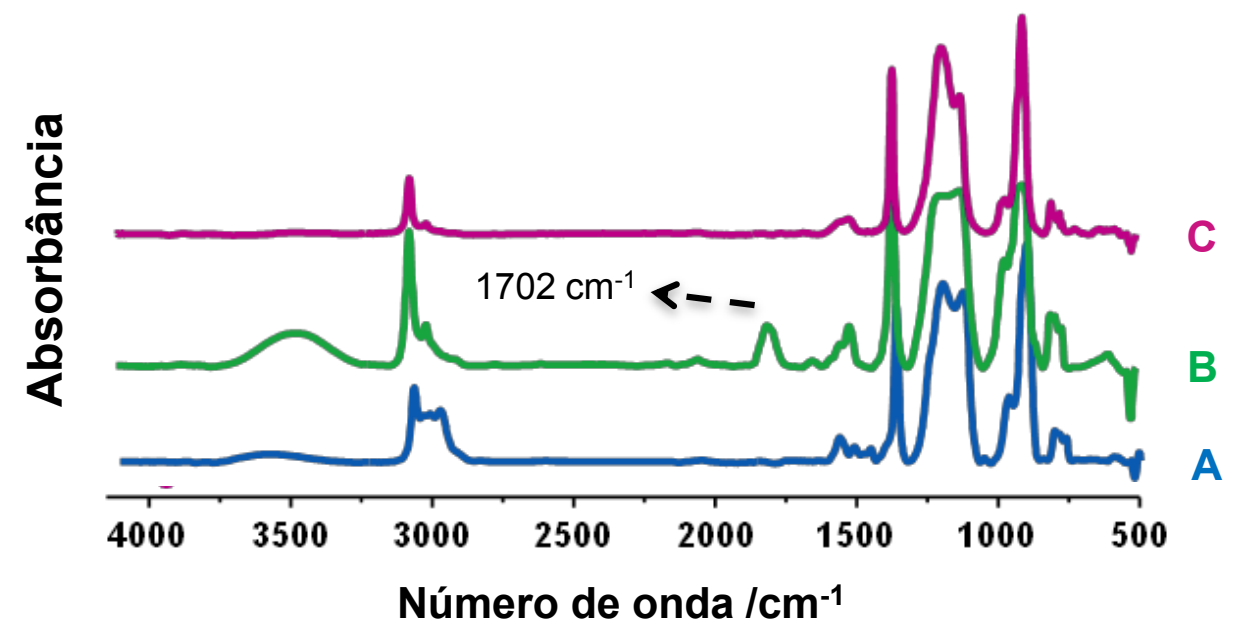

Figura 6.16 Espectros de absorção na região do IV de amostras dos ingredientes cosméticos estudados (A, B e C).

A Figura 6.17 ilustra a comparação dos espectros FTIR do dimeticone e das respectivas formulações. Como o dimeticone é o componente majoritário, os 
espectros no IV das formulações são muito similares ao espectro do veículo isolado. Também, os espectros no IV dos ingredientes isolados são similares ao espectro do próprio veículo. Esses fatos não permitem diferenciar os espectros das três formulações, principalmente porque algumas bandas de maior intensidade que aparecem nos espectros dos ingredientes estão encobertas pelas bandas absorção do dimeticone. Mesmo o ingrediente $\mathrm{B}$, o único que apresenta a banda de absorção em $1702 \mathrm{~cm}^{-1}$, não pode ser identificado na formulação, porque o dimeticone apresenta banda de absorção na mesma região espectral. Esses resultados não permitem evidenciar que possam existir interações de alguma natureza ingrediente/dimeticone ou que possa explicar o fato do aumento de estabilidade térmica dos ingredientes na formulação, conforme observado por termogravimetria.

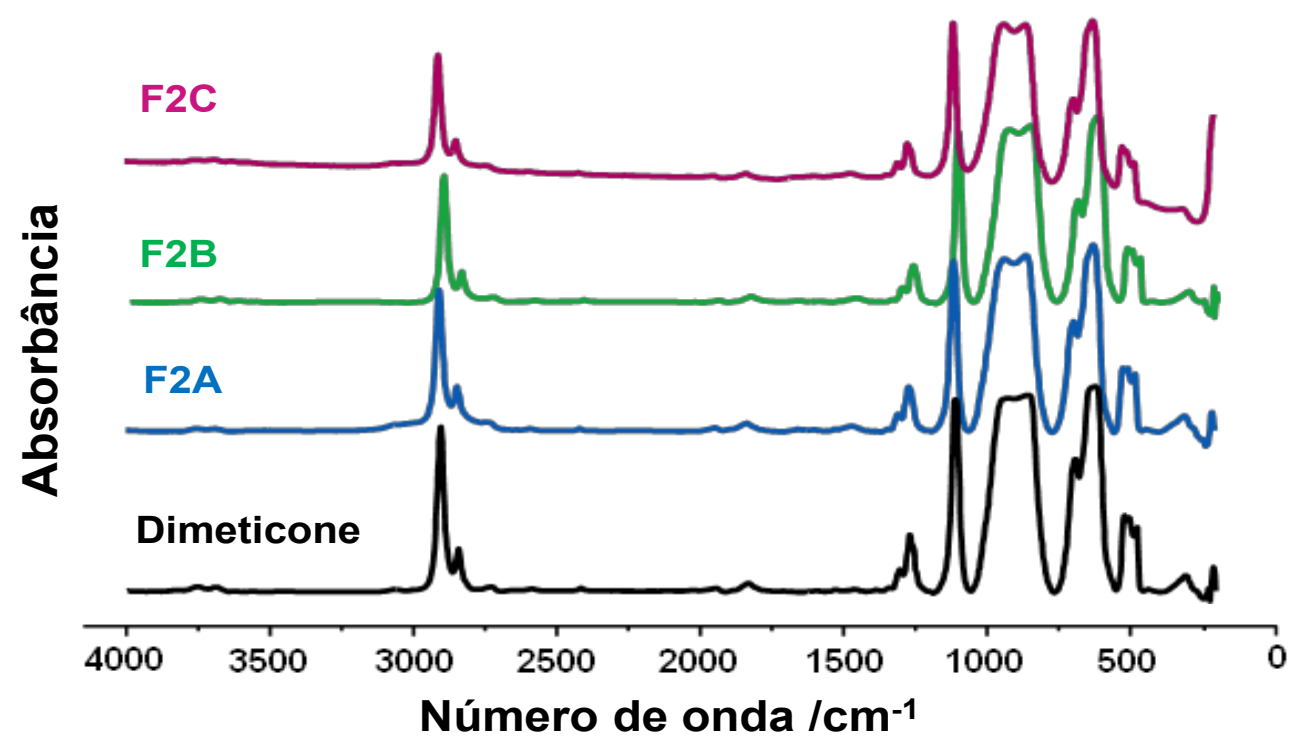

Figura 6.17 Espectros de absorção na região do IV das amostras: F2 (dimeticone) e das formulações F2A, F2B e F2C (dimeticone + ingredientes cosméticos A, B e C).

Os espectros no IV da Figura 6.18 ilustram as bandas de absorção encontradas na amostra do condicionador leave-on e das formulações F3A, F3B e F3C. De acordo com o espectro F3 (condicionador leave-on sem a incorporação dos ingredientes cosméticos), verificou-se a presença de picos relacionados aos grupos principais presentes em emulsões cosméticas. Exemplos destes apareceram em 1745, 2955, uma banda larga em $3386 \mathrm{~cm}^{-1}$, relacionadas a vibrações dos grupos $\mathrm{C}=\mathrm{O}, \mathrm{C}=\mathrm{CH}$ e $\mathrm{OH}$, respectivamente (MASMOUDIA et al., 
2005). Comparando os espectros, observa-se a predominância das principais bandas somadas às bandas de maior intensidade e mais alargadas características dos ingredientes que correspondem às vibrações dos grupos $\mathrm{Si}-\mathrm{O}$ mencionadas no item 6.2.4.1. Como no caso das formulações anteriores, o condicionador leave on é o componente majoritário, e os espectros no IV das formulações são muito similares ao espectro do veículo isolado. A única diferença marcante, ocorreu no caso do espectro da formulação F3B que mostrou um aumento na intensidade da banda de absorção na região entre 1700 e $1500 \mathrm{~cm}^{-1}$, possivelmente devido a alguma interação ingrediente/veículo.

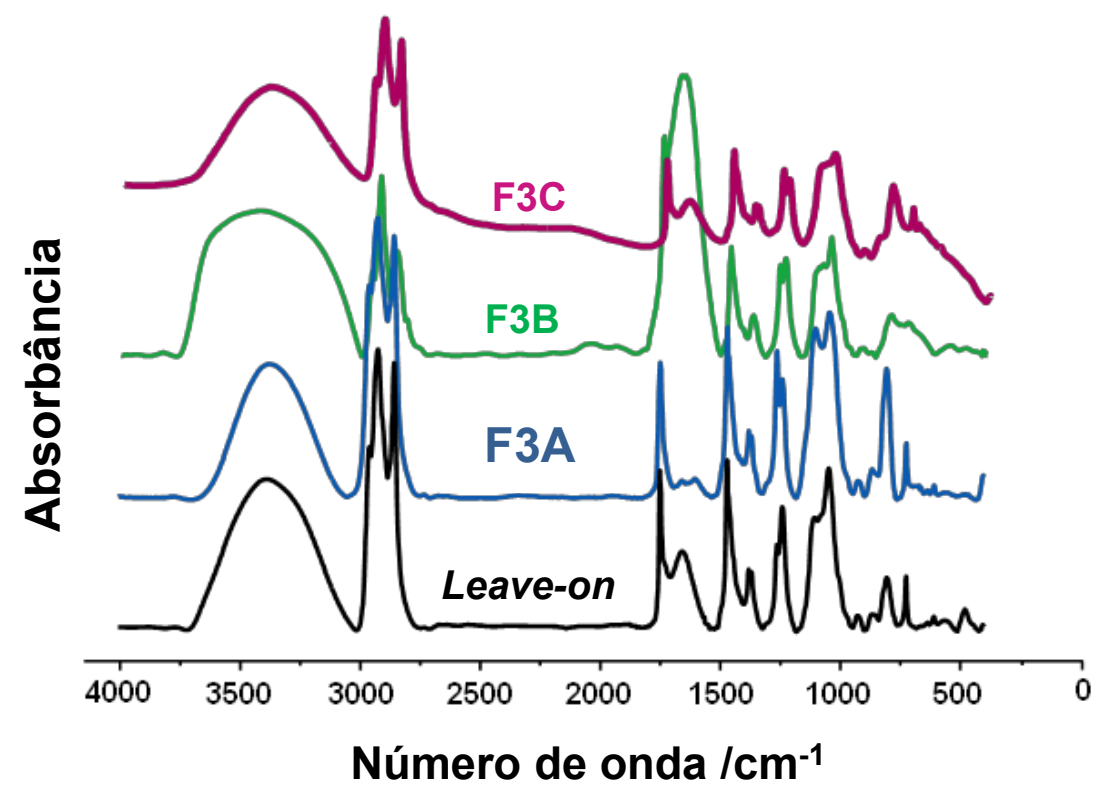

Figura 6.18 Espectros de absorção na região do IV das amostras: F3 (condicionador leave-on) e das formulações F3A, F3B e F3C (condicionador leave-on + ingredientes cosméticos A, B e C ).

\subsection{Estudo de estabilidade das formulações cosméticas}

\subsubsection{Teste de estabilidade preliminar}

As informações obtidas no estudo de estabilidade são particularmente importantes para os veículos emulsionados, pois quando estocados podem fornecer sinais de desestabilização (IDSON, 1993).

A emulsão condicionadora foi adquirida do mercado com estudo de estabilidade já devidamente estabelecido pela fabricante. Porém, a fim de se 
verificar alguma alteração nas formulações após a incorporação dos ingredientes cosméticos, foi realizado um estudo de estabilidade acelerado pelo período de 30 dias.

Amostras das formulações $\mathrm{F} 3 \mathrm{~A}, \mathrm{~F} 3 \mathrm{~B}$ e $\mathrm{F} 3 \mathrm{C}$ foram submetidas ao teste de centrifugação a $3.000 \mathrm{rpm}$ durante 30 minutos antes de iniciar os Estudos de Estabilidade. O produto permaneceu estável, sem sinais de separação de fases.

\subsubsection{Estudo de estabilidade acelerada}

Os resultados da análise macroscópica das amostras das formulações F3A, F3B e F3C (condicionadores leave-on) estão listados na Tabela 6.16. As amostras não apresentaram alteração nos parâmetros organolépticos, mantido nas condições de $5 \pm 2{ }^{\circ} \mathrm{C}$, (geladeira), $25 \pm 2^{\circ} \mathrm{C}$ (Temperatura Ambiente), $45 \pm$ $2{ }^{\circ} \mathrm{C}$ (estufa) e luz solar, ao final do estudo de estabilidade acelerada de 30 dias. Os valores de $\mathrm{pH}$ e de viscosidade aparente também não apresentaram alterações significativas, mesmo em condições de temperatura elevada, um ciclo de congelamento em geladeira e descongelamento em estufa. Desta forma, é possível afirmar que as formulações incorporadas aos ingredientes cosméticos permaneceram estáveis, pelo período de 30 dias, nas condições estabelecidas (Figura 6.19).

Os valores de $\mathrm{pH}$ das formulações condicionadoras foram compatíveis ao do $\mathrm{pH}$ capilar, que é em torno de 5 . Valores de $\mathrm{pH}$ um pouco abaixo em produtos capilares ajudam no condicionamento dos cabelos (MONTE, 2013).

As formulações $\mathrm{F} 3 \mathrm{~A}$ e F3B apresentaram valores de $\mathrm{pH}$ um pouco acima de 4 e muito próximos entre si. Já formulação $\mathrm{F} 3 \mathrm{C}$ apresentou um comportamento um pouco diferente, apresentando o menor valor de pH, ligeiramente abaixo de 4 . O cabelo sendo constituído por ambas cargas elétricas positivas e negativas (aminoácidos anfóteros), em pH próximo ao ponto isoelétrico do cabelo $(\mathrm{pH}$ onde as cargas se igualam que é em torno 3,8 ), não há repulsão dos fios, ocorrendo um equilíbrio de cargas. Porém quando o cabelo é deixado em contato com produtos cujo valor $\mathrm{pH}$ é superior a 3,8 , torna-se mais negativo, uma vez que o grupo $-\mathrm{NH}_{3}{ }^{+}$perde a sua carga. 


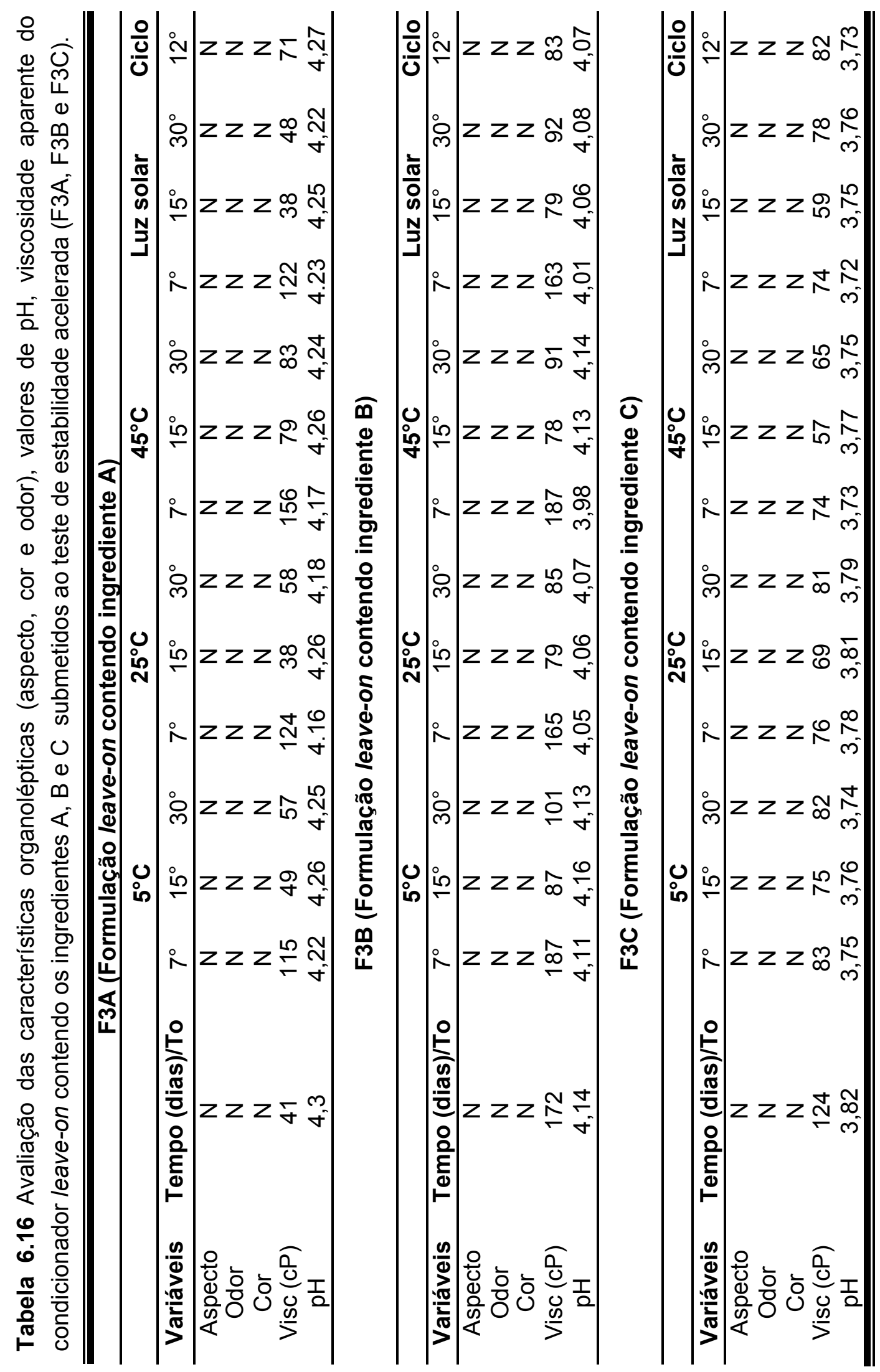




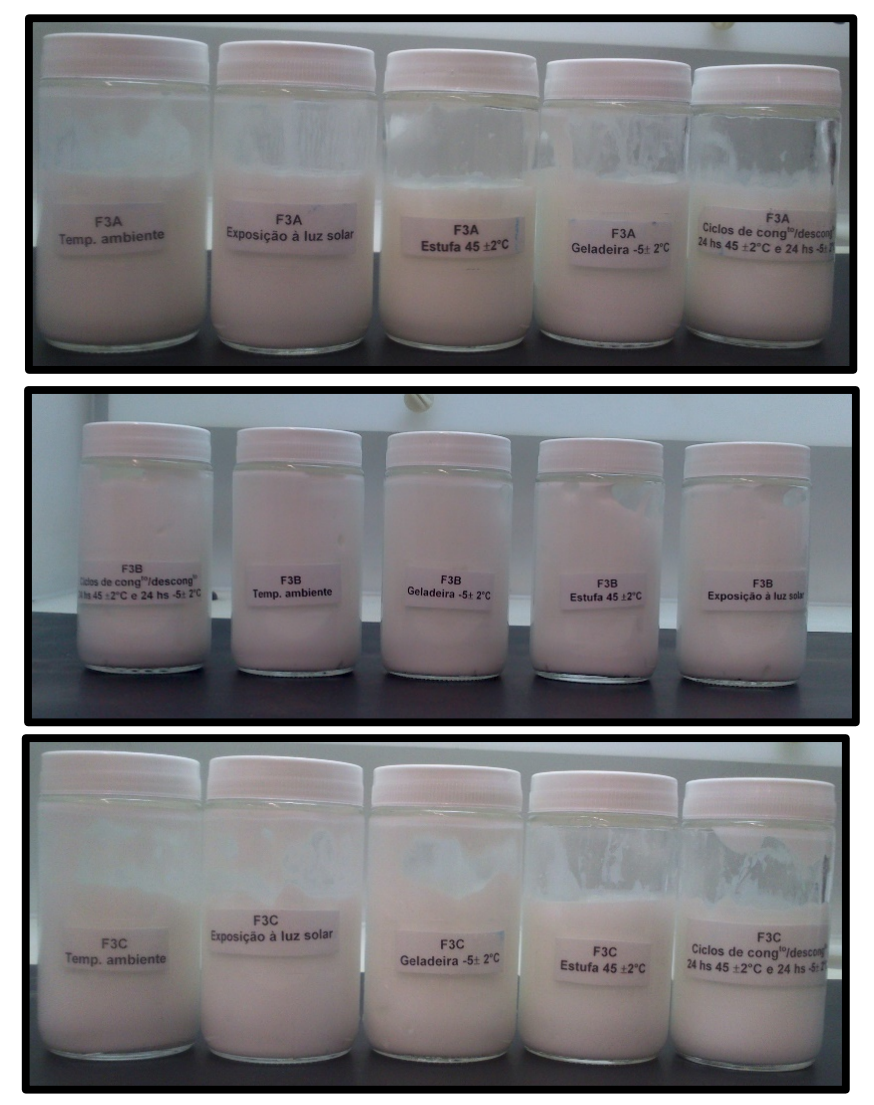

Figura 6.19 Imagem dos frascos das formulações F3A, F3B e F3C no teste de estabilidade acelerada (Ciclos de congelamento $5 \pm 2^{\circ} \mathrm{C}$ e descongelamento $45 \pm$ $2^{\circ} \mathrm{C}$, geladeira a $5 \pm 2^{\circ} \mathrm{C}$, temperatura ambiente, estufa a $45 \pm 2^{\circ} \mathrm{C}$ e radiação solar).

Porém, em valores de $\mathrm{pH}$ 3,8 ou menores o cabelo se torna mais positivo, os grupos carboxila estão protonados e neutralizados, e existe uma predominância do grupo $-\mathrm{NH}_{3}{ }^{+}$. No entanto, quando em contato com a água do banho ( $\mathrm{pH}$ 5-7), há prevalência de carga negativa no cabelo, tendo efeito de repulsão dos fios, que podem causar efeito de "abertura" das cutículas causando o embaraçamento (JUEZ \& GIMIER, 1983; ROBBINS, 1994; CORRÊA, 2008). Desta forma, podemos concluir que os valores de $\mathrm{pH}$ obtidos no presente estudo estão de acordo com a funcionalidade a que as formulações testadas apresentam, que é, dentre outras, condicionar e tornar os cabelos mais maleáveis. Isto ocorre porque sob estes valores de $\mathrm{pH}$ as cutículas dos fios de cabelo se encontram mais fechadas. Monte (2013) desenvolveu e avaliou condicionadores à base de óleo de pequi e obtiveram valores de $\mathrm{pH}$ em torno de 4, também sem variação significativa. 


\subsection{Caracterização e avaliação de amostras de cabelo submetidas a tratamentos com ingredientes cosméticos}

Este estudo envolveu duas etapas, as quais mechas de cabelo padrão virgem caucasiano e oriental e mechas de cabelo brasileiro virgem e descolorido foram submetidas a caracterização antes e após tratamento térmico conforme exposto no item 5.3 p. 54. Esta sequência de procedimentos objetivou, principalmente, a comparação entre o comportamento das amostras de cabelo com e sem o emprego de dispositivos térmicos (no caso a piastra), em ambos casos envolvendo a aplicação de formulações cosméticas. Desta forma, a eficiência das formulações foi testada quanto à proteção térmica dos cabelos.

Os procedimentos dos ciclos de aquecimento e lavagens foram realizados conforme descrito em 5.3.3. As amostras de cabelo foram cortadas em pequenas frações, pesadas em cadinhos de alumínio e armazenadas por 48 horas antes dos experimentos em DSC em ambiente controlado e seco $22 \pm 2{ }^{\circ} \mathrm{C} ; 20 \pm 2 \%$. Este procedimento foi realizado com o intuito de analisar a capacidade de cada formulação/ingrediente/veículo/mecha reter água na matriz capilar sem a influência da umidade do ambiente. Como já discutido anteriormente, o teor de água presente na matriz capilar pode alterar algumas propriedades dos cabelos.

Devido à dificuldade em se encontrar mechas de cabelo afro-étnico com um tamanho considerável para os estudos, esta etapa não foi realizada para este tipo de cabelo.

$\mathrm{Na}$ Tabela 6.17 apresenta um resumo, para melhor visualização, das técnicas empregadas no estudo de aplicação das formulações, bem como as mechas que foram avaliadas. 
Tabela 6.17 Técnicas utilizadas nas etapas de caracterização das amostras de cabelo submetidas aos tratamentos com formulações cosméticas antes e após o emprego de dispositivo térmico.

\begin{tabular}{|c|c|c|c|c|c|c|c|c|}
\hline & Mechas & TG & DSC & $\begin{array}{l}\text { IV- } \\
\text { ATR }\end{array}$ & $\mathrm{AE}$ & $\begin{array}{c}\text { Tensão- } \\
\text { deformação }\end{array}$ & Penteabilidade & $\begin{array}{c}\text { Quebra } \\
\text { por } \\
\text { escovação }\end{array}$ \\
\hline \multirow{3}{*}{ 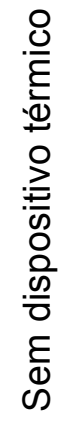 } & $\begin{array}{c}\text { Caucasiano } \\
\text { virgem }\end{array}$ & $x$ & $\mathrm{X}$ & --- & $X$ & $\mathrm{X}$ & $\mathrm{X}$ & --- \\
\hline & $\begin{array}{l}\text { Oriental } \\
\text { virgem }\end{array}$ & $x$ & $x$ & --- & $X$ & $x$ & $\mathrm{X}$ & --- \\
\hline & $\begin{array}{c}\text { Brasileiro } \\
\text { virgem e } \\
\text { descolorido }\end{array}$ & --- & $\mathrm{X}$ & --- & $X$ & --- & --- & --- \\
\hline \multirow{3}{*}{ 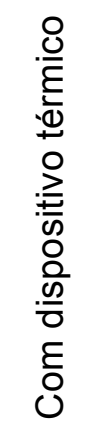 } & $\begin{array}{c}\text { Caucasiano } \\
\text { virgem }\end{array}$ & --- & $x$ & $\mathrm{X}$ & $X$ & --- & --- & --- \\
\hline & $\begin{array}{l}\text { Oriental } \\
\text { virgem }\end{array}$ & --- & $x$ & $\mathrm{X}$ & $x$ & --- & --- & --- \\
\hline & $\begin{array}{c}\text { Brasileiro } \\
\text { virgem e } \\
\text { descolorido }\end{array}$ & --- & $\mathrm{X}$ & $\mathrm{X}$ & $x$ & --- & $x$ & $\mathrm{X}$ \\
\hline
\end{tabular}

${ }^{*}$ Dispositivo térmico refere-se à piastra e não secador de cabelos, o qual foi utilizado em ambos procedimentos. $(\mathrm{X})$ - realizado (---) - não realizado.

Para facilitar o entendimento durante a exposição dos resultados, todas as mechas avaliadas foram codificadas e descritas conforme consta na Tabela 6.18. 
Tabela 6.18 Denominação das mechas de cabelo empregadas no estudo de avaliação da proteção dos ingredientes/formulações cosméticas.

\begin{tabular}{|c|c|c|c|}
\hline Etnia & Amostra & Tratamento & Sigla \\
\hline \multirow{7}{*}{$\begin{array}{c}\text { Caucasiana } \\
\text { (C) }\end{array}$} & Controle 1 & $s / f$ & MCCont1 \\
\hline & Com ingrediente $A$ & Dimeticone $+A$ & $\mathrm{MCDM}+\mathrm{A}$ \\
\hline & Com ingrediente $B$ & Dimeticone + B & MCDM+B \\
\hline & Com ingrediente $\mathrm{C}$ & Dimeticone $+C$ & $M C D M+C$ \\
\hline & Com ingrediente $A$ & Leave-on + A & MCLo+A \\
\hline & Com ingrediente $B$ & Leave-on + B & MCLo+B \\
\hline & Com ingrediente $\mathrm{C}$ & Leave on + C & MCLo+C \\
\hline \multirow{7}{*}{$\begin{array}{l}\text { Oriental } \\
\text { (O) }\end{array}$} & Controle 1 & $s / f$ & MOCont1 \\
\hline & Com ingrediente $A$ & Dimeticone $+A$ & $\mathrm{MODM}+\mathrm{A}$ \\
\hline & Com ingrediente $B$ & Dimeticone + B & MODM+B \\
\hline & Com ingrediente $\mathrm{C}$ & Dimeticone + C & $\mathrm{MODM}+\mathrm{C}$ \\
\hline & Com ingrediente $A$ & Leave-on + A & MOLo+A \\
\hline & Com ingrediente $B$ & Leave-on + B & MOLO+B \\
\hline & Com ingrediente $\mathrm{C}$ & Leave-on + C & MOLo+C \\
\hline \multirow{8}{*}{$\begin{array}{l}\text { Brasileiro } \\
\text { (B) }\end{array}$} & Controle & $s / f$ e $s / d$ & MBCont \\
\hline & Controle 1 & Desc. s/f & MBCont1 \\
\hline & Com ingrediente $A$ & Desc. + Dimeticone + A & $M B D M+A$ \\
\hline & Com ingrediente $B$ & Desc. + Dimeticone + B & $\mathrm{MBDM}+\mathrm{B}$ \\
\hline & Com ingrediente $\mathrm{C}$ & Desc. + Dimeticone + C & $\mathrm{MBDM}+\mathrm{C}$ \\
\hline & Com ingrediente $A$ & Desc. +Leave-on + A & MBLo+A \\
\hline & Com ingrediente $B$ & Desc. + Leave-on + B & MBLo+B \\
\hline & Com ingrediente $\mathrm{C}$ & Desc. + Leave-on + C & MBLo+C \\
\hline
\end{tabular}

${ }^{*} \mathrm{M}=$ Mecha; $\mathrm{C}=$ Caucasiana; $\mathrm{O}=$ Oriental; Cont = Controle; $\mathrm{B}=$ Brasileira; Desc = Descolorida; $\mathrm{DM}=$ Dimeticone; Lo= leave-on; $\mathrm{A}, \mathrm{B}$ e $\mathrm{C}=$ ingredientes cosméticos; $\mathrm{s} / \mathrm{f}=$ sem formulação; s/d = sem descoloração. 


\subsubsection{Termogravimetria/Termogravimetria derivada}

As amostras de cabelo caucasiano e oriental foram submetidas a dois ciclos de lavagem e aplicação das formulações (sem emprego da piastra) e em seguida conduzidas para os ensaios de termogravimetria.

As curvas TG/DTG das Figuras 6.20 a 6.23 ilustram o comportamento térmico de amostras de cabelo caucasiano e oriental, respectivamente, tratadas com as formulações contendo os ingredientes cosméticos estudados e estão apresentados na Tabela 6.19.

De acordo com as curvas TG, pode-se verificar que as amostras apresentaram três eventos principais de perda de massa, conforme discutido no item 6.1.1.: desidratação, decomposição térmica da queratina capilar e eliminação do material carbonáceo formado anteriormente. Como as $\mathrm{T}_{\text {pico DTG }}$ da etapa de decomposição térmica da queratina (segundo evento de perda de massa) de amostras de cabelo são superiores às temperaturas de desnaturação térmica da queratina obtidas por DSC (vide item 6.1.2.), escolheu-se as temperaturas de início da decomposição térmica (temperatura em que $\mathrm{dm} / \mathrm{dT}$ deixou de ser zero, a qual denominamos de $\mathrm{T}_{\mathrm{DTG}}$ ) como parâmetro comparativo da estabilidade térmica das amostras de cabelo.

As mechas de cabelo caucasiano contendo as formulações F2A, F2B e F2C (dimeticone contendo ingredientes $A, B$ e $C$, respectivamente) não apresentaram mudanças significativas em suas $T_{D T G}$ (eventos 2 - Tabela 6.19). Porém, para este grupo, observou-se que as mechas MCDM+B apresentaram um aumento de cerca de $8^{\circ} \mathrm{C}$ (de $190^{\circ} \mathrm{C}$ - temperatura apresentada pela MCCont1para $198^{\circ} \mathrm{C}$ ) na $\mathrm{T}_{\mathrm{DTG}}$. $\mathrm{O}$ restante das mechas não apresentou resultados significativos de mudanças.

As $\mathrm{T}_{\mathrm{DTG}}$ de decomposição térmica de amostras das mechas de cabelo oriental contendo as formulações F3A, F3B e F3C (condicionador leave-on contendo ingrediente $A, B$ e $C$, respectivamente) apresentaram um aumento significativo em relação a mecha controle, ou seja, 28,27 e $19^{\circ} \mathrm{C}$, respectivamente.

As $\mathrm{T}_{\mathrm{DTG}}$ das amostras de mechas de cabelo oriental contendo as formulações F2A, F2B e F2C também aumentaram em 12, 9 e $11{ }^{\circ} \mathrm{C}$, respectivamente. Porém, esse o aumento foi menor do que aquele observado para mechas tratadas pelas formulações F3A, F3B e F3C. 
Comparando os resultados obtidos pelos tratamentos nas mechas orientais com aqueles obtidos nas mechas caucasianas, observa-se que o veículo leave-on (quando incorporado aos ingredientes - F3A, F3B e F3C) apresentou uma melhora na estabilidade térmica das amostras de cabelo em relação ao dimeticone contendo os ingredientes (F2A, F2B e F2C).

Para a avaliação de eficiência em proteção de formulações cosméticas em amostras de cabelo optou-se por utilizar ensaios por medidas de DSC, pois esta técnica é a mais indicada para este tipo de avaliação, o qual será discutido mais adiante.

Tabela 6.19 Resultados de TG/DTG de amostras das mechas de cabelo caucasiano e oriental submetidas às formulações contendo os ingredientes cosméticos.

\begin{tabular}{|c|c|c|c|c|c|c|c|}
\hline \multirow{2}{*}{ Tratamento } & \multirow{2}{*}{ Evento } & \multicolumn{2}{|c|}{$\begin{array}{c}\text { Faixa de temperatura } \\
I^{\circ} \mathrm{C} \\
\end{array}$} & \multicolumn{2}{|c|}{$\begin{array}{l}\mathrm{T}_{\text {pico DTG }} \\
I^{\circ} \mathrm{C}\end{array}$} & \multicolumn{2}{|c|}{$\begin{array}{c}\text { Massa } \\
1 \%\end{array}$} \\
\hline & & Caucasiano & Oriental & Caucasiano & Oriental & Caucasiano & Oriental \\
\hline \multirow{3}{*}{ Cont1 (s/t) } & 1 & $25-190$ & $25-186$ & 74 & 61 & 9,4 & 13,0 \\
\hline & 2 & $190-450$ & $186-448$ & 299 & 296 & 44,0 & 41,0 \\
\hline & 3 & $450-690$ & $448-688$ & 576 & 568 & 44,0 & 44,0 \\
\hline \multirow{3}{*}{$\mathrm{F} 2 \mathrm{~A}$} & 1 & $25-188$ & $25-198$ & 77 & 66 & 8,8 & 9,0 \\
\hline & 2 & $188-500$ & $198-461$ & 299 & 308 & 49,0 & 44,0 \\
\hline & 3 & $500-750$ & $461-748$ & 609 & 583 & 38,0 & 43,0 \\
\hline \multirow{3}{*}{$\mathrm{F} 2 \mathrm{~B}$} & 1 & $25-189$ & $25-195$ & 70 & 74 & 9,2 & 9,0 \\
\hline & 2 & $189-458$ & $195-462$ & 296 & 303 & 44,5 & 44,0 \\
\hline & 3 & $458-750$ & $462-725$ & 584 & 589 & 39,5 & 42,0 \\
\hline \multirow{3}{*}{ F2C } & 1 & $25-190$ & $25-197$ & 64 & 59 & 11,0 & 10,0 \\
\hline & 2 & $190-480$ & $197-460$ & 306 & 303 & 45,0 & 42,0 \\
\hline & 3 & $480-740$ & $460-733$ & 604 & 592 & 39,0 & 41,0 \\
\hline \multirow{3}{*}{ F3A } & 1 & $25-188$ & $25-214$ & 66 & 60 & 10,0 & 11,0 \\
\hline & 2 & $188-450$ & $214-457$ & 300 & 301 & 44,5 & 43,0 \\
\hline & 3 & $450-700$ & $457-717$ & 582 & 571 & 43,0 & 44,0 \\
\hline \multirow{3}{*}{ F3B } & 1 & $25-198$ & $25-213$ & 78 & 64 & 8,7 & 13,0 \\
\hline & 2 & $198-450$ & $213-457$ & 300 & 302 & 46,8 & 43,0 \\
\hline & 3 & $450-700$ & $457-722$ & 603 & 631 & 42,8 & 44,0 \\
\hline \multirow{3}{*}{ F3C } & 1 & $25-183$ & $25-205$ & 78 & 71 & 10,0 & 11,0 \\
\hline & 2 & $183-455$ & $205-453$ & 309 & 305 & 44,0 & 43,0 \\
\hline & 3 & $455-700$ & $453-705$ & 616 & 568 & 43,0 & 44,0 \\
\hline
\end{tabular}

s/t = sem tratamento; Cont1 = controle (mecha virgem); A, B e C = ingredientes cosméticos. 


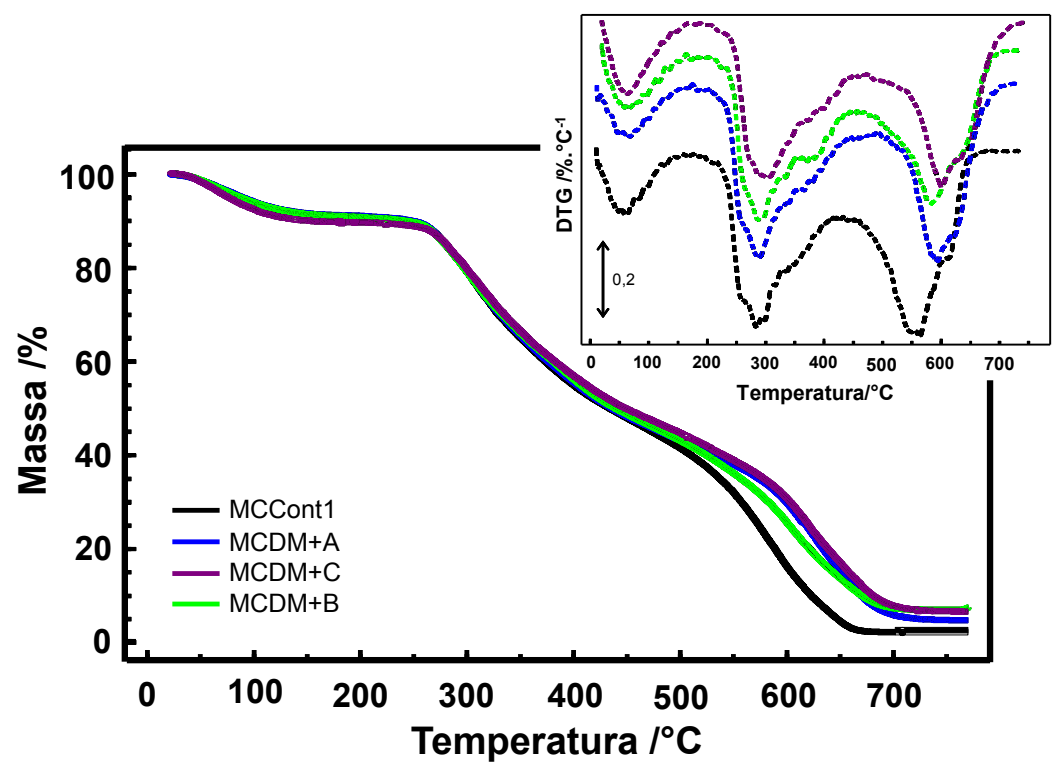

Figura 6.20 Curvas TG e DTG obtidas a $10^{\circ} \mathrm{C} \mathrm{min}^{-1}$, sob atmosfera dinâmica de ar e empregando cápsula de Pt contendo cerca de $15 \mathrm{mg}$ de amostras das mechas controle de cabelo caucasiano e tratadas com as formulações cosméticas (F2A, F2B e F2C).

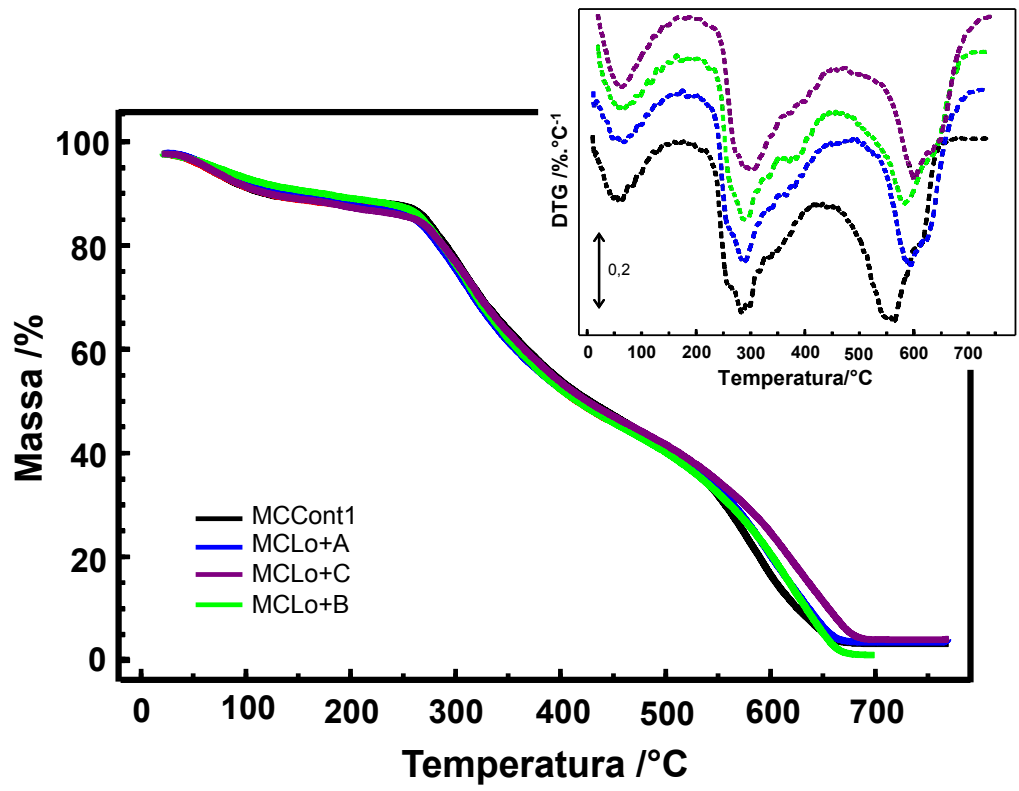

Figura 6.21 Curvas TG e DTG obtidas a $10^{\circ} \mathrm{C} \mathrm{min}^{-1}$, sob atmosfera dinâmica de ar e empregando cápsula de Pt contendo cerca de $15 \mathrm{mg}$ de amostras das mechas controle de cabelo caucasiano e tratadas com as formulações cosméticas (F3A, F3B e F3C). 


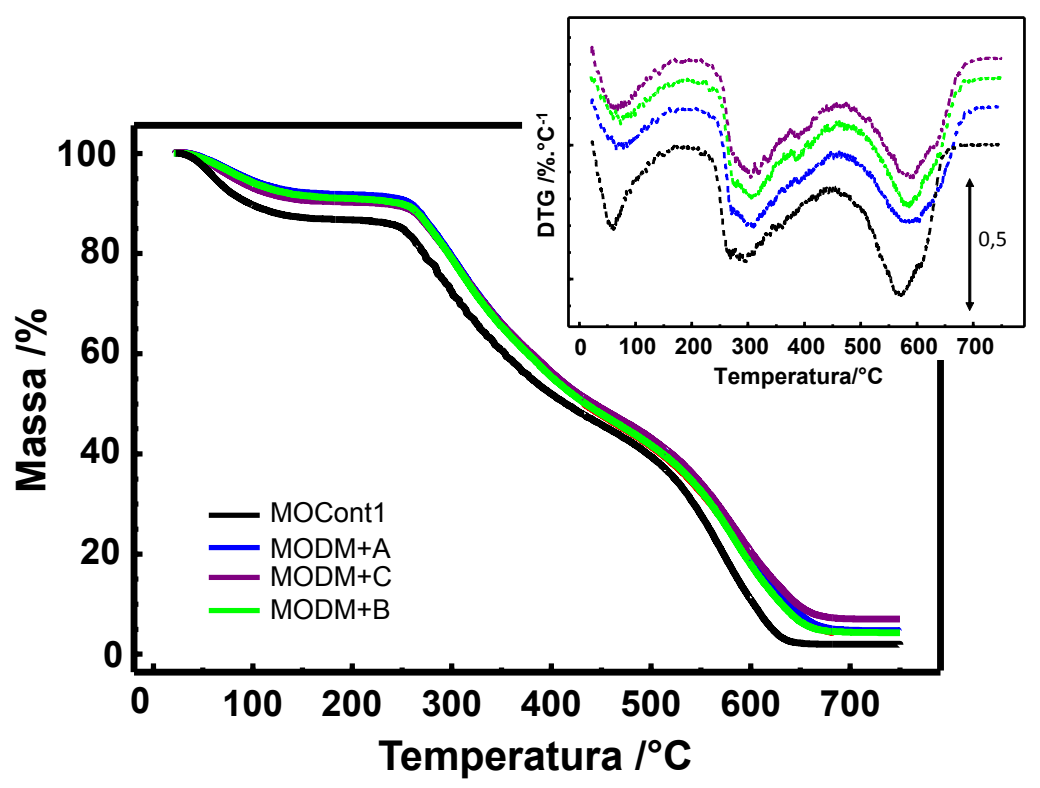

Figura 6.22 Curvas TG e DTG obtidas a $10^{\circ} \mathrm{C} \mathrm{min}^{-1}$, sob atmosfera dinâmica de ar e empregando cápsula de Pt contendo cerca de $15 \mathrm{mg}$ de amostras das mechas controle de cabelo oriental $e$ tratadas com as formulações cosméticas (F2A, F2B e F2C).

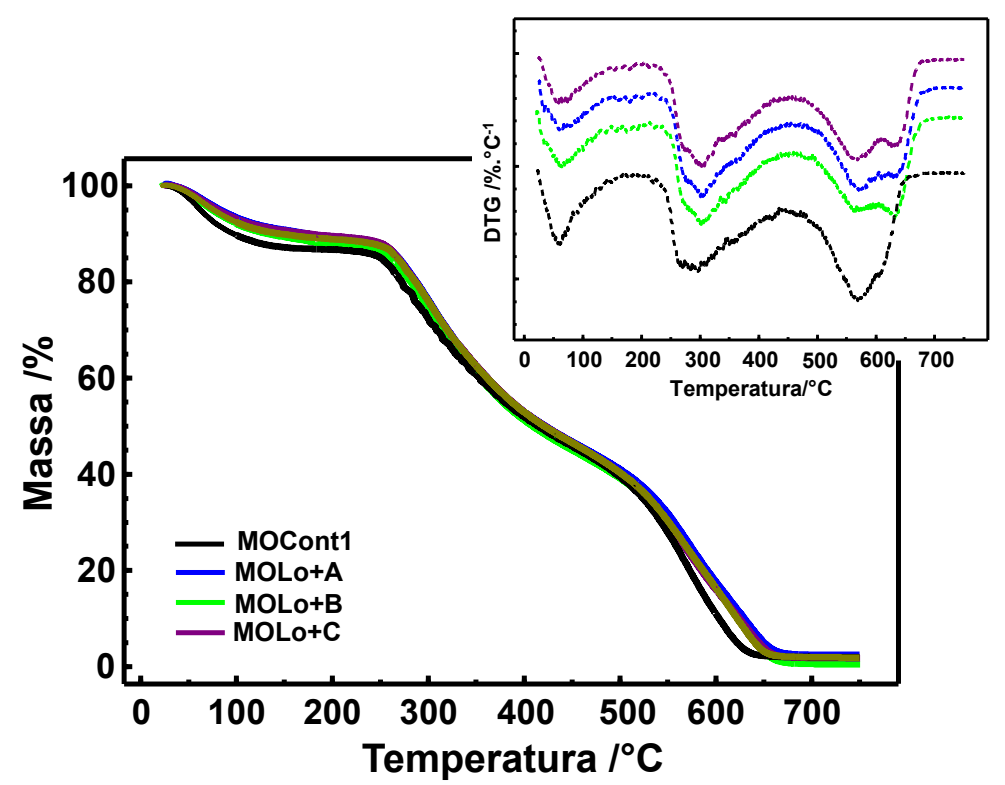

Figura 6.23 Curvas TG e DTG obtidas a $10^{\circ} \mathrm{C} \mathrm{min}^{-1}$, sob atmosfera dinâmica de ar e empregando cápsula de Pt contendo cerca de $15 \mathrm{mg}$ de amostras das mechas controle de cabelo oriental e tratadas com as formulações cosméticas (F3A, F3B e F3C). 


\subsubsection{Calorimetria exploratória diferencial (DSC)}

Para esse tipo de estudo, a DSC têm se mostrado uma técnica eficiente na avaliação dos efeitos dos tratamentos térmicos de amostras de cabelos. Permite a obtenção de dois parâmetros relacionados à transição térmica de proteínas: a) temperatura de desnaturação ou a temperatura de pico, que nesse trabalho representamos por $T_{D}$ (temperatura de desnaturação da queratina helicoidal do cabelo) e a entalpia de desnaturação ou a área do pico, representada por $\Delta H_{D}$ (ZHOU et al., 2011). Trata-se também de uma técnica eficaz para a avaliação do comportamento térmico de água presente no cabelo, visto que permite a determinação da energia de ligação de água na fibra capilar.

Com o objetivo de investigar os efeitos (ou não) da hidratação e proteção térmica das formulações estudadas, foram avaliadas as $T_{d}$, (temperatura de desidratação), $\Delta \mathrm{H}_{\mathrm{H}_{2} \mathrm{O}}$ (entalpia de desidratação), $\mathrm{T}_{\mathrm{D}}$ e $\Delta \mathrm{H}_{\mathrm{D}}$ referentes à etapa de fusão da fração cristalina da matriz das amostras de cabelo. As condições de ambiente escolhidas para a armazenagem das amostras de cabelo no estudo envolvendo a DSC foi, para todos os ensaios temperatura de $22 \pm 2{ }^{\circ} \mathrm{C}$ e U.R. de $20 \pm 2 \%$.

Como discutido nos resultados do item 6.1.2. a curva DSC evidenciou que as amostras de cabelo se decompõem em torno de $250^{\circ} \mathrm{C}$. Por este motivo, os experimentos de DSC foram realizados até $300^{\circ} \mathrm{C}$.

No caso de cabelo humano, há dois componentes dominantes, filamentos intermediários (IF) e as proteínas associadas aos filamentos intermediários (IFAPs). Esses componentes, em grande parte, determinam as propriedades mecânicas do cabelo, que, de acordo com sua estrutura molecular, são importante para o desempenho e efeitos de tratamentos cosméticos a serem estudados (WORTMANN et al. 1997). Os IF correspondem à fase filamentosa cristalina embebida em uma matriz que compreende também o restante dos componentes morfológicos, como as IFAPs (componente principal), mas também incluindo a cutícula, complexo de membrana de células, restos nucleares e outros. Os IF possuem uma estrutura em a-hélice e a organização desses filamentos, as ligações a outros filamentos e a sua função de sustentação 
dependem das IFAPs (ZAHN et al., 1996). A $\triangle \mathrm{H}_{\mathrm{D}}$ depende da quantidade e da integridade estrutural do material helicoidal dos IF enquanto a temperatura de decomposição é cineticamente controlada pela densidade de reticulação da matriz (IFAPs) em que os IFs são incorporados no córtex do cabelo humano. Quanto mais elevada for a densidade de ligações cruzadas nas IFAPs, maior será sua viscosidade e mais prejudicada será a transição hélice/folha nas IFs e viceversa (WORTMANN et al. 1993; WORTMANN et al. 1998; WORTMANN et al. 2002).

As Figuras 6.24 a 6.29 ilustram a sobreposição das curvas DSC das amostras de cabelo caucasiano, oriental e brasileiro antes e após tratamento com as formulações sem aplicação da piastra. Observou-se a presença dos eventos térmicos característicos de amostras de cabelo conforme descrito no item 6.1.2.: (1) endotérmico e relacionado a desidratação do material; eventos (2) e (3) endotérmicos relacionado a fusão da fase cristalina da queratina do cabelo com decomposição das células dos para-córtex e orto-córtex, respectivamente.

Segundo Istrate (2011), quatro parâmetros principais em DSC são importantes para analisar amostras de cabelo: -a temperatura e entalpia de remoção de água ( $\mathrm{T}_{\mathrm{d}}$ e $\Delta \mathrm{H}_{2} \mathrm{O}$ ), consideradas como sinal da extensão da absorção de água na fase de matriz amorfa; -a temperatura e a entalpia de desnaturação da a-hélice da queratina $\left(T_{D}\right.$ e $\left.\Delta H_{D}\right)$, que indicam as alterações químicas que ocorrem na fase cristalina da fibra.

Os resultados extraídos das curvas DSC das Figuras 6.24-29 estão compilados na Tabela 6.20. Em relação ao evento de desidratação, é possível observar que as $T_{d}$ não apresentaram diferenças significativas em seus valores. Comparando os valores de $\Delta \mathrm{H}_{2} \mathrm{O}$ de todas as amostras de cabelo, observou-se que o veículo não influenciou na retenção de água na matriz. Os valores de $\Delta \mathrm{H}_{2} \mathrm{O}$ das amostras de cabelo brasileiro descolorido apresentaram valores superiores aos apresentados pelas mechas de cabelo caucasiano e oriental. Este resultado era esperado, uma vez que vários estudos da literatura descrevem este fenômeno como consequência da maior porosidade quando os fios são descoloridos. Por exemplo, Guthrie et al. (1995) avaliaram amostras de cabelo virgem e descolorido por DSC e identificaram uma maior tendência deste último em absorver água do 
que o cabelo não tingido, com uma significante tendência em se ligar a água absorvida mais firmemente.

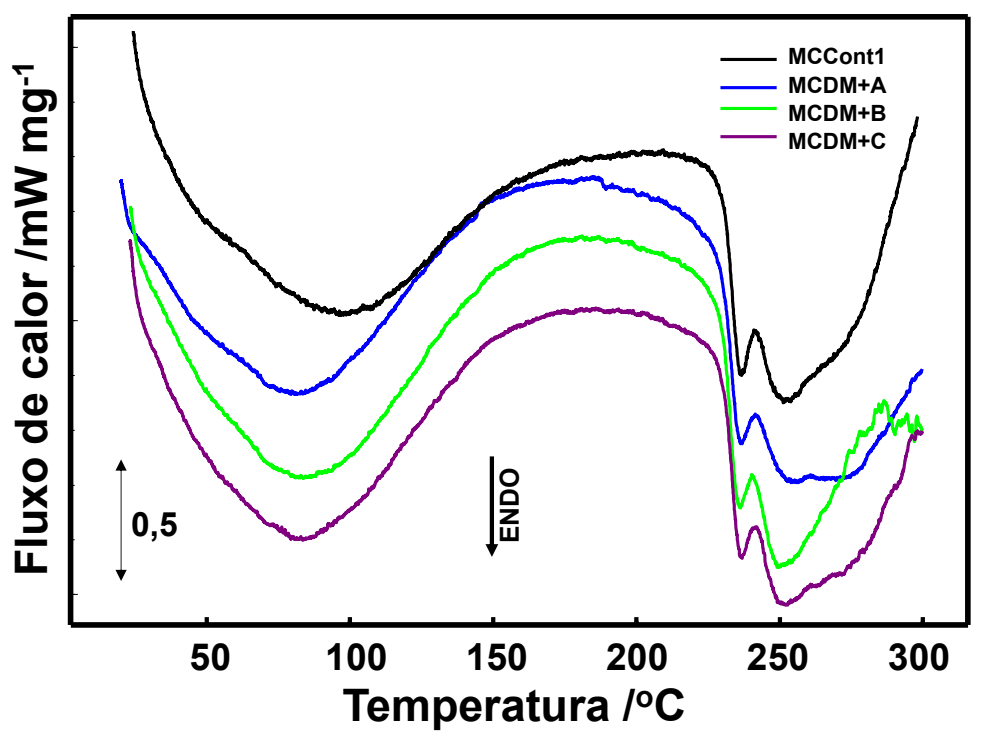

Figura 6.24 Curvas DSC obtidas a $10^{\circ} \mathrm{C} \mathrm{min}^{-1}$, atmosfera dinâmica de $\mathrm{N}_{2}$ e empregando cápsula de Al parcialmente fechada contendo cerca de $2 \mathrm{mg}$ de amostra das mechas controle de cabelo virgem padrão caucasiano e tratadas com as formulações F2A, F2B e F2C antes do tratamento térmico.

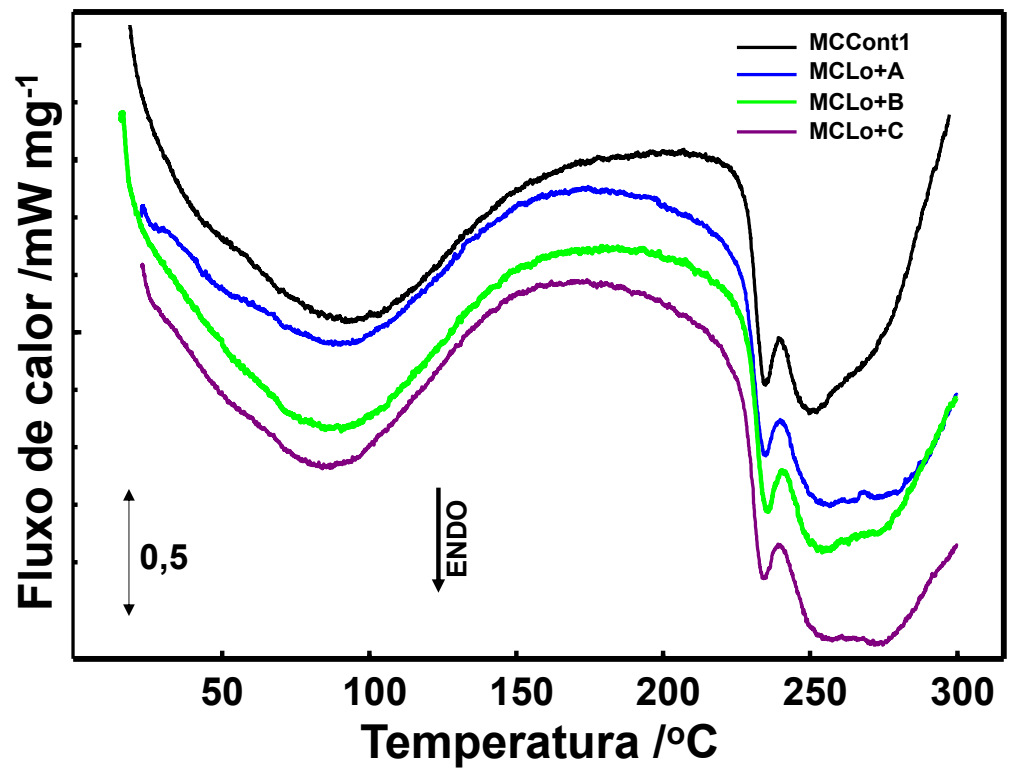

Figura 6.25 Curvas DSC obtidas a $10^{\circ} \mathrm{C} \mathrm{min}^{-1}$, atmosfera dinâmica de $\mathrm{N}_{2} \mathrm{e}$ empregando cápsula de Al parcialmente fechada contendo cerca de $2 \mathrm{mg}$ de amostras das mechas de cabelo virgem padrão caucasiano e tratadas com as formulações F3A, F3B e F3C sem tratamento térmico. 


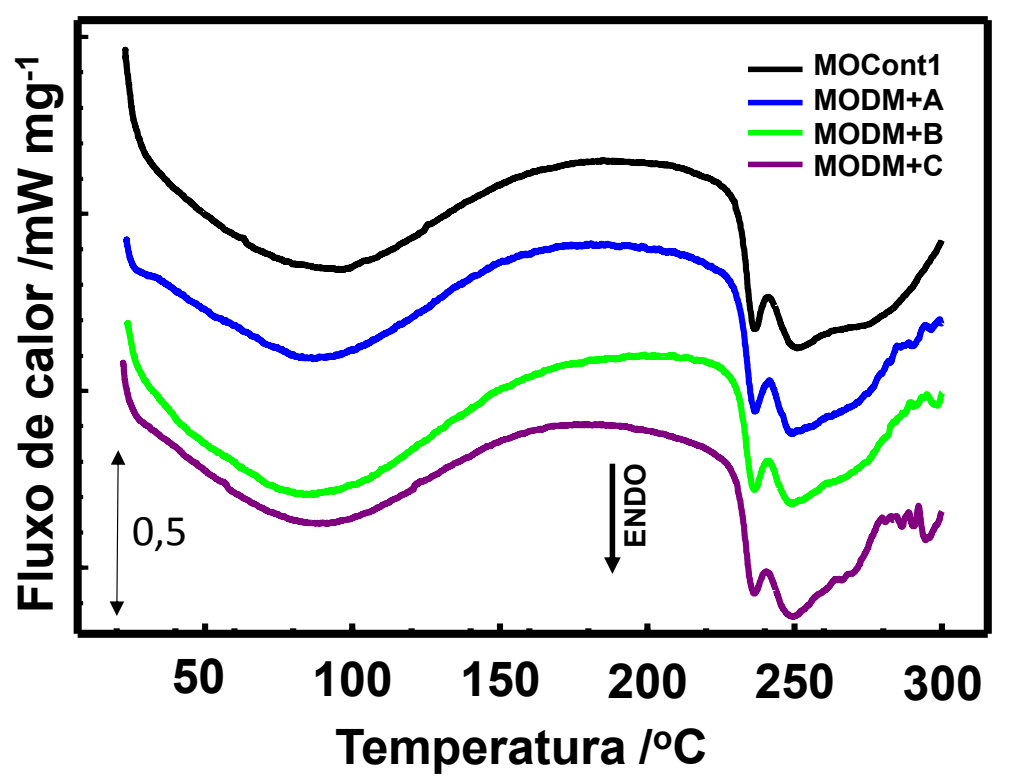

Figura 6.26 Curvas DSC obtidas a $10^{\circ} \mathrm{C} \mathrm{min}^{-1}$, atmosfera dinâmica de $\mathrm{N}_{2}$ e empregando cápsula de Al parcialmente fechada contendo cerca de $2 \mathrm{mg}$ de amostras das mechas de cabelo virgem oriental e tratadas com as formulações F2A, F2B e F2C sem tratamento térmico.

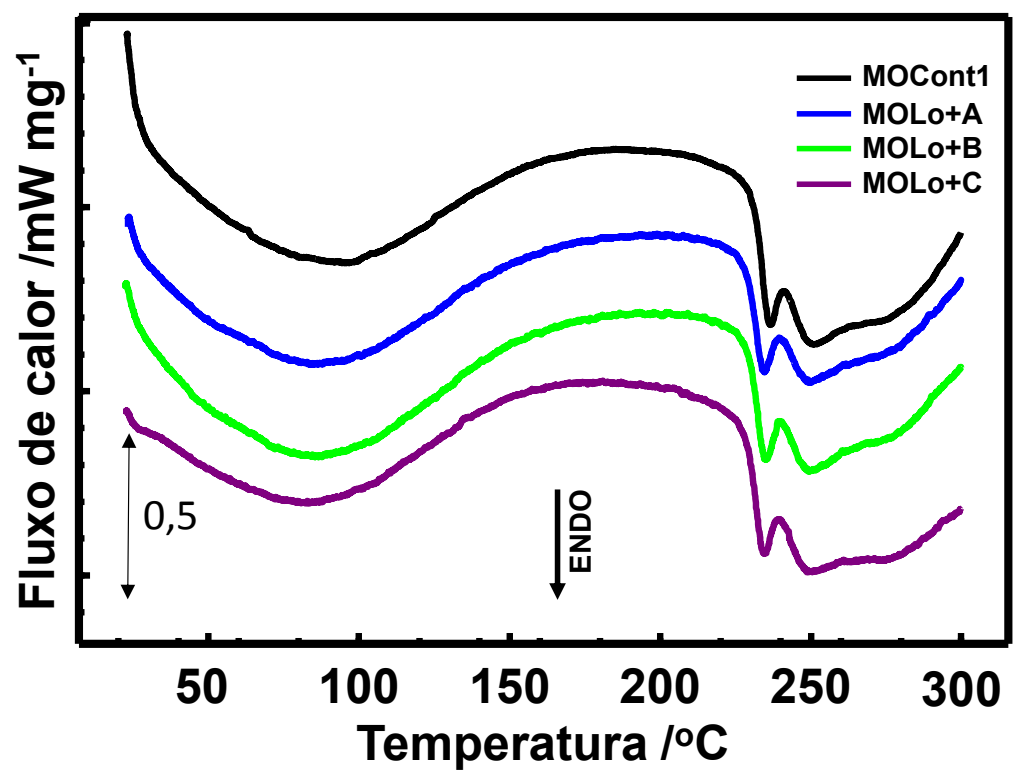

Figura 6.27 Curvas DSC obtidas a $10^{\circ} \mathrm{C} \mathrm{min}^{-1}$, atmosfera dinâmica de $\mathrm{N}_{2} \mathrm{e}$ empregando cápsula de Al parcialmente fechada contendo cerca de $2 \mathrm{mg}$ de amostras das mechas de cabelo virgem padrão oriental e tratadas com as formulações F3A, F3B e F3C sem tratamento térmico. 


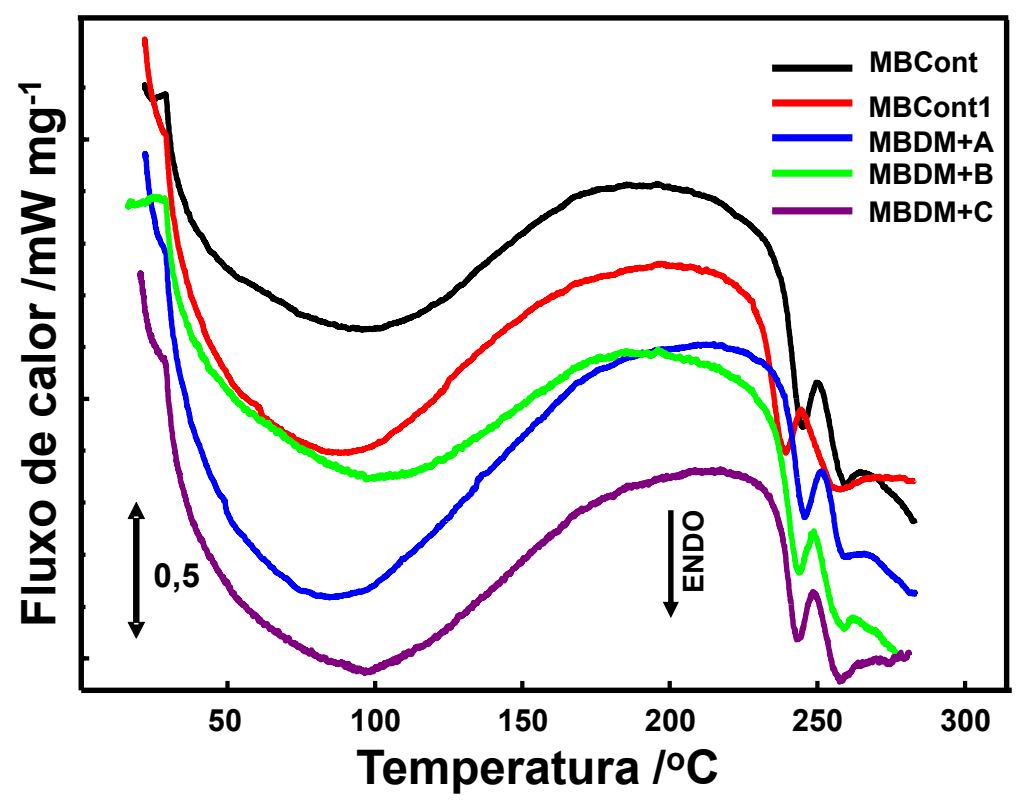

Figura 6.28 Curvas DSC obtidas a $10^{\circ} \mathrm{C} \mathrm{min}^{-1}$, atmosfera dinâmica de $\mathrm{N}_{2}$ e empregando cápsula de Al parcialmente fechada contendo cerca de $2 \mathrm{mg}$ de amostras das mechas de cabelo brasileiro virgem e descoloridas tratadas com as formulações F2A, F2B e F2C sem tratamento térmico.

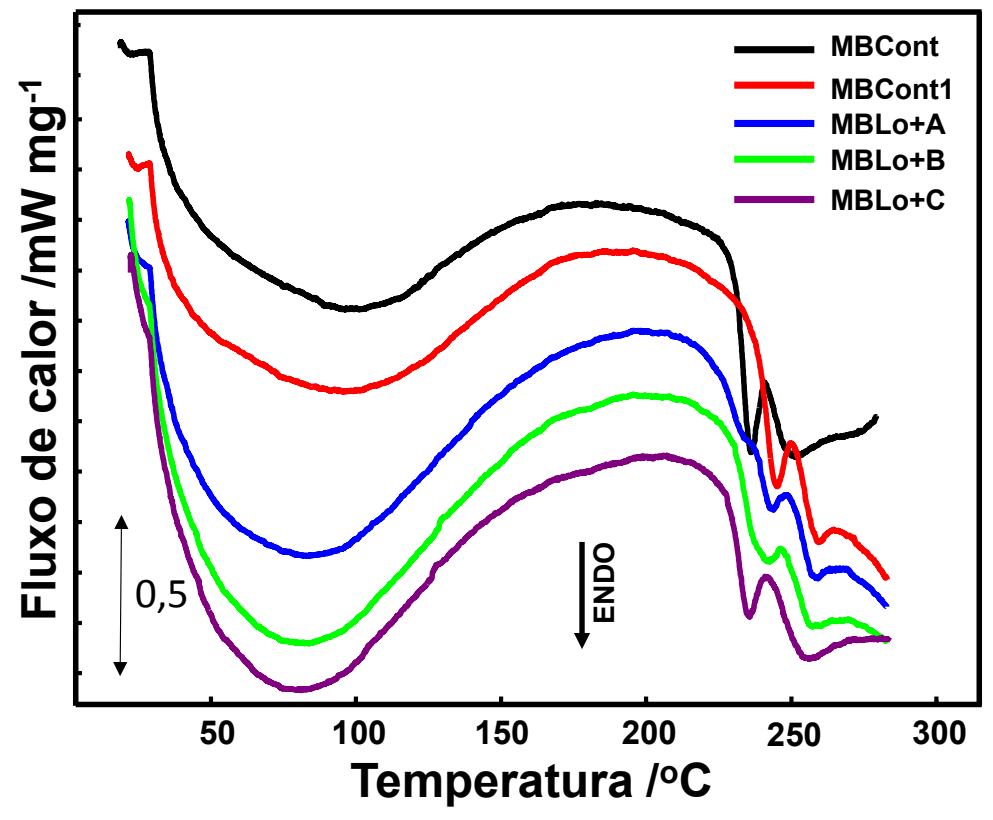

Figura 6.29 Curvas DSC obtidas a $10^{\circ} \mathrm{C} \min ^{-1}$, atmosfera dinâmica de $\mathrm{N}_{2} \mathrm{e}$ empregando cápsula de Al parcialmente fechada contendo cerca de $2 \mathrm{mg}$ de amostras das mechas de cabelo brasileiro virgem e descoloridas tratadas com as formulações F3A, F3B e F3C sem tratamento térmico. 
Tabela 6.20 Resultados de DSC (evento da desidratação) de amostras das mechas de cabelo caucasiano, oriental e brasileiro submetidas às formulações contendo os ingredientes cosméticos e estocadas em ambiente controlado $22 \pm 2{ }^{\circ} \mathrm{C} ; 20 \pm 2 \%$.

\begin{tabular}{ccccccc}
\hline \hline \multirow{2}{*}{ Tratamento } & \multicolumn{3}{c}{$\mathrm{T}_{\mathrm{d}} l^{\circ} \mathrm{C}$} & & \multicolumn{4}{c}{$\Delta \mathrm{H}_{\mathrm{H}_{2}} \mathrm{O} / \mathrm{J} \mathrm{g}^{-1}$} \\
\cline { 2 - 7 } & Caucasiano & Oriental & Brasileiro & Caucasiano & Oriental & Brasileiro \\
\hline \hline Cont (s/t) & - & - & 96 & - & - & 203 \\
Cont1 (s/t) & 95 & 97 & 96 & 178 & 174 & 234 \\
F2A & 81 & 87 & 85 & 141 & 122 & 345 \\
F2B & 84 & 84 & 97 & 175 & 192 & 216 \\
F2C & 83 & 87 & 97 & 186 & 147 & 290 \\
F3A & 88 & 86 & 83 & 98 & 161 & 275 \\
F3B & 90 & 88 & 83 & 157 & 197 & 307 \\
F3C & 84 & 84 & 81 & 112 & 118 & 299 \\
\hline \hline
\end{tabular}

$\mathrm{s} / \mathrm{t}=$ sem tratamento; Cont = controle (virgem, apenas para mecha de cabelo brasileiro); Cont1 = controle (virgem para amostras de cabelo caucasiano e oriental; descolorida para cabelo brasileiro); A B e C = ingredientes cosméticos.

Colenci (2007) também reportou um aumento na $\Delta \mathrm{H}_{\mathrm{H}_{2} \mathrm{O}}$ de amostras de cabelo caucasiano descolorido em relação a sua amostra controle (virgem), estudando o efeito de uma formulação cosmética por DSC.

Belletti et al. (2003) avaliaram a eficiência de hidratação de dois diferentes condicionadores rinse-off em amostras de cabelo virgem e descoloridos por DSC. Estas amostras apresentaram valores mais elevados de $\Delta \mathrm{H}_{2} \mathrm{O}$ quando comparadas as mechas virgens tratadas com formulações (de $164 \mathrm{~J} \mathrm{~g}^{-1}$ na mecha controle para $192 \mathrm{~J} \mathrm{~g}^{-1}$ e $231 \mathrm{~J} \mathrm{~g}^{-1}$ nas mechas de cabelo tratadas com os produtos). Os autores sugerem duas hipóteses para explicar este resultado; a primeira é que estes tratamentos aumentaram o teor de água nas fibras, ou seja, quanto maior a quantidade de água ligada às fibras, maior a energia necessária para liberação, e a segunda é que os tratamentos impediram a liberação das moléculas de água. Essa interferência pode ser devido à formação de uma barreira (filme) e/ou à presença de substâncias hidrófilas pois hidratantes capilares podem aumentar a quantidade de água na fibra do cabelo e/ou formar uma barreira que impede a dessorção de água.

Outro estudo que envolveu semelhantes resultados foi o de Benaiges et al. 
(2012) que avaliaram as etapas de desidratação e fusão da fase cristalina de amostras de cabelo submetidos ao clareamento, por DSC. Os autores observaram que estas demonstraram se tornar quimicamente e mecanicamente danificadas aumentando a permeabilidade da fibra e diminuindo a $\Delta \mathrm{H}_{\mathrm{D}}$. Os resultados indicaram também que as amostras de cabelo clareado sofreram um aumento na $\Delta \mathrm{H}_{2} \mathrm{O}$. Os autores atribuíram estes resultados a uma mudança na superfície da fibra, devido ao tratamento químico, que pode resultar em uma fibra mais porosa com um aumento da sua hidrofilicidade, devido ao processo de oxidação.

Os resultados da Tabela 6.21 evidenciaram que houve variação nas $T_{D} \mathrm{e}$ nos valores de $\Delta \mathrm{H}_{\mathrm{D}}$ de amostras de cabelo caucasiano, oriental e brasileiro. $\mathrm{A}$ maior variação na $T_{D}$ foi obtida entre a mechas de cabelo brasileiro controle (virgem) e descolorida (de 236 para $245^{\circ} \mathrm{C}$ ). A variação de $T_{\mathrm{D}}$ tem sido muito discutida e interpretada de formas diferentes na literatura. $O$ aumento ou diminuição da $T_{D}$ da queratina cristalina depende de alguns fatores e entre eles o meio em que as medidas de DSC são realizadas (aquoso ou seco).

Tabela 6.21 Resultados de DSC (evento da fusão da fase cristalina da queratina) de amostras das mechas de cabelo caucasiano, oriental e brasileiro submetidas às formulações contendo os ingredientes cosméticos e estocadas em ambiente controlado de temperatura $22 \pm 2^{\circ} \mathrm{C}$ e $20 \pm 2 \%$ U.R.

\begin{tabular}{ccccccc}
\hline \hline \multirow{2}{*}{ Tratamento } & \multicolumn{3}{c}{$\mathrm{T}_{\mathrm{D}} /{ }^{\circ} \mathrm{C}$} & \multicolumn{3}{c}{$\Delta \mathrm{H}_{\mathrm{D}} / \mathrm{J} \mathrm{g}^{-1}$} \\
\cline { 2 - 7 } & Caucasiano & Oriental & Brasileiro & Caucasiano & Oriental & Brasileiro \\
\hline \hline Cont (s/t) & - & - & 236 & - & - & 6,9 \\
Cont1 (s/t) & 237 & 237 & 245 & 5,5 & 6,6 & 6,1 \\
F2A & 237 & 237 & 246 & 5,5 & 6,5 & 5,4 \\
F2B & 237 & 236 & 244 & 5,1 & 5,5 & 5,2 \\
F2C & 237 & 236 & 243 & 5,0 & 5,7 & 5,3 \\
F3A & 235 & 235 & 244 & 5,9 & 6,0 & 4,1 \\
F3B & 236 & 235 & 243 & 5,6 & 6,5 & 5,5 \\
F3C & 234 & 235 & 236 & 5,6 & 6,3 & 5,4 \\
\hline \hline
\end{tabular}

$\mathrm{s} / \mathrm{t}=$ sem tratamento; Cont = controle (virgem, apenas para mecha de cabelo brasileiro); Cont1 = controle (virgem para amostras de cabelo caucasiano e oriental; descolorida para cabelo brasileiro); $\mathrm{A}, \mathrm{B}$ e $\mathrm{C}=$ ingredientes cosméticos. 
Spei \& Holzem (1987) e Leory et al. (1992) mostraram que o pico de desnaturação pode ser detectado de forma adequada e também avaliada para fibras em meio seco (valor obtido em torno de $240^{\circ} \mathrm{C}$ ). Esse valore corrobora com os dados obtidos em nosso trabalho, conforme discutido no item 6.1.2, mesmo porque ambos foram realizados em meio seco. Monteiro et al. (2005) observaram que a temperatura de desnaturação aumentou após as fibras de cabelo caucasiano serem clareadas e cloradas. Os autores atribuíram este aumento ao fato de que estes dois processos promovem o aumento das interações iônicas, aumentando a estabilidade da estrutura da queratina e mudando a temperatura de desnaturação para valores mais elevados. O ambiente reativo pode ter aumentado a concentração de ácido cistéico, produzido pela oxidação da cistina e como consequência deslocando a temperatura de desnaturação para valores mais elevados. Em contrapartida, os valores de $\Delta H_{D}$ diminuíram com o aumento do tempo de imersão na solução oxidante. Ou seja, foi necessária mais energia para desorganizar a estrutura cristalina de queratina do cabelo não tratado do que para desorganizar o cabelo quimicamente tratado. Segundo Chandrashekara \& Ranganathaiah (2010), o aumento da $T_{D}$ é indicativo de alguma fragilização da fibra, possivelmente devido a configuração de novas forças moleculares compensando ou até mesmo anulando os efeitos das ligações dissulfeto quebradas. As novas ligações, que podem ser de hidrogênio ou de iônica, são sensíveis à umidade, mas ainda capazes de manter a estabilidade térmica da fibra, pelo menos sob as condições ambientes.

Leroy et al. (1992) investigaram o cabelo ondulado virgem, clareado e com permanente por DSC em meio seco. Para o cabelo virgem, observaram curvas DSC com picos duplos conforme observamos em nosso trabalho (e discutida no item 6.1.2.). Eles atribuíram estes resultados às frações de células corticais diferentes em termos de conteúdo de cisteína. Eles observaram que o clareamento das mechas de cabelo deslocou as $T_{D}$ para temperaturas mais elevadas e uma diminuição da área do pico de desnaturação e atribuíram este fato a uma perda de material cristalino. Porém, Wortmann et al. (2000) e Marsh et al. (2007) observaram o contrário nos valores de $T_{D}$ quando estudaram fibras capilares clareadas, porém estes resultados foram obtidos em meio aquoso. Eles reportaram que o clareamento levou ao aumento da concentração de ácido cistéico, e, portanto, ao aumento de interações iônicas. Pode presumir-se que, desta forma, serão eficazes na fibra em meio seco, mas serão quebradas em 
meio aquoso, conduzindo assim para as diferentes direções de deslocamento dos picos de desnaturação. No estado úmido, por outro lado, o aumento do teor de grupos aniônicos induz um aumento no conteúdo de água. Isto leva a uma diminuição contínua da viscosidade da matriz e, assim, de $\mathrm{T}_{\mathrm{D}}$. Alguns autores atribuem essa mudança a um efeito de plastificação ou de perda de densidade de reticulação da matriz (formação de uma rede tridimensional com ligações cruzadas). Quando a matriz de queratina é plastificada pela água, a desnaturação dos microfilamentos cristalinos da a-queratina ocorrem a temperaturas mais baixas (DUSSAUD et al., 2012).

Para as amostras de cabelo caucasiano, observou-se que as amostras quando tratadas com as formulações apresentaram a área do pico relacionado ao material cristalino diminuídas, com exceção da amostra das mechas MCLo+A. As amostras de cabelo oriental tiveram suas áreas diminuídas mais acentuadamente, chegando a diminuir cerca de $17 \%$ do valor da entalpia de fusão para a amostra de MOLo+B e MODM+C. Já as mechas de cabelo brasileiro descolorido tiveram todos os seus valores de entalpia de desnaturação diminuídos. Não se sabe ao certo o que pode ter provocado esses resultados, porém existe a hipótese de que a aplicação das formulações tenham alterado a permeabilidade das fibras, revestindo-as e aumentando ou diminuindo o material cristalino das mesmas (BENAIGES et al., 2013).

As Figuras 6.30 a 6.35 ilustram a sobreposição das curvas DSC das amostras de cabelo caucasiano, oriental e brasileiro após os ciclos de tratamento térmico e lavagens intercalando com aplicação das formulações (conforme procedimento do item 5.3.3). A Tabela 6.22 lista os valores de $T_{d}$ e $\Delta H_{H_{2}} \mathrm{O}$ extraídos dessas curvas DSC.

É possível observar que os valores de $T_{d}$ não apresentaram diferenças significativas entre si. Comparando os resultados obtidos para as mechas controle submetidas ao tratamento térmico com aqueles das mechas não submetidas ao tratamento térmico, observou-se que o aumento no valor de $\Delta \mathrm{H}_{2} \mathrm{O}$ para as mechas caucasainas foi maior do que em relação aos outros tipos de cabelo. Esta diferença pode estar associada ao fato de que a MCCont1 pode apresentar maior porosidade devido ao tratamento térmico submetido, e desta maneira, reter mais água. 


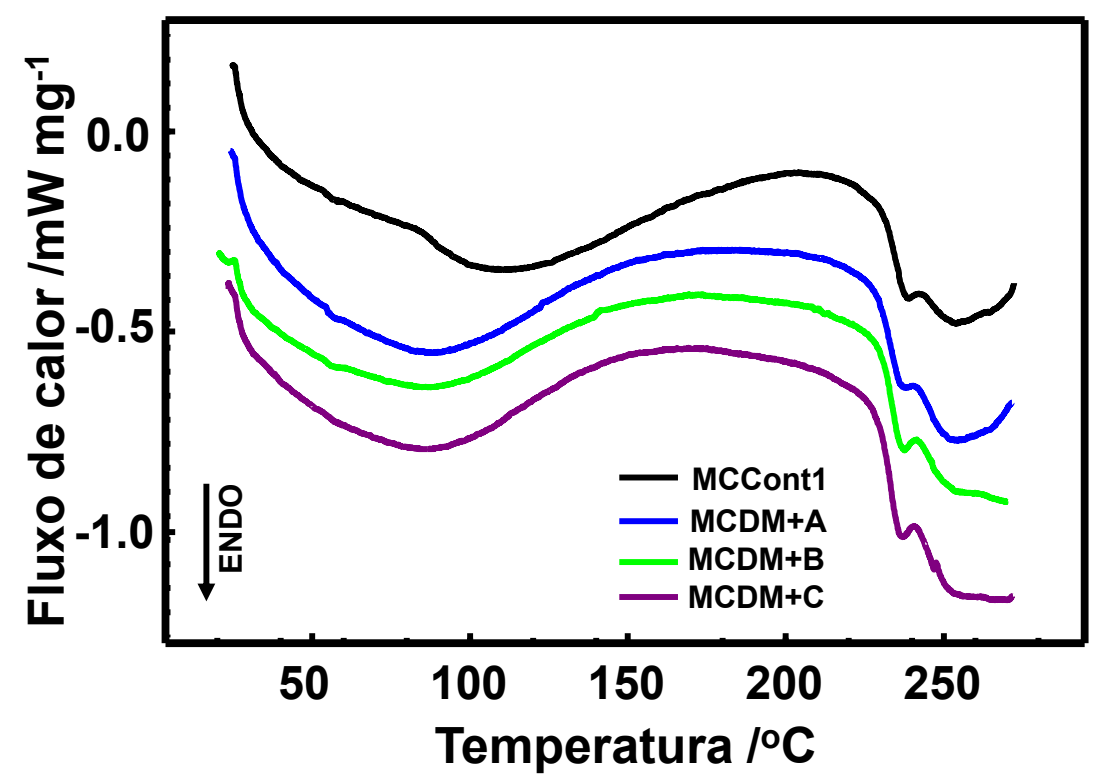

Figura 6.30 Curvas DSC obtidas a $10^{\circ} \mathrm{C} \mathrm{min}^{-1}$, sob atmosfera dinâmica de $\mathrm{N}_{2} \mathrm{e}$ empregando cápsula de Al parcialmente fechada contendo cerca de $2 \mathrm{mg}$ de amostras das mechas de cabelo virgem caucasiano e tratadas com as formulações $F 2 A, F 2 B$ e F2C após o tratamento térmico.

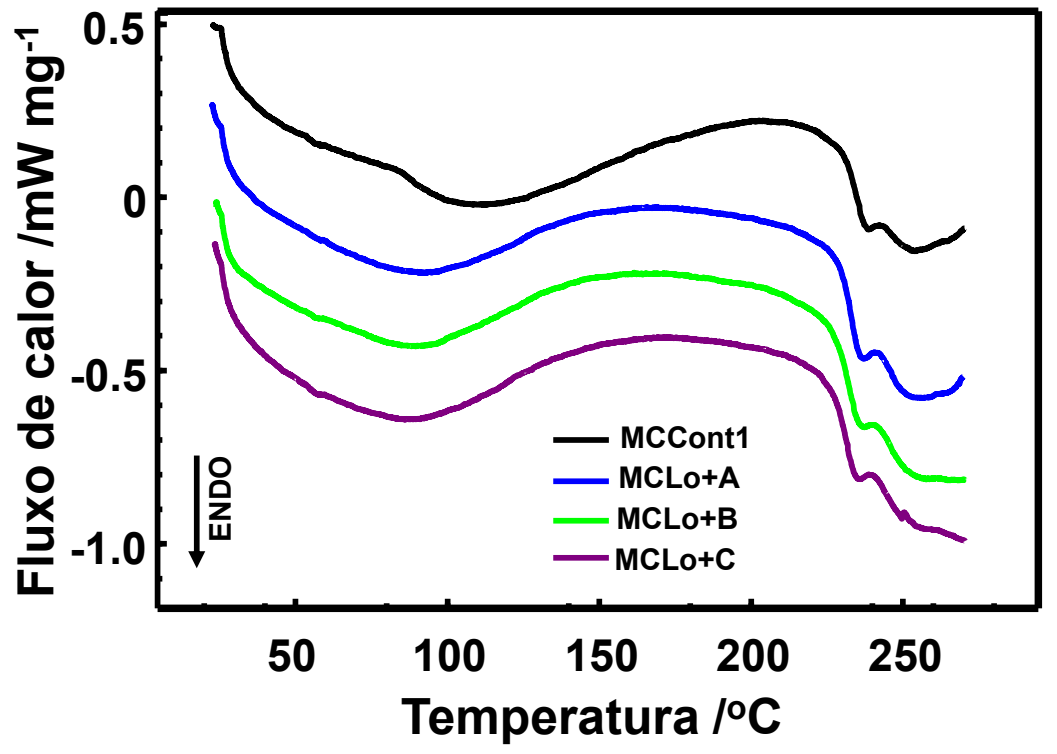

Figura 6.31 Curvas DSC obtidas a $10^{\circ} \mathrm{C} \mathrm{min}^{-1}$, sob atmosfera dinâmica de $\mathrm{N}_{2} \mathrm{e}$ empregando cápsula de Al parcialmente fechada contendo cerca de $2 \mathrm{mg}$ de amostras das mechas de cabelo virgem caucasiano e tratadas com as formulações F3A, F3B e F3C após o tratamento térmico. 


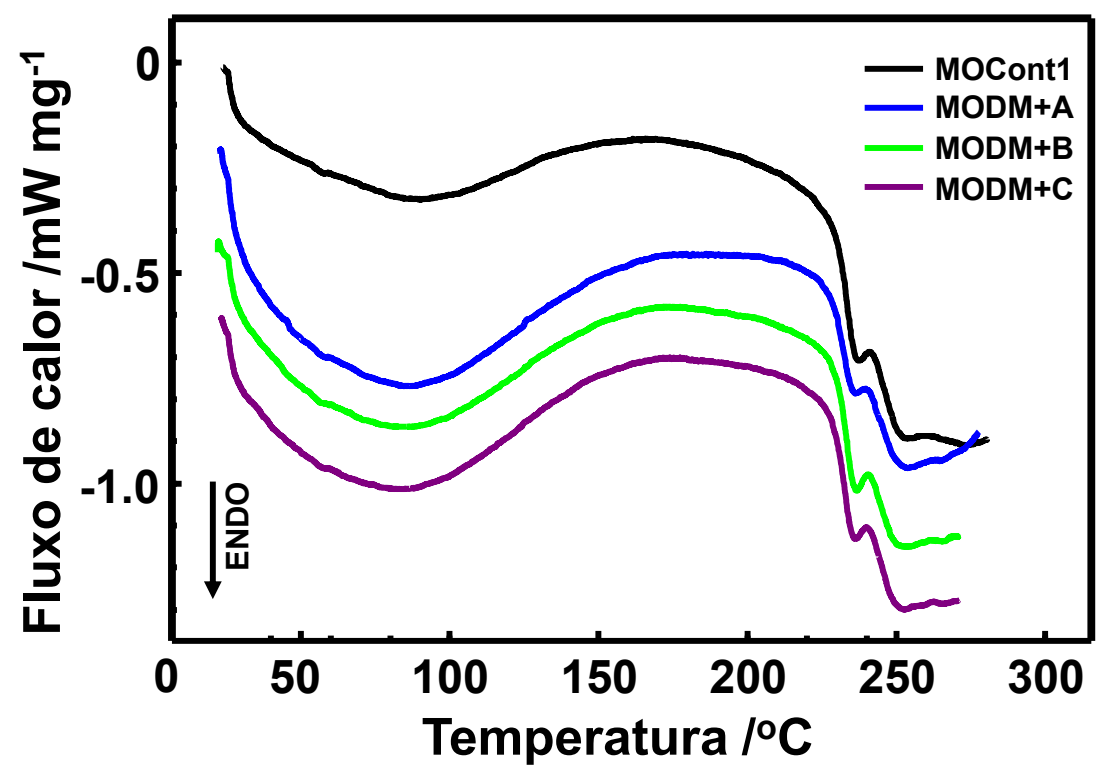

Figura 6.32 Curvas DSC obtidas a $10^{\circ} \mathrm{C} \mathrm{min}^{-1}$, sob atmosfera dinâmica de $\mathrm{N}_{2} \mathrm{e}$ empregando cápsula de Al parcialmente fechada contendo cerca de $2 \mathrm{mg}$ de amostras das mechas de cabelo virgem oriental e tratadas com as formulações F2A, F2B e F2C após o tratamento térmico.

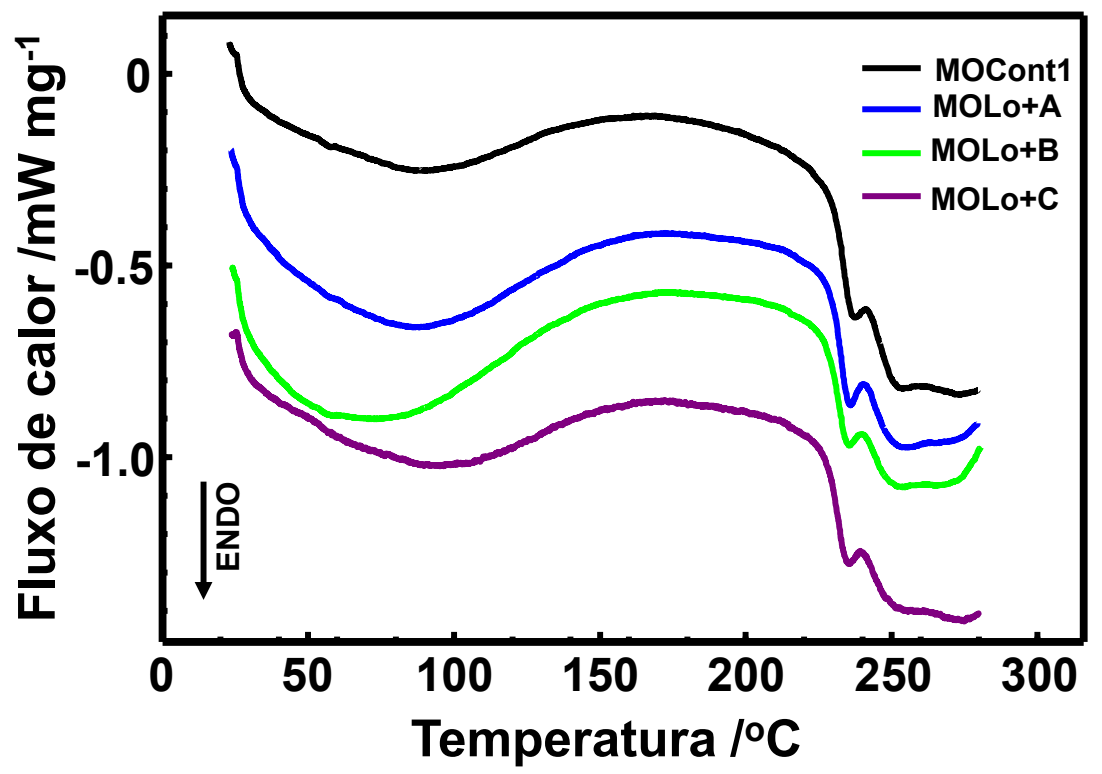

Figura 6.33 Curvas DSC obtidas a $10^{\circ} \mathrm{C} \mathrm{min}^{-1}$, sob atmosfera dinâmica de $\mathrm{N}_{2} \mathrm{e}$ empregando cápsula de Al parcialmente fechada contendo $2 \mathrm{mg}$ de amostras das mechas de cabelo virgem oriental e tratadas com as formulações F3A, F3B e F3C após o tratamento térmico. 


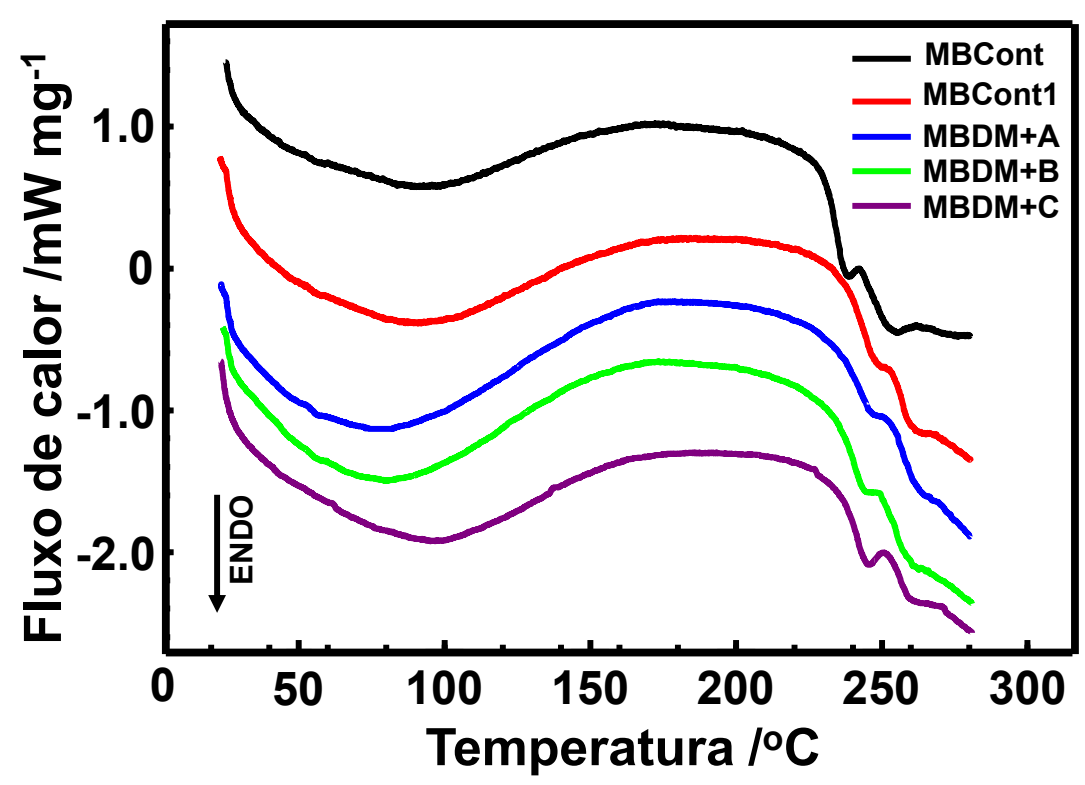

Figura 6.34 Curvas DSC obtidas a $10^{\circ} \mathrm{C} \mathrm{min}^{-1}$, sob atmosfera dinâmica de $\mathrm{N}_{2} \mathrm{e}$ empregando cápsula de Al parcialmente fechada contendo cerca de $2 \mathrm{mg}$ de amostras das mechas de cabelo brasileiro virgem e descoloridas tratadas com as formulações F2A, F2B e F2C após tratamento térmico.

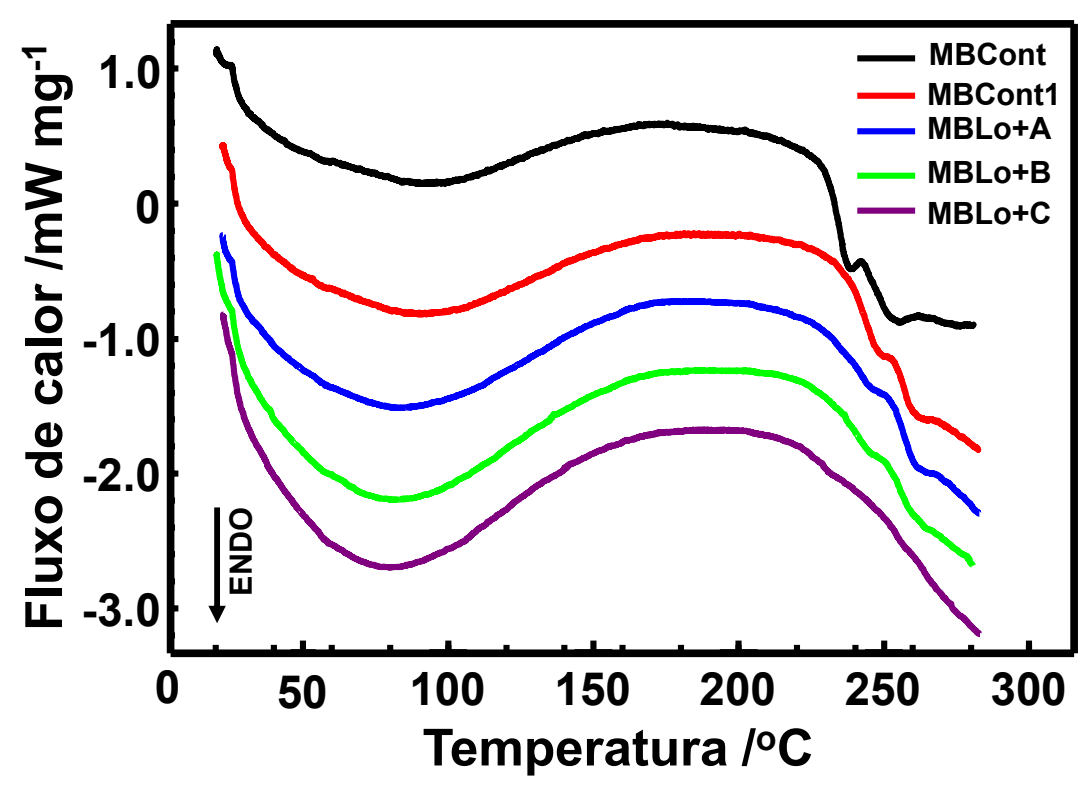

Figura 6.35 Curvas DSC obtidas a $10^{\circ} \mathrm{C} \mathrm{min}^{-1}$, sob atmosfera dinâmica de $\mathrm{N}_{2} \mathrm{e}$ empregando cápsula de Al parcialmente fechada contendo cerca de $2 \mathrm{mg}$ de amostras das mechas de cabelo brasileiro virgem e descoloridas tratadas com as formulações F3A, F3B e F3C após o tratamento térmico. 
Tabela 6.22 Resultados de $\mathrm{T}_{\mathrm{d}}$ e $\Delta \mathrm{H}_{2} \mathrm{O}$ de amostras das mechas de cabelo caucasiano, oriental e brasileiro tratadas com as formulações cosméticas, submetidas ao tratamento térmico (piastra/lavagem com LESS $10 \% \mathrm{~m} / \mathrm{m}$ ) e estocadas em ambiente controlado com temperatura $22 \pm 2^{\circ} \mathrm{C}$ e $20 \pm 2 \%$ U.R.

\begin{tabular}{ccccccc}
\hline \multirow{2}{*}{ Tratamento } & \multicolumn{5}{c}{ Etnia } \\
\cline { 2 - 7 } & \multicolumn{5}{c}{$\mathrm{T}_{\mathrm{d}} I^{\circ} \mathrm{C}$} & \multicolumn{5}{c}{$\Delta \mathrm{H}_{2} \mathrm{O} / \mathrm{J} \mathrm{g}^{-1}$} \\
\cline { 2 - 7 } Cont (s/aq) & Caucasiano & Oriental & Brasileiro & Caucasiano & Oriental & Brasileiro \\
\hline Cont (c/aq) & ---- & --- & 96 & ---- & ---- & 203 \\
Cont1 (s/aq) & 95 & ---- & 90 & ---- & ---- & 163 \\
Cont1 (c/aq) & 112 & 97 & 96 & 178 & 174 & 234 \\
F2A & 89 & 85 & 75 & 236 & 257 & 207 \\
F2B & 87 & 84 & 81 & 162 & 207 & 214 \\
F2C & 85 & 83 & 96 & 188 & 205 & 262 \\
F3A & 91 & 87 & 82 & 186 & 201 & 227 \\
F3B & 88 & 73 & 81 & 166 & 204 & 294 \\
F3C & 86 & 95 & 80 & 215 & 156 & 321 \\
\hline \hline
\end{tabular}

Cont $=$ controle $($ virgem, apenas para mecha de cabelo brasileiro); Cont1 $=$ controle (virgem para amostras de cabelo caucasiano e oriental; descolorida para cabelo brasileiro); A, B e C = ingredientes cosméticos. $\mathrm{s} / \mathrm{aq}=$ sem tratamento térmico; $\mathrm{c} / \mathrm{aq}=\mathrm{com}$ tratamento térmico.

Há que se levar em conta alguns parâmetros para concluir que a formulação de fato aumentou o nível de hidratação nos cabelos apenas com dados de DSC. Isto porque o evento de desidratação da matriz capilar pode sofrer influência tanto da água presente na formulação quanto do aumento da porosidade causada por processos de aquecimento e descoloração, por exemplo. Comparando as mechas de cabelo caucasiano entre si, notou-se que MCDM+A e MCLo+C (submetidas às F2A e F3C, respectivamente) foram as que apresentaram maiores valores de $\Delta \mathrm{H}_{2} \mathrm{O}$, mostrando que o veículo, neste caso, não influenciou na retenção de água nas amostras, mas sim os ingredientes cosméticos ou até mesmo a associação das duas espécies. Neste caso, é válido lembrar que, diferentemente da F3C (que contém alta concentração de água pois 
trata-se de uma emulsão condicionadora), a F2A é apenas uma mistura de silicones (dimeticone + ingrediente A).

Em relação as amostras de cabelo oriental, o maior valor de $\Delta \mathrm{H}_{\mathrm{d}}$ foi obtido para as mechas submetida à F2A. Todas as mechas submetidas aos ingredientes cosméticos apresentaram valores de $\Delta \mathrm{H}_{2} \mathrm{O}$ superiores ao da mecha controle. Isto pode indicar uma maior retenção de água em suas matrizes quando estes foram utilizados.

A mecha virgem MBCont (mecha virgem) apresentou um $\Delta \mathrm{H}_{2} \mathrm{O}$ menor quando comparado à mecha MBCont1, a qual foi descolorida. Este fato corrobora com vários estudos da literatura e pode ser explicado pela maior porosidade que os cabelos descoloridos apresentam, uma vez que se tornam mais hidrofílicos, como discutido anteriormente.

Nas mechas de cabelo brasileiro descoloridas tratadas termicamente foram observados altos valores de $\Delta \mathrm{H}_{2} \mathrm{O}$ e a diminuição ou até ausência do evento correspondente à fusão da fase cristalina quando comparados aos resultados obtidos para as mechas controle MBCont1 (controle descolorida). Este fato nos leva a crer que nestes casos as fibras capilares se encontram parcial ou totalmente amorfas contendo alta porosidade e facilitando a permeação da água na matriz. Ou pode até mesmo ser oriunda da formulação, uma vez que as amostras foram acondicionadas em ambiente seco (20\% U.R.). Segundo Halal (2011) cabelos descoloridos têm sua porosidade aumentada e desta forma, absorvem mais colorações e alisamentos futuros, condicionadores ou quaisquer outros produtos cosméticos (HALAL, 2011). Outro fator que pode colaborar para a diminuição da área do pico relacionado à desnaturação da queratina é o $\mathrm{pH}$ da solução clareadora, que varia entre 9,5 e 11. Sob estas condições, a queratina do cabelo se expande e dilata fazendo com que as cutículas dos fios se abram, permitindo a penetração do clareador no córtex. Lembrando que, no trabalho, foi utilizada na mistura clareadora, $\mathrm{H}_{2} \mathrm{O}_{2}$ a 40 volumes (HALAL, 2011). Bhushan (2010) reportaram que o cabelo quimicamente danificado é mais hidrofílico do que o cabelo virgem. O condicionador pode revestir a superfície danificada tornando esta menos hidrofílica. Portanto, danos químicos tornam a cutícula mais permeável à água, levando a um maior inchaço diametral. Nos cabelos tratados e 
danificados quimicamente, é também possível que as moléculas de condicionador ocupem o caminho das moléculas de água (BHUSHAN, 2010).

A Tabela 6.23 lista os valores de $T_{D}$ e $\Delta H_{D}$ das amostras de cabelo caucasiano, oriental e brasileiro submetidas aos sucessivos ciclos de tratamento térmico. Os resultados evidenciaram que houve um aumento nos valores de $T_{D}$ para as mechas MCCont1, MOCont1 e MBCont (controles) antes e após o tratamento térmico. Como estas mechas não foram submetidas à nenhuma formulação e apenas aos ciclos de aquecimento e lavagens, pode-se concluir que este aumento não se deve à nenhum efeito destas formulações. Observa-se, também, que houve um aumento nos valores de $T_{D}$ para as amostras de cabelo brasileiro não descoloridos e descoloridos, de 236 para $245^{\circ} \mathrm{C}$ (MBCont e MBCont1), respectivamente. Porém os valores de $\Delta \mathrm{HD}$ diminuíram para todas as mechas controles submetidas aos ciclos de aquecimento e lavagens.

Tabela 6.23 Resultados de $T_{D}$ e $\Delta H_{D}$ de amostras das mechas de cabelo caucasiano, oriental e brasileiro tratadas com as formulações, submetidas ao tratamento térmico (piastra/lavagens com LESS $10 \% \mathrm{~m} / \mathrm{m}$ ) e estocadas em ambiente controlado $22 \pm 2^{\circ} \mathrm{C}$; $20 \pm 2 \%$.

\begin{tabular}{ccccccc}
\hline \hline & \multicolumn{5}{c}{ Etnia } \\
\cline { 2 - 7 } Tratamento & \multicolumn{5}{c}{$\mathbf{T}_{\mathrm{D} \text { (pico) }} /{ }^{\circ} \mathrm{C}$} & \multicolumn{4}{c}{$\Delta \mathbf{H}_{\mathrm{D}} / \mathrm{J} \mathrm{g}^{-1}$} \\
\cline { 2 - 7 } & Caucasiano & Oriental & Brasileiro & Caucasiano & Oriental & Brasileiro \\
\hline \hline Cont (s/aq) & ---- & ---- & 236 & ---- & ---- & 6,9 \\
Cont (c/aq) & ---- & ---- & 239 & ---- & ---- & 4,4 \\
Cont1 (s/aq) & 237 & 237 & 245 & 5,5 & 6,6 & 6,1 \\
Cont1 (c/aq) & 239 & 238 & 249 & 3,2 & 4,6 & 2,5 \\
F2A & 239 & 236 & 248 & 3,3 & 3,6 & 1,9 \\
F2B & 238 & 237 & 246 & 4,3 & 4,9 & 3,0 \\
F2C & 237 & 236 & 246 & 4,4 & 4,8 & 4,3 \\
F3A & 237 & 236 & 245 & 5,0 & 5,8 & 1,4 \\
F3B & 237 & 236 & 245 & 4,0 & 4,8 & 1,2 \\
F3C & 236 & 236 & --- & 4,1 & 4,8 & -- \\
\hline \hline
\end{tabular}

Cont $=$ controle (virgem, apenas para mecha de cabelo brasileiro); Cont1 = controle (virgem para amostras de cabelo caucasiano e oriental; descolorida para cabelo brasileiro); A, B e C = ingredientes cosméticos. $\mathrm{s} / \mathrm{aq}=\mathrm{sem}$ tratamento térmico; $\mathrm{c} / \mathrm{aq}=\mathrm{com}$ tratamento térmico . 
Estes resultados corroboram com estudos apresentados na literatura. Desta forma, pode-se concluir que esta diminuição nos valores de $T_{D}$ foi devido a uma fragilização das fibras capilares, não levando em consideração como parâmetro indicativo do aumento de estabilidade térmica em relação à proteção térmica. Neste caso, foram avaliados como este indicativo os valores de $\Delta H_{D}$.

Zhou et al. (2011) avaliaram os valores de $T_{D}$ e $\Delta H_{D}$ de amostras de cabelo submetidos a tratamentos com produtos cosméticos e sucessivos ciclos de tratamento térmico utilizando piastra em duas temperaturas diferentes (205 e $232^{\circ} \mathrm{C}$ ). Os autores observaram que alguns cosméticos aumentaram o valor da $T_{D}$ em $1-2^{\circ} \mathrm{C}$ nas mechas submetidas ao tratamento térmico a $205^{\circ} \mathrm{C}$, porém houve redução no valor de $\Delta H_{D}$, indicando que o tratamento térmico provocou danos na proteína dos cabelos e a temperatura de aquecimento mais elevada (em torno de $232^{\circ} \mathrm{C}$ ) tornou a degradação da proteína ainda mais grave. Fato que não foi observamos neste trabalho, visto que os valores de $T_{D}$ aumentaram entre 1 a $3^{\circ} \mathrm{C}$. É válido relembrar que os experimentos de DSC foram conduzidos aqui em ambiente seco, o que não ocorreu com o trabalho desenvolvido por Zhou et al. (2011).

Comparando os valores de $\Delta \mathrm{HD}$, observou-se que para as mechas controles, MCCont1, MOCont1 e MBCont não ocorreram diferenças significativas entre si, fato que não foi observado quando estas foram tratadas com as formulações e submetidas ao tratamento térmico. Estes resultados não apontam que as formulações aumentaram os teores de proteína helicoidal, mas, possivelmente, permitiram que o tratamento térmico não os diminuíssem ainda mais, indicando desta maneira, uma proteção térmica por parte das formulações.

As amostras das mechas controle MCCont1, MOCont1 e MBCont1 submetidas aos ciclos de aquecimento apresentaram uma diminuição em torno de 42,30 e $36 \%$ nos valores de $\Delta H_{D}$, respectivamente, quando comparadas as amostras das mesmas mechas mas que não foram submetidas aos ciclos. Diante destes dados nota-se que a amostra de cabelo oriental apresentou menor perda de material cristalino quando relacionada aos outros. Estes resultados evidenciam, também, que as fibras capilares virgem quando expostas à repetitivos tratamentos térmicos podem sofrer diminuição de sua integridade cristalina e tornar-se amorfas (ou parcialmente amorfas). Se o calor provoca este 
tipo de dano aos cabelos virgens, qual seria o grau de dano causado aos cabelos submetidos a tratamentos químicos de transformação? Isto é preocupante para as indústrias cosméticas fabricantes de produtos de transformação química capilar, principalmente as que comerciam as "famosas" e denominadas "escovas progressivas" ou "escovas ácidas" à base de substâncias que necessitam de ativação do calor para se fixarem aos cabelos para que os resultados do alisamento sejam melhores. O formol é um dos ativos mais conhecidos e pertencentes à esta classe de alisantes, mas está proibido pela ANIVSA, por ser comprovadamente prejudicial à saúde em determinadas concentrações. Sá Dias et al. (2014) comprovaram através de um estudo de amostras de cabelo por DSC que o aumento da concentração de formol (2, 5 e 10\%) na composição de alisantes diminui a integridade cristalina das fibras causando uma acentuada diminuição nos valores de $\Delta \mathrm{HD}$.

Observamos que as amostras de cabelo brasileiro descolorido apresentaram uma diminuição mais acentuada em seu valor de $\Delta \mathrm{HD}_{\mathrm{D}}$, de $6,1 \mathrm{~J} \mathrm{~g}^{-1}$ para $2,5 \mathrm{~J} \mathrm{~g}^{-1}$, representando cerca de $59 \%$ do valor inicial, ou seja, quando não foi exposta ao tratamento térmico. Este resultado pode ser uma evidência que a amostra de cabelo brasileiro descolorido já se encontrava fragilizado pelo processo de descoloração ao qual foi submetida.

Sabe-se que os silicones são frequentemente utilizados no tratamento térmico do cabelo por causa de sua estabilidade térmica (O'LENICK Jr., 2008; BHUSHAN, 2010). Também devido à sua baixa tensão superficial, eles podem formar filmes reduzindo a força de aplicação de dispositivos térmicos, condicionando os fios de cabelo e produzindo uma maior interação fibra-fibra com um efeito anti-encaracolado (DUSSAD \& FIESCHI-CORSO, 2009).

Das mechas de cabelo caucasiano, a amostra de MCLo+A (submetidas a F3A) apresentou maior valor de $\Delta H_{D}\left(5,0 \mathrm{~J} \mathrm{~g}^{-1}\right)$ quando comparada aos valores obtidos para amostra de MCCont1 submetidas ao tratamento térmico $\left(3,2 \mathrm{~J} \mathrm{~g}^{-1}\right)$. Por outro lado, para as mechas submetidas às $F 2 C$, F2B e F3B e F3C os valores foram muito próximos entre si (em torno de $\left.4,0 \mathrm{~J} \mathrm{~g}^{-1}\right)$ e por último $\mathrm{F} 2 \mathrm{~A}\left(3,3 \mathrm{~J} \mathrm{~g}^{-1}\right)$.

Das mechas de cabelo oriental, a amostra de MOLo+A (submetidas a F3A) apresentou o maior valor de $\Delta \mathrm{HD}_{\mathrm{D}}\left(5,8 \mathrm{~J} \mathrm{~g}^{-1}\right)$ quando comparado com os valores obtidos para as amostras de MOCont1 submetida ao tratamento térmico $\left(4,6 \mathrm{~J} \mathrm{~g}^{-1}\right)$ 
e em seguida as mechas submetidas às $\mathrm{F} 3 \mathrm{C}, \mathrm{F} 2 \mathrm{~B}$ e $\mathrm{F} 2 \mathrm{C}$ com valores em torno de $4,8 \mathrm{~J} \mathrm{~g}^{-1}$.

Das mechas de cabelo brasileiro, a amostra de MBDM+C (submetidas a F2C) apresentou o maior valor de $\Delta H_{D}\left(4,3 \mathrm{~J} \mathrm{~g}^{-1}\right)$ e em seguida a amostra de MBDM+B, que foi 3,0 $\mathrm{J} \mathrm{g}^{-1}$. As amostras das outras mechas apresentaram valores de $\Delta H_{D}$ inferiores ao obtido pela amostra de MBCont1 submetida ao tratamento térmico, que foi $2,5 \mathrm{~J} \mathrm{~g}^{-1}$, como pode ser observado na Tabela 6.20. Estes resultados indicam que nestas mechas, MBDM+A, MBLo+A, MBLo+B e MBLo+C, as formulações não foram eficientes para a proteção das cadeias polipeptídicas da queratina cristalina das fibras de cabelo nas condições estudadas.

Dos resultados de $\Delta H_{D}$ apresentados na Tabela 6.23 (anteriormente exibida) foram calculadas as porcentagens de proteção térmica da proteína helicoidal das fibras capilares. Os cálculos foram realizados com base na diferença de $\Delta \mathrm{H}_{\mathrm{D}}$ entre as amostras de cabelo não tratados (sem tratamento térmico) e tratados com as formulações e posteriormente submetidas ao tratamento térmico com a piastra conforme estudo realizado por Zhou et al. (2011) e que estão apresentados na Tabela 6.24. Melhor visualização dos resultados pode ser vista na Figura 6.36.

Tabela 6.24 Resultados de $\Delta \mathrm{H}_{\mathrm{D}}$ e porcentagens de proteção térmica de amostras das mechas de cabelos caucasiano, oriental e brasileiro tratadas com as formulações e submetidas ao tratamento térmico (piastra/lavagens com LESS $10 \% \mathrm{~m} / \mathrm{m}$ ).

\begin{tabular}{cccccccccc}
\hline \multirow{2}{*}{ Tratamento } & \multicolumn{3}{c}{$\Delta \mathbf{H}_{\mathrm{D}}$} & \multicolumn{4}{c}{ Diferença $\Delta \mathbf{H}_{\mathrm{D}}$} & \multicolumn{4}{c}{$\begin{array}{c}\text { \% Proteção da } \\
\text { proteína helicoidal }\end{array}$} \\
\cline { 2 - 10 } & $\mathbf{C}$ & $\mathbf{O}$ & $\mathbf{B}$ & $\mathbf{C}$ & $\mathbf{O}$ & $\mathbf{B}$ & $\mathbf{C}$ & $\mathbf{0}$ & $\mathbf{B}$ \\
\cline { 2 - 10 } Cont1 (s/aq) & 5,5 & 6,6 & 6,1 & ---- & ---- & ---- & --- & ---- & ---- \\
Cont1 (c/aq) & 3,2 & 4,6 & 2,5 & 2,3 & 2,0 & 3,6 & --- & ---- & ---- \\
F2A & 3,3 & 3,6 & 1,9 & 2,2 & 3,0 & 4,2 & 4,3 & 0,0 & 0,0 \\
F2B & 4,3 & 4,9 & 3,0 & 1,2 & 1,7 & 3,1 & 47,8 & 15,0 & 13,9 \\
F2C & 4,4 & 4,8 & 4,3 & 1,1 & 1,8 & 1,8 & 52,1 & 10,0 & 50,0 \\
F3A & 5,0 & 5,8 & 1,4 & 0,5 & 0,8 & 4,7 & 78,3 & 60,0 & 0,0 \\
F3B & 4,0 & 4,8 & 1,2 & 1,5 & 1,8 & 4,9 & 34,8 & 10,0 & 0,0 \\
F3C & 4,1 & 4,8 & 0,0 & 1,8 & 1,8 & 0,0 & 39,1 & 10,0 & 0,0 \\
\hline \hline
\end{tabular}

$\mathrm{C}=$ Caucasiano, $\mathrm{O}=$ Oriental e $\mathrm{B}=\mathrm{Brasileiro;}$ Cont1 = controle (virgem para amostras de cabelo caucasiano e oriental; descolorida para cabelo brasileiro); $\mathrm{A}, \mathrm{B}$ e $\mathrm{C}=$ ingredientes cosméticos; s/aq = sem tratamento térmico; $\mathrm{c} / \mathrm{aq}=\mathrm{com}$ tratamento térmico 


\section{Proteção da proteína helicoidal}

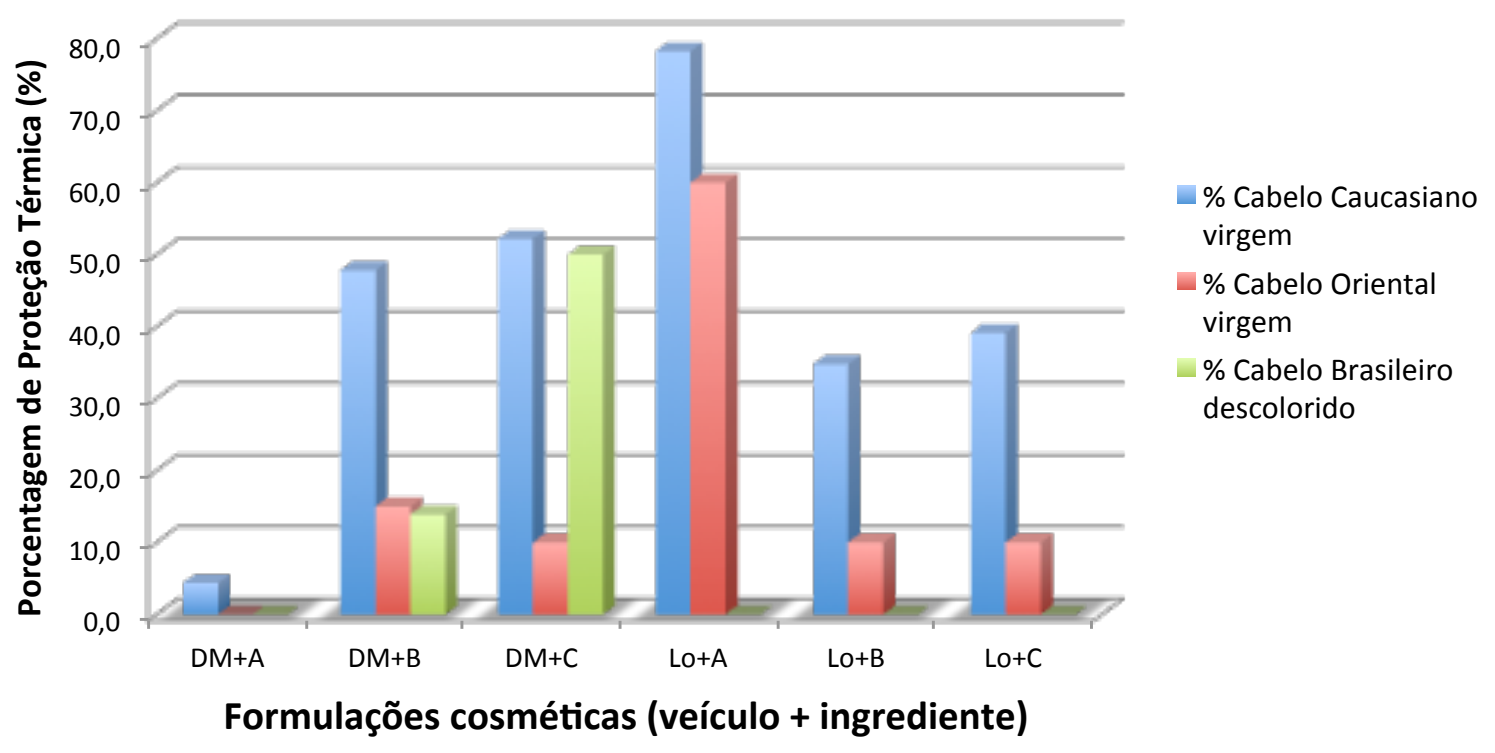

Figura 6.36 Resultados da \% de proteção da proteína helicoidal calculados com base nas diferenças de $\Delta H_{D}$ das amostras de cabelo submetidas tratamento térmico com as respectivas mechas controle (valores apresentados na Tabela 6.24). $\mathrm{DM}=$ dimeticone; Lo = leave-on; A, B e C = ingredientes cosméticos.

Os dados de DSC mostram que os tratamentos com os silicones reduziram a degradação de proteínas. Isto porque os resultados demonstraram que o tratamento com as formulações contendo os silicones proporcionam redução significativa nos valores de $\Delta \mathrm{H}_{\mathrm{D}}$.

De modo geral, notou-se que os níveis de proteção foram mais influenciados pelos ingredientes ou associação destes com os veículos do que apenas pelos veículos. As mechas contendo leave-on apresentaram uma diminuição menos acentuada nos valores de $\Delta H_{D}$ quando associada ao ingrediente A (silicone amino funcional) e aplicadas nas mechas de cabelo caucasiano e oriental. Em outras palavras, a formulação F3A apresentou maior eficiência na proteção térmica dos cabelos quando comparado a $F 2 A$, que não apresentou eficiência de proteção nos cabelos nas condições estudadas. Um fato que pode explicar a maior eficiência de proteção de condicionadores nos cabelos pode estar associada as suas propriedades anti estáticas. Existem dois mecanismos possíveis por meio dos quais os condicionadores podem reduzir carga no cabelo. O primeiro é o efeito de lubrificação dos condicionadores, onde a 
fase oleosa mais o silicone lubrificam a superfície do cabelo. Eles podem repor a camada 18-MEA desintegrada pelos danos e diminuir o atrito o que leva à diminuição da carga negativa. O segundo efeito, e o mais provavelmente dominante é o aumento da condutividade elétrica da superfície. Desta maneira, qualquer carga negativa depositada na superfície dos fios é rapidamente dissipada pela camada do condicionador (BHUSHAN, 2010).

Seshadri \& Bhushan (2008) avaliaram amostras de cabelo submetidas a dois tipos de condicionadores contendo silicones (um contendo silicone amino funcionais e outro contendo polidimetilsiloxano). Ambos condicionadores nas amostras de cabelo tratadas demonstraram alterações potenciais de superfície. $O$ silicone polidimetilsiloxano adere fisicamente à superfície enquanto o silicone amino funcional se liga quimicamente, e, portanto, recobre uniformemente a superfície. Eles observaram que mesmo uma camada de condicionador não uniforme sobre a fibra pode aumentar de forma significativa a condutividade elétrica. Tanto o condicionador contendo o silicone amino funcional como aquele contendo o polidimetilsiloxano demonstraram uma redução significativa de condutividade elétrica em comparação com o cabelo danificado ou mesmo virgem. Os autores observaram que ambos tipos de condicionadores podem reduzir drasticamente o potencial de alteração da carga da superfície e deposição no cabelo. Ou seja, foi detectada por eles quase nenhuma carga na superfície devido à fricção em cabelos tratados com condicionador.

As mechas MBLo+A, MBLo+B e MBLo+C apresentaram valores de $\Delta H_{D}$ de 1,4, 1,2 e $0 \mathrm{~J} \mathrm{~g}^{-1}$ e as mechas MBDM+A, MBDM+B, MBDM+C $\Delta H_{D}$ de 1,9, 3,0 e 4,3 $\mathrm{J} \mathrm{g}^{-1}$, respectivamente. Neste caso, o veículo pode ter influenciado nos resultados de melhora no desempenho do ingrediente. Uma explicação para estes resultados pode estar relacionada ao fato de que o cabelo descolorido, apresentando-se mais poroso, e com a aplicação de formulações constituídas em sua maioria por água (emulsão como o caso da F3A, F3B e F3C) há penetração destas mais facilmente nas fibras. É sabido que a superfície da cutícula dos cabelos é carregada negativamente e esta carga é aumentada ainda mais quando os cabelos são tratados quimicamente. Como resultado, as partículas carregadas positivamente de condicionador têm uma atração ainda mais forte à superfície destes (BHUSHAN, 2010). O contato da formulação com a matriz pode causar 
uma mudança de densidade de reticulação alterando sua viscosidade e desta forma, a desnaturação da proteína helicoidal. Outro aspecto a se levar em conta é que se formulação penetrou nas fibras não permaneceu na superfície dos fios, ou seja, na cutícula, e desta maneira não diminuiu os danos causados pela agressão sucessiva de calor e lavagens com LESS $10(\mathrm{~m} / \mathrm{m})$. Como já discutido anteriormente, cabelos danificados quimicamente são susceptíveis a possíveis penetração de moléculas do condicionador que podem ocupar o caminho de moléculas de água (BHUSHAN, 2010).

Diferentemente do que ocorreu com as mechas de cabelo brasileiro descolorido, as mechas de cabelo caucasiano e oriental apresentaram maiores níveis de proteção térmica quando receberam a formulação F3A. Este resultado mostra que mesmo a formulação contendo concentração menor de silicone pode proteger as fibras de cabelo da degradação térmica. Como as mechas controle também foram expostas ao mesmo tratamento térmico que as contendo os ingredientes cosméticos, é possível atribuir esta melhora na proteção térmica dos fios aos ingredientes cosméticos.

Lim et al. (2010) estudaram o efeito de silicones amino-funcionais e não amino-funcionais no condicionamento de amostras de cabelo após diferentes tratamentos térmicos variando a temperatura de 90 a $170^{\circ} \mathrm{C}$ e o tempo de exposição ao calor de 1 a 5 minutos. Os autores verificaram que maiores teores de silício foram observados nas amostras de cabelo tratadas com silicones aminofuncionais do que as que foram tratadas com polidimetilsiloxano. A adsorção de silicone amino foi reforçada em maior temperatura e tempo de tratamento mais longo. Os resultados obtidos por Lim et al. (2010) podem explicar os resultados alcançados no presente trabalho. Os ingredientes $A$ e $B$ possuem função amino ou seja, são amino-funcionais, e desta forma, podem se aderir mais facilmente à superfície da fibra capilar e consequentemente protegê-las dos danos causados tanto pelo aquecimento como pelas sucessivas lavagens com LESS. Os espectros FTIR das amostras de cabelo tratadas com as formulações, apresentados no item a seguir, mostram que todas as amostras contendo o ingrediente $B$ foram as que apresentaram maior intensidade (comparados com as amostras submetidas aos outros ingredientes) na banda em torno de $800 \mathrm{~cm}^{-1}$, que está relacionada aos grupos $\mathrm{Si}\left(\mathrm{CH}_{3}\right)$ que juntamente com a banda em torno de $1260 \mathrm{~cm}^{-1}$ fazem parte da composição dos silicones. $O$ ingrediente $C$ não 
possui função amino porém apresentou-se eficiente na associação com ambos veículos na proteção das cadeias polipeptídicas da a-queratina quando aplicados nas mechas de cabelo caucasiano e oriental. Todavia, na amostra de cabelo brasileiro descolorido observou-se que apenas o ingrediente $\mathrm{C}$ apresentou grau de proteção de cerca de $50 \%$ quando incorporado ao dimeticone (F2C), como discutido anteriormente.

Lee et al. (2011) estudaram as mudanças na estrutura, forma e conteúdo de umidade e cor em amostras de cabelos não tratados e tingidos após repetidas lavagens com xampu e secagem com secador de cabelos a diferentes condições de temperatura, distância do secador de cabelos e tempo de exposição ao calor. A temperatura maior utilizada foi $95^{\circ} \mathrm{C}$. Os autores observaram que as mechas que foram submetidas ao calor do secador de cabelos apresentaram danos na cutícula e também em um clareamento na cor das mechas.

Neste trabalho, as mechas de cabelo caucasiano e oriental apresentaram maiores níveis de proteção térmica quando submetidas à as formulações do que àquelas de cabelo brasileiro. Este resultado corrobora os resultados de TG/DTG que demostraram que, mesmo sem exposição aos ciclos de aquecimento e lavagens, as mechas orientais apresentaram maiores valores de $\Delta \mathrm{HD}$ quando tratadas com as formulações. Observou-se, também, que o ingrediente $A$ apresentou maior porcentagem de proteção comparado aos outros ingredientes e sua eficiência nesta proteção foi maior quando incorporado ao condicionador leave-on quando aplicados nos cabelos caucasiano e oriental (cerca de 78 e 60\%, respectivamente).

Zhou et al. (2011) estudaram o efeito de pré-tratamentos cosméticos na proteção térmica em amostras de cabelo utilizando piastra em duas temperaturas diferentes (205 e $232^{\circ} \mathrm{C}$ ) e avaliaram os danos térmicos por meio de DSC e FTIR. Os autores constataram cerca de $50 \%$ de proteção térmica utilizando polímeros cosméticos em amostras de cabelo oriental submetido a um tratamento térmico de $205^{\circ} \mathrm{C}$. Obtiveram também 3 a $90 \%$ de proteção térmica utilizando os mesmos ingredientes em amostras de cabelo caucasiano, porém submetidas a um tratamento térmico com temperatura mais elevada, $232^{\circ} \mathrm{C}$. Os produtos utilizados pelos autores se tratavam de polímeros que não contém grupo siloxanos, como aqueles utilizados neste trabalho. 


\subsubsection{Análise elementar}

Os resultados de $\mathrm{AE}$ das mechas controle (virgem e descolorida) e das mechas tratadas com as formulações (antes e após os ciclos de tratamento térmico e lavagens) estão apresentados na Tabela 6.25 .

Tabela 6.25 Resultados de análise elementar (CHN) de amostras das mechas de cabelo caucasiano, oriental e brasileiro tratadas com as formulações e submetidas ao tratamento térmico (piastra/lavagem com LESS $10 \% \mathrm{~m} / \mathrm{m}$ ).

\begin{tabular}{|c|c|c|c|c|c|c|c|c|c|}
\hline \multirow{2}{*}{ Tratamento } & \multicolumn{3}{|c|}{$\% \mathrm{C}$} & \multicolumn{3}{|c|}{$\% \mathrm{H}$} & \multicolumn{3}{|c|}{$\% \mathrm{~N}$} \\
\hline & C & 0 & B & C & 0 & B & C & 0 & B \\
\hline Cont & --- & --- & 43,4 & --- & --- & 6,5 & --- & --- & 13,7 \\
\hline Cont $^{*}$ & --- & --- & 45,2 & --- & --- & 6,5 & --- & --- & 14,3 \\
\hline Cont1 & 43,6 & 42,9 & 41,7 & 6,8 & 7,1 & 6,7 & 14,1 & 13,8 & 13,5 \\
\hline Cont1* & 45,6 & 45,3 & 43,7 & 7,0 & 6,8 & 6,5 & 14,4 & 14,4 & 13,9 \\
\hline $\mathrm{F} 2 \mathrm{~A}$ & 43,6 & 43,1 & 41,7 & 7,2 & 7,1 & 6,8 & 13,2 & 13,1 & 12,9 \\
\hline $\mathrm{F} 2 \mathrm{~A}^{*}$ & 43,8 & 43,8 & 42,4 & 6,6 & 6,6 & 6,6 & 14,0 & 14,0 & 13,5 \\
\hline $\mathrm{F} 2 \mathrm{~B}$ & 43,9 & 43,4 & 43,4 & 7,0 & 7,1 & 7,0 & 13,3 & 13,1 & 13,2 \\
\hline $\mathrm{F} 2 \mathrm{~B}^{*}$ & 43,7 & 45,0 & 43,2 & 6,6 & 6,7 & 6,7 & 13,8 & 14,2 & 13,3 \\
\hline F2C & 42,6 & 43,1 & 40,7 & 7,0 & 7,1 & 6,6 & 13,0 & 13,3 & 12,4 \\
\hline $\mathrm{F} 2 \mathrm{C}^{*}$ & 43,7 & 43,8 & 42,8 & 6,6 & 6,4 & 6,9 & 14,0 & 13,9 & 13,6 \\
\hline F3A & 44,5 & 44,0 & 39,6 & 7,2 & 7,2 & 6,8 & 13,6 & 13,8 & 11,9 \\
\hline F3A* & 45,0 & 45,4 & 42,4 & 7,0 & 7,3 & 6,6 & 14,1 & 13,8 & 13,4 \\
\hline F3B & 45,0 & 44,8 & 41,4 & 7,3 & 7,3 & 6,6 & 13,8 & 14,0 & 11,4 \\
\hline F3B* & 44,8 & 45,0 & 43,0 & 6,7 & 6,7 & 6,4 & 14,1 & 14,1 & 13,3 \\
\hline F3A & 44,8 & 44,8 & 40,8 & 7,1 & 6,9 & 7,0 & 13,8 & 14,1 & 12,4 \\
\hline F3A* & 45,6 & 44,8 & 43,3 & 7,1 & 6,7 & 6,7 & 14,3 & 14,1 & 13,3 \\
\hline
\end{tabular}

*após tratamento térmico; C=caucasiano; $\mathrm{O}=$ oriental; $\mathrm{B}=$ brasileiro; Cont $=$ controle (virgem, apenas para mecha de cabelo brasileiro); Cont1 = controle (virgem para amostras de cabelo caucasiano e oriental; descolorida para cabelo brasileiro); A, B e C = ingredientes cosméticos.

As amostras das mechas de cabelo brasileiro virgem (MBCont) e descolorido (MBCont1) que não foram submetidas ao tratamento térmico apresentaram diminuição no teor de C (de 43,4 para $41,7 \%$ ). Como os teores de 
$\mathrm{H}$ e $\mathrm{N}$ permaneceram praticamente os mesmos, esta diminuição no teor de $\mathrm{C}$ pode ser explicada pela eliminação de material orgânico com o tratamento químico de descoloração. Este percentual pode tanto ser de material graxo presente na cutícula ou no córtex do cabelo como, também, de material proteico. Isto porque no processo de descoloração de cabelos pode, também, ocorrer a diminuição do teor de S.

Pode-se observar que, de maneira geral, houve diminuição nos teores $\mathrm{C} \mathrm{e}$ $\mathrm{N}$ obtidos para as amostras das mechas de cabelo brasileiro descolorido com as diferentes formulações. Isto pode sugerir que as mesmas, apresentando-se mais porosas, a formulação "preencheu estes poros", e proporcionalmente contribuiu para a diminuição no teor de $\mathrm{C}$, componente majoritário em ambos materiais. $\mathrm{O}$ mesmo não ocorreu com as amostras das mechas de cabelo caucasiano e oriental que, no estado virgem, apresentam-se com a superfície mais uniforme e íntegra, então, a incorporação da formulação é menor. Isto permite entender porque praticamente não ocorreu diminuição no teor de $\mathrm{C}$ nestas amostras.

As mechas tratadas com as formulações foram analisadas por $A E$ antes do tratamento térmico para que, diante dos resultados, seja possível verificar se as alterações nos teores de $\mathrm{CHN}$ foram causadas ou não pelo uso do aquecimento.

As amostras das mechas virgens de cabelo caucasiano, oriental e brasileiro descolorido que foram submetidas ao tratamento térmico apresentaram um aumento no teor de $\mathrm{C}$ e $\mathrm{N}$, o que sugere uma diminuição no teor de $\mathrm{S}$ e/ou $\mathrm{O}$, quando o teor de $\mathrm{H}$ se apresenta constante.

Segundo Brebu \& Spiridon (2011), a etapa de degradação da queratina de amostras de cabelo ocorre na de faixa de $170-300^{\circ} \mathrm{C}$ e é dominada pela evolução dos gases inorgânicos $\left(\mathrm{NH}_{3}, \mathrm{CO}_{2}, \mathrm{SCS}, \mathrm{SCO}, \mathrm{H}_{2} \mathrm{~S}\right.$ e $\left.\mathrm{SO}_{2}\right)$ e de tióis. Nitrilos e compostos aromáticos (4-metilfenol e fenol são os compostos de degradação mais importantes) e são formadas acima $300^{\circ} \mathrm{C}$. As principais classes de compostos contendo heteroátomos foram os nitrilos, os pirroles, pirimidinas, amidas, sulfuretos, tióis, tiazoles e tiofenos e que se originam a partir dos aminoácidos iniciais na composição de queratina (BREBU \& SPIRIDON, 2011). No presente trabalho, as mechas foram submetidas à piastra aquecida a $200^{\circ} \mathrm{C}$, $\mathrm{O}$ que indica que, nestas condições, as mechas não alcançaram temperatura superior a $300^{\circ} \mathrm{C}$. Associando os resultados obtidos pelos autores aos aqui 
obtidos, pode-se inferir que o que ocorreu, possivelmente, foi a formação de gases como por exemplo $\mathrm{SO}_{2}$ e/ou $\mathrm{H}_{2} \mathrm{~S}$, uma vez o teor de $\mathrm{C}$ e $\mathrm{N}$ aumentaram (com exceção apenas da amostra das mecha de cabelo caucasiano que apresentou um ligeiro aumento no teor de $\mathrm{H}$ ).

As amostras das mechas de cabelo virgem caucasiano e oriental e brasileiro descolorido que foram tratadas com as formulações contendo dimeticone e leave-on e posteriormente submetidas ao tratamento térmico, apresentaram diminuição nos teores de $C$ e $N$. Porém, aquelas que foram submetidas ao leave-on apresentaram uma diminuição menor quando comparadas as outras contendo dimeticone. Isto pode significar a formação de $\mathrm{NH}_{3}$ e/ou $\mathrm{CO}_{2}$ para o caso das mechas tratadas com dimeticone (para aquelas que apresentaram diminuição também no teor de $\mathrm{H}$ ) ou até mesmo de perda de material orgânico e/ou proteico. De qualquer maneira, como as mechas tratadas com leave-on apresentaram maiores teores de $\mathrm{C}$ e $\mathrm{N}$, pode-se inferir que estas se degradaram menos, com uma menor liberação de gases e/ou de material orgânico. Os resultados de DSC das amostras de cabelo caucasiano e oriental apresentaram menores perdas de material cristalino do que aquelas que foram tratadas com leave-on como veículo.

A partir dos resultados de $\mathrm{CHN}$ das amostras de cabelo brasileiro descolorido submetidas ao tratamento térmico, observou-se que as mesmas não apresentaram um comportamento semelhante àqueles obtidos para as outras etnias. Os danos causados a estes fios de cabelo devido ao tratamento de descoloração podem explicar essa diferença, uma vez que as formulações podem associar a estes fios de maneira diferente daquelas que não foram tratadas quimicamente.

\subsubsection{Espectroscopia na região do infravermelho com transformada de Fourier- Refletância total atenuada (FTIR-ATR)}

Um indicativo da desnaturação de proteínas é a alteração que pode ocorrer em sua conformação. Como já discutido anteriormente, o cabelo não danificado possui uma conformação a-helicoidal, que é uma estrutura bem organizada que se encontra no córtex (ROBBINS, 1997). Quando a proteína é danificada, esta 
pode se desdobrar e se converter em cadeias proteicas estendidas ou estrutura de folha beta ( $\beta$-sheet). Estas alterações afetam a estrutura das ligações de hidrogênio, que estabiliza a estrutura helicoidal e, portanto, podem alterar a acessibilidade da água para o fio de cabelo (ZHOU et al., 2011).

A FTIR permite verificar mudanças na estrutura das proteínas e tem sido bastante utilizada para análises em amostras de cabelo. No item 6.1.4. já foram discutidas as principais bandas de absorção que são atribuídas nos espectros de amostras de cabelo a efeito de comparação entre as amostras de diferentes etnias. Porém, não foram discutidas as alterações que podem ocorrer devido a processos químicos e térmicos nos cabelos, as quais serão discutidas neste item. No entanto, deve-se considerar que esta técnica (com ATR) analisa as amostras apenas na cutícula e, possivelmente, na região periférica do córtex (BARTON, 2011).

A Tabela 6.26 apresenta os resultados de IV obtidos para as amostras de cabelo caucasiano das mechas controle (antes e após o tratamento térmico) e das mechas submetidas às formulações (após consecutivos ciclos de aquecimento e lavagens). É possível observar a presença das principais bandas de absorção nos espectros de todas amostras, porém algumas alterações podem ser melhor visualizadas nas Figuras 6.37 e 6.38 . 
Tabela 6.26 Atribuição das principais bandas dos espectros no IV de amostras de cabelo virgem caucasiano tratadas com as formulações e submetidas ao tratamento térmico (piastra/lavagem com LESS $10 \% \mathrm{~m} / \mathrm{m}$ ).

\begin{tabular}{|c|c|c|c|c|c|c|c|c|}
\hline \multirow{3}{*}{$\begin{array}{l}\text { Grupo } \\
\text { funcional }\end{array}$} & \multicolumn{8}{|c|}{ Número de onda $/ \mathrm{cm}^{-1}$} \\
\hline & \multicolumn{8}{|c|}{ Tratamento } \\
\hline & Cont1 & Cont1* & F2A & F2B & F2C & F3A & F3B & F3C \\
\hline Amida A & 3277 & 3280 & 3279 & 3280 & 3279 & 3281 & 3280 & 3280 \\
\hline Amida B & 3073 & 3072 & 3073 & 3071 & 3074 & 3073 & 3073 & 3074 \\
\hline $\mathrm{CH}_{3} \mathrm{Assim}$ & 2958 & 2961 & 2963 & 2963 & 2962 & 2958 & 2959 & 2958 \\
\hline $\mathrm{CH}_{2} \mathrm{Assim}$ & 2920 & 2925 & 2932 & 2933 & 2933 & 2921 & 2921 & 2920 \\
\hline $\mathrm{CH}_{2} \mathrm{Sim}$ & 2851 & 2854 & $* *$ & $* *$ & $* *$ & 2852 & 2852 & 2852 \\
\hline Amida I & 1633 & 1633 & 1637 & 1634 & 1631 & 1635 & 1632 & 1637 \\
\hline Amida II & 1535 & 1518 & 1523 & 1521 & 1519 & 1519 & 1518 & 1520 \\
\hline $\begin{array}{c}\mathrm{CH}_{2} \\
\text { (lipídeos) }\end{array}$ & 1451 & 1450 & 1450 & 1451 & 1450 & 1451 & 1451 & 1451 \\
\hline Amida III & 1236 & 1235 & $* *$ & $* *$ & 1237 & 1236 & 1236 & 1236 \\
\hline $\begin{array}{l}\text { Monóxido } \\
\text { de cistina }\end{array}$ & 1075 & 1076 & 1077 & 1078 & 1075 & 1075 & 1076 & $* *$ \\
\hline $\begin{array}{c}\text { Ácido } \\
\text { sulfônico }\end{array}$ & 1043 & 1042 & 1041 & 1041 & 1043 & 1043 & 1042 & 1044 \\
\hline $\mathrm{NO}_{2}$ & 874 & 874 & 873 & 873 & $* *$ & --- & ** & 873 \\
\hline $\mathrm{N}-\mathrm{H}_{2}$ & 803 & 802 & 796 & 795 & 801 & 802 & 802 & 802 \\
\hline
\end{tabular}

**bandas sobrepostas ou com expressiva diminuição na intensidade do sinal; Cont1 = controle (virgem, sem tratamento térmico); Cont $1^{*}=$ controle (virgem, após tratamento térmico); A, B e C = ingredientes cosméticos.

Comparando os espectros das amostras de cabelo caucasiano controle antes e após o tratamento térmico, observou-se que este último apresentou algumas alterações, provavelmente, devido à exposição excessiva de calor. Isto foi concluído observando que houve em seu espectro: 
1) diminuição da intensidade das bandas em 2920 e $2851 \mathrm{~cm}^{-1}$ relacionadas aos grupos $\mathrm{CH}_{3}$ e $\mathrm{CH}_{2}$ oriundos de aminoácidos, nos modos assimétrico e simétrico, respectivamente (KIM \& PARK, 2013).

2) deslocamento da banda de amida II (de 1535 para $1518 \mathrm{~cm}^{-1}$ ). Bandas na região espectral de $1700-1480 \mathrm{~cm}^{-1}$ são sensíveis às alterações na conformação estrutural secundária da proteína do cabelo, ou seja, no caso de ocorrer transformações químicas na estrutura da a-queratina. A banda de Amida II em torno de $1545 \mathrm{~cm}^{-1}$ consiste essencialmente na estiramento de C-N (60\%) e deformação de N-H (40\%) da conformação $\alpha$ - helicoidal e da forma amorfa espiral aleatória em $1536 \mathrm{~cm}^{-1}$. A absorção forte e estreita em torno de $1511 \mathrm{~cm}^{-1}$ está diretamente relacionada ao estiramento de C-N $(60 \%)$ e deformação de $\mathrm{N}-\mathrm{H}(40 \%)$ da conformação folha $\beta$. Estes resultados indicam que, possivelmente, houve uma mudança de conformação espiral amorfa para a folha $\beta$. Desta forma, pode-se sugerir que esta última conformação dominou a estrutura da cutícula e esta se mostrou ser menos ordenada, ou seja, amorfa, em oposição ao córtex subjacente (NISHIKAWA et al., 1998; BARTON, 2011, ZHOU et al., 2011);

3) dois sinais em 1259 e $1235 \mathrm{~cm}^{-1}$ relacionados à banda de amida III que estão relacionados às conformações folha $\beta$ e espiral aleatória (amorfa) (Espinoza et al., 2008). As bandas espectrais entre 1300-1200 $\mathrm{cm}^{-1}$ estão exclusivamente associadas com o modo de vibração de amida III. A banda de absorção principal em torno de $1235 \mathrm{~cm}^{-1}$ está associada com o estiramento do C-N (30\%) e deformação no plano do $\mathrm{N}-\mathrm{H}(30 \%)$ da conformação folha $\beta$. O aparecimento do pico em número de onda maior, ou seja, em torno de $1259 \mathrm{~cm}^{-1}$ pode ser um indicio que ocorreu alteração na cutícula das fibras. Isto porque os fios não tratados termicamente (amostra da mecha controle) apresentaram apenas a banda em torno de $1235 \mathrm{~cm}^{-1}$ relacionada a folha $\beta$.

4) aumento na intensidade da banda em torno de $803 \mathrm{~cm}^{-1}$ que está relacionada a deformação fora do plano em $\mathrm{N}-\mathrm{H}_{2}$.

Das mechas de cabelo caucasiano tratadas com as formulações contendo o dimeticone como veículo (Figura 6.37), os espectros mostraram que as mechas 
que foram submetidas à formulação F2C apresentaram maior semelhança com o espectro da amostra da mecha controle (antes do tratamento térmico). Isto quer dizer que, comparando os espectros das amostras das mechas MCDM+A, $M C D M+B$ e $M C D M+C$, os dois primeiros apresentaram maiores alterações (comparando com o espectro das amostras das mechas controle) e maior semelhança entre si no que diz respeito a estas alterações, que compreendem:

1) um aumento na intensidade da banda em $2963 \mathrm{~cm}^{-1}$ que corresponde ao modo de alongamento $\mathrm{C}-\mathrm{H}$ simétrico de grupos $\mathrm{CH}_{2}$ e $\mathrm{CH}_{3}$. É característica de deformação axial assimétrica de ligações $\mathrm{C}-\mathrm{H}$ de alcanos terciários, onde duas ligações $\mathrm{C}-\mathrm{H}$ se estendem, enquanto a terceira se contrai (SILVERSTEIN et al., 2007). Danos em fibras de cabelo podem acarretar em um aumento na intensidade da vibração ligação $\mathrm{C}-\mathrm{H}$, a qual pode ser correlacionada com as alterações de conformação da queratina de $\alpha$-hélice para folha beta (SAIKIA, 2013). Esta alteração foi observada nos espectros das amostras das mechas MCDM+A e MCDM+B e não no espetro da amostra das mechas MCDM+C. Zhou et al. (2011) utilizaram esta banda para avaliar a modificação de proteínas do cabelo após tratamento térmico. Segundo os autores ela é atribuída, principalmente, aos resíduos de aminoácidos terminais das proteínas do cabelo com menor contribuição de lipídeos. Utilizando imagens obtidas da secção transversal de fios de cabelo por FT-IRIS (Fourier transform infrared imaging spectroscopy) os autores verificaram uma contribuição menor de lipídeos obtida a partir da área da banda $\mathrm{CH}_{3}$ para os espectros das amostras termicamente tratadas. Ou seja, existe uma perda de proteína total e de lipídeos no cabelo tratado termicamente.

2) o deslocamento das bandas da amida II, demonstrando a alteração na conformação da proteína;

3) o aparecimento de bandas em $1259 \mathrm{~cm}^{-1}$; as quais podem estar tanto relacionadas à amida III da conformação aleatória espiral (ESPINOZA et al., 2008) quanto aos grupos $\mathrm{Si}-(\mathrm{CH})_{3}$, que possuem bandas em torno de $1260 \pm 5$ e $800 \pm 10 \mathrm{~cm}^{-1}(\mathrm{SMITH}, 1999)$ presentes nos espectros das amostras das formulações F2A, F2B e F2C aplicadas nas mechas de 
cabelos, sobrepondo a banda de amida III (folha beta) em torno de 1235 $\mathrm{cm}^{-1}$.

4) o aumento na intensidade das bandas relacionadas à oxidação do aminoácido cistina (em torno de $1075 \mathrm{~cm}^{-1}$ ) presente nos espectros das amostras das mechas MCDM+A e MCDM+B. Este aumento não foi observado no espectro da amostra das mechas $M C D M+C$, que apresentou-se de menor intensidade até mesmo quando comparada ao espectro da amostra das mechas controle após o tratamento térmico. As bandas em torno de $1075 \mathrm{~cm}^{-1}$ estão relacionadas ao monóxido de cisteína, oriundos da oxidação do aminoácido cistina (SMITH, 1999; BARTON, 2011). Esta alteração se deu, provavelmente, devido à oxidação deste aminoácido na exposição contínua do calor fornecido pela piastra. Isto pode ser um indicativo que esta formulação foi capaz de prevenir parcialmente a oxidação deste aminoácido nas fibras de cabelo pelo uso do calor;

5) o deslocamento da banda que corresponde à deformação fora do plano em $\mathrm{N}-\mathrm{H}_{2}$, em torno $803 \mathrm{~cm}^{-1}$, pela sobreposição das bandas em 79 e $796 \mathrm{~cm}^{-1}$ (nos espectros das amostras de MCDM+A e MCDM+B, respectivamente), o que fez aumentar sua intensidade. Bandas em torno de $800 \mathrm{~cm}^{-1}$ também podem estar relacionadas aos grupos funcionais presentes nas formulações aplicadas, que se fixaram nos fios de cabelo mesmo após as sucessivas lavagens com LESS. Isto porque a banda relacionada ao grupo $\mathrm{Si}-\left(\mathrm{CH}_{3}\right)$ de siloxanos (presente nos espectros de amostras dos ingredientes cosméticos e no dimeticone) vibra em torno de $800 \pm 10 \mathrm{~cm}^{-1}$. Esta banda foi observada nos resultados de IV das formulações no item 6.2.3.1. corroborando os resultados aqui obtidos. Este efeito na superfície dos fios pode ser confirmado pelas imagens de MEV (no item logo adiante) que demonstrou a presença da formulação na superfície dos fios de cabelo, claramente visível nas amostras de MCDM+B (Figura $6.43 \mathrm{c}$ ).

6) o aumento na intensidade da bandas em torno de $873 \mathrm{~cm}^{-1}$ nos espectros das amostras de MCDM+A e MCDM+B. Estas bandas, juntamente com a banda em $1303 \mathrm{~cm}^{-1}$, que aparecem em todos os espectros correspondem à vibração de flexão dos grupos C-H fora e no plano (PENG et al., 2008). 
De todas as alterações acima relatadas, o espectro da amostra das mechas MCDM $+C$ apresentou apenas o deslocamento da banda de amida II. Porém, este espectro quando comparado ao das amostras de cabelo caucasiano controle (antes do tratamento térmico), também apresentou uma diminuição na intensidade das bandas em torno de 2933 e $2851 \mathrm{~cm}^{-1}$.

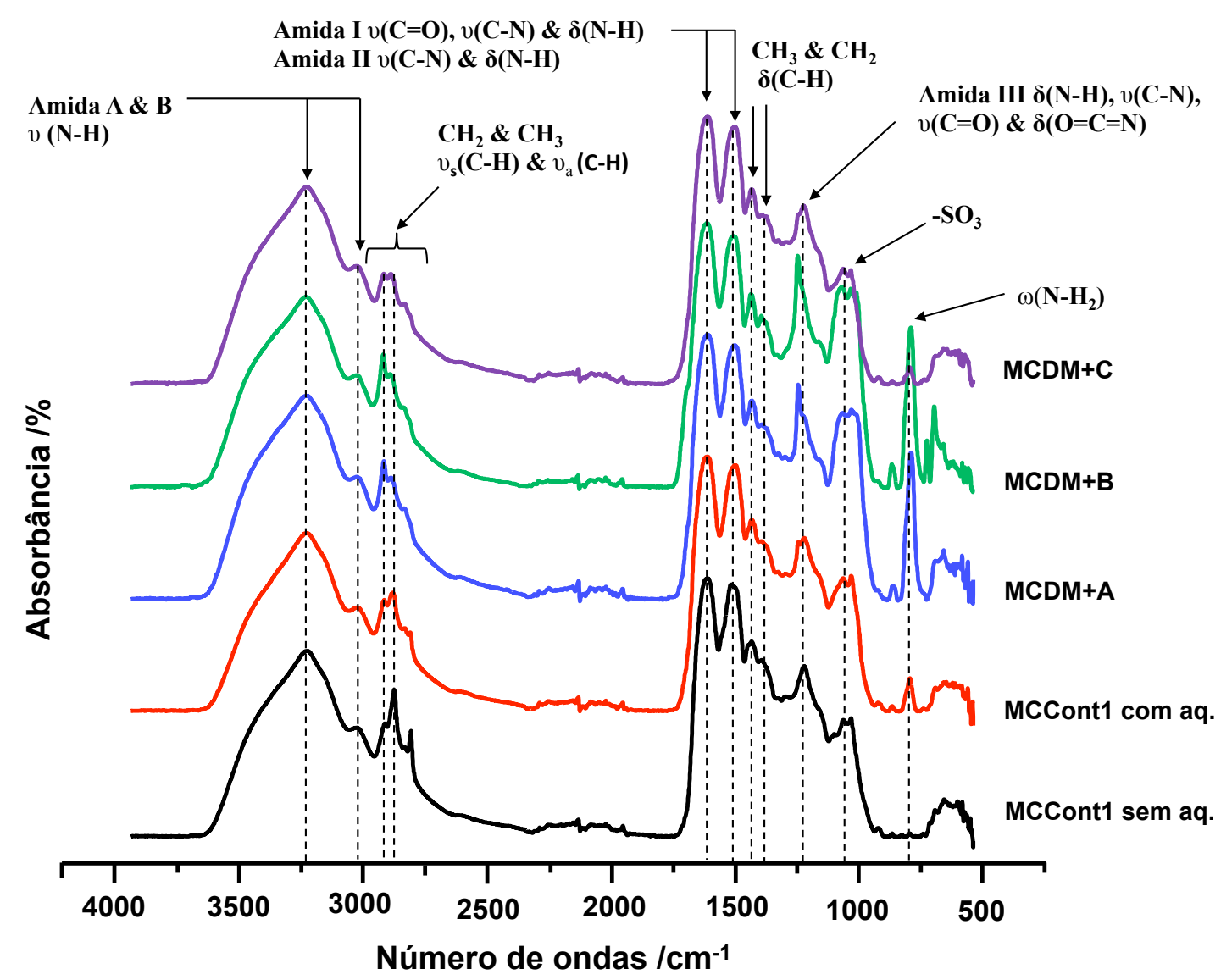

Figura 6.37 Espectros de absorção na região do IV de amostras das mechas de cabelo caucasiano padrão antes e após tratamento térmico e aplicação das formulações F2A, F2B e F2C.

A Figura 6.38 apresenta os espectros no VI das amostras de cabelo caucasiano das mechas controle (antes e após tratamento térmico) e submetidas às formulações contendo o condicionador leave-on como veículo (após tratamento térmico). Pela semelhança apresentada entre estes espectros, podese dizer que estas mechas sofreram menores alterações em suas estruturas do que àquelas contendo dimeticone como veículo.

Não obstante, estas alterações, estão descritas como: 
1) deslocamento das bandas da amida II (de $1535 \mathrm{~cm}^{-1}$ observada no espectro da amostra das mechas virgem antes do tratamento térmico para 1518, 1519, 1517 e $1520 \mathrm{~cm}^{-1}$, observadas nos espectros das amostras de cabelo virgem, MCLo+A, MCLo+B e MCLo+C, após o tratamento térmico, respectivamente.

2) aumento na intensidade da banda de deformação angular de $\mathrm{N}-\mathrm{H}_{2}$ com vibração em torno de $800 \mathrm{~cm}^{-1}$ observada nos espectros de todas as amostras submetidas ao tratamento térmico com a piastra. $\mathrm{O}$ espectro da amostra das mechas MCLo+B apresentou esta banda com maior intensidade do que àquelas observadas nos espectros das outras amostras das mechas submetidas às formulações. Este aumento na intensidade desta banda, porém, ainda apresentou-se menor do que o observado no espectro da amostras das mechas controle submetidas ao tratamento térmico.

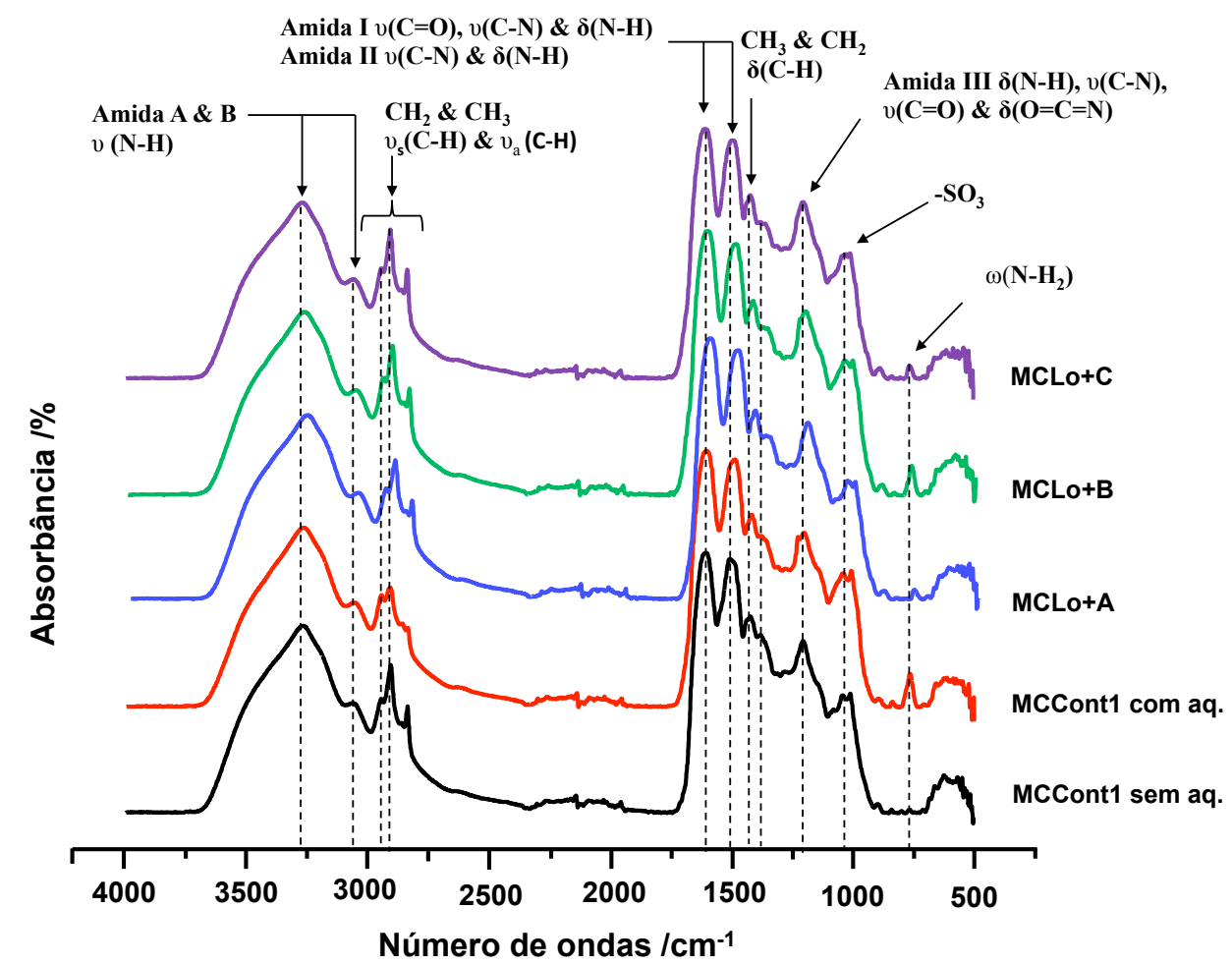

Figura 6.38 Espectros de absorção na região do IV de amostras das mechas de cabelo caucasiano padrão antes e após tratamento térmico e aplicação das formulações F3A, F3B e F3C. 
A Tabela 6.27 apresenta os resultados das principais bandas de absorção presentes nos espectros das amostras de cabelo oriental controle (antes do tratamento térmico) e submetidas aos ciclos de aquecimento e lavagens. Assim como no espectro da amostra de cabelo caucasiano, foi possível observar a presença das mesmas bandas de absorção nos espectros destas amostras. Porém, como mostrado nas Figuras 6.39 e 6.40, nota-se que houve alterações em algumas regiões destes espectros.

Tabela 6.27 Atribuição das principais bandas dos espectros no IV de amostras das mechas de cabelo virgem oriental tratadas com as formulações e submetidas ao tratamento térmico (piastra/lavagem com LESS $10 \% \mathrm{~m} / \mathrm{m}$ ).

\begin{tabular}{|c|c|c|c|c|c|c|c|c|}
\hline \multirow{3}{*}{$\begin{array}{c}\text { Grupo } \\
\text { funcional }\end{array}$} & \multicolumn{8}{|c|}{ Número de ondas $/ \mathrm{cm}^{-1}$} \\
\hline & \multicolumn{8}{|c|}{ Tratamento } \\
\hline & Cont1 & Cont1* & F2A & F2B & F2C & F3A & F3B & F3C \\
\hline Amida A & 3280 & 3279 & 3279 & 3278 & 3277 & 3280 & 3281 & 3283 \\
\hline Amida B & 3075 & 3076 & 3073 & 3074 & 3074 & 3075 & 3074 & 3069 \\
\hline $\mathrm{CH}_{3} \mathrm{Assim}$ & 2958 & 2961 & 2962 & 2963 & 2963 & 2959 & 2959 & 2957 \\
\hline $\mathrm{CH}_{2}$ Assim & 2920 & 2925 & 2934 & 2934 & $* *$ & 2922 & 2921 & 2921 \\
\hline $\mathrm{CH}_{2} \mathrm{Sim}$ & 2851 & 2854 & ** & ** & ** & 2853 & 2852 & 2852 \\
\hline Amida I & 1633 & 1633 & 1631 & 1630 & 1634 & 1634 & 1637 & 1638 \\
\hline Amida II & 1535 & 1518 & 1519 & 1523 & 1521 & 1520 & 1521 & 1518 \\
\hline $\begin{array}{c}\mathrm{CH}_{2} \\
\text { (lipídeos) }\end{array}$ & 1451 & 1450 & 1449 & 1450 & 1450 & 1452 & 1451 & 1451 \\
\hline Amida III & 1236 & 1235 & 1237 & ** & $* *$ & 1236 & 1232 & 1236 \\
\hline $\begin{array}{l}\text { Monóxido } \\
\text { de cistina }\end{array}$ & 1075 & 1076 & 1077 & 1079 & 1079 & 1076 & 1078 & $* *$ \\
\hline $\begin{array}{c}\text { Ácido } \\
\text { sulfônico }\end{array}$ & 1043 & 1042 & 1042 & 1041 & 1042 & 1043 & 1042 & 1043 \\
\hline $\mathrm{NO}_{2}$ & 874 & 874 & 874 & 872 & 871 & - & 874 & - \\
\hline $\mathrm{N}-\mathrm{H}_{2}$ & 803 & 802 & 799 & 796 & 796 & 802 & 800 & 797 \\
\hline
\end{tabular}

** bandas sobrepostas ou com expressiva diminuição na intensidade do sinal; Cont1 = controle (virgem, sem tratamento térmico); Cont $1^{*}=$ controle (virgem, após tratamento térmico); $\mathrm{A}, \mathrm{B}$ e $\mathrm{C}=$ ingredientes cosméticos. 
Comparando os espectros das amostras de cabelo oriental controle antes e após o tratamento térmico, observou-se que esta última apresentou as seguintes alterações (já foram discutidas logo acima):

1) diminuição das bandas em 2920 e $2851 \mathrm{~cm}^{-1}$ relacionadas aos grupos $\mathrm{CH}_{3}$ e $\mathrm{CH}_{2}$ oriundos de aminoácidos, nos modos assimétrico e simétrico, respectivamente (KIM \& PARK, 2013).

2) deslocamento da banda de amida II e

3) aumento na intensidade da banda em torno de $803 \mathrm{~cm}^{-1}$.

Os espectros das mechas de cabelo oriental submetidas às formulações contendo o dimeticone como veículo (Figura 6.39), mostraram que houveram:

1) o aumento na intensidade da banda em $2963 \mathrm{~cm}^{-1}$ que podem estar associada com alterações conformacionais de proteínas, conforme já discutido (SILVERSTEIN et al., 2007);

2) a diminuição das bandas em 2920 e $2851 \mathrm{~cm}^{-1}$ em todas as amostras submetidas ao tratamento térmico;

3) o deslocamento da banda de amida II em todas as amostras tratadas termicamente;

4) o aparecimento de bandas em torno de $1259 \mathrm{~cm}^{-1}$. Essa banda pode estar relacionada tanto com a amida III da conformação aleatória espiral, quanto aos grupos siloxanos conforme discutido logo acima;

5) e o aumento na intensidade da banda em torno de $803 \mathrm{~cm}^{-1}$ (deformação fora do plano em $\mathrm{N}-\mathrm{H}_{2}$ ), devido, provavelmente, a sobreposição das bandas em torno de $800 \mathrm{~cm}^{-1}$ também relacionada ao sinal dos grupos Si$\left(\mathrm{CH}_{3}\right)$ oriundo das formulações contendo o dimeticone como veículo. Este aumento deslocou as bandas em torno de $800 \mathrm{~cm}^{-1}$ para 799, 796 e 796 $\mathrm{cm}^{-1}$, observadas nos espetros das amostras de MODM+A, MODM+B e $M O D M+C$, respectivamente. As duas últimas apresentaram este aumento mais acentuado. 


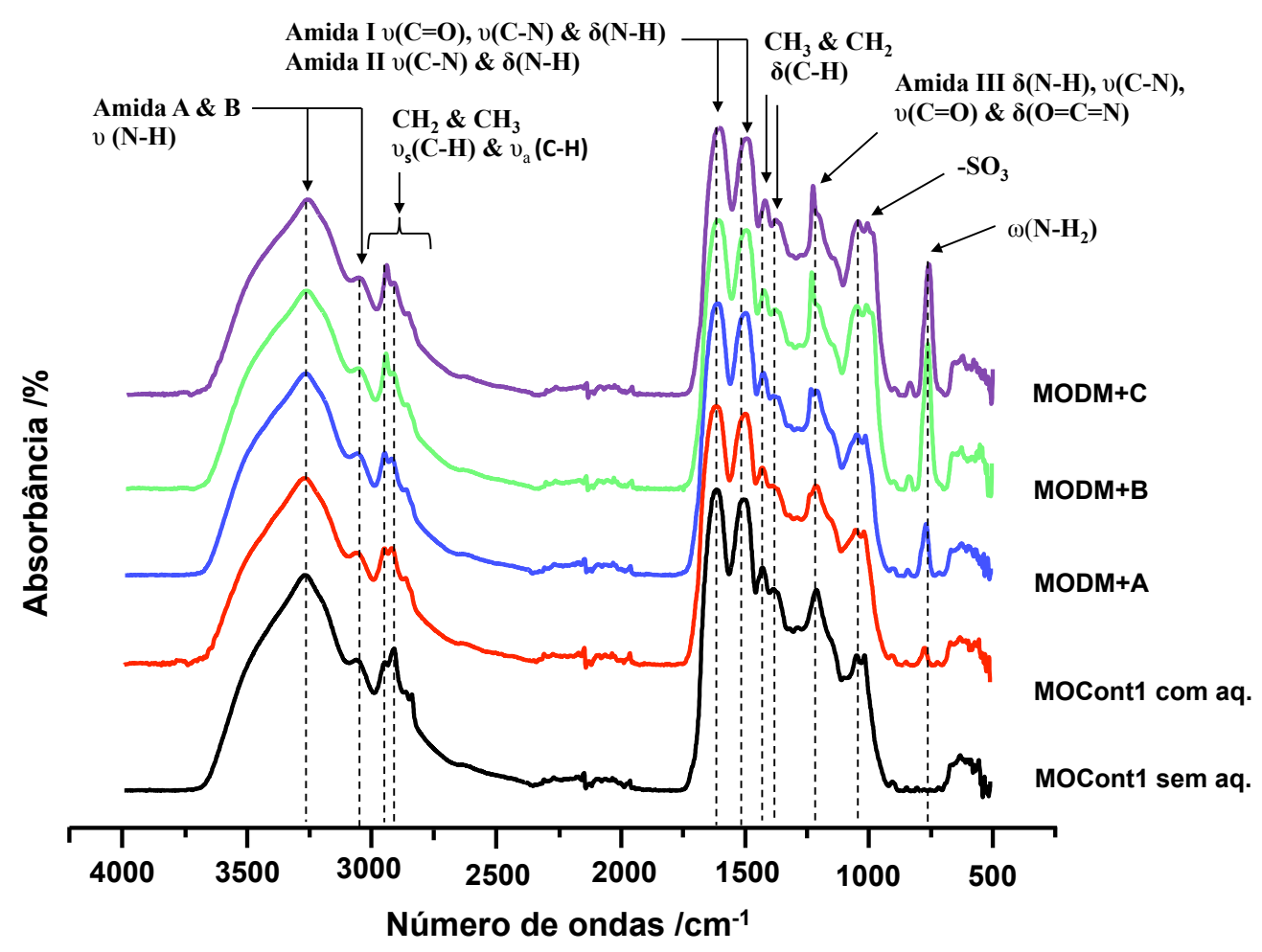

Figura 6.39 Espectros de absorção na região do IV de amostras das mechas de cabelo oriental padrão antes e após tratamento térmico e aplicação das formulações F2A, F2B e F2C.

A Figura 6.40 apresenta os espectros na região do IV das amostras de cabelo oriental das mechas de cabelo controle (antes e após tratamento térmico) e submetidas às formulações contendo o condicionador leave-on como veículo (após tratamento térmico). É possível notar que os espectros das amostras submetidas ao tratamento térmico mostraram:

1) aumento na intensidade das bandas em $2920 \mathrm{~cm}^{-1}$ (com exceção da amostra das mechas controle) e $2850 \mathrm{~cm}^{-1}$ (em MODM+B e MODM+C);

2) deslocamento das bandas de amida II;

3) aumento na intensidade das bandas em torno de $800 \mathrm{~cm}^{-1}$ para todas as amostras das mechas submetidas ao tratamento térmico, sendo que as amostras das mechas submetidas a F3B esse aumento apresentou-se maior do que para as amostras submetidas a F3A e F3C.

4) o surgimento da banda em torno $1250 \mathrm{~cm}^{-1}$ foi observado apenas para as amostras de MOLo+B, demonstrando uma possível presença de grupos Si$\left(\mathrm{CH}_{3}\right)$ juntamente com a presença da banda em $800 \mathrm{~cm}^{-1}$ mais intensa que 
a observada no espetro da amostra da mecha controle. Como já discutido anteriormente, este resultado pode estar associado à aderência de F3B nas amostras de cabelo.

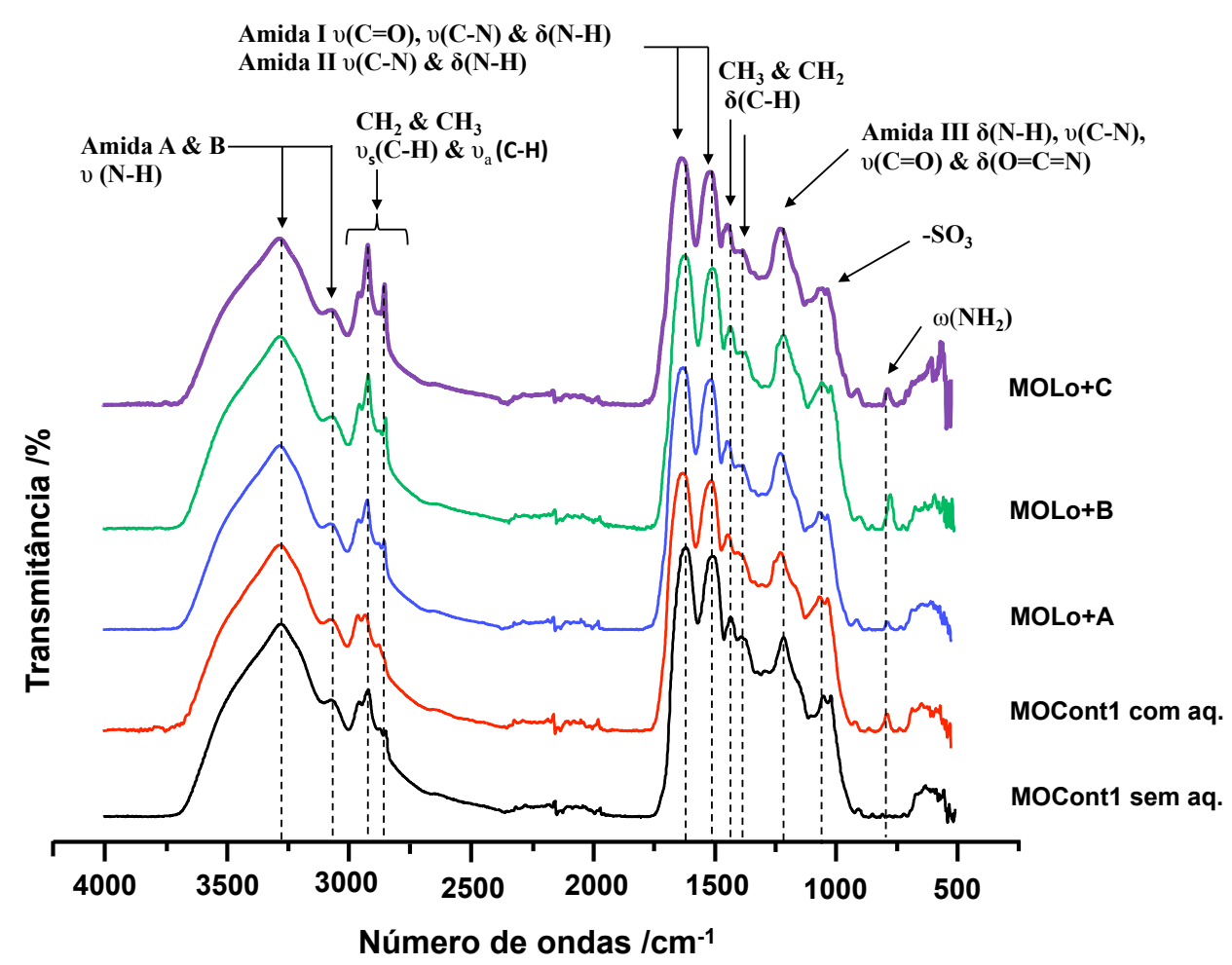

Figura 6.40 Espectros de absorção na região do IV de amostras das mechas de cabelo oriental padrão antes e após tratamento térmico e aplicação das formulações F3A, F3B e F3C.

A Tabela 6.28 destaca as principais bandas de absorção presentes nos espectros das amostras de cabelo brasileiro virgem e descolorido (sem tratamento térmico) e tratadas com as formulações (com tratamento térmico). 


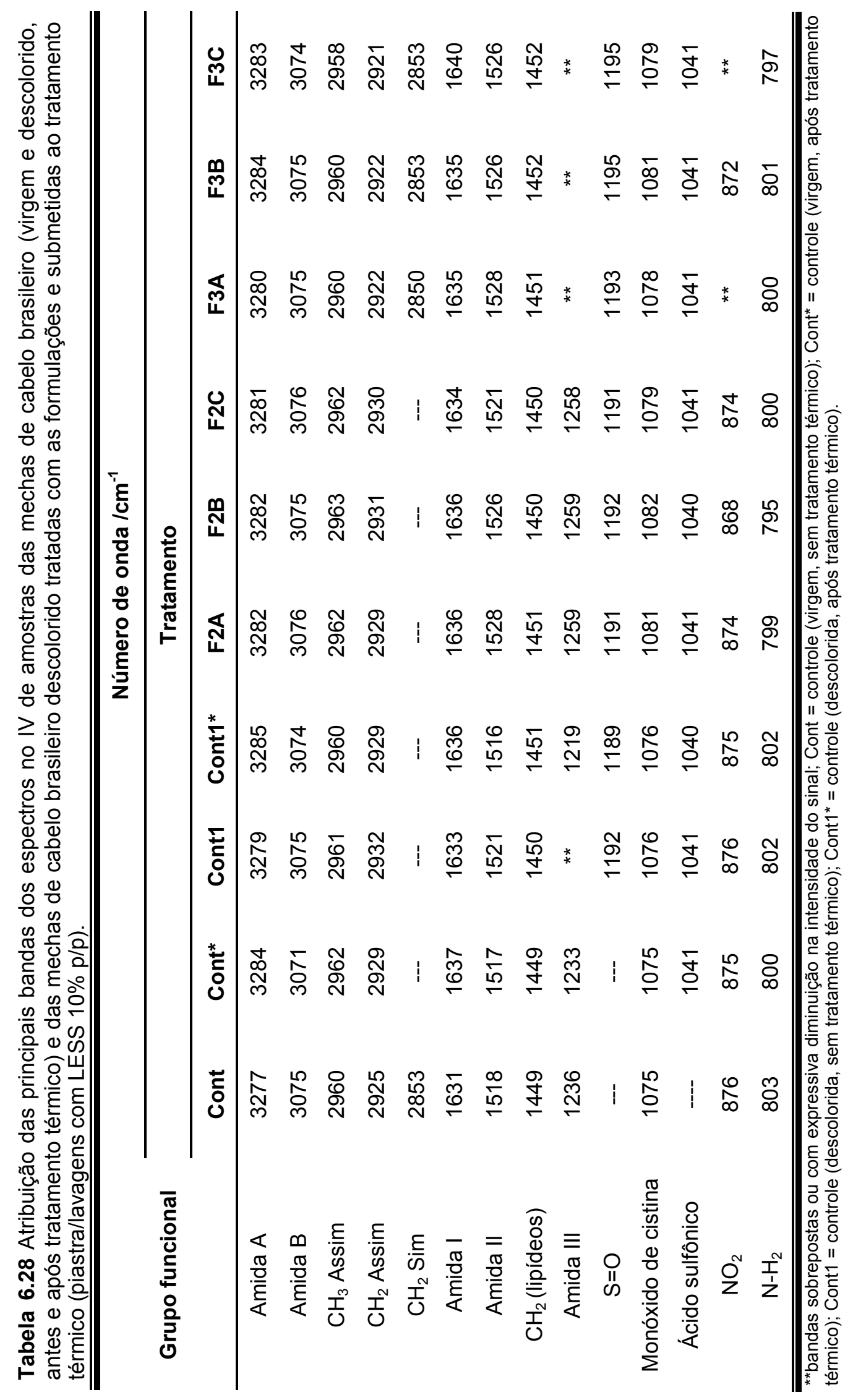


Pode-se observar, pelas Figuras 6.41 e 6.42, as diferenças nos espectros destas amostras em relação aos espectros apresentados até o momento. Isto porque mechas de cabelo submetidas a transformações químicas, como clareamento, produzem espectros com sinais específicos, o que não ocorre com amostras de cabelo não tratadas, ou seja, virgem (mechas de cabelo caucasiano e oriental não foram submetidas a transformações químicas com produtos).

Comparando os espectros das amostras de cabelo brasileiro virgem controle (MBCont) antes e após o tratamento térmico, observou-se que para esta última ocorreram algumas alterações devido, provavelmente, à exposição excessiva de calor. Estas alterações manifestaram nos espectros:

1) diminuição na intensidade das bandas em $2920 \mathrm{~cm}^{-1}$;

2) deslocamento da banda de amida III;

3) aumento na intensidade das bandas em torno $873 \mathrm{e}$ de $800 \mathrm{~cm}^{-1}$ relacionadas à vibração dos grupos $\mathrm{NO}_{2}$ e N-H , respectivamente.

4) A banda em $929 \mathrm{~cm}^{-1}$ (que não está sinalizado nas Figuras 6.41 e 6.42) presente apenas na mecha MBCont (com tratamento térmico) é atribuída a modos de vibração da amida IV, que consiste principalmente da flexão em $\mathrm{O}=\mathrm{C}-\mathrm{N}$ e pode ser, neste caso, considerado mais um dos fatores que evidencia a mudança na estrutura da queratina capilar.

Os espectros das amostras das mechas MBCont1 (antes e após o tratamento térmico) apresentaram:

1) aparecimento da banda $1411 \mathrm{~cm}^{-1}$ que evidencia a transformação química de cabelos utilizando produto cosmético contendo $\mathrm{pH}$ acima de 4,2, pois neste $\mathrm{pH}$ os grupos de ácido carboxílicos estão nas suas formas ionizáveis, podendo resultar no modo simétrico $\mathrm{CO}_{2}$ (WILLIAMS \& FLEMING, 1995).

2) deslocamento da banda de amida III pelo surgimento da banda em 1192 $\mathrm{cm}^{-1}$, referente ao ácido cistéico assimétrico, produto gerado na transformação química;

3) aumento na intensidade da banda em $1075 \mathrm{~cm}^{-1}$ que refere-se ao monóxido de cistina, produto de reação oxidativa da queratina capilar. Além dos espectros das amostras das mechas tratadas quimicamente (MBCont1), o espectro da amostra das mechas virgens (MBCont) apresentou uma banda em $1076 \mathrm{~cm}^{-1}$, referente ao monóxido de cisteína. 
Isto porque, os cabelos virgens também podem sofrer danos oxidativos devido à radiação ultravioleta (SIGNORI \& LEWIS, 1997), como já mencionado anteriormente, $\mathrm{e}$

4) diminuição na intensidade do sinal em $800 \mathrm{~cm}^{-1}$.

Correlacionando os espectros das amostras das mechas virgens com aqueles das mechas descoloridas (ambas antes do tratamento térmico), observase uma diferença básica entre eles, que é aumento na intensidade do sinal da banda em torno de $1040 \mathrm{~cm}^{-1}$ (sulfóxido) e o surgimento da banda em torno de $1192 \mathrm{~cm}^{-1}$ (sulfito), referente ao estiramento de $\mathrm{SO}_{2}$, produtos da oxidação da cistina. Esta última banda geralmente aparece como um ombro na banda de amida III. Essas bandas, em conjunto, compreendem uma região espectral importante no que diz respeito às respostas de oxidação do aminoácido cistina e trata-se de um indicador prático de um cabelo submetido a tratamentos cosméticos. Esta região se encontra, normalmente, entre 1200 e $1000 \mathrm{~cm}^{-1}$. As bandas nesta faixa de absorção fornecem evidências de alterações químicas decorrentes de danos oxidativos à fibra como consequência de tratamentos químicos de clareamento, tingimento permanente e/ou ondulação permanente. Sob estas condições as ligações cruzadas dissulfeto da cistina são oxidadas para ácido cistéico $\left(\mathrm{SO}_{3}\right)$ e intermediários oxidativos, monóxido de cistina $(\mathrm{S}=\mathrm{O})$, dióxido de cistina $\left(\mathrm{SO}_{2}\right)$ e tiossulfato de cisteína. Porém, uma banda com sinal fraco em $1040 \mathrm{~cm}^{-1}$ pode ser encontrada em espectros de amostras de cabelo não tratados, ou seja, virgem (BARTON, 2011).

Os espectros das amostras das mechas de cabelo brasileiro descoloridas submetidas às formulações contendo o dimeticone como veículo, indicaram algumas alterações em seus espectros (comparadas aos espectros das amostras das mechas controle descolorida), são elas:

1) aumento na intensidade das bandas em $2920 \mathrm{~cm}^{-1}$ e $2850 \mathrm{~cm}^{-1}$ (das três mechas tratadas com as formulações, a MBDM+C apresentou um maior aumento), o qual correspondem à deformação axial $\mathrm{C}$-H alifático e aos grupos $\mathrm{CH}_{2}$ assimétricos, respectivamente;

2) deslocamento da banda de absorção amida II;

3) aumento na intensidade da banda em $1192 \mathrm{~cm}^{-1}$ e deslocamento da banda de amida III; 
4) apenas o espectro das amostras de MBDM+B apresentou um aumento na intensidade da banda em torno de $800 \mathrm{~cm}^{-1}$, devido, provavelmente, ao acúmulo da formulação na superfície dos fios de cabelo, como já discutido anteriormente.

Os espectros da amostra das mechas controle, virgens, antes do tratamento térmico, não apresentaram os dois sinais da banda de amida III, e sim um em $1236 \mathrm{~cm}^{-1}$. Porém, o espectro da amostra das mechas controle, virgens, após o tratamento térmico apresentou dois sinais da banda de amida III, em 1233 e $1260 \mathrm{~cm}^{-1}$, sendo o último com maior intensidade. Como estas mechas não foram descoloridas, podemos concluir que esta mudança na conformação da proteína se deve ao tratamento térmico utilizado nestas. Em outras palavras, podemos sugerir que cabelos submetidos ao uso contínuo de dispositivos térmicos, associados a constantes lavagens podem levar a danos de nível estrutural aos seus fios.

Os espectros das amostras das mechas descoloridas, antes e após o tratamento térmico, apresentaram o surgimento de uma banda em torno de 1192 $\mathrm{cm}^{-1} \mathrm{com}$ intensidade suficiente para sobrepor a banda de amida III. Porém a segunda apresentou a banda de amida III em $1219 \mathrm{~cm}^{-1}$ quase que sobreposta pela banda de $1192 \mathrm{~cm}^{-1}$. Este dado já é um indício de que além do tratamento de descoloração, a aplicação do calor nas condições estabelecidas por esse estudo, propiciou um aumento ainda maior na mudança da conformação da proteína secundária presentes na matriz capilar.

Os espectros das amostras das mechas descoloridas que foram tratadas com as formulações (contendo dimeticone como veículo) e posterior tratamento térmico, apresentaram dois sinais da banda de amida III (com intensidade maior em $1259 \mathrm{~cm}^{-1}$ ) e uma outra em torno de $1192 \mathrm{~cm}^{-1}$. Isto não foi observado para as mechas tratadas com leave-on como veículo, pois apresentaram a banda de 1192 $\mathrm{cm}^{-1}$ totalmente sobrepondo as bandas de amida III.

Os resultados de IV mostraram, também, que os fios de cabelo não tiveram seus córtex expostos. As bandas de amida I e II da proteína cristalina (presente no córtex) são em torno de 1650 e $1540 \mathrm{~cm}^{-1}$, respectivamente, valores estes que não foram obtidos no trabalho, indicando também, que as transformações estão 
sendo analisadas nas regiões da cutícula e/ou periferia do córtex. Pelas imagens de MEV (mostrados no item 6.4.1.5), é possível observar que os fios não apresentaram o córtex exposto, mesmo com severos danos às cutículas. Apenas a amostra da MCLo+C apresentou trechos em que o córtex se expandiu para fora da camada da cutícula.

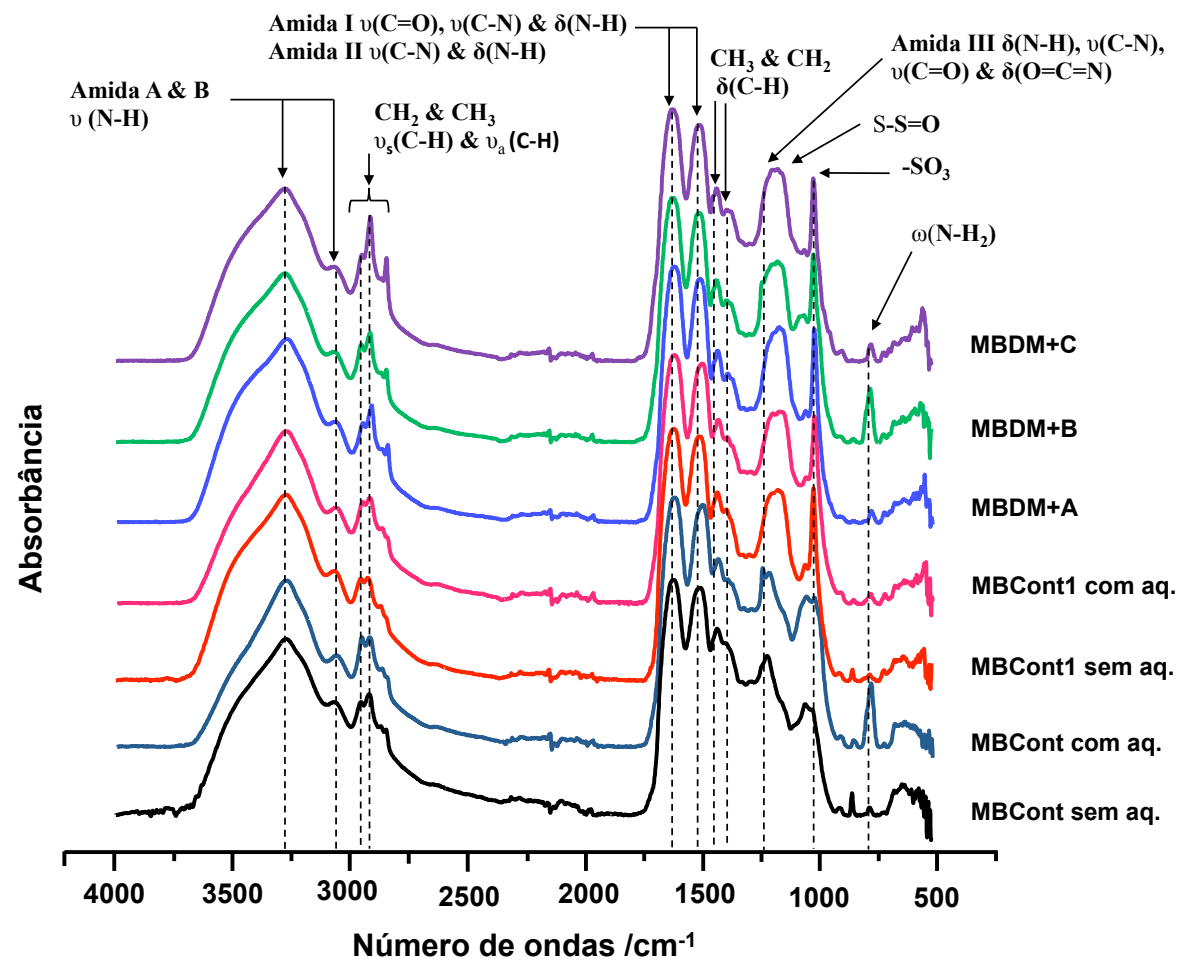

Figura 6.41 Espectros de absorção na região do IV de amostras das mechas de cabelo brasileiro virgem e descolorido antes e após tratamento térmico e aplicação das formulações F2A, F2B e F2C.

A partir da Figura 6.42, pode-se observar que os espectros das amostras das mechas descoloridas submetidas ao tratamento térmico após utilização das formulações contendo leave-on como veículo, indicaram um maior número de alterações quando comparadas as mechas descoloridas que foram tratadas com dimeticone. São elas:

1) MBLo+B apresentou um aumento na intensidade da banda em $2963 \mathrm{~cm}^{-1}$;

2) deslocamento da banda de amida II;

3) aumento da intensidade da banda em $1192 \mathrm{~cm}^{-1}$ sobrepondo a banda de amida III; 
4) aumento na intensidade da banda em torno de $873 \mathrm{~cm}^{-1}$ (mais intenso para a amostra de MBLo+B).

5) aumento das bandas em torno de $800 \mathrm{~cm}^{-1}$. Este aumento pode ser devido ao aumento da aderência das formulações nas fibras de cabelo, que possuem forte sinal nesta região, mesmo após consecutivas lavagens.

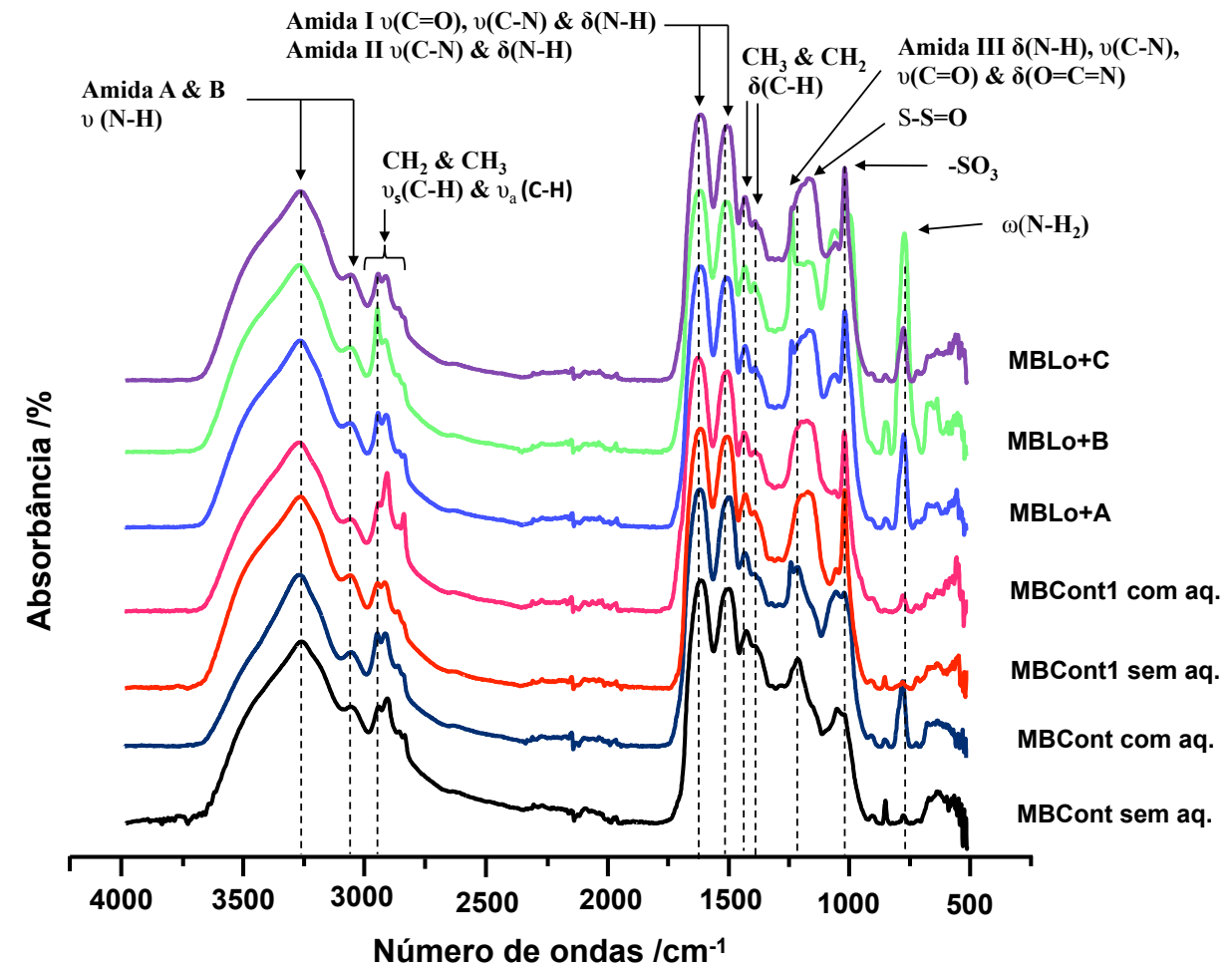

Figura 6.42 Espectros de absorção na região do IV de amostras das mechas de cabelo brasileiro virgem e descolorido antes e após tratamento térmico e aplicação das formulações F3A, F3B e F3C.

\subsubsection{Microscopia eletrônica de varredura}

Esta técnica foi utilizada com o intuito de avaliar o efeito na superfície de fios de cabelos contendo diferentes ingredientes cosméticos submetidos ao estresse de repetidos ciclos de lavagens e aquecimentos. Foram utilizadas para comparação as imagens obtidas de amostras das mechas controle, ou seja, sem a aplicação das formulações. É válido relatar que, para cada mecha, foram coletados diversos fios aleatórios e cortados em pequenas porções com o intuito de assegurar a reprodutibilidade das medidas. 
A proteção da superfície do cabelo pode assegurar a integridade da cutícula e desempenha um papel importante no seu efeito anti-quebra além de proteger a proteína córtex de danos térmicos.

As Figuras 6.43-6.45 apresentam as imagens de fibras de cabelo caucasiano, oriental e brasileiro que foram submetidas a este estudo. Observando as imagens é possível averiguar que o tratamento térmico provocou danos graves nas cutículas das fibras capilares com agravamento principalmente nas amostras das mechas controle (sem formulações) e descoloridas. Uma vez que a cutícula está danificada, o cabelo pode quebrar facilmente já que não há proteção para o córtex.

As imagens de MEV evidenciaram que as amostras das mechas tratadas termicamente não aparentaram exposição do córtex, estando as cutículas com um certo grau de danos. A partir das medidas de DSC não foi possível obter dados de entalpia da desnaturação da queratina para algumas destas amostras, sugerindo que há uma pequena porção ou até mesmo a ausência de material cristalino. Isto leva a crer que, mesmo com a camada cuticular com uma certa integridade, o córtex pode sofrer danos, como por exemplo, a desnaturação da queratina cristalina. Estes resultados podem ser explicados conforme aqueles obtidos por Istrate et al. (2012). Os autores mostraram que, com o aquecimento, o material do córtex pode fundir formando espécies de micro tubos de material cuticular envolto. Como já mencionado (item 6.1.2), o material ordenado se funde, enquanto a cutícula, que é constituída de material amorfo, permaneceu intacta, também verificados nos resultados de IV deste trabalho. Os autores atribuem este comportamento às diferentes morfologias das camadas, ou seja, a camada amorfa sendo mais resistente termicamente. Além disto, podemos afirmar que cabelos com aparência saudável nem sempre significam fios saudáveis. Isto pode ser ainda explicado pelos resultados obtidos por Sá Dias (2015) que verificou que fios tratados quimicamente com ativos alisantes apresentaram diminuição no valor de entalpia relacionada à desnaturação do material cristalino. Porém, as imagens de MEV obtidas pela autora mostraram que estes fios ainda possuíam uma certa regularidade na camada cuticular, mesmo apresentando danos e não expondo o córtex. É claro que estas mechas foram quimicamente oxidadas e posteriormente reduzidas com fechamento das cutículas. Porém, os resultados do presente 
trabalho mostraram que apenas o tratamento térmico (sem aplicação de produto químico) pode causar danos ao córtex dos fios de cabelo tanto quanto àqueles quimicamente tratados. Isto porque as mechas de cabelo caucasiano, oriental e brasileiro (MCCont1, MOCont1 e MBCont) que não foram descoloridas demonstraram alterações estruturais com diminuição nos valores de entalpia de desnaturação da queratina cristalina em 42, 30 e 36\% para as amostras de cabelo caucasiano e oriental virgem e brasileiro descolorido, respectivamente (resultados que podem ser observados na Tabela 6.23).

Comparando as amostras das mechas da Figura 6.43, (cabelo caucasiano), pode-se visualizar que aquelas que foram submetidas às formulações contendo o dimeticone como veículo apresentaram-se com as cutículas com um bom nível de integridade. Analisando vários fios das mesmas mechas, verificou-se que houve o depósito da formulação F2B na superfície dos fios, não deixando dúvidas que há um filme sobre estes, no entanto não foi observado a exposição do córtex. Este efeito pode resultar em fios mais uniformes, apresentando-se mais lisos. Nos resultados de FTIR, a banda referente aos grupos siloxanos apresentou-se com uma intensidade maior para estas amostras, juntamente com as amostras de MCDM+A. Porém, esta última não foi possível observar, pelas imagens, a aderência do silicone na superfície dos fios.

As imagens das amostras das mechas tratadas com as formulações contendo leave-on como veículo mostraram que as cutículas se mantiveram íntegras com exceção das amostras tratadas com F3C.

Comparando as imagens de MEV das amostras das mechas na Figura 6.44 (cabelo oriental) é possível verificar que aquelas que foram submetidas às formulações contendo o dimeticone como veículo apresentaram-se com as cutículas mais uniformes do que as que foram tratadas com as formulações F3A, F3B e F3C. As mechas submetidas a estas últimas formulações apresentaram-se com as cutículas mais "levantadas", mais agredidas do que as observadas nas imagens das amostras de cabelo caucasiano. Estas observações corroboram com os dados de DSC obtidos para os ambos tipos de cabelo, que estão demonstrados na Tabela 6.20. Apesar das cutículas se mostrarem com certo 
nível de repulsão pelo tratamento térmico intercalado com as lavagens, não se observou exposição do córtex nas imagens. Os danos internos e a superfície resultante do tratamento térmico pode aumentar a ruptura das fibras especialmente com o esforço adicional quando se penteia o cabelo.

A Figura 6.45 apresenta as imagens de MEV das amostras de cabelo brasileiro virgem e descolorido submetidas ao tratamento térmico. É possível observar que neste grupo os danos causados foram mais agressivos dentre os grupos estudados. Este fato era esperado uma vez que a aplicação de produtos com altos valores de $\mathrm{pH}$ ( $\mathrm{pH}$ médio 11), ocasiona danos, fazendo com que o fio torne-se cada vez mais fragilizado por tração mecânica, escovação e aplicação de calor (JACHOWICZ,1987; GAMA et al.,2011).

Foi possível observar que a amostra das mechas que foram tratadas com F3C apresentaram o depósito da formulação na superfície dos fios. Isto pode explicar o resultado de elevada proteção térmica indicada pelos dados de DSC para esta formulação neste grupo de cabelo, uma vez que os fios se encontram "plastificados". Porém, foi observada uma desintegração das cutículas com algumas partes faltantes e/ou camadas de cutículas irregulares. Nestas últimas pode-se observar, principalmente nas amostras de MBDM+A e MBLo+C, que as camadas cuticulares foram removidas, tornando o córtex exposto, rompendo para fora da camada da cutícula. Este comportamento foi observado em toda esta amostragem, ou seja, a imagem não representa um resultado isolado. Os resultados de DSC mostraram que as amostras de cabelo descolorido tratadas com leave-on não apresentaram a fase cristalina da matriz capilar. Isto pode estar associado à uma exposição do córtex ou até mesmo a uma certa porosidade deste tipo de cabelo que leva a uma dificuldade do produto em se manter na superfície dos fios. As imagens de MEV mostraram a importância desta técnica quando associada a outras, porém, isolada não é suficiente para afirmar que o tratamento com os ingredientes cosméticos evitou e/ou diminuiu os danos na cutícula devido ao tratamento térmico.

Pelas imagens, também é possível notar que não apenas os cabelos tratados quimicamente (com descolorante, por exemplo) podem sofrer danos severos aos fios, mas também aqueles que são submetidos a tratamentos físicos, como repetidas lavagens, secagem, escovar e pentear. E o dano é cumulativo. 

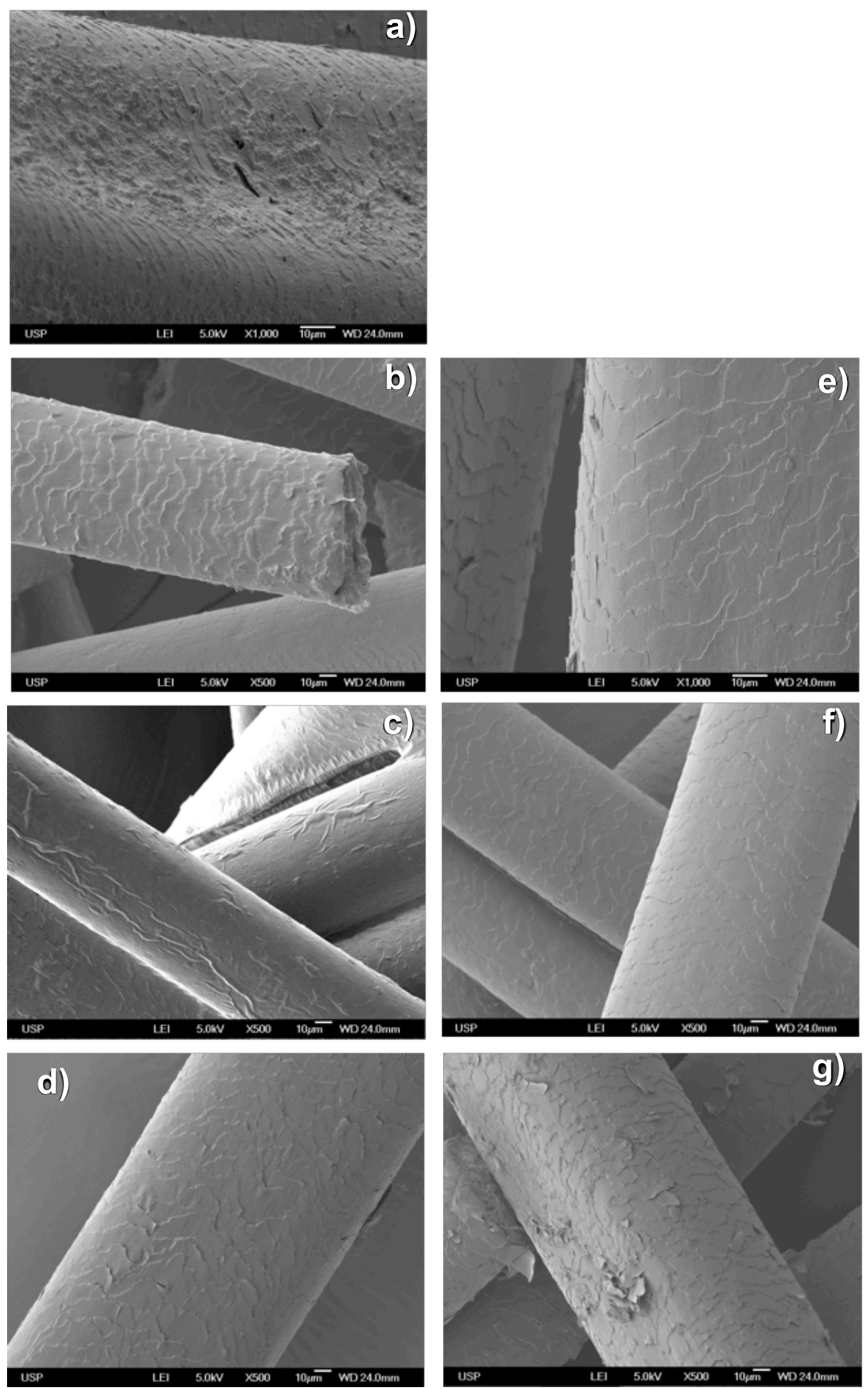

Figura 6.43 Imagens de MEV de amostras das mechas de cabelo caucasiano padrão virgem controle e submetidas às formulações: a) MCCont1; b) MCDM+A; c) MCDM+B; d) MCDM+C; e) MCLo+A; f) MCLo+B; g) MCLo+C. 

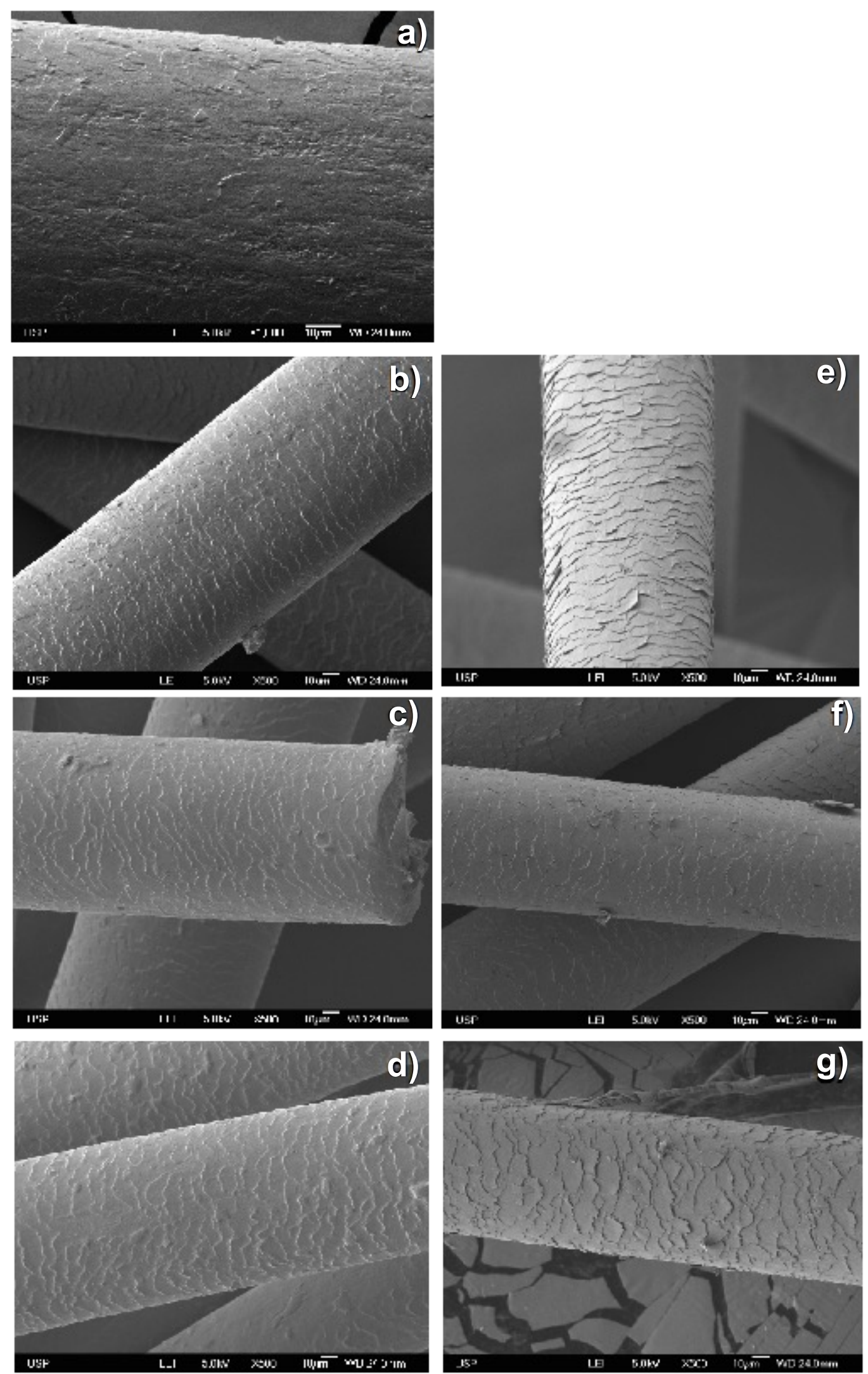

Figura 6.44 Imagens de MEV de amostras das mechas de cabelo oriental padrão virgem controle e submetidas às formulações: a) MOCont1; b) MODM+A; c) MODM+B; d) MODM+C; e) MOLo+A; f) MOLo+B; g) MOLo+C. 

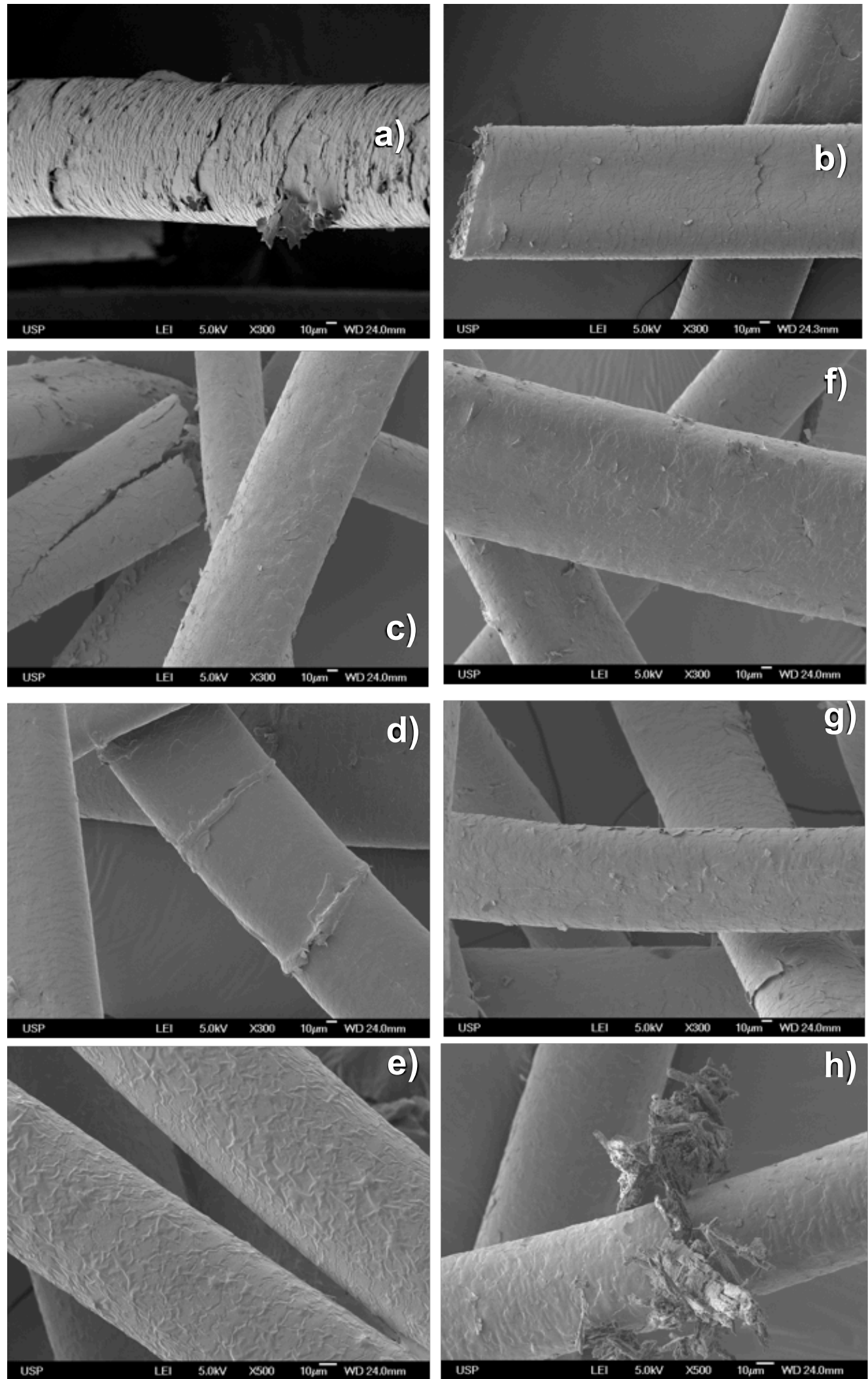

Figura 6.45 Imagens de MEV de amostras das mechas de cabelo brasileiro (grau de ondulação II) virgem controles e descoloridas submetidas às formulações: a) MBCont; b) MBCont1; c) MBDM+A; d) MBDM+B; e) MBDM+C; f) MBLo+A; g) MBLo+B; h) MBLO+C. 


\subsubsection{Avaliação de resistência à penteabilidade}

As mechas virgens e descoloridas de cabelo brasileiro (grau de ondulação II, de acordo com estudo realizado por De La Mettrie et al., 2007) tratadas com as formulações e submetidas ao tratamento térmico foram encaminhadas para os testes de penteabilidade a seco. Os resultados de força $(\mathrm{N})$ e trabalho (em joules) necessários para realização do teste destas mechas de cabelo estão apresentados na Tabela 6.29.

A partir dos resultados desses testes é possível observar que as mechas de cabelo descolorido apresentaram valor médio de trabalho de 0,044J. Gama (2011) avaliaram mechas de cabelos caucasiano submetido à aplicação das tinturas oxidativas pelo método de penteabilidade e observaram que o trabalho necessário para pentear a seco estas mechas variou em uma faixa de 0,02 a 0,034 J com valor médio de $0,027 \mathrm{~J}$. Porém as condições experimentais não foram as mesmas, o que pode resultar em uma diferença na obtenção dos resultados e impossibilitar, desta maneira, a comparação entre estes.

Os dados obtidos pelo teste de penteabilidade a seco foram submetidos à análise de variância para verificar diferenças estatísticas significativas entre as amostras e estão listados nas Tabelas 6.30 e 6.31 e melhor visualizados na Figura 6.46 e 6.47. Primeiramente foi aplicado o teste (ANOVA one-way, $\alpha=$ $0,05)$ para os resultados de todas as mechas, incluindo as mechas controle MBCont e MBCont1 (virgem e descolorida submetida ao tratamento térmico) e obteve-se um $p=0,349$, ou seja, as mechas tratadas não diferiram significativamente das virgens (Tabela 6.30). Este resultado não era esperado, uma vez que as mechas quando descoloridas apresentam-se com a superfície mais áspera devido aos processos químicos, descoloração e coloração, que influenciam no coeficiente de fricção elevando-o, alterando a estrutura da cutícula (SÁ DIAS et al., 2008). Segundo Halal (2011), cabelos clareados se tornam porosos e quebradiços. Uma explicação para estes resultados pode ser o fato de que a descoloração sob as condições experimentais do trabalho não foi o suficiente para alterar de forma significativa as propriedades de penteabilidade mesmo que tenha modificado a estrutura do córtex e da cutícula. 
Tabela 6.29 Valores de extensão $(\mathrm{m})$, força média $(\mathrm{N})$ e trabalho $(\mathrm{J})$ obtidos no teste de penteabilidade a seco das mechas de cabelo brasileiro tratadas com as formulações $e$ submetidas ao tratamento térmico (piastra/lavagem com LESS $10 \% \mathrm{~m} / \mathrm{m}$ ).

\begin{tabular}{|c|c|c|c|c|}
\hline Mecha & Mecha & Extensão (m) & Força Média (N) & Trabalho (J) \\
\hline \multirow{4}{*}{ MBCont } & 1 & 0,061 & 1,130 & 0,069 \\
\hline & 2 & 0,076 & 0,330 & 0,025 \\
\hline & 3 & 0,075 & 1,000 & 0,075 \\
\hline & $M \pm D P$ & $0,071 \pm 0,000$ & $0,82 \pm 0,430$ & $0,056 \pm 0,001$ \\
\hline \multirow{4}{*}{ MBCont1 } & 1 & 0,115 & 0,580 & 0,067 \\
\hline & 2 & 0,115 & 0,320 & 0,037 \\
\hline & 3 & 0,115 & 0,240 & 0,028 \\
\hline & $M \pm D P$ & $0,115 \pm 0,000$ & $0,38 \pm 0,180$ & $0,044 \pm 0,001$ \\
\hline \multirow{4}{*}{ MBDM+A } & 1 & 0,069 & 1,420 & 0,098 \\
\hline & 2 & 0,067 & 0,940 & 0,063 \\
\hline & 3 & 0,064 & 0,070 & 0,004 \\
\hline & $M \pm D P$ & $0,067 \pm 0,000$ & $0,810 \pm 0,680$ & $0,055 \pm 0,004$ \\
\hline \multirow{4}{*}{ MBDM+B } & 1 & 0,070 & 0,180 & 0,013 \\
\hline & 2 & 0,060 & 0,160 & 0,010 \\
\hline & 3 & 0,049 & 0,190 & 0,009 \\
\hline & $M \pm D P$ & $0,060 \pm 0,000$ & $0,180 \pm 0,010$ & $0,011 \pm 0,000$ \\
\hline \multirow{4}{*}{$\mathrm{MBDM}+\mathrm{C}$} & 1 & 0,071 & 1,860 & 0,132 \\
\hline & 2 & 0,095 & 0,100 & 0,010 \\
\hline & 3 & 0,065 & 0,850 & 0,055 \\
\hline & $M \pm D P$ & $0,077 \pm 0,001$ & $0,940 \pm 0,880$ & $0,066 \pm 0,008$ \\
\hline \multirow{4}{*}{ MBLo+A } & 1 & 0,064 & 1,760 & 0,113 \\
\hline & 2 & 0,070 & 1,280 & 0,090 \\
\hline & 3 & 0,072 & 0,530 & 0,038 \\
\hline & $M \pm D P$ & $0,069 \pm 0,000$ & $1,190 \pm 0,620$ & $0,080 \pm 0,003$ \\
\hline \multirow{4}{*}{ MBLo+B } & 1 & 0,075 & 0,180 & 0,014 \\
\hline & 2 & 0,067 & 0,600 & 0,040 \\
\hline & 3 & 0,066 & 0,830 & 0,055 \\
\hline & $M \pm D P$ & $0,069 \pm 0,000$ & $0,530 \pm 0,330$ & $0,036 \pm 0,001$ \\
\hline \multirow{4}{*}{ MBLo+C } & 1 & 0,073 & 0,950 & 0,069 \\
\hline & 2 & 0,066 & 0,430 & 0,028 \\
\hline & 3 & 0,072 & 0,120 & 0,009 \\
\hline & $M \pm D P$ & $0,070 \pm 0,000$ & $0,500 \pm 0,420$ & $0,035 \pm 0,002$ \\
\hline
\end{tabular}

MBCont = mecha de cabelo brasileiro virgem; MBCont1 = mecha de cabelo brasileiro descolorido; $\mathrm{M}$ = média; $\mathrm{DP}$ = desvio padrão. 
Tabela 6.30 Modelo de ANOVA para os resultados obtidos no teste de penteabilidade a seco das mechas de cabelo brasileiro (virgem e descolorido) tratadas com as formulações e submetidas ao tratamento térmico (piastra/lavagem com LESS $10 \% \mathrm{~m} / \mathrm{m}$ ).

\begin{tabular}{|c|c|c|c|c|c|c|c|c|}
\hline \multirow[b]{2}{*}{ Mecha } & \multicolumn{8}{|c|}{ Força Média (N) } \\
\hline & Cont $^{*}$ & Cont1* & $\mathbf{F 2 A}$ & F2B & $\mathrm{F} 2 \mathrm{C}$ & F3A & F3B & $\mathrm{F} 3 \mathrm{C}$ \\
\hline 1 & 0,58 & 1,13 & 1,76 & 0,18 & 0,95 & 1,42 & 0,18 & 1,86 \\
\hline 2 & 0,32 & 0,33 & 1,28 & 0,6 & 0,43 & 0,94 & 0,16 & 0,1 \\
\hline 3 & 0,24 & 1,00 & 0,53 & 0,83 & 0,12 & 0,07 & 0,19 & 0,85 \\
\hline Média & 0,38 & 0,82 & 1,19 & 0,54 & 0,50 & 0,81 & 0,18 & 0,94 \\
\hline D.P. & 0,18 & 0,43 & 0,62 & 0,33 & 0,42 & 0,68 & 0,02 & 0,88 \\
\hline Mínimo & 0,24 & 0,33 & 0,53 & 0,18 & 0,12 & 0,07 & 0,16 & 0,1 \\
\hline Mediana & 0,32 & 1,00 & 1,28 & 0,60 & 0,43 & 0,94 & 0,18 & 0,85 \\
\hline Máximo & 0,58 & 1,13 & 1,76 & 0,83 & 0,95 & 1,42 & 0,19 & 1,86 \\
\hline
\end{tabular}

$p$-valor $\quad 0,349$

Cont $^{*}=$ controle (virgem, sem formulação, após tratamento térmico); Cont1* = controle (descolorido, sem formulação, após tratamento térmico); A, B e C = ingredientes cosméticos.

Em uma segunda etapa, apenas os resultados das mechas submetidas aos tratamentos com as formulações e posterior tratamento térmico foram consideradas para o teste estatístico (ANOVA one-way, $\alpha=0,05$ ). Como $p=$ 0,359 (Tabela 6.31) não é rejeitada a hipótese de que todos os tratamentos são iguais. Em outras palavras, não foi observada nenhuma diferença entre os seis tratamentos (mechas submetidas a F2A, F2B, F2C, F3A, F3B e F3C), que pode ser observada nas Figuras 6.46 e 6.47.

De maneira geral, analisando os resultados obtidos, pode-se observar que os valores de força $(\mathrm{N})$ apresentaram uma notável variabilidade entre as mechas que foram submetidas ao mesmo tipo de tratamento. Este fato pode ser explicado pelo efeito da descoloração nas mechas de cabelo, que pode ter atribuído à elas um nível de porosidade diferente ou até mesmo ter alterado as propriedades das fibras em graus diferentes de danos. 
Tabela 6.31 Modelo de ANOVA para os resultados obtidos no teste de penteabilidade a seco das mechas de cabelo brasileiro descolorido tratadas com as formulações e submetidas ao tratamento térmico (piastra/lavagem com LESS $10 \% \mathrm{~m} / \mathrm{m}$ ).

\begin{tabular}{ccccccc}
\hline \hline Mecha & F2A & F2B & F2C & F3A & F3B & F3C \\
\hline \hline 01 & 1,42 & 0,18 & 1,86 & 1,76 & 0,18 & 0,95 \\
02 & 0,94 & 0,16 & 0,1 & 1,28 & 0,6 & 0,43 \\
03 & 0,07 & 0,19 & 0,85 & 0,53 & 0,83 & 0,12 \\
\hline Média & 0,8 & 0,2 & 0,9 & 1,2 & 0,5 & 0,5 \\
D.P. & 0,7 & 0,02 & 0,9 & 0,6 & 0,3 & 0,4 \\
Mínimo & 0,1 & 0,2 & 0,1 & 0,5 & 0,2 & 0,1 \\
Mediana & 0,9 & 0,2 & 0,9 & 1,3 & 0,6 & 0,4 \\
Máximo & 1,4 & 0,2 & 1,9 & 1,8 & 0,8 & 1,0 \\
\hline p-valor & & & 0,359 & & \\
\hline \hline
\end{tabular}

A, B e C = ingredientes cosméticos

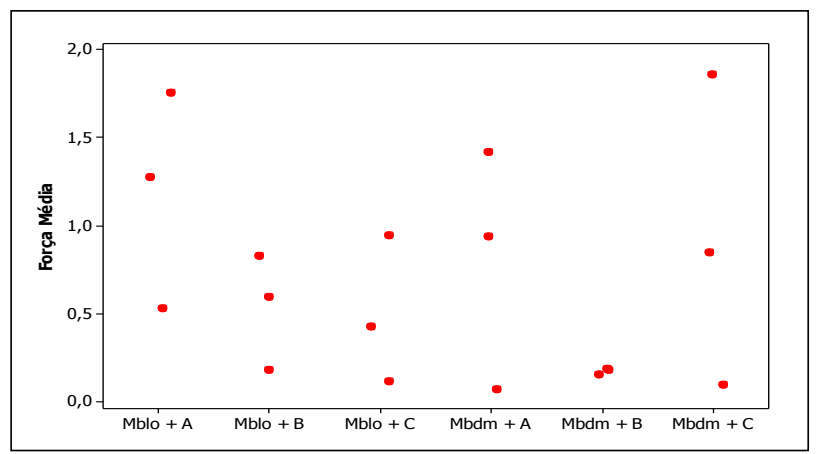

Figura 6.46 Gráfico de valores individuais por tratamento nas mechas de cabelo brasileiro descolorido submetidas ao teste de penteabilidade.

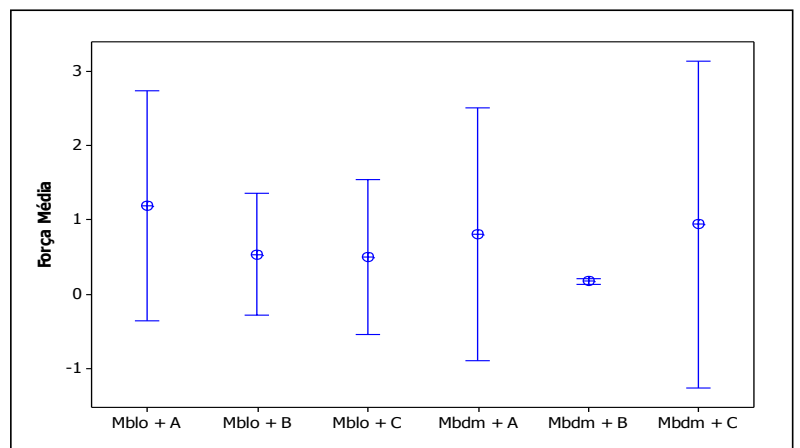

Figura 6.47 Gráfico de Intervalo de confiança de 95\% por tratamento das mechas de cabelo brasileiro descolorido submetidas ao teste de penteabilidade. 


\subsubsection{Eficácia pelo método de quebra por escovação}

As mechas de cabelo brasileiro (grau de ondulação II, já descritas) virgem e descoloridas após a aplicação das formulações e posterior tratamento térmico foram submetidas também ao teste de quebra por escovação. Este método é bastante utilizado, assim como o de penteabilidade, pelas indústrias do ramo cosmético para comprovação de eficácia em produtos para cabelos. $E$ também em suportes para claims de propaganda como por exemplo "cabelos $\mathrm{x} \%$ vezes mais fortes ou mais resistentes ou $x \%$ menos quebra". Os números de fios quebrados foram contados e estão apresentados na Tabela 6.32.

Pode-se notar que as mechas virgens que foram submetidas ao tratamento térmico apresentaram valor médio de fios quebrados superior ao das mechas que foram descoloridas e tratadas termicamente. Este resultado não era o esperado, uma vez que mechas de cabelo quando expostas a tratamentos de transformação química apresentam a estrutura tanto do córtex quanto da cutícula alterados (conforme resultados obtidos por DSC e IV). Porém, no procedimento do tratamento térmico observou-se que ocorreu uma quebra significativa dos fios das mechas de cabelo descoloridas, o que não foi observado nas mechas de cabelo virgem.

De acordo com os resultados, é possível observar que houve uma menor tendência à quebra das mechas tratadas com as formulações contendo o condicionador leave-on como veículo. Porém, nos resultados obtidos por DSC, estas mechas apresentaram menores valores de entalpia de desnaturação da queratina (praticamente zero ou não foi possível efetuar o cálculo), demonstrando, desta forma, danos internos aos fios destas mechas. Diante destes resultados, pode-se concluir que fios de cabelo mesmo apresentando-se com danos em seu córtex ainda possuem uma certa resistência ao ato de pentear, por exemplo, como foi demonstrando pelo método de quebra por escovação. Este resultado pode ser explicado pela resistência oferecida pela camada da cutícula que é mais resistente termicamente do que a o córtex como explicado anteriormente pelos resultados de DSC obtidos por Istrate et al. (2011). 
Tabela 6.32 Quantidade de fios quebrados obtida no teste de quebra por escovação das mechas de cabelo brasileiro (virgem e descolorido) e submetidas ao tratamento térmico (piastra/lavagens com LESS $10 \% \mathrm{~m} / \mathrm{m}$ ).

\begin{tabular}{|c|c|c|}
\hline \multicolumn{2}{|c|}{ Mecha } & \multirow{2}{*}{$\frac{\text { Fios quebrados }}{30}$} \\
\hline \multirow{4}{*}{ MBCont } & 1 & \\
\hline & 2 & 22 \\
\hline & 3 & 38 \\
\hline & $M \pm D P$ & $30 \pm 8$ \\
\hline \multirow{4}{*}{ MBCont1 } & 1 & 12 \\
\hline & 2 & 10 \\
\hline & 3 & 4 \\
\hline & $M \pm D P$ & $9 \pm 4$ \\
\hline \multirow{4}{*}{$M B D M+A$} & 1 & 470 \\
\hline & 2 & 306 \\
\hline & 3 & 76 \\
\hline & $M \pm D P$ & $284 \pm 198$ \\
\hline \multirow{4}{*}{$\mathrm{MBDM}+\mathrm{B}$} & 1 & 16 \\
\hline & 2 & 19 \\
\hline & 3 & 42 \\
\hline & $M \pm D P$ & $26 \pm 14$ \\
\hline \multirow{4}{*}{$\mathrm{MBDM}+\mathrm{C}$} & 1 & 46 \\
\hline & 2 & 73 \\
\hline & 3 & 78 \\
\hline & $M \pm D P$ & $66 \pm 17$ \\
\hline \multirow{4}{*}{ MBLo+A } & 1 & 23 \\
\hline & 2 & 64 \\
\hline & 3 & 13 \\
\hline & $M \pm D P$ & $33 \pm 27$ \\
\hline \multirow{4}{*}{ MBLo+B } & 1 & 8 \\
\hline & 2 & 4 \\
\hline & 3 & 33 \\
\hline & $M \pm D P$ & $15 \pm 16$ \\
\hline \multirow{4}{*}{ MBLo+C } & 1 & 2 \\
\hline & 2 & 9 \\
\hline & 3 & 7 \\
\hline & $M \pm D P$ & $6 \pm 4$ \\
\hline
\end{tabular}

MBCont = mecha de cabelo brasileiro virgem; MBCont1 = mecha de cabelo brasileiro descolorido; MBDM+A, MBDM+B; MBDM+C; MBLo+A; MBLo+B; MBLo+C = mechas brasileiras descoloridas tratadas com F2A, F2B, F2C, F3A, F3B e F3C, respectivamente; $M$ = média; $D P$ = Desvio padrão. 
Os dados obtidos pelo teste de quebra por escovação foram submetidos à análise de variância (ANOVA one-way) para verificar diferenças estatísticas significativas entre as amostras. Assim como para o teste de penteabilidade, primeiramente foi aplicado o teste (ANOVA one-way, $\alpha=0,05$ ) em todas as mechas, incluindo as mechas controle MBCont e MBCont1 (virgem e descolorida submetida ao tratamento térmico) e obteve-se um $p=0,0035$, concluindo, desta forma, que as mechas tratadas variaram significativamente entre si (Tabela 6.33).

Tabela 6.33 Modelo de ANOVA para os resultados obtidos no teste de quebra por escovação das mechas de cabelo brasileiro (virgem e descolorido) tratadas com as formulações e submetidas ao tratamento térmico (piastra/lavagens com LESS $10 \% \mathrm{~m} / \mathrm{m}$ ).

\begin{tabular}{ccccccccc}
\hline \hline & \multicolumn{8}{c}{ Número de fios quebrados } \\
\hline Mecha & Cont & Cont1 & F2A & F2B & F2C & F3A & F3B & F3C \\
$\mathbf{1}$ & 83 & 12 & 470 & 16 & 46 & 23 & 8 & 2 \\
$\mathbf{2}$ & 83 & 10 & 306 & 19 & 73 & 64 & 4 & 9 \\
$\mathbf{3}$ & 72 & 4 & 76 & 42 & 78 & 13 & 33 & 7 \\
Média & 79 & 9 & 284 & 26 & 66 & 33 & 15 & 6 \\
D.P & 6 & 4 & 198 & 14 & 17 & 27 & 16 & 4 \\
Mínimo & 72 & 4 & 76 & 16 & 46 & 13 & 4 & 2 \\
Mediana & 83 & 10 & 306 & 19 & 73 & 23 & 8 & 7 \\
Máximo & 83 & 12 & 470 & 42 & 78 & 64 & 33 & 9 \\
\hline p-valor & & \multicolumn{7}{c}{$\mathbf{0 , 0 0 3 5}$} \\
\hline
\end{tabular}

Cont = controle (virgem, sem formulação, após tratamento térmico); Cont1 = controle (descolorido, sem formulação, após tratamento térmico); A, B e C = ingredientes cosméticos.

Em seguida, apenas os resultados das mechas submetidas aos tratamentos com as formulações (sem incluir as mechas controle) e posterior tratamento térmico foram submetidas ao teste de (ANOVA one-way, $\alpha=0,05$ ). Como $p=0,011$ (Tabela 6.34), conclui-se, desta maneira, que um ou alguns tratamentos são diferentes (ou seja, rejeita-se a hipótese de que os tratamentos sejam iguais). Portanto, foi realizado o teste de comparação múltipla LSD de Fisher (Tabela 6.35) para comparação entre todos pares de médias e desta forma, identificar o/ou tratamento que se mostrou diferente dos outros. 
Tabela 6.34 Modelo de ANOVA para os resultados obtidos no teste de quebra por escovação das mechas de cabelo brasileiro descolorido tratadas com as formulações e submetidas ao tratamento térmico (piastra/lavagem com LESS $10 \% \mathrm{~m} / \mathrm{m}$ ).

\begin{tabular}{lcccccc}
\hline \hline \multicolumn{7}{c}{ Fios quebrados } \\
\hline Mecha & F2A & F2B & F2C & F3A & F3B & F3C \\
\hline \hline 01 & 470 & 16 & 46 & 23 & 8 & 2 \\
02 & 306 & 19 & 73 & 64 & 4 & 9 \\
03 & 76 & 42 & 78 & 13 & 33 & 7 \\
\hline Média & $\mathbf{2 8 4 , 0}$ & $\mathbf{2 5 , 7}$ & $\mathbf{6 5 , 7}$ & $\mathbf{3 3 , 3}$ & $\mathbf{1 5 , 0}$ & $\mathbf{6 , 0}$ \\
D.P. & $\mathbf{1 9 7 , 9}$ & $\mathbf{1 4 , 2}$ & $\mathbf{1 7 , 2}$ & $\mathbf{2 7 , 0}$ & $\mathbf{1 5 , 7}$ & $\mathbf{3 , 6}$ \\
Mínimo & 76,0 & 16,0 & 46,0 & 13,0 & 4,0 & 2,0 \\
Mediana & 306,0 & 19,0 & 73,0 & 23,0 & 8,0 & 7,0 \\
Máximo & 470,0 & 42,0 & 78,0 & 64,0 & 33,0 & 9,0 \\
\hline \multicolumn{1}{c}{$\boldsymbol{p}$-valor } & \multicolumn{7}{c}{$\mathbf{0 , 0 1 1}$} \\
\hline \hline
\end{tabular}

Foi observada diferença significativa entre os tratamentos (Figuras $6.48 \mathrm{e}$ 6.49). As mechas $M B D M+A$ apresentaram o número de fios quebrados superior em comparação com todos os demais tratamentos. Os dados de DSC mostraram que as mechas tratadas com F2A $(\mathrm{MBDM}+\mathrm{A})$ apresentaram a maior diminuição no valor de entalpia relacionada à queratina cristalina. Estes resultados de DSC foram observados não apenas nas mechas de cabelo brasileiro descoloridas, as quais já se encontravam quimicamente danificadas mas também, nas mechas de caucasiano e oriental virgem (vide Tabela 6.24 e/ou Figura 6.36). 
Tabela 6.35 Tratamento de Fisher (LSD)/Análise das diferenças entre as categorias com intervalo de confiança de $95 \%$.

\begin{tabular}{|c|c|c|c|c|}
\hline Contraste & Diferença & Prob & Alfa & Significância \\
\hline MBLo+B vs MBLo+A & -18 & 0,75704 & 0,05 & Não \\
\hline MBLo+C vs MBLo+A & -27 & 0,64524 & 0,05 & Não \\
\hline MBLo+C vs MBLo+B & -9 & 0,87915 & 0,05 & Não \\
\hline MBDM+A vs MBLo+A & 251 & $5,47 \mathrm{E}-04$ & 0,05 & Sim \\
\hline MBDM+A vs MBLo+B & 269 & $2,85 E-04$ & 0,05 & Sim \\
\hline$M B D M+A$ vs MBLo+C & 278 & $2,08 \mathrm{E}-04$ & 0,05 & Sim \\
\hline MBDM+B vs MBLo+A & -8 & 0,89693 & 0,05 & Não \\
\hline MBDM+B vs MBLo+B & 11 & 0,85701 & 0,05 & Não \\
\hline MBDM+B vs MBLo+C & 20 & 0,74004 & 0,05 & Não \\
\hline$M B D M+B$ vs $M B D M+A$ & -258 & $4,16 \mathrm{E}-04$ & 0,05 & Sim \\
\hline $\mathrm{MBDM}+\mathrm{C}$ vs $\mathrm{MBLo}+\mathrm{A}$ & 32 & 0,58653 & 0,05 & Não \\
\hline$M B D M+C$ vs MBLo+B & 51 & 0,39727 & 0,05 & Não \\
\hline$M B D M+C$ vs MBLo+C & 60 & 0,32093 & 0,05 & Não \\
\hline $\mathrm{MBDM}+\mathrm{C}$ vs $\mathrm{MBDM}+\mathrm{A}$ & -218 & 0,00175 & 0,05 & Sim \\
\hline $\mathrm{MBDM}+\mathrm{C}$ vs $\mathrm{MBDM}+\mathrm{B}$ & 40 & 0,50212 & 0,05 & Não \\
\hline MBCont1 vs MBLo+A & -25 & 0,6776 & 0,05 & Não \\
\hline MBCont1 vs MBLo+B & -6 & 0,91477 & 0,05 & Não \\
\hline MBCont1 vs MBLo+C & 3 & 0,96405 & 0,05 & Não \\
\hline MBCont1 vs MBDM+A & -275 & $2,28 \mathrm{E}-04$ & 0,05 & $\operatorname{Sim}$ \\
\hline MBCont1 vs MBDM+B & -17 & 0,77416 & 0,05 & Não \\
\hline MBCont1 vs MBDM+C & -57 & 0,34238 & 0,05 & Não \\
\hline MCont vs MBLo+A & 46 & 0,44126 & 0,05 & Não \\
\hline MCont vs MBLo+B & 64 & 0,28575 & 0,05 & Não \\
\hline MCont vs MBLo+C & 73 & 0,22612 & 0,05 & Não \\
\hline MCont vs MBDM+A & -205 & 0,00288 & 0,05 & $\operatorname{Sim}$ \\
\hline MCont vs MBDM+B & 54 & 0,37058 & 0,05 & Não \\
\hline$M C o n t$ vs $M B D M+C$ & 14 & 0,81748 & 0,05 & Não \\
\hline MCont vs MBCont1 & 71 & 0,24268 & 0,05 & Não \\
\hline
\end{tabular}




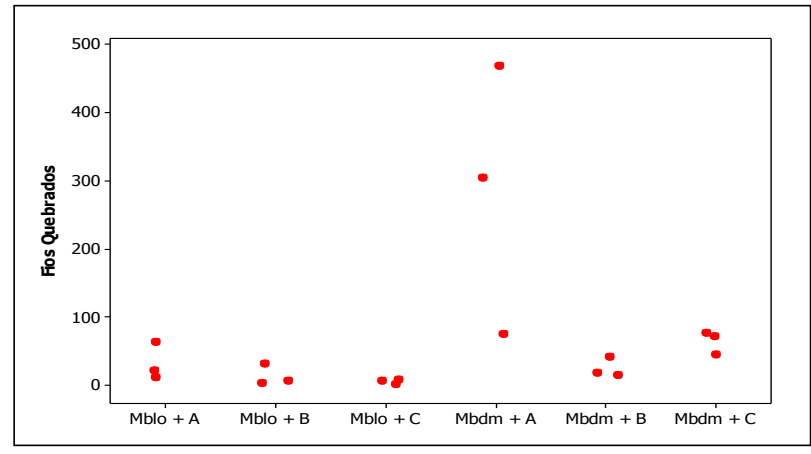

Figura 6.48 Gráfico de valores individuais por tratamento nas mechas de cabelo brasileiro descolorido submetido ao teste de quebra por escovação.

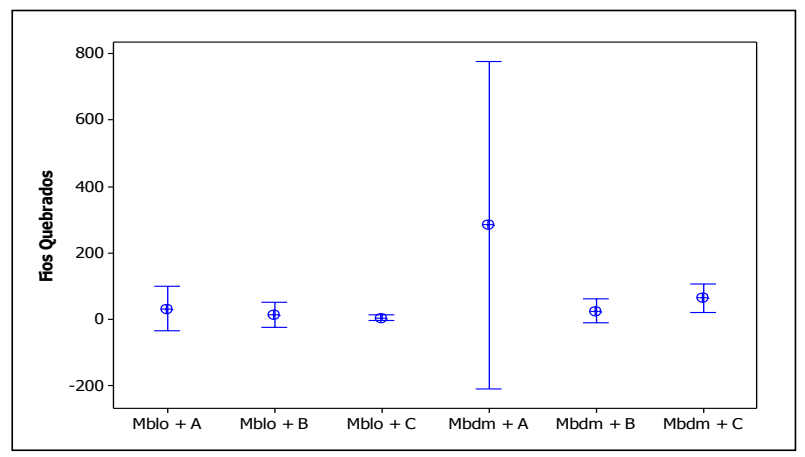

Figura 6.49 Gráfico de Intervalo de confiança de $95 \%$ por tratamento das mechas de cabelo brasileiro descolorido submetidas ao teste de quebra por escovação.

Diante do exposto, fica claro que, o tratamento térmico, nas condições experimentais do trabalho, favoreceu para que as mechas tratadas com esta formulação (F2A), apresentassem um nível de quebra acentuado quando comparado as outras mechas submetidas aos outros tratamentos. Esta fragilidade demonstrada pelas fibras MBDM+A pode ser explicada pela associação dos danos causados tanto ao córtex dos fios como aqueles causados na superfície destes. É sabido, dos resultados de DSC, que a formulação F3A (condicionador leave-on + A) se apresentou eficaz na proteção da queratina cristalina presente no córtex dos fios das mechas de cabelo caucasiano e oriental submetidas ao tratamento térmico. Desta forma, pode-se deduzir que o resultado negativo obtido pela formulação F2A nas mechas de cabelo (observado pelo método de quebra por escovação e a DSC), não foi devido ao ingrediente $A$, e sim a associação deste com o dimeticone. 


\section{CONCLUSÕES}

De acordo com os resultados observou-se que:

- amostras de cabelo das diferentes etnias apresentaram semelhanças sob o aspecto químico, físico-químico e térmico. Porém as amostras das mechas de cabelo pertencentes à etnia afro-étnica apresentaram uma estabilidade térmica menor quando comparadas com as outros, conforme os resultados obtidos pelas técnicas TG/DTG (e cinética de decomposição térmica pelo método de Ozawa) e DSC. Os resultados de AE permitiram verificar que a amostra de cabelo afro-étnico foi a que apresentou menor teor de água em sua matriz, corroborando com estudos reportados na literatura;

- o tipo de cabelo que se apresentou mais estável foi o oriental. Apresentou o maior valor de energia de ativação pelo estudo de cinética de decomposição não-isotérmica por TG;

- os resultados de penteabilidade e tensão-deformação constataram que não existe diferença significativa entre as amostras avaliadas de cabelo caucasiano e oriental;

- os resultados de DSC, após a aplicação de dispositivo térmico (piastra) nas mechas de cabelo, mostraram que há mudanças nas cadeias polipeptídicas da fase cristalina da queratina, conforme evidenciado pela diminuição do valor de entalpia de desnaturação nas curvas DSC;

- A DSC e IV mostraram-se ferramentas úteis para avaliar alterações estruturais no córtex e nas cutículas de fios de cabelo, respectivamente;

- MEV mostrou ser uma técnica capaz de avaliar a superfície dos fios de cabelo quando associada com as outras técnicas físico-químicas e analíticas;

No início deste trabalho, foram levantados alguns questionamentos (descritos no capítulo de Justificativa) que na época se fizeram necessários. Qual é a influência causada quando tratamentos capilares envolvendo dispositivos térmicos são realizados na presença de ingredientes cosméticos 
protetores? - Como esses ingredientes cosméticos contribuem como agente protetor das fibras capilares?

Com base nos resultados obtidos, é possível concluir que há influência dos ingredientes cosméticos estudados (bem como a associação destes aos veículos) em tratamentos para cabelos envolvendo a utilização de dispositivos térmicos. Os resultados de DSC evidenciaram que estes ingredientes/formulações contribuem na diminuição dos danos causados ao córtex, onde se localizam as cadeias polipeptídicas de a-queratina dos fios de cabelo.

Como as amostras de cabelo virgem caucasiano e oriental apresentaram maiores valores de "proteção" pelas formulações, pode-se concluir, desta maneira, que, cabelos tratados quimicamente (descoloridos) não respondem da mesma forma que os virgens. Estes últimos demonstraram ser mais estáveis termicamente do que àqueles tratados quimicamente. Este fato confirma que alterações na superfície dos fios quimicamente tratados resultam em uma menor aderência das formulações e com isso a eficiência destas é menor. Isto porque a piastra desliza pelos fios trocando calor com a sua superfície. Desta forma, conclui-se que a condição em que se encontram os cabelos influencia na eficiência ou não das formulações aqui estudadas. Por outro lado, a temperatura de aplicação da piastra é muito importante. Os resultados de análise térmica evidenciaram que a decomposição térmica de amostras de cabelo se inicia próximo a $250^{\circ} \mathrm{C}$, e demonstrou ser irreversível o dano causado aos fios a partir desta temperatura. Também, é importante o tempo em que as mechas devem permanecem entre as placas da piastra numa temperatura próximo a $200^{\circ} \mathrm{C}$, dependendo do tempo de permanência parte dos fios podem degradar.

Contudo, conclui-se ainda que, a associação das técnicas utilizadas na avaliação da eficiência de produtos cosméticos em cabelos podem auxiliar pesquisadores da área cosmética. Isto porque, o presente estudo mostrou que, a eficiência da proteção térmica nos cabelos depende do tipo de formulação cosmética. As técnicas de análise térmica mostraram-se úteis no desenvolvimento de formulações para proteção térmica bem como no auxílio para o desenvolvimento de equipamentos térmicos para modelagem capilar. 


\section{REFERÊNCIAS}

AGÊNCIA NACIONAL DE VIGILÂNCIA SANITÁRIA. Guia de estabilidade de produtos cosméticos. Brasília: ANVISA, 2004. 47p. (Séries temáticas da Anvisa. Qualidade em cosméticos; 1).

ARNOLD, W.; SACHS, H. Hair analysis for medicaments: the best proof for a drug career. Fresenius Journal of Analytical Chemistry, v. 348, n.8/9, p.484-489, 1994.

ÁVILA, S.G. São Paulo, 2015. Síntese, caracterização e modificação de surperfícies de sílicas mesoporosas ordenadas para captura de $\mathrm{CO}_{2}$. Tese de Doutorado, Universidade de São Paulo.

BARNICOT, N. A. Paper chromatography of human hair follicles and hair extracts, British Journal of Dermatology, v.71, p.303-308, 1959.

BARTON, P.M.J. A forensic investigation of single human hair fibres using FTIR-ATR spectroscopy and chemometrics. Brisbane, 2011. 103-114p. Tese de Doutorado - Queensland University of Technology.

BADDLEL, C.B. Structure and reactions of human hair keratin: an analysis by infrared spectroscopy. Journal of Molecular Biology, v.38, p.181-199, 1968.

BELLARE, J.; IYER, R.; MAINKARY, A.R.; JOLLYY C.I. A study on the conditioning effects of natural shampoos using the scanning electron microscope. International Journal of Cosmetic Science, v.23, p.139-145, 2001.

BELLETTI, K.M.S.; FEFERMAN, I.H.; MENDES, T.R.O.; PIACESKI, A.D.; MONTEIRO, V.F.; CARRE'O, N.L.V.; VALENTINI, A.; LEITE, E.R.; LONGO, E. Evaluation of hair fiber hydration by differential scanning calorimetry, gas chromatooraphy and sensory analysis. Journal Cosmetic Science, v.54, p.527535, 2003. 
BENAIGES, A.; FERNÁNDEZ, E.; MARTÍNEZ-TEIPEL, B.; ARMENGOL, R.; BARBA, C.; CODERCH, L. Hair efficacy of botanical extracts. Journal of Applied Polymer Science, v.128, n.1, p.861-868, 2013.

BERMEJO BARRERA, A.M.; ROSSI, S.S. Hair and urine analysis - relative distribution of drugs and their metabolites. Forensic Science International, v.70, n.1/3, p.203-210, 1995.

BHUSHAN, B. Biophysics of human hair. New York: Springer, 2010.

BISCHOF, J.C.; HE, X. Thermal stability of proteins Annals of the New York Academy of Sciences, v.1066, n.1, p.12-33, 2005.

BOLDUC, C.; SHAPIRO, J. Hair care products: waving, straightening, conditioning, and coloring. Clinics in Dermatology, v.19, p.431-436, 2001.

BREBU, M.; SPIRIDON, I. Thermal degradation of keratin waste. Journal of Analytical and Applied Pyrolysis, v.91, p.288-295, 2011.

BROWN, K.C. Hair coloring. In: JOHNSON, D.H., ed. Hair and hair care. New York: Marcel Dekker, 1997. p.191-215. (Cosmetic Science and Technology, 17).

BUDRUGEAC, P. LUMINITA PETRE, A.L.; SEGAL, E. Approximation of the TG curve through a temperature power series in order to evaluate the non-isothermal kinetic parameters of solid-gas decompositions and degradation. Thermochimica Acta, v.275, p.193-213, 1996.

CAMMENGA, H.K.; EPPLE, M. Basic principles of thermoanalytical techniques and their applications in preparative chemistry. Angewandte Chemie International Edition, v.34, n.11, p.1171-1187, 1995.

CAO, J.; K. JOKO, K.; COOK, J.R. DSC studies of the melting behavior of a-form crystallites in wool keratin. Textile Research Journal, v.67, n.2, p.117-123, 1997.

CAO, J. Melting study of the a-form crystallites in human hair keratin by DSC. Thermochimica Acta, v.335, p.5-9, 1999. 
CAO, J.; LEROY, F. Depression of the melting temperature by moisture for $\alpha$-form crystallites in human hair keratin. Biopolymers, v.77, p.38-43, 2005.

CHANDRASHEKARA, M.N.; RANGANATHAIAH, C. Chemical and photochemical degradation of human hair: A free-volume microprobe study. Journal of Photochemistry and Photobiology B: Biology, v. 101, p.286-294, 2010.

CIDES, L.C.S.; ARAÚJO, A.A.S.; SANTOS-FILHO, M.; MATOS, J.R. Thermal behaviour, compatibility study and decomposition kinetics of glimepiride under isothermal and non-isothermal conditions. Journal of Thermal Analysis and Calorimetry, v.84, n.2, p.441-445, 2006.

COLENCI, A.V.P. Estudo de uma formulação contendo o biopolímero quitosana sobre a fibra capilar caucasiana. São Carlos, 2007. Dissertação Mestrado, Universidade de São Paulo.

CORREA, M.A. Cosmetologia ciência e técnica. São Paulo: Medifarma, 2012. p.108-114, 224-228.

CORRÊA, M.A. Apostila de cosmetologia. Ribeirão Preto, 2008. p.38-42. [Apostila - Curso de Cosmetologia ministrado na Associação Farmacêutica de Ribeirão Preto (AFAR)].

CRIGHTON, J.S.; HOLE, E.R. The effect of heat on wools: thermogravimetry of keratin fibres. Proceedings of the 5th International Wool Textile Research Conference, Aachen; Vol. II, 1976.

CRIGHTON, J.S.; HOLE, E.R. A study of wool in aqueous media by high pressure differential analysis. Proceedings of the $7^{\text {th }}$ International Wool Textile Research Conference, Tokyo, Japan; Vol. I, pp. 283-292, 1985.

CRIGHTON, J.S.; HAPPEY, F. Differential thermal analysis of keratin and related protein fibers. Symposium on Fibrous Proteins, Plenum Press, New York, USA, 1968.

DANKERS, L.M. Physical analysis of human hair. Rolla, 2007. Dissertação de Mestrado - University of Missouri-Rolla. 
DAVIS-SIVASOTHY, A. The Science of Black Hair: A Comprehensive Guide to Textured Hair Care. Saja Publishing Company, LLC., 2011, 170-172p.

DE LA METRIE, R.; SAINT-L'EGER, L.G.; GARCEL, A.; PORTER, C.; LANGANEY,A. Shape variability and classification of human hair: A worldwide approach. Human Biology, v. 79, n. 3, p. 265- 281, 2007.

DRAELOS, Z.D. Hair cosmetics. Dermatologic Clinics, v.9, p.19-27, 1991.

DRAELOS, Z.D. Shampoos, conditioners, and camouflage techniques. Dermatological Clinics, v.310, p.173-178, 2013.

DUSSAUD, A.; FIESCHI-CORSO, L. Influence of functionalized silicones on hair fiber-fiber interactions and on the relationship with the macroscopic behavior of hair assembly. Journal Cosmetic Science, v. 60, p.261-271, 2009.

DUSSAUD, A.; RANA, B.; LAM, H.T. Progressive hair straightening using an automated flat iron: Function of silicones. Journal Cosmetic Science, v. 64, p.113, 2013.

ÉHEN, Z.S.; NOVÁK, C.S.; SZTATISZ, J.; BENE, O. Thermal characterization of hair using TG-MS combined thermoanalytical technique. Journal of Thermal Analysis and Calorimetry, v.78, p.427-440, 2004.

ESPINOZA, E.O.; BAKER, B.W.; MOORES, T.D.; VOIN, D. Forensic identification of elephant and giraffe hair artifacts using HATR FTIR spectroscopy and discriminant analysis. Endangered Species Research, v.9, p.239-246, 2008.

FARWICK, M.; MACZKIEWITZ, U.; SPRINGER, O.; LERSCH, P. Characterization of different types of hair damages - strategies for prevention and repair. Livro de resumos. In: CONGRESS OF THE INTERNATIONAL FEDERATION OF SOCIETIES OF COSMETIC CHEMISTS, 26, Buenos Aires, 2010. Book of Abstracts. Buenos Aires: Asociación Argentina de Químicos Cosméticos, 2010.

FELIX, W.D. MCDOWALL, M.A.; EYRING, H. The Differential thermal analysis of natural and modified wool and mohair. Textile Research Journal, v.33, p.465471, 1963. 
FEUGHELMAN, M. Morphology and properties of hair. In: JOHNSON, D.H., ed. Hair and hair care. New York: Marcel Dekker, 1997. p.1-32. (Cosmetic Science and Technology, 17).

FEVOLA, M.J. Polímeros em cosméticos: dimeticone. Cosmetics \& Toiletries, v.25, p.54-59, 2013.

FLORENCE, A.T.; ATTWOOD, D. Princípios físico químicos em farmácia. São Paulo: USP, 2003. p.345-375, 413-455.

FRANBOURG, A.; HALLEGOT, P.; TOUTAIN, C.; LEROY F. Current research on ethnic hair. Journal of the American Academy of Dermatology, v.48, p.115119, 2003.

FRANÇA, S.A. Caracterização dos cabelos submetidos ao alisamento/relaxamento e posterior tingimento. São Paulo, 2014. Dissertação de mestrado, Universidade de São Paulo.

GAMA, R.M.; BALOGH, T.S.; FRANÇA, S.; DIAS, T.C.D.; BEDIN, V.; BABY, A.R.; MATOS, J.R.; VELASCO, M.V.R. Thermal analysis of hair treated with oxidative hair dye under influence of conditioners agents. Journal of Thermal Analisys and Calorimetry, v.106, n.2, p.399-405, 2011.

GOMES, L.A. O uso da tecnologia cosmética no trabalho do profissional cabeleireiro. 3.ed. São Paulo: Senac São Paulo, 2008. p.18-19, 23.

GRAY, J. Hair care and hair care products. Clinics in Dermatology, v.19, n.2, p.227-236, 2001.

GRAY, J. The world of hair the world of hair: a scientific companion. Basingstoke: London: Macmillan, 1997. 142p.

GUTHRIE, J.T.; KAZLAUCIUNAS, A.; RONGONG, L.; RUSH, S. The characterisation of treated and dyed hair. Dyes and Pigments, v.29, n.1, p.23-44, 1995. 
HALAL, J. Tricologia e a química cosmética capilar. São Paulo: Cengage Learning, 2011.

HAM, A.W.; CORMACK, D.H. O sistema tegumentar (pele e anexos). 8.ed. Rio de Janeiro: Guanabara Koogan, 1983. p.577-605.

HARRIS, M.I.C. Pele estrutura, propriedades e envelhecimento. 3.ed. São Paulo: Senac São Paulo, 2009. p.67-89.

HARRIS, R.T. Hair relaxing. Cosmetic Toiletries, v.94, p.51-56, 1979.

HARTUNG, C.; KORTEMEIER, U.; WESTERHOLT, U.; WINTER, P.; DAHL, V.; TRAMBITAS, A.; LANGER, S.; SCHWAB, P.; JHA, B. T-shaped siloxane microemulsion for improved hair conditioning and protection. Cosmetics \& Toiletries, v.123, n.8, p.160-168, 2013.

HASSANA, M.M.; TAKAHASHI, T.; KOYAMA, Y. Preparation and characterisation of $\mathrm{Si} O$ ceramics made from a preceramic polymer and rice bran. Journal of the European Ceramic Society, v,33, p.1207-1217, 2013.

HELEN, P. Vibrational spectroscopy of keratin fibers a forensic approach. Brisbane, 2004. 134-135p. Tese de Doutorado - Queensland University of Technology.

HOSHOWSKI, M.A. Conditioning of hair. In: JOHNSON, D.H., ed. Hair and hair care. New York: Marcel Dekker, 1997. p.65-104. (Cosmetic Science and Technology, 17).

HUMPHRIES, W.T.; MILLER, D.L.; WILDNAUER, R.H. The Thermomechanical analysis of natural and chemically modified human hair. Journal of the Society of Cosmetic Chemists, V. 23, p. 359-370, 1972.

IDSON, B. Stability testing of emulsions: part 2. Drug and Cosmetic Industry, v.152, n.2, p.38-43, 1993. 
INOUE, T.; IWAMOTO, Y.; OHTA, N. Structural analysis of human hair cuticle using microbeam X-ray diffraction: relationship with effects of hair dyeing. Research Frontiers, $2005 . \quad$ p.135-136. Disponível em: http://www.spring8.or.jp/pdf/en/res_fro/05/135-136.pdf. Acesso em: 04 abr. 2013.

IONASHIRO, M.A.; GIOLITO, I. Nomenclatura, padrões e apresentação dos resultados em análise térmica. Cerâmica, v.26, n.121, p.17-24, 1980.

ISTRATE, D. Heat induced denaturation of fibrous hard $\alpha$-keratins and their reaction with various chemical reagentes. Aachen, 2011. Tese de Doutorado, RWTH Aachen University.

ISTRATE, D.; POPESCU, C.; MOELLER, M. Non-isothermal kinetics of hard akeratin thermal denaturation. Macromolecular Bioscience, v. 9, 805-812, 2009.

ISTRATE, D.; POPESCU, C.; RAFIK, M. E.; MÖLLER, M. The effect of pH on the thermal stability of fibrous hard alpha-keratins. Polymer Degradation and Stability, v. 98, n. 2, p.542-549, 2013.

JACHOWICZ, J. Hair damage and attempts to its repair. Journal of the Society of Cosmetic Chemists, v.38, n.4, p.263-286, 1987.

JOERISSEN, K. Ueber den thermischen Abbau von Keratinen. Aachen, 1982. Tese de doutorado. Aachen University of Technology.

JOHNSON, D.H., ed. Hair and hair care. New York: Marcel Dekker, 1997. 370p. (Cosmetic Science and Technology, 17).

JUEZ, J.L.; GIMIER, L. Ciencia cosmética. 2.ed. Madrid: Sociedad Espanhola de Químicos Cosméticos, 1983. p.98-119.

KIM, K.S.; PARK, H.-K. Analysis of aging effects on chemical property of human hair by Fourier transform infrared spectroscopy. Skin Research and Technology, v.19, n.1, p.e325-e331, 2013.

KOGA, N. Ozawa's kinetic method for analyzing thermoanalytical curves. Journal of Thermal Analysis and Calorimetry, v.113, p. 1527-1541, 2013. 
KOLAR, G.; MILLER, A. Hair straighteners. In: BALSAM, MS.; SAGARIN, E., eds. Cosmetics science and technology. 2.ed. New York: Interscience, 1972. p.150277.

LAU, K.; HEDEGAARD, M.A.B.; KLOEPPER, J.E.; PAUS, R. Visualization and characterization if defined hair follicle compartments by Fourier transform infrared (FTIR) imaging without labeling. Journal of Dermatological Science, v.63, p.191-198, 2011.

LEE, Y.; KIM, Y-D.; HYUN, H-J.; PI, L-Q.; JIN, X.; LEE, W-S. Hair Shaft Damage from Heat and Drying Time of Hair Dryer. Annals of Dermatology, v. 23, p455462, 2011.

LEHNINGER, A.L. Bioquímica: biossíntese e a utilização. São Paulo: Edgard Blücher, 1976. v.1, p.88, 151.

LEROY, F.; FRANBOURG, A.; LÉVÊQUE, J.L. Thermoanalytical investigations of reduced hair. 8th International Hair Science Symposium of the German Wool Research Institute, Kiel, 1992.

LIM, Y. H.; PARK,C. H.; KIM, J. Hair conditioning effect of amino silicone softeners in varied treatment conditions. Fibers and Polymers, v. 11, p. 507-515, 2010.

LISBÔA, C.P. Estudo comparativo da sorção de lipídios em cabelos caucasiano e negroide. Campinas, 2007. 41p. Dissertação de Mestrado Instituto de Química - Universidade Estadual de Campinas.

MACHADO, L.D.B.; MATOS, J.R.; Análise térmica diferencial e calorimetria exploratória diferencial. In: CANEVAROLO Jr., S.V., ed. Técnicas de caracterização de polímeros. São Paulo: Artliber, 2004. p.229-261.

MARIAN, E.; TITA, B.; JURCA, T.; FULIAS, A.; VICAS, L.; TITA, D. Thermal behaviour of erythromycin-active substance and tablets. Part 1. Kinetic study of the active substance under non-isothermal conditions. Journal of Thermal Analysis and Calorimetry, v.111, p.1025-1031, 2013. 
MARSH, J. M.; CLARKE, C. J.; MEINERT, K.; DAHLGREN, R. M. High pressure differential scanning calorimetry of colorant products. Journal Cosmetic Science, v. 58, p.621-627, 2007.

MASMOUDIA, H.; DREAU, Y.L.; PICCERELLEB, P.; KISTERA, J. The evaluation of cosmetic and pharmaceutical emulsions aging process using classical techniques and a new method: FTIR. International Journal of Pharmaceutics, v.289, p.117-131, 2005.

MATOS, J. R.; MIYANO, M. H.; SIQUEIRA, L.; MOURA, M. F. V.; LUIZ, J. M. llustração da influencia da razão de aquecimento nos resultados de termogravimetria, Química Nova, v. 23, 2000.

MENEFEE, E.; YEE, G. Thermally-induced structural changes in wool. Textile Research Journal, v.35, n.9, p.801, 1965.

McMULLEN, R.; JACHOWICZ, J. Thermal degradation of hair. I. Effect of curling irons. Journal of Cosmetic Science, v.49, p.223-244, 1998.

MCMULLEN, R.; JACHOWICZ, J. Thermal degradation of hair. II. Effect of selected polymers and surfactants. Journal of Cosmetic Science, v.49, p.245256, 1998.

MILCZAREK, P. ZIELINSKI, M. GARCIA, M.L. The mechanism and stability of thermal transitions in hair keratin. Colloid Polymer Science, v. 270, p.1106-1115, 1992.

MOITA, G.C. Propriedades físico-quimicas de cabelo: avaliação de interações com corante e surfactantes. Campinas, 1089. Tese de Mestrado - Universidade Estadual de Campinas.

MONTE, G.C. Desenvolvimento e avaliação da estabilidade física de condicionador capilar contendo óleo de pequi (Caryocar brasiliense Camb.). Brasília: Universidade de Brasília, 2013. 10p. [Trabalho de conclusão de curso]. 
MONTEMAYOR, B.P.; PRICE, B.B.; VAN EGMOND, R.A. Accounting for intended use application in characterizing the contributions of cyclopentasiloxane (D5) to aquatic loadings following personal care product use: antiperspirants, skin care products and hair care products. Chemosphere. v. 93, n. 5, p.735-740, 2013.

MONTEIRO, V.F.; MACIEL, A.P.; LONGO, E. Thermal analysis of Caucasian human hair. Journal of Thermal Analysis and Calorimetry, v.79, n.2, p.289293, 2005.

NAKANO, A.K. Comparação de danos induzidos em cabelos de três etnias por diferentes tratamentos. Campinas, 2006. 14p. Dissertação de Mestrado Instituto de Química - Universidade Estadual de Campinas.

NISHIKAWA, N.; TANIZAWA, Y.; TANAKA, S.; HORIGUCHI, Y. ASAKURA, T. Structural change of keratin protein in human hair by permanent waving treatment. Polymer, v. 39, p3835-3840, 1998.

OBUKOWHO, P.; BIRMAN, M. Alisantes para cabelos: avaliação da função, da química e da produção. Cosmetics \& Toiletries, Edição em Português, v.8, n.3, p.44-49, 1996.

O'LENICK Jr., A.J. Silicones for personal care. 2.ed. Carol Stream: Allured Publishing Corporation, 2008.

OZAWA, T. A new method of analyzing thermogravimetric data. Bulletin of the Chemical Society of Japan, v.38, n.11, p.1881-1886, 1965.

PAULING, L.; COREY, R.B. Compound helical configurations of polypeptide chains: structure of proteins of the alpha-keratin type. Nature, v.171, n.4341, p.59-61; 1953.

PASSWATER, R.A.; CRANTON, E.M. Trace elements, hair analysis and nutrition. New Canaan: Keats Publishing, 1983. 384p.

PENG, Y.; SUN, B.; WU, P. Two-dimensional correlation infrared spectroscopic study on the crystallization and gelation of poly(vinylidene fluoride) in cyclohexanone. Applied Spectroscopy, v.62, n.3, p.295-301, 2008. 
PRASONG, S.; WASAN, T. Preparation and characterization of hair keratin/gelatina blend films. Pakistan Journal of Biological Sciences, v.14, n.5, p.351-356, 2011.

POPESCU C, HÖCKER H. Hair-the most sophisticated biological composite material. Chemistry Society Review. v. 36, p.1282-1291, 2007.

QUADFLIEG, J.M. Fundamental properties of Afro-American hair as related to their straightening/relaxing behaviour. Disponível em: http://sylvester.bth.rwthaachen.de/dissertationen/2004/094/04_094.pdf. Acesso em: 15/10/2015.

RIEGER, M.M.; BRECHNER, S. Depilatories. In: DE NAVARRE, M.G., ed. The chemistry and manufacture of cosmetics. 2.ed. Wheaton: Allured Publishing, 1988. cap.61, v.4, p.1229-1273.

RIGOLETTO, R.; KAROLAK, J.; KOELMEL, D. Quantification of fiber fragmentation of hair through combing as a measure of thermal protection. Journal of Cosmetic Science, v.60, p.278-279, 2009.

ROBBINS, C.R. Chemical and physical behavior of human hair. 3.ed. New York: Springer Verlag, 1994. 391p.

ROBBINS, C.R. Chemical and physical behavior of human hair. 4.ed. New York: Springer-Verlag, 2002. 125-130p.

ROBBINS C.R. Chemical aspects of bleaching human hair. Journal of the Society of Cosmetic Chemistry, v.22, n.6, p.339-348, 1971.

RODRIGUES, P.O.; CARDOSO, T.F.M.; SILVA, M.A.S.; MATOS, J.R.M. Aplicação de técnicas termoanalíticas na caracterização, determinação da pureza e cinética de degradação da zidovudina (AZT). Acta Farmacêutica Bonaerense, v.24 n.3, p.383-387, 2005.

SÁ DIAS, T.C., BABY, A. R., KANEKO, T.M. , VELASCO, M.V.R. Protective effect of conditioning agents on Afro ethnic hair chemically treated with thyoglicolatebased straightening emulsion. Journal of Cosmetic Dermatology, v.7, n.2, p.120-126, 2008. 
SÁ DIAS. Avaliação in vitro do efeito de diferentes processos de Alisamento químico/térmico na fibra capilar. São Paulo, 2015. Tese de doutorado, Univesidade de São Paulo.

SAIKIA, J. P. Hair waving natural product: Dillenia indica seed sap. Colloids and Surfaces B: Biointerfaces, v. 102, p.9005-907, 2013.

SCANAVEZ, C.S. Alterações na ultra-estrutura do cabelo induzidas por cuidados diários e seus efeitos nas propriedades de cor. Campinas, 2001. 6p. Tese de Doutorado - Instituto de Química - Universidade Estadual de Campinas.

SCHWENKER, R.F., DUSENBURY, J.H. Differential thermal analysis of protein fibers. Textile Research Journal, v. 30, p. 800-801, 1960.

SESHADRI, I.P.; BHUSHAN, B. In-situ tensile deformation characterization of human hair with atomic force microscopy. Acta Materialia, v. 56, p.774-781, 2008.

SIGNORI, L.; LEWIS, D.M. FTIR investigation of the damage produced on human hair by weathering and bleaching processes: implementation of different sampling techniques and data processing. International Journal of Cosmetic Science, v.19, n.1, p.1-14, 1997.

SILVA, E.C.; VELASCO DE PAOLA, M.V.R.; MATOS, J.R. Análise térmica aplicada à cosmetologia. Brazilian Journal of Pharmaceutical Sciences, v.43, n.3, p.347-356, 2007.

SILVA, E.M.; MERCURI, L.P.; JÚNIOR, D.S.; CARVALHO, F.M.S.; MATOS, J.R. Estudo cinético da etapa de desidratação de cabelos caucasianos por análise térmica. In: CONGRESSO BRASILEIRO DE ANÁLISE TÉRMICA, São Pedro, 2010. Livro de Resumos. São Paulo: CBRATEC, 2010.

SILVA, M.C.D.; BOTELHO, J.R.; SOUZA, A.G. Estudo cinético do corante bixina por decomposição térmica dinâmica. Revista Tecnologia \& Ciência Agropecuária, v.2, n.1, p.11-14, 2008.

SILVERSTEIN, R.M.; BASSLER, G.C.; MORRILL, T.C. Spectrometric identification of organic compounds. 5.ed. New York: John Wiley, 1991. 
SKOOG, D. A.; HOLLER, J.F.; CROUCH, S.R. Princípios de Análise Instrumental, $6^{\mathrm{a}}$ ed., Porto Alegre, 2009.

SMITH, B.C. Infrared spectral interpretation: a systematic approach. Boca Raton: CRC Press, 1998. 265p.

SMITH, B.C. Infrared spectral interpretation: a systematic approach. Boca Raton: CRC Press, 1998. 93p.

SPEI, M.; HOLZEM, R. Thermoanalytical investigations of extended and annealed keratins. Colloid and Polymer Science, v. 265, p.965-970, 1987.

SOLOMONS, T.W.G.; FRYHLE, C.B. Química orgânica. 7.ed. Rio de Janeiro: LTC - Livros Técnicos e Científicos, 2001.

SWIFT, J.A.; BEWS, B.; The chemistry of human hair cuticle. I. A new method for the physical isolation of cuticle. Journal of the Society of Cosmetic Chemists, v.25, p.13-22, 1974.

SYED, A.N. Ethnic hair care products. In: JOHNSON, D.H., ed. Hair and hair care. New York: Marcel Dekker, 1997. p.235-259. (Cosmetic Science and Technology, 17).

VELASCO, M.V.R.; RIBEIRO, M.E.; BEDIN, V.; BONZANINI, V. Cabelos étnicos. Cosmetics \& Toiletries, Edição em Português, v.11, p.36-44, 1999.

VELASCO, M. V. R.; DIAS, T. C. S.; FREITAS, A. Z.; JÚNIOR, N. D. V.; PINTO, C. A. S. O. KANEKO, T. M.; BABY, A. R. Hair fiber characteristics and methods to evaluate hair physical and mechanical properties, Brazilian Journal Pharmaceutical Sciences, v. 45, p.153-62, 2009.

VELASQUEZ-ARMIJO, C.J.; COSTA, I.M.; LONGHINI, R.; PETZHOLD, C.L.; PETROVICK, P.R. Métodos termo-analíticos e suas aplicações nas ciências farmacêuticas. Caderno de Farmácia, v.20, n.1. p.29-47, 2004. 
VILLA, A.L.V.; SANTOS, J.A. PEREIRA, S.M.N.; SANTOS, E.P. Avaliação de Perda Protéica em Cabelos Étnicos pelo método Kjeldahl. Cosmetics \& Toiletries (Brasil). Vol. 20, p. 60- 63, 2008.

WENDLANDT, W.W. Thermal analysis. 3.ed. New York: John Wiley, 1986.

WILKINSON, J.B.; MOORE, R.J. Cosmetologĺa de Harry. Madri: Ediciones Díaz de Santos, 1990.

WILLIAMS D.H.; FLEMING I. Spectroscopic methods in organic chemistry. Glasgow: McGraw-Hill, 1995.

WOJCIECHOWSKA, E.; WOCHOWICZ, A.; WESELUCHA-BIRCZYNSKA, A. Application of Fourier-transform infrared and Raman spectroscopy to study degradation of the wool fiber keratin. Journal of Molecular Structure, v.511-512, p.307-318, 1999.

WOLFRAM L.J. Human hair: a unique physicochemical composite. Journal of the American Academy of Dermatology, v.48, n.6, p.S106-S114, 2003.

WORTMANN, F.J.; DEUTZ, H. Characterizing keratins using high-pressure differential scanning calorimetry (HPDSC). Journal of Applied Polymer Science, v.48, p.137-150, 1993.

WORTMANN, F.J.; DEUTZ, H. Thermal-analysis of ortho-cortical and para-cortical cells isolated from wool fibers. Journal Applied Polymer Science, v.68, n.12, p.1991-1995, 1998.

WORTMANN, F.-J.; POPESCU, G.; SENDELBACH, G. Effects of reduction on the denaturation kinetics the human hair. Biopolymers, v.89, n.7, p.600-605, 2008.

WORTMANN, F.J.; SPRINGOB, C.; SENDELBACH, G. Investigations of cosmetically treated human hair by differential scanning calorimetry in water. Journal of Cosmetic Science, v.53, n.4, p.219-228, 2002.

WORTMANN, F.J.; WORTMANN, G.; MARSH, J.; MEINERT, K. Thermal denaturation and structural changes of a-helical proteins in keratins. Journal of Structural Biology, v. 177, p.553-560, 2012. 
THIBAUT, S. BARBARAT, P.; LEROY, F. BERNARD, B.A. Human hair keratin network and curvature. International Journal of Dermatology, v.46, suppl.1, p.7-10, 2007.

THIBAUT, S.; GAILLARD, O.; BOUHANNA, P.; CANNELL, D.W.; BERNARD, B.A. Human hair shape is programmed from the bulb. British Journal of Dermatology, v.152, n.4, p.632-638, 2005.

TORRADO, G.; GARCÍA-ARIETA, A.; DE LOS RÍOS, F.; MENÉNDEZ, J.C. TORRADO, S. Quantitative determination of dimethicone in commercial tablets and capsules by Fourier transform infrared spectroscopy and antifoaming activity test. Journal of Pharmaceutical and Biomedical Analysis, v.19, p.285-292, 1999.

YANG, Z.; FENG, L.; DIAO, S.; FENG, S.; ZHANG, C. Study on the synthesis and thermal degradation of silicone resin containing silphenylene units. Thermochimica Acta, v.521, p.170-175, 2011.

YOSHIDA, M.I. Cinética e mecanismo de reações de decomposição térmica no estado sólido: influência de variações estruturais no ligante, sobre o parâmetro cinético. Belo Horizonte, 1993. Tese de Doutorado - Instituto de Ciências Exatas - Universidade Federal de Minas Gerais.

ZAHN, H.; SPEI, M. Wool as a biological compound. Chemiker-Zeitung, n.102, n.6, p.227, 1978.

ZHAI, J.; SHAN, Z.; LI, J.; LI, X.; GUO, X.; YANG, R. Study on Influence of terminal structure on mechanical properties of GAP elastomers. Journal of Applied Polymer Science, v.128, n.4, p.2319-2324, 2012.

ZHOU, Y.; RIGOLETTO, R.; KOELMEL, D.; ZHANG, G.; GILLECE, T.W.; FOLTIS, L.; MOORE, D.J.; QU, X.; SUN, C. The effect of various cosmetic pretreatments on protecting hair from thermal damage by hot flat ironing. Journal Cosmetic Science, v. 62, 265-282, 2011. 